Time activity patterns in exposure assessment: the case of livestock related infections

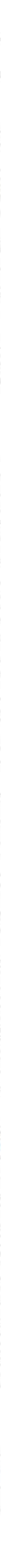





\section{Time activity patterns in exposure assessment: the case of livestock related infections}

Gijs Klous 


\section{Colofon}

(c) Gijs Klous, 2020

Thesis, Utrecht University

ISBN: 978-90-393-7318-7

Printing: Proefschriftprinten.nl

All rights reserved. No part of this thesis may be reproduced or transmitted in any from or by any means without prior written admission from the author. The copyright of papers that have been published, has been transferred to the respective journals.

\section{Cover and artwork throughout the book:}

Mock example of a GPS track and farms, this is an aggregation of GPS data measured in Utrecht and surroundings. Data was provided in test runs by: the author, dr. Astrid Martens, dr. Myrna de Rooij and Erik van Nunen MSc. 


\title{
Time activity patterns in exposure assessment: the case of livestock related infections
}

\author{
Tijd-activiteiten patronen bij beoordeling van \\ blootstelling aan vee-gerelateerde infecties \\ (met een samenvatting in het Nederlands)
}

\section{Proefschrift}

ter verkrijging van de graad van doctor aan de Universiteit Utrecht op gezag van de rector magnificus, prof.dr. H.R.B.M. Kummeling, ingevolge het besluit van het college voor promoties in het openbaar te verdedigen op donderdag 17 september 2020 des morgens te 9.15 uur

door

\section{Gijs Klous}

geboren op 14 december 1985

te Graft-De Rijp 


\section{Promotoren:}

Prof. dr. R.A. Coutinho

Prof. dr. ir. D.J.J. Heederik

\section{Copromotor:}

Dr. A. Huss 


\section{Table of contents}

$\begin{array}{ll}\text { Chapter 1: General Introduction } & \text { p.8 }\end{array}$

Chapter 2: Human-livestock contacts and their relationship to transmission of $\quad$ p.24 zoonotic pathogens, a systematic review of literature

One Health 2 (2016) 65-76

Gijs Klous, Anke Huss, Dick Heederik and Roel Coutinho

Chapter 3: Mobility assessment of a rural population in the Netherlands using $\quad$ p.56

GPS measurements

International Journal of Health Geographics (2017) 16:30

Gijs Klous, Lidwien Smit, Floor Borlée, Roel Coutinho,

Mirjam Kretzschmar, Dick Heederik and Anke Huss

Chapter 4: Pneumonia risk of people living close to goat and poultry farms - $\quad$ p.100

Taking GPS derived mobility patterns into account

Environment International 115 (2018) 150-160

Gijs Klous, Lidwien Smit, Gudrun Freidl, Floor Borlée, Wim van der Hoek, Joris IJzermans, Mirjam Kretzschmar, Dick Heederik, Roel Coutinho and

Anke Huss

Chapter 5: Prediction of human active mobility in rural areas: development and

p.128

validity tests of three different approaches

Journal of Exposure Science and Environmental Epidemiology (2019)

Gijs Klous, Mirjam Kretzschmar, Roel Coutinho, Dick Heederik and

Anke Huss

Chapter 6: Relationship between Coxiella burnetii ( $Q$ fever) antibody serology and p.154 time spent outdoors

Journal of Infection (2020) 81(1) 90-97

Gijs Klous, Lidwien Smit, Wim van der Hoek, Mirjam Kretzschmar, Piet Vellema, Roel Coutinho, Dick Heederik and Anke Huss

Chapter 7: General discussion

p.190

Summary

p.206

Samenvatting

p. 212

Author affiliations

p. 218

List of publications

p. 220

Dankwoord (Acknowledgements)

p. 221

Curriculum Vitea

p. 223 
Chapter 1

General introduction 


\section{Introduction}

\section{Historical context and geographical perspective}

Early May 2007, a medical-microbiologist working in a regional hospital in the southeastern part of the Netherlands, province of Noord-Brabant, informed the public health service about a cluster of pneumonia cases that were not well responding to antibiotic treatment. This initial signal did not lead to a response, but at the end of May 2007 a General Practitioner (GP) working in the same region, reported an increase in atypical pneumonia among adults in his practice area. Two weeks after this first GP notification a second GP, operating from a village nearby, also reported an increase in atypical pneumonia in the practice area. These GP signals triggered an investigation and at first Mycoplasma pneumonia was thought to be the causative agent of these pneumonia cases.[1] Additional analyses revealed that Coxiella burnetii, probably originating from abortion-waves in dairy goat farms, was the causative agent of human $\mathrm{Q}$ fever cases in Noord-Brabant.[1-3] The $\mathrm{Q}$ fever outbreak grew out to be the largest described outbreak to date [3], with over 4000 notified human cases between 2007 and 2010.[46] The outbreak was contained through large scale interventions: voluntary vaccination of goats starting in 2008 and compulsory vaccination of goats starting in 2009 [7], mandatory PCR-checks of bulk milk tanks for $C$. burnetii presence [8] and culling of pregnant goats on bulk milk tank C. burnetii positive farms.[8-10] However, now, a decade after this outbreak, people are still suffering from effects of chronic $\mathrm{Q}$ fever and Q fever-related chronic fatigue syndrome.[11]

For an infectious disease outbreak to occur, certain criteria have to be met: the infectious agent must be transmissible, via, e.g. air, fluids, vectors, food products or direct contact. The agent must be infectious for a susceptible population. Finally, an infectious source, e.g. human, animal, animal related food product or environment and susceptible population need to interact.[12] An outbreak of a zoonotic infectious disease, an infectious disease transmissible from animals to humans, in the Netherlands did not emerge entirely unexpected: In their 2008 paper, Jones et al [13] predicted the Netherlands to be at high risk for zoonoses originating from non-wildlife animals by analysing emerging infectious disease notifications occurring between 1940 and 2004.[13] This prediction was illustrated by spill-overs of Avian Influenza $\mathrm{H}_{7} \mathrm{~N}_{7}$ from poultry during an outbreak period to primarily occupationally exposed humans.[14] Furthermore, spill-overs of antibiotic resistant bacteria occurred, both Methicillin Resistant Staphylococcus aureus (MRSA) [15] and Extended-Spectrum Beta-Lactamase (ESBL) producing Enterobacteriaceae transferred from livestock to humans.[16]

When the outbreak criteria are put in the perspective of the Netherlands as a country, we can conclude that the country is indeed at an increased risk for outbreaks of especially livestock-related zoonotic infectious diseases. First, the Netherlands is a small country with a land surface of about $38.000 \mathrm{~km}^{2}[17]$, second the country is densely populated with 17 million inhabitants [18] and third (intensive-) livestock and dairy production is an important economic activity in the country, hosting on average 124 million livestock animals (data from 2016: 0.5 million goats, 0.8 million sheep, 4.3 million cattle, 12.5 million pigs and 105.5 million poultry).[19] This means that if we calculate population and animal numbers per square kilometre of land surface, every Dutch $\mathrm{km}^{2}$ hosts on average 450 people (range $25-6289$ people) and 3268 livestock animals (range 
$0-56426$ animals). More precisely, 13 goats, 21 sheep, 114 cattle, 330 pigs and 2790 poultry animals per $\mathrm{km}^{2}$. These are of course country averages and locally figures can deviate from these values in both directions. When population densities and livestock densities are mapped, a clear spatial difference in distribution can be observed between population density and livestock density (Figure 1). The highest population densities in the Netherlands are found in the mid-western Randstad area (roughly: Amsterdam, Utrecht, Den Haag and Rotterdam) and highly urbanised city municipalities spread around the country. The highest livestock densities are predominantly found in the south-eastern part of the country; the area were the $\mathrm{Q}$ fever outbreak occurred.[3] Next to having a high livestock density, this part of the country is also highly populated (Figure 1, detail-map 'Population density'), giving a home to approximately 1.8 Million inhabitants (2015:[20]). Consequently, in these high livestock density areas living close to livestock stables and being exposed to emissions coming from these stables is highly likely for non-occupationally exposed residents. If a highly infectious [21] and durable agent $[22,23]$, like $C$. burnetii infects livestock in this area, people are likely to be exposed to the agent.

\section{Livestock and their associated emissions}

Next to infectious disease spill-over incidents [14-16] and outbreaks like the $\mathrm{Q}$ fever outbreak [3], living close to large numbers of livestock animals may also effect human health in other ways.[24-31] Livestock farms are known to emit a wide range of pollutants [24,32], first of all these are gasses directly derived from the animals in the stables. Livestock animals emit gasses such as carbon dioxide, ammonia and methane. Some of these gasses add to the greenhouse effect and are dangerous for the earth's atmosphere [32], more importantly for direct health effects is the emission of ammonia.[28,33] Ammonia is a known irritant substance for the lungs, furthermore, ammonia is a reactive substance and is a common precursor in the formation of Particulate Matter (PM or fine dust).[24,30,31,34-36] Exposure to ammonia concentrations can act as a proxy for exposure to livestock-related PM particles and was shown to be associated with reduced lung function in healthy adults.[37] Exposure to livestock-origin PM is known to cause adverse health effects in farmers, especially lungrelated diseases such as chronic cough, chronic bronchitis, allergic reactions and asthma-like symptoms. [24] However, PM originating from livestock farms does not only contain particles that were formed out of ammonia, this PM is a complex mixture of proteins and polycarbonates [25], volatile organic compounds [27], endotoxins (parts of bacterial cell walls potentially causing lung inflammation and allergic reactions when inhaled $[25,38,39])$ and microorganisms. $[25,40]$ In this thesis the primary focus is on exposure to goat farms and to a lesser extent to poultry farms.[41,42] While poultry farms are notorious for their high PM and endotoxin emissions [24,43-45], goat farms in the Netherlands are the least PM emitting stables when compared to PM emissions from other livestock species.[45,46] Although goat farms are the least PM emitting stables in the Netherlands, they were the source of $C$. burnetii leading to the 2007-2010 $\mathrm{Q}$ fever outbreak. During and after the outbreak, no live $C$. burnettii was ever cultured from goat stable dust. This is because bacterial culturing of $C$. burnetii is only allowed in biosafety level 3 laboratories [47] and most diagnostic labs do not reach this biosafety level. 


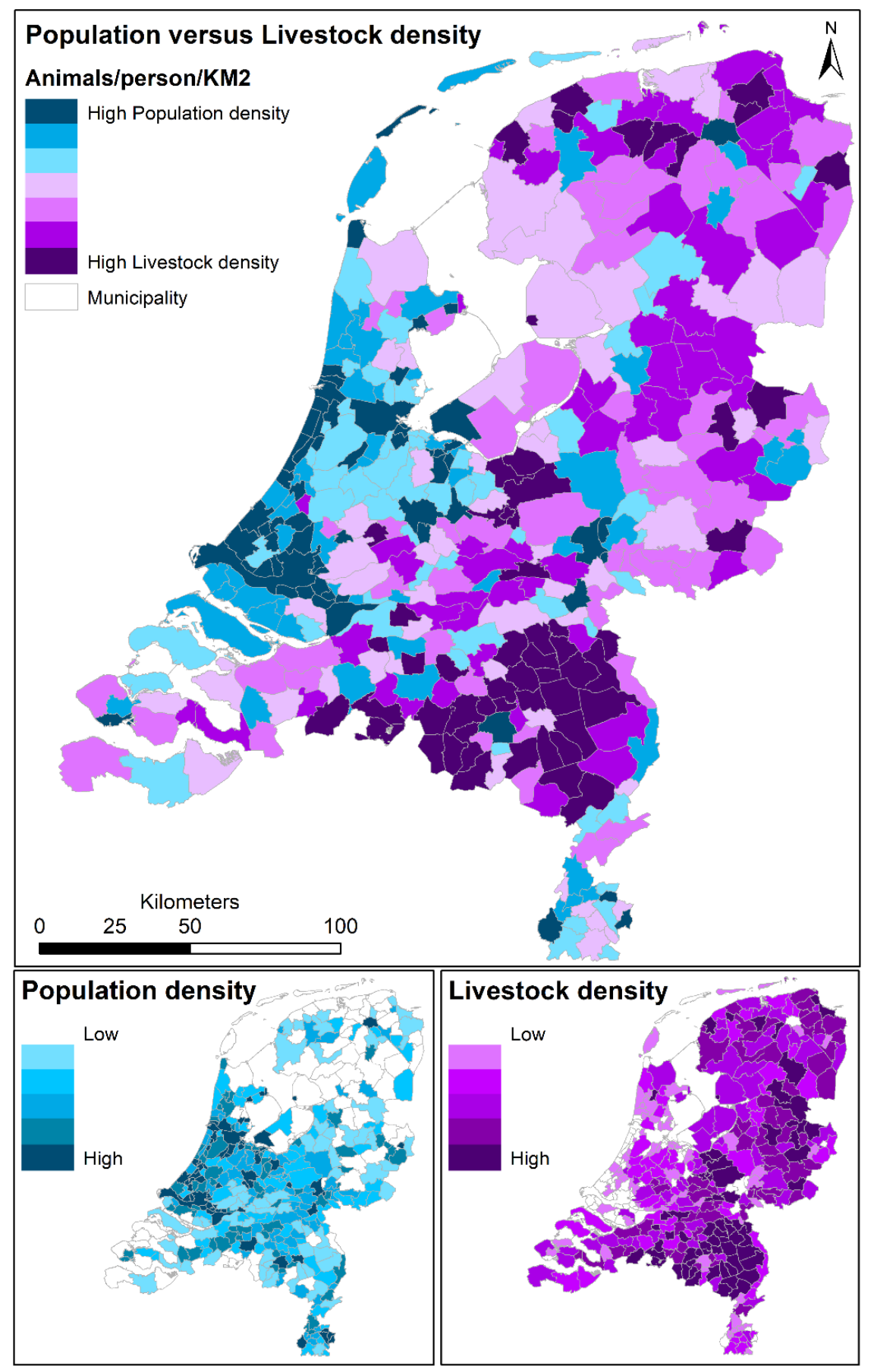

Figure 1. The Netherlands, population versus livestock density and detail maps of population density and livestock density per municipality. Information available from: [18,19] 
Still, C. burnetii DNA has been found in goat stable emissions in multiple studies. $[9,46]$ It has been hypothesised that especially, resuspension in the air of bacteria attached to dust particles from straw are the mode of transmission for $C$. burnetii.[9,46] Providing this is true, this transmission mode may also occur with other microorganisms originating from goat stables.

\section{Exposure-assessment for livestock emissions}

Livestock farms are known to emitted PM, endotoxins and microorganisms $[24,25,40,45,48]$ what is not considered yet, is how people get exposed to livestock emissions and how these exposures are evaluated. Environmental epidemiology is fairly limited in the usage of epidemiological study designs, only observational studies can be applied in this field of research.[49] Applying experimental studies such as randomised control trials $(R C T)$, where one study group is intentionally treated with a specific substance and a control group is not [50], is not possible for environmental epidemiology. Exposures arise from the environment and it is often not feasible or ethical to influence these environmental factors.

Natural experiments, where health outcomes for a specific population are an effect of an unintentional event, are concerning their outcomes closest to an RCT for environmental epidemiologists. [49] In 2003 for example, an outbreak of Avian Influenza was discovered in poultry farms in the central area of the Netherlands, one of the containment interventions was culling of poultry on infected and surrounding farms. [14] As a secondary result of this intervention, the prevalence of campylobacteriosis decreased significantly. Campylobacteriosis is an infection of the gastro-intestinal tract with Campylobacter species bacteria. These bacteria are known food related pathogens, but the found associations indicate that another infectious pathway is likely through air.[51]

When certain differences in prevalence of health effects between two populations are of a more persistent nature, these can be observed by applying an ecological study design.[52] In these type of studies prevalence of disease are compared between two populations that are exposed to other environmental factors. For example, in the Netherlands a population living in a rural area with a high density of livestock farms was compared to a population living in a rural, but low livestock density area. Higher prevalence was observed for lung related diseases (e.g. chronic bronchitis, lower respiratory tract infections and pneumonia) in the population living in the high livestock density area. However, a lower prevalence was observed for other lung diseases (e.g. Chronic Obstructive Pulmonary Disease (COPD) and allergic rhinitis).[52,53]

Although ecological study designs are relatively easy and inexpensive to perform, they only provide an indication whether certain health effects are more prevalent in specific areas or populations.[50] These studies are therefore often used to develop hypotheses, focussing research to a specific area, investigate disease patterns on an individual level or focus research towards potential causal agents, using study designs such as casecontrol studies and cohort studies.[49,50]

VGO study

An example of such a focused study is the Dutch 'Farming and Neighbouring Residents' Health' study ('Veehouderij en Gezondheid Omwonenden' studie, Dutch acronym: VGO 
study [53]). This study was initiated because after the $\mathrm{Q}$ fever outbreak [3], the study by Friesema et al. [51] and the associations found between farm emission exposure and adverse health effects in farmers [28,38], an interest was sparked in the potential effects of livestock keeping on human health.[54] The Netherlands was the "ideal" country to perform such a study because of the large human population living close to large numbers of livestock.(Figure 1) In 2012, after a pilot study performed between 2009 and 2011 [54-56], four institutes, the Institute for Risk Assessment Sciences (IRAS) of Utrecht University, the National Institute for Public Health and the Environment (RIVM), the Netherlands Institute for Health Services Research (NIVEL) and Wageningen University and Research (WUR) joined to perform this VGO study. The aim of the VGO study was to investigate whether living in the vicinity of livestock farms has an impact on the health of non-occupationally exposed neighbouring residents.[33,53] The original VGO study involved two major components: a health assessment (VGO health study [33]) of residents living in the research area (Figure 2) and an investigation of ambient air in this area (VGO air measurements), an area with a high density and variety of livestock operations.[57] Data from the VGO health study was used for the analyses in this thesis $[41,42,58,59]$, therefore a brief summary is given about the performed analyses in this study component.

The VGO health study involved three steps, besides an analysis of GP-registered electronic medical records (EMR). $[52,53]$ It also involved sending out a questionnaire inquiring about lung health including e.g. diagnoses of asthma, COPD, nasal allergies, wheeze and usage of inhaled corticosteroids [60] to $\mathrm{N} 12000$ people registered with a GP in the research area.[37] Finally, the VGO study enabled the formation of a cohort of volunteers (VGO cohort) for an in-depth health assessment. VGO cohort members $(\mathrm{N}=2494)$ were invited to take part in a medical assessment which was performed in a field study using twelve temporary research stations from March 2014-February 2015.[33] During the medical assessment, a more extensive questionnaire was filled in (VGO questionnaire) with questions regarding health, personal characteristics, life history traits and residential and work addresses. Next, blood and serum samples $[61,62]$, nose and cheek swaps [63], a stool sample $[16,64]$ and permission to use GPregistered EMRs for analysis were collected and lung function measurements were performed.[33,53,65]

The VGO study identified several health effects associated with living near livestock farms. For instance, living near many livestock farms (>15 farms) was associated with a decreased lung function in VGO cohort members.[37] Living near poultry or especially, goat farms was found to be associated with an increased risk for pneumonia and positive C. burnetii antibody serology.[61,65] No associations were identified for increased positive serology for Hepatitis $E$ and living close to pig stables [62] and carriage of bacteria (Methicillin-Resistant Staphylococcus aureus (MRSA), Enterobacteriaceae

carrying Extended-Spectrum Beta Lactamases (ESBLs) and Clostridium difficile). $[16,63,64]$ Furthermore, living near livestock farms was found to reduce risks for allergies.[66] 


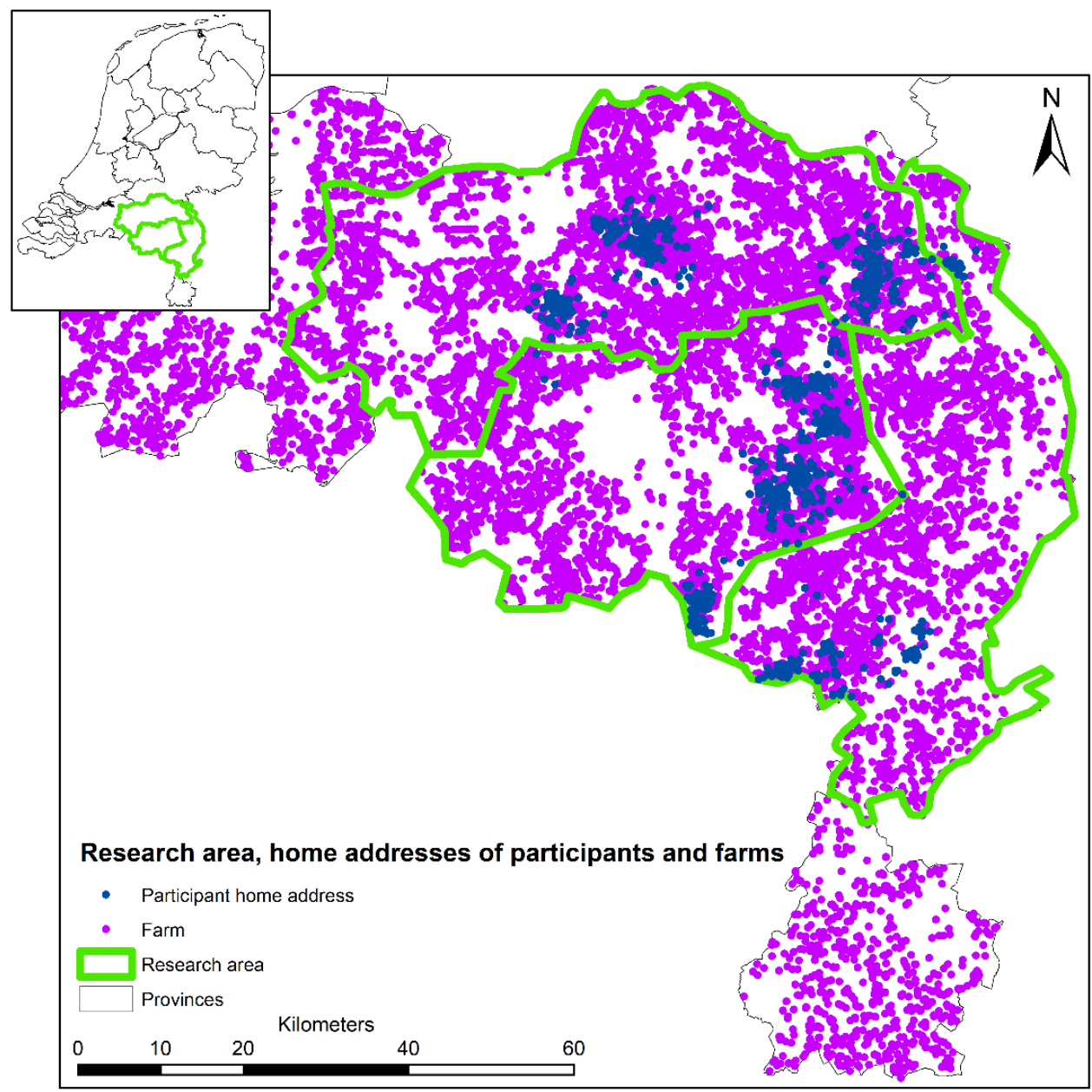

Figure 2. The research area, with distributions of farms and home addresses of participants. Information available from: $[53,84,85]$

Home address as a proxy for exposure

In all previously mentioned studies, living in a specific area or at a certain address is considered as being exposed to livestock. People spent a lot of time in their home, according to the 'time use study' (Dutch acronym: TBO $[67,68]$ ), performed every 5 years by the Netherlands governments' Social and Cultural Planning agency (SCP [69]). For this study, questionnaires and week-long activity diaries are sent to groups of randomly selected Dutch citizens.[70] The data coming from this study represents a cross-section of the time spent on specific activities by the Dutch population. For example, the 2016 TBO report observed that 19 hours/week are spent on housekeeping, 20 hours/week are spent on media usage and 77 hours/week are 'personal time' (sleeping, eating, drinking and personal hygiene).[68] Assuming that these activities 
primarily take place at home, people on average spent at least 116 hours/week in their home. Using the home address as the primary proxy of exposure may therefore be a valid approach, but people also spent 52 hours/week somewhere else. During these hours, they may be exposed to other substances and concentrations of exposures.

In addition, the concentrations of substances that we encounter outdoors are not necessarily the same as those indoors. This has been shown in urban areas with higher outdoors concentrations of $\mathrm{PM}_{10}, \mathrm{PM}_{2.5}$ (PM with a diameter $<10 \mu \mathrm{m}$, or $<2.5 \mu \mathrm{m}$, respectively), sulphate and soot, all agents arising from combustion processes, when compared to indoor measurements.[71] More importantly for our study is that studies focusing on rural areas, in general identified higher concentrations of endotoxins outdoors than indoors.[72-75] The urban study of Hoek et al showed that smaller particles $\mathrm{PM}_{2.51}$ sulphate and soot were more likely to penetrate homes than lager particles such as $\mathrm{PM}_{10}$.[71] Although single bacteria have the small size to penetrate houses [76], the fact that endotoxin levels are generally lower indoors than outdoors suggests that spending time outdoors may be an important factor in exposure to livestock emissions and uptake of livestock-related pathogens.

\section{Aims of this thesis}

The VGO health study indicated an exposure-response association between living in vicinity of livestock farming and adverse health effects. The study did not consider interactions between livestock and humans leading to potential transmissions of infectious diseases. Therefore, we reviewed and summarised current knowledge about the role of intensity and type of interactions between livestock and humans with regards to microorganism transmission.

\section{VGO GPS study}

When an exposure assessment is performed, three dimensions of the exposure have to be considered: concentration of the agent in the medium the population is exposed to (e.g. concentration in $\mathrm{mg} \mathrm{m}^{-3}$ for air), duration of the exposure (e.g. minutes, hours, or longer in case of effects from chronic exposure) and frequency of the exposure (e.g. times per week or per year).[49] Exposure to livestock-origin emissions in most studies published so far has generally been assigned using the residential address as proxy of exposure. $[61,65,66]$ By applying this method duration and frequency of exposures were not considered in the previous studies. The fact that people spent time outdoors and are mobile through their surroundings has also not been assessed in previous calculations. Moreover, during and after the Dutch $\mathrm{Q}$ fever outbreak [3], it has been questioned whether mobility and time spent outdoors played a role in the exposure to $C$. burnetii bacteria. $[5,77,78]$ Mobility and time spent outdoors may therefore be important factors in exposure pathways of livestock-related infectious diseases. Combining mobility and time spent outdoors to generate time activity patterns, can help to understand the effect of duration and frequency of exposure to livestock emissions leading to infectious diseases transmission. A person that spends more time outdoors may have a higher risk of being exposed to concentrations of livestock-related infectious agents that exceed the threshold of infectivity. $[79,80]$

Therefore, in this thesis we describe the outcomes of the VGO GPS study. In this study we evaluated how much time people spent outdoors near their home using self- 
reporting and we measured human mobility using Global Positioning System (GPS [81]) logging.[82] These measurements were performed in a subset of participants ( $N=1014)$ invited from the VGO cohort $(\mathrm{N}=2494)$. This provided a rich dataset with information regarding mobility, general characteristics, health data, information about weekly time spent outdoors near the home, and home and work addresses for 941 VGO GPS study participants after GPS data collection and cleaning.[41,42,58,59] The gathered GPS data was translated into hours per week of walking, biking and motorised transport using an algorithm developed by Huss et al.[83] The hours per week assigned to walking and biking were considered as active mobility and acted as exposure time when spent within specified distances of farms.[41,42] Combined with self-reported hours per week spent outdoors near the home address, we aimed to investigate whether time activity patterns played a role in exposure assessment. For our studies we focussed on livestock exposure associated with increases in pneumonia incidence $[41,65]$ and exposures to goat farms and previous $Q$ fever infections.[42] The outcomes of these investigations were used to evaluate whether time activity patterns should be included to exposure assessment methods for livestock related infectious diseases.

\section{Chapters in this thesis}

Chapter $\mathbf{2}$ describes a systematic review of current literature on livestock-associated zoonotic diseases and what is known about human-livestock contact patterns and how these contact patterns may lead to transmission of micro-organisms from livestock to humans.

In Chapter 3 the GPS data cleaning process, as performed in the VGO GPS study, is explained. The algorithm is introduced that was used to translate GPS data into percentages of time spent on three different transport modes: walking, biking and motorised transport. In this chapter is also explored whether characteristics could be identified that explained differences in patterns of mobility between participants. Furthermore, self-reported mobility patterns were compared to GPS measured mobility patterns.

Chapter 4 evaluates whether mobility patterns and time spent outdoors close to home in the vicinity of goat or poultry farms added to the risk for pneumonia in the VGO GPS study population.

Mobility data is not always available for exposure assessment studies, especially not in large study populations. Therefore, in Chapter 5 three different estimation methods are evaluated to individually predict active mobility (walking and biking). Estimation methods were based on in chapter 3 identified general characteristics that explained differences in mobility patterns, adjusted self-reported data and location information of participants. The generated predictions were validated with matched GPS measurements from the VGO GPS study participants.

Chapter 6 focusses on $C$. burnetii ( $Q$ fever) exposure. In this chapter, it is evaluated whether total hours/week spent outdoors in the vicinity of goat farms, was associated with the risk for positive C. burnetii antibody serology after the Dutch 2007-2010 outbreak. In this chapter, self-reported hours/week spent outdoors near the home and GPS measured active mobility in the vicinity of goat farms were combined to generate time activity patterns.

In Chapter 7 is discussed whether, on the basis of the results shown in previous chapters, 
time activity patterns should be included to exposure assessment. In this chapter is furthermore explored how time activity information can be included in future exposure assessment studies. Finally, the implications of spending time outdoors and human mobility during livestock-related zoonotic outbreaks, are considered for public health contingency planning. 


\section{References}

$1 \quad$ Karagiannis I, Morroy G, Rietveld A, et al. Q fever outbreak in the Netherlands: a preliminary report. Euro Surveill 2007;12. doi:10.2807/esw.12.32.03247-en

2 Karagiannis I, Schimmer B, Van Lier A, et al. Investigation of a $Q$ fever outbreak in a rural area of The Netherlands. Epidemiol Infect 2009;137:1283-94. doi:10.1017/So950268808001908 Roest HIJ, Tilburg JJHC, Van Der Hoek W, et al. The Q fever epidemic in the Netherlands: History, onset, response and reflection. Epidemiol Infect 2011;139:1-12. doi:10.1017/So950268810002268 Dijkstra F, van der Hoek W, Wijers N, et al. The 2007-2010 Q fever epidemic in the Netherlands: Characteristics of notified acute $\mathrm{Q}$ fever patients and the association with dairy goat farming. FEMS Immunol Med Microbiol 2012;64:3-12. doi:10.1111/j.1574-695X.2011.00876.X De Rooij MMT, Van Leuken JPG, Swart A, et al. A systematic knowledge synthesis on the spatial dimensions of $Q$ fever epidemics. Zoonoses Public Health 2019;66:14-25. doi:10.1111/zph.12534 RIVM. Q koorts. https://www.rivm.nl/q-koorts Hogerwerf L, van den Brom R, Roest HIJ, et al. Reduction of coxiella burnetii prevalence by vaccination of goats and sheep, The Netherlands. Emerg Infect Dis 2011;17:379-86. doi:10.3201/eid1703.101157 Van den Brom R, Santman-Berends I, Luttikholt S, et al. Bulk tank milk surveillance as a measure to detect Coxiella burnetii shedding dairy goat herds in the Netherlands between 2009 and 2014. J Dairy Sci 2015;98:3814-25. doi:10.3168/jds. 2014-9029 Hogerwerf $L$, Borlée F, Still K, et al. Detection of Coxiella burnetii DNA in inhalable airborne dust samples from goat farms after mandatory culling. Appl Environ Microbiol 2012;78:5410-2. doi:10.1128/AEM.00677-12 Vellema $P$, van den Brom R. The rise and control of the 2007-2012 human $Q$ fever outbreaks in the Netherlands. Small Rumin Res 2014;118:69-78. doi:10.1016/j.smallrumres.2013.12.006 van Roeden SE, Reukers DFM, van Jaarsveld CHM, et al. Chronic $Q$ fever: patient and treatmentrelated factors influencing long-term quality of life. QJM 2018;111:791-7. doi:10.1093/qjmed/hcy171 Webber R. Communicable Disease Epidemiology and Control, A Global Perspective. 3rd ed. Cabi Publishing 2004. Jones KE, Patel NG, Levy MA, et al. Global trends in emerging infectious diseases. Nature 2008;451:990-3. doi:10.1038/natureo6536 Koopmans, Wilbrink, Conyn, et al. Transmission of $\mathrm{H}_{7} \mathrm{~N}_{7}$ avian influenza A virus to human beings during a large outbreak in commercial poultry farms in the Netherlands. Infect Dis Clin Pract 2004;12:276-7. doi:10.1097/01.idc.0000130890.12611.f3

Graveland H, Duim B, van Duijkeren E, et al. Livestock-associated methicillin-resistant Staphylococcus aureus in animals and humans. Int J Med Microbiol 2011;301:630-4. doi:10.1016/j.ijmm.2011.09.004 Wielders $\mathrm{CCH}$, van Hoek AHAM, Hengeveld PD, et al. Extended-spectrum $\beta$-lactamase- and pAmpC-producing Enterobacteriaceae among the general population in a livestock-dense area. Clin Microbiol Infect 2017;23:120.e1-120.e8. doi:10.1016/j.cmi.2016.10.013 Statistics Netherlands (CBS). Landsurface. http://statline.cbs.nl/\%oAStatweb/publication/?DM=SLNL\&PA=70262ned\&D1=0-2\&D $2=0-$ $4 \& D_{3}=3-7 \& \% \circ A V W=T \% \circ A$ Statistics Netherlands (CBS). Population Netherlands http://statline.cbs.nl/\%oAStatweb/publication/?DM=SLNL\&PA=37296ned\&D1=0-2,19-28,52$58,68 \& D_{2}=\% 0 A 0,10,20,30,40,50,(\mathrm{l}-1)-1 \& V W=T$ Statistics Netherlands (CBS). Livestock Netherlands (2016). http://statline.cbs.nl/\%oAStatweb/publication/?DM=SLNL\&PA=81302NED\&D1=387$536 \& D_{2}=0,5,10,13-\% 0 A 16 \& H D R=G 1 \& S T B=T \& V W=T /$ Statistics Netherlands (CBS). Population Brabant (2015). https://opendata.cbs.nl/statline/\#/CBS/nl/dataset/o3759ned/table?ts=1571653480811 Brooke RJ, Kretzschmar MEE, Mutters NT, et al. Human dose response relation for airborne exposure to Coxiella burnetii. BMC Infect Dis 2013;13. doi:10.1186/1471-2334-13-488 Raoult D, Marrie TJ, Mege JL. Natural history and pathophysiology of Q fever. Lancet Infect Dis 2005;5:219-26. doi:10.1016/S1473-3099(05)70052-9 Angelakis E, Raoult D. Q fever. 2010;140:297-309. doi:10.1016/j.vetmic.2009.07.016 
Cambra-López M, Aarnink AJA, Zhao Y, et al. Airborne particulate matter from livestock production systems: A review of an air pollution problem. Environ Pollut 2010;158:1-17. doi:10.1016/j.envpol.2009.07.011 Seedorf J. An emission inventory of livestock-related bioaerosols for Lower Saxony, Germany. Atmos Environ 2004;38:6565-81. doi:10.1016/j.atmosenv.2004.08.023 . personal exposure to dust and endotoxin in livestock farming. J Expo Sci Environ Epidemiol 2015;25:123-37. doi:10.1038/jes.2013.83 Beck JP, Heutelbeck A, Dunkelberg $\mathrm{H}$. Volatile organic compounds in dwelling houses and stables of dairy and cattle farms in Northern Germany. Sci Total Environ 2007;372:440-54. doi:10.1016/j.scitotenv.2006.10.009 Blanes-Vidal V, Suh H, Nadimi ES, et al. Residential exposure to outdoor air pollution from livestock operations and perceived annoyance among citizens. Environ Int 2012;40:44-50. doi:10.1016/j.envint.2011.11.010 Gyldenkærne S, Skjøth CA, Hertel O, et al. A dynamical ammonia emission parameterization for use in air pollution models. J Geophys Res Atmos 2005;110:1-14. doi:10.1029/2004JDo05459 Erisman JW, Grennfelt P, Sutton M. The European perspective on nitrogen emission and deposition. Environ Int 2003;29:311-25. doi:10.1016/S0160-4120(02)00162-9 Backes AM, Aulinger A, Bieser J, et al. Ammonia emissions in Europe, part II: How ammonia emission abatement strategies affect secondary aerosols. Atmos Environ 2016;126:153-61. doi:10.1016/j.atmosenv.2015.11.039 Bellarby J, Tirado R, Leip A, et al. Livestock greenhouse gas emissions and mitigation potential in Europe. Glob Chang Biol 2013;19:3-18. doi:10.1111/j.1365-2486.2012.02786.x Borlée F, Yzermans CJ, Krop E, et al. Spirometry, questionnaire and electronic medical record based COPD in a population survey: Comparing prevalence, level of agreement and associations with potential risk factors. PLoS One 2017;12:1-16. doi:10.1371/journal.pone.0171494 reductions in Europe. Environ Pollut 2004;129:159-63. doi:10.1016/j.envpol.2003.08.042 Renner E, Wolke R. Modelling the formation and atmospheric transport of secondary inorganic aerosols with special attention to regions with high ammonia emissions. Atmos Environ 2010;44:1904-12. doi:10.1016/j.atmosenv.2010.02.018

$$
\text { Loftus C, Yost M, Sampson P, et al. Ambient Ammonia Exposures in an Agricultural Community }
$$
and Pediatric Asthma Morbidity. 2015;26. doi:10.1097/EDE.0000000000000368 Borlée F, Yzermans CJ, van Dijk CE, et al. Increased respiratory symptoms in COPD patients living in the vicinity of livestock farms. Eur Respir J 2015;46:1605-14. doi:10.1183/13993003.00265-2015

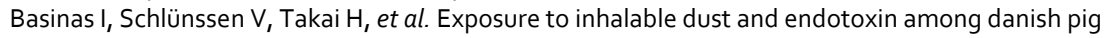
farmers affected by work tasks and stable characteristics. Ann Occup Hyg 2013;57:1005-19. doi:10.1093/annhyg/meto29

Rooij MMT De, Heederik DJJ, Borlée F, et al. Spatial and temporal variation in endotoxin and PM10 concentrations in ambient air in a livestock dense area. Environ Res 2017;153:161-70.

doi:10.1016/j.envres.2016.12.004

De Rooij MMT, Hoek G, Schmitt H, et al. Insights into Livestock-Related Microbial Concentrations in Air at Residential Level in a Livestock Dense Area. Environ Sci Technol 2019;53:7746-58. doi:10.1021/acs.est.8bo7029

Klous G, Smit LAM, Freidl GS, et al. Pneumonia risk of people living close to goat and poultry farms - Taking GPS derived mobility patterns into account. Environ Int 2018;115. doi:10.1016/j.envint.2018.03.020

Klous G, Smit LAM, van der Hoek W, et al. Relationship between Coxiella burnetii ( $\mathrm{Q}$ fever) antibody serology and time spent outdoors. Submitted.

Smit LAM, Boender GJ, de Steenhuijsen Piters WAA, et al. Increased risk of pneumonia in residents living near poultry farms: does the upper respiratory tract microbiota play a role? Pneumonia 2017;9:1-35. doi:10.1186/s41479-017-0027-0 Jonges $\mathrm{M}$, Van Leuken J, Wouters I, et al. Wind-mediated spread of low-pathogenic avian influenza virus into the environment during outabreaks at commercial poultry farms. PLoS One 2015;10:115. doi:10.1371/journal.pone.0125401 houses in the Netherlands. Atmos Environ 2015;111:202-12. doi:10.1016/j.atmosenv.2015.03.047 

melkgeitenstallen. 2012. RIVM LCI. Q koorts, diagnostiek. https://lci.rivm.nl/richtlijnen/q-koorts\#index_Diagnostiek de Rooij MMT, Smit LAM, Erbrink HJ, et al. Endotoxin and particulate matter emitted by livestock farms and respiratory health effects in neighboring residents. Environ Int 2019;132:105009. doi:10.1016/j.envint.2019.105009 Nieuwenhuijsen MJ. Exposure Assessment in Environmental Epidemiology. 2nd ed. Oxford University Press Inc 2015. Rothman K. Epidemiology, An introduction. 2nd ed. Oxford University Press Inc 2012. Friesema IHM, Havelaar AH, Westra PP, et al. Poultry culling and campylobacteriosis reduction among humans, The Netherlands. Emerg Infect Dis 2012;18:466-8. doi:10.3201/eid1803.111024 van Dijk CE, Zock JP, Baliatsas C, et al. Health conditions in rural areas with high livestock density: Analysis of seven consecutive years. Environ Pollut 2017;222:374-82.

doi:10.1016/j.envpol.2016.12.023

Maassen K, Smit L, Wouters I, et al. Veehouderij en gezondheid omwonenden. Published Online First: 2016.http://rivm.openrepository.com/rivm/handle/10029/617909 Heederik PDJJ, ljzermans CJ. van omwonenden : onderzoek naar potentiële blootstelling en gezondheidsproblemen IRAS Universiteit Utrecht, NIVEL, RIVM , 7 juni 2011. 2011;:4-204. Smit LAM, Hooiveld M, Van Der Sman-de Beer F, et al. Air pollution from livestock farms, and asthma, allergic rhinitis and COPD among neighbouring residents. Occup Environ Med 2014;71:134-40. doi:10.1136/oemed-2013-101485 Hooiveld M, Smit LAM, Van Der Sman-De Beer F, et al. Doctor-diagnosed health problems in a region with a high density of concentrated animal feeding operations: A cross-sectional study. Environ Heal A Glob Access Sci Source 2016;15:1-9. doi:10.1186/s12940-016-0123-2 measured in ambient PM10 in a livestock-dense area: Implementation of a land-use regression approach. Environ Health Perspect 2018;126:1-11. doi:10.1289/EHP2252 Klous G, Smit LAM, Borlée F, et al. Mobility assessment of a rural population in the Netherlands using GPS measurements. Int J Health Geogr 2017;16:30. doi:10.1186/s12942-017-0103-Y Klous G, Kretzschmar MEE, Coutinho RA, et al. Prediction of human active mobility in rural areas: development and validity tests of three different approaches. J Expo Sci Environ Epidemiol Published Online First: 26 November 2019. doi:10.1038/s41370-019-0194-6 ECHRS 3. Change in respiratory symptoms in young adults as they age: European community respiratory health survey 3 (ECRHS 3 ). Eur Respir J 2013;42:1809. Pijnacker R, Reimerink J, Smit LAM, et al. Remarkable spatial variation in the seroprevalence of Coxiella burnetii after a large Q fever epidemic. BMC Infect Dis 2017;17:1-8. doi:10.1186/s12879017-2813-y van Gageldonk-Lafeber AB, van der Hoek W, Borlée F, et al. Hepatitis E virus seroprevalence among the general population in a livestock-dense area in the Netherlands: A cross-sectional population-based serological survey. BMC Infect Dis 2017;17:1-9. doi:10.1186/s12879-016-2160-4 Zomer TP, Wielders $\mathrm{CCH}$, Veenman $\mathrm{C}$, et al. MRSA in persons not living or working on a farm in a livestock-dense area: prevalence and risk factors. J Antimicrob Chemother 2017;72:893-9. doi:10.1093/jac/dkw483

4 Teunis PFM, Evers EG, Hengeveld PD, et al. Time to acquire and lose carriership of ESBL/ pAmpC producing E. coli in humans in the Netherlands. PLoS One 2018;13:1-14.

doi:10.1371/journal.pone.0193834

Freidl GS, Spruijt IT, Borlée F, et al. Livestock-associated risk factors for pneumonia in an area of intensive animal farming in the Netherlands. PLOS One 2017;12:1-16.

doi:10.1371/journal.pone.0174796 Borlee F, Yzermans CJ, Krop EJM, et al. Residential proximity to livestock farms is associated with a lower prevalence of atopy. Occup Environ Med 2018;75:453-60. doi:10.1136/oemed-2017-104769 SCP. Tijdbestedingsonderzoek (TBO). https://www.scp.nl/Onderzoek/tijdsbesteding Roeters A, de Boer A, van den Broek A, et al. Alle ballen in de lucht; Alle ballen in de lucht. 2018 ;:1223.www.scp.nl

SCP. Home page. https://www.scp.nl/

Arends J, Hofman I, Knops J, et al. Tijdsbestedingsonderzoek 2016: Onderzoeksdocumentatie en Kwaliteitsrapportage. Published Online First: 2017.file:///C:/Users/s129388/Downloads/TBO 2016 Onderzoeksdocumentatie_en_Kwaliteitsanalyse_Extern_v1.pdf 
Hoek G, Kos G, Harrison R, et al. Indoor-outdoor relationships of particle number and mass in four European cities. Atmos Environ 2008;42:156-69. doi:10.1016/j.atmosenv.2007.09.026 endotoxin concentrations in residential environments. Atmos Environ 2014;92:221-30. doi:10.1016/j.atmosenv.2014.04.025

73 Pavilonis BT, Anthony TR, O'Shaughnessy PT, et al. Indoor and outdoor particulate matter and endotoxin concentrations in an intensely agricultural county. J Expo Sci Environ Epidemiol 2013;23:299-305. doi:10.1038/jes.2012.123

74 Wheeler AJ, Dobbin NA, Lyrette N, et al. Residential indoor and outdoor coarse particles and associated endotoxin exposures. Atmos Environ 2011;45:7064-71. doi:10.1016/j.atmosenv.2011.09.048 Hennekes M, Hennekes M. VGO personal exposure pilot study: comparing outdoor, indoor and personal PM10 and endotoxin exposure levels in a livestock dense area. 2016 Masterthesis Toxicology and Environmental Health Utrecht University Levin PA, Angert ER. Small but mighty: Cell size and bacteria. Cold Spring Harb Perspect Biol 2015;7:1-11. doi:10.1101/cshperspect.a019216 van der Hoek W, Van De Kassteele JVD, Bom B, et al. Smooth incidence maps give valuable insight into $Q$ fever outbreaks in the Netherlands. Geospat Health 2013;7:127-34. van Leuken JPG, van de Kassteele J, Sauter FJ, et al. Improved correlation of human Q fever incidence to modelled $C$. burnetii concentrations by means of an atmospheric dispersion model. Int $J$ Health Geogr 2015;14:1-14. doi:10.1186/s12942-015-0003-y RIVM LCI. LCI RIVM. https://lci.rivm.nl/

CDC. Diseases Conditions. https://www.cdc.gov/DiseasesConditions/ Al-Rabbany A. Introduction to GPS, the Global Positioning System. Second, re. 2006. Beekhuizen J, Kromhout $\mathrm{H}$, Huss A, et al. Performance of GPS-devices for environmental exposure assessment. J Expo Sci Environ Epidemiol 2013;23:498-505. doi:10.1038/jes.2012.81 Huss A, Beekhuizen J, Kromhout $H$, et al. Using GPS-derived speed patterns for recognition of transport modes in adults. Published Online First: 2014. doi:10.1186/1476-072X-13-40 BVB Brabant https://bvb.brabant.nl/

85 BVB Limburg https://limburg.vaa.com/ 


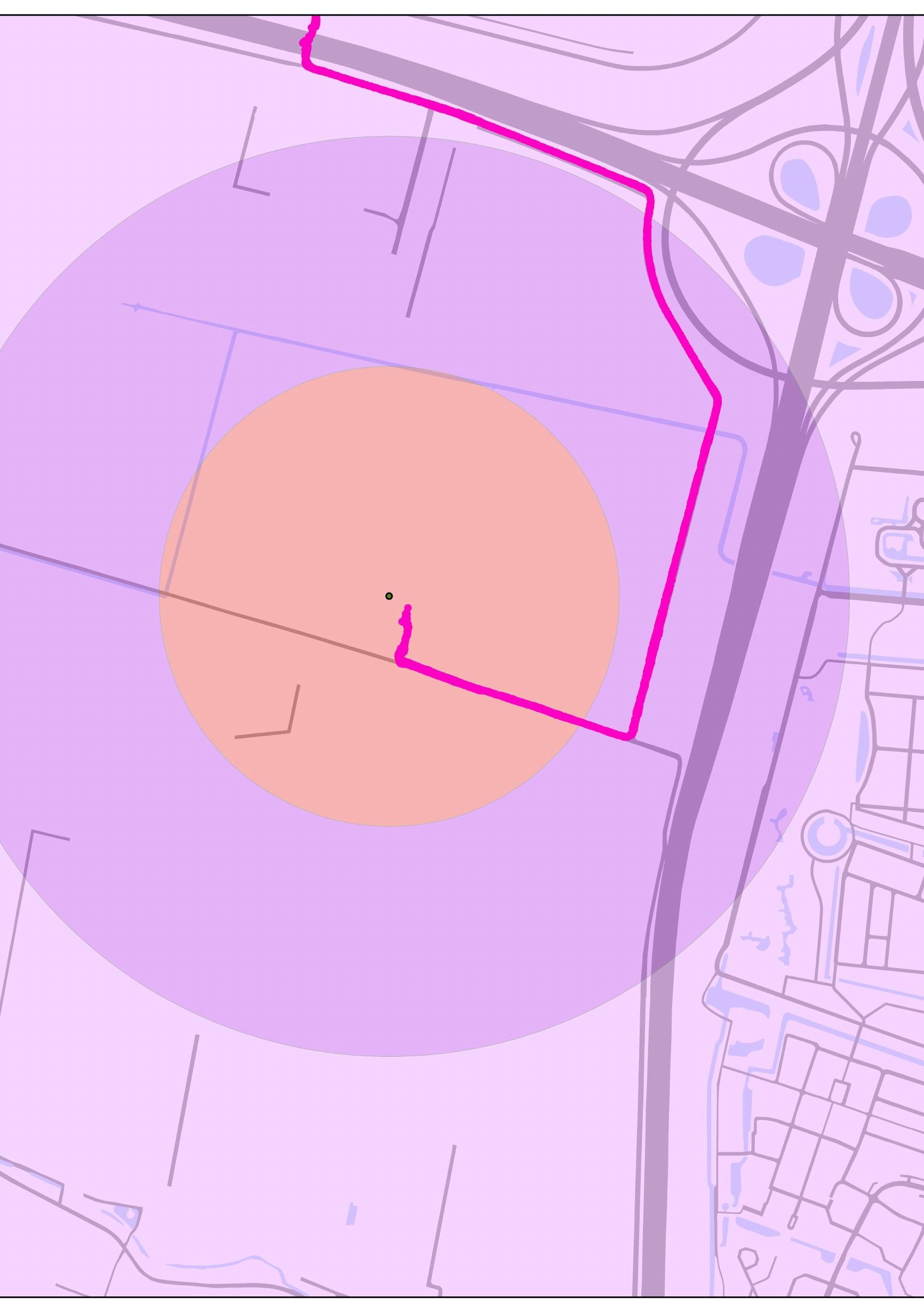


Chapter 2

Human-livestock contacts and their relationship to transmission of zoonotic pathogens, a systematic review of literature 


\title{
Human-livestock contacts and their relationship to transmission of zoonotic pathogens, a systematic review of literature
}

Background: Micro-organisms transmitted from vertebrate animals -including livestock- to humans account for an estimated $60 \%$ of human pathogens. Microorganisms can be transmitted through inhalation, ingestion, via conjunctiva or physical contact. Close contact with animals is crucial for transmission. The role of intensity and type of contact patterns between livestock and humans for disease transmission is poorly understood. In this systematic review we aimed to summarise current knowledge regarding patterns of human-livestock contacts and their role in micro-organism transmission.

Methods: We included peer-reviewed publications published between 1996 and 2014 in our systematic review if they reported on human-livestock contacts, human cases of livestock-related zoonotic diseases or serological epidemiology of zoonotic diseases in human samples. We extracted any information pertaining the type and intensity of human-livestock contacts and associated zoonoses.

Results: 1522 papers were identified, 75 were included: 7 reported on incidental zoonoses after brief animal-human contacts (e.g. farm visits), 10 on environmental exposures and 15 on zoonoses in developing countries where backyard livestock keeping is still customary. 43 studies reported zoonotic risks in different occupations. Occupations at risk included veterinarians, culling personnel, slaughterhouse workers and farmers. For culling personnel, more hours exposed to livestock resulted in more frequent occurrence of transmission. Slaughterhouse workers in contact with live animals were more often positive for zoonotic micro-organisms compared to coworkers only exposed to carcasses. Overall, little information was available about the actual mode of micro-organism transmission.

Conclusions: Little is known about the intensity and type of contact patterns between livestock and humans that result in micro-organism transmission. Studies performed in occupational settings provide some, but limited evidence of exposure response-like relationships for livestock-human contact and micro-organism transmission. Better understanding of contact patterns driving micro-organism transmission from animals to humans is needed to provide options for prevention and thus deserves more attention.

\author{
Abbreviations \\ LA Livestock-Associated \\ MRSA Methicillin-Resistant Staphylococcus aureus \\ PPE Personal Protective Equipment \\ VTEC VeroToxin-producing Escherichia coli
}




\section{Introduction}

Zoonotic infectious diseases - diseases transmitted from vertebrate animals to humansaccount for an estimated $60 \%$ of all human infectious diseases.[1] The rise of zoonotic diseases in humans began after the introduction of agriculture and the domestication of animals when humans started living in large numbers together, in close contact with other vertebrate animals.[2,3] Nowadays, livestock associated infectious diseases are still a major threat to human health, as recently illustrated by the outbreak of pig origin $\mathrm{H}_{1} \mathrm{~N}_{1}$ influenza A pandemic in 2009 or the emergence of camel-origin Middle-East Respiratory Syndrome Coronavirus.[4-6] The occurrence of a zoonotic disease may lead to large economic losses in the agricultural sector.[7-14] When it comes to recent emerging infectious diseases, zoonoses again account for the majority of the newly introduced infectious diseases to the human population. Although zoonoses with a wildlife origin dominate among emerging pathogens, livestock associated zoonotic diseases occur mainly in densely human populated areas in the world [15] and can therefore have a considerable public health impact. In developing countries humans often live close to their livestock [16-18]; in developed countries there are mainly occupational contacts with large numbers of live [19], ill [20] or dead animals [21-24], but there are also reports of micro-organism transmissions via the environment $[25,26]$ or after brief contact. $[27,28]$

Contact with livestock animals can lead to transmission of micro-organisms by inhalation, ingestion, via conjunctiva, or during incidents such as biting or other injuries inflicted by animals.[29] Furthermore, aerosols contaminated with micro-organisms from respiratory [30-34] or fluid sources [35], can play an important role in the transmission of micro-organisms between humans [30-35], but also from animals to humans. Aerosols have been suggested to play a role in micro-organism transmission over very short distances, sometimes as a parallel route to direct contact.[30] It is thus clear that for transmission of zoonotic diseases to occur, the presence of animals or some type of contact with (livestock-) animals is crucial. Initiatives to control livestockassociated zoonotic diseases are already in place, as reviewed by Zinnstag et al [36] and others.[37,38] However, better understanding of contact patterns driving microorganism transmission from animals to humans is needed to provide options for prevention and thus deserves more attention. Therefore, in this study we reviewed current literature on livestock-associated zoonotic diseases, to evaluate current knowledge regarding human-livestock contact patterns. We conducted a systematic review to identify papers reporting on livestock-related zoonoses. We searched the publications regarding reports of contact patterns between livestock animals and humans that led to a transmission of infectious diseases or micro-organisms from livestock to man.

\section{Methods}

We searched EMBASE and Medline for reports on livestock associated (LA) zoonoses combined with human-livestock interactions. Our search terms and selection steps are given in Appendix 1. We also scrutinized references of the included publications. Publications until the $22^{\text {nd }}$ of September 2014 were included.

We included publications reporting on zoonoses from livestock animals, humanlivestock contacts, human-livestock contacts and infectious disease transmission, and 
in case of multiple human LA-zoonosis case reports, exact DNA matches between livestock and human isolates. Peer-reviewed, original research in English, Dutch or German language was included.

We excluded articles describing; vector borne diseases, experimental laboratory studies, xenotransplantation-related diseases, reports on diseases with livestock as a dead-end host (e.g. Rabies, Schistosomiasis, Malaria, and Trypanosoma), papers evaluating diseases linked to wildlife hosts (e.g. bat-related and primate (bushmeat)-related diseases), as well as papers discussing food related zoonosis outbreaks. These articles were excluded because these zoonotic pathogens, are not transmitted through direct contact between livestock and humans.

Selected papers were either articles or articles in press, other publication types were removed from the selection. Titles and abstracts of retrieved publications were evaluated regarding the inclusion and exclusion criteria by GK together with RAC.

\section{Results}

We included seventy-five articles (figure 1) and an overview is given in table 1. Eighteen infectious agents were studied in the selected papers: Methicillin Resistant Staphylococcus aureus (MRSA) was studied most often ( $\mathrm{N}=20$ papers), followed by Avian Influenza ( $\mathrm{Al}, \mathrm{N}=19)$ and Coxiella burnetii $(C$. burnetii, $\mathrm{N}=10)$. An overview of microorganisms and their associated host animals is provided in table 2 . The results are divided in two sections; occupational contact and non-occupational contact. This division was based on the level of reported or assumed contact between humans and livestock, with the assumption that people in livestock handling occupations have greater exposure. Publications reporting on zoonoses from developing countries are classified within the non-occupational contact section, because occupations in these countries are difficult to specify and livestock exposure is not comparable to occupational livestock exposure in developed countries.

\section{Occupational contact}

The 42 selected papers in this section all originate from developed countries. Humanlivestock contacts mainly occurred in occupational settings and concerned primarily veterinarians and veterinary medicine students, people culling animals for zoonotic outbreak control, hereafter named 'cullers', slaughterhouse workers and farmers and their family members. Publications discussed occurrence of: MRSA ( $\mathrm{N}=18$ papers), Avian Influenza $(\mathrm{N}=10)$, C. burnetti $(\mathrm{N}=5)$, Swine Influenza $(\mathrm{N}=3)$, Hepatitis $\mathrm{E}$ virus $(\mathrm{N}=2)$, Antibiotic Resistant Escherichia coli, Avian Metapneumovirus, Brucella spp., Chlamydophila psittaci (C. psittaci), and Leptospira spp. (all $\mathrm{N}=1$ ).

\section{Veterinarians and veterinary medicine students}

With respect to contact with infected animals, veterinarians and veterinary medicine students have an increased risk of acquiring infections. Veterinarians are the first people who come in contact with infected animals in case of an outbreak.[39] They are at increased risk to acquire a wide range of zoonotic infections, as was illustrated in a study among veterinarians from South-Africa.[20] In Denmark, 36\% of veterinarians and 11\% of other occupationally exposed people in contact with dairy cattle were found positive for serological markers of $C$. burnetii; these markers are indicative of (previous-) 
infection after exposure to infected animals.[40] Seroconversion for $C$. burnetii was found in $18.7 \%$ of students whom provided a blood sample in the study of De Rooij et al. A clear exposure-response relationship was found for the prevalence of converted sera which increased with every year the students advanced in their education within the study specialization 'farm animals'. [41] In $44 \%$ of a cohort of Dutch veterinarians, LAMRSA carriage was found on at least one of the repetitive measuring moments, $13 \%$ of all participants were persistent carriers of LA-MRSA. This makes MRSA carriage among veterinarians extremely high, because in the general Dutch population MRSA carriage is very rare $(<0.1 \%)$. [42] In veterinary medicine students MRSA carriage was detected after contact with MRSA carrying horses.[43]

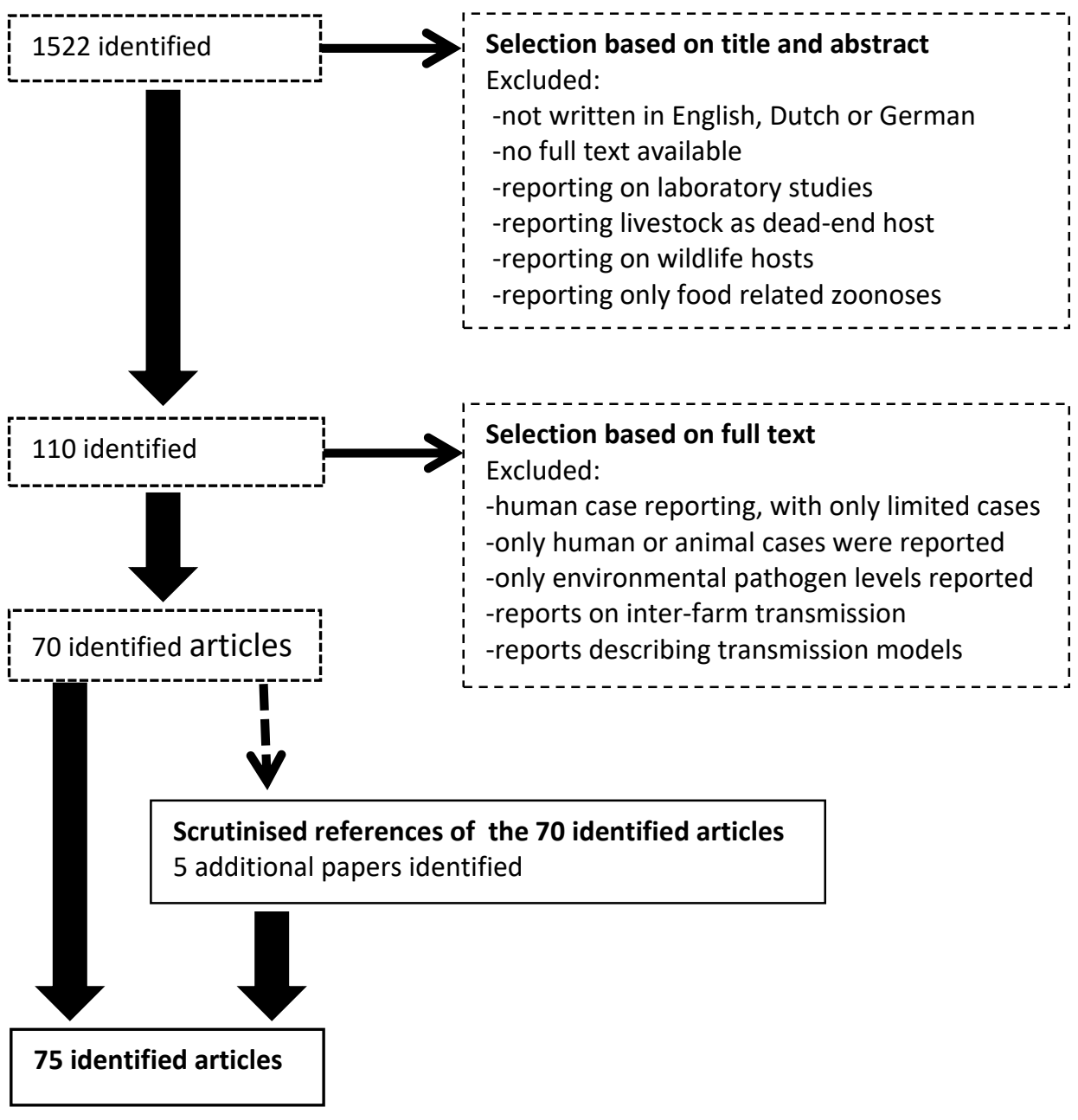

Figure 1. Flowchart of the selection steps, after the Embase and Medline search and filtering procedures. 


\section{Cullers}

After the first cases of a zoonotic outbreak are identified [39], control measure sometimes consist of the culling of the entire flock or herd on the affected farm. Cullers are usually equipped with personal protective equipment and receive personal hygiene instructions, although it has been shown that such measures can reduce exposure, but are not fully protective.[44,45] Secondary cases among contacts of cullers can also occur, as reported after a large outbreak of $\mathrm{H}_{7} \mathrm{~N}_{7}$ Avian Influenza in Dutch poultry farms in 2003.[46] After this outbreak, risk factors for the acquisition [39] and transmission [47] of an infection were 'clinical inspection of poultry in the area surrounding infected flocks' [39,47], and 'active culling during depopulation'.[39] A more quantitative relationship was reported by Whelan et al during the large Q-fever outbreak in the Netherlands between 2007 and 2009.[48] In cullers working on Q-fever infected goat farms, an exposure-response-like relationship between the 'total number of hours worked inside the farm perimeter' and 'working mostly inside stables' and the risk of seroconversion for C. burnetii markers was discovered.[48]

\section{Slaughterhouse workers}

The most relevant observations in this occupational group are the exposure-response relationships for micro-organism carriage or transmission found in slaughterhouse personnel, in particular those individuals in close contact with live animals. [21-24] Four reports, three addressing MRSA and one C. psittaci, in both pig and poultry slaughterhouses, demonstrated clear relationships between the position of the workers on the slaughter line and carriage of micro-organisms or occurrence of disease.[21-24] This was supported by evidence for both temporal and spatial variation for microorganism levels in air, on gloves and surface contamination. Temporal, because during the day an increase of MRSA and C. psittaci environmental levels were shown.[22,24] Spatial, because people at the start of the slaughter line working with live animals, were more often found to be carriers of MRSA, compared to people only working with carcasses.[21-24]

That living animals were the main risk factor for carriage or infections with microorganisms was also shown by Myers et al: they reported that farmers showed the highest Swine Influenza $\mathrm{H}_{1} \mathrm{~N}_{1}$ specific titres in their blood, compared to a pool of veterinarians, control subjects and slaughterhouse workers.[49]

Scott et al found no relationship between antibiotic resistance patterns of $E$. coli isolated from pigs and isolates from slaughterhouse workers.[50] However, Staphylococcus aureus isolates carried by slaughterhouse workers were found to be more extensively resistant to antibiotics compared to community controls.[51] An increased risk for Hepatitis E virus infection in people occupationally exposed to pigs was found, especially for slaughterhouse workers.[52] Also, meat-processing workers had been more often infected with avian Metapneumovirus compared to controls.[53] 


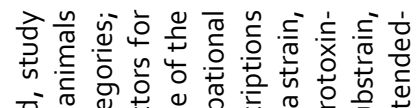

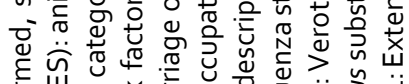

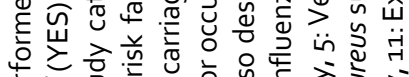

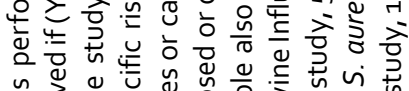

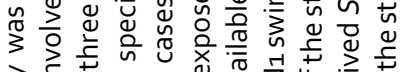

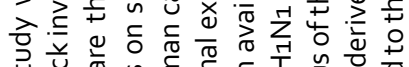

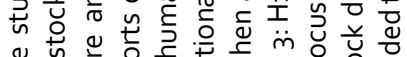

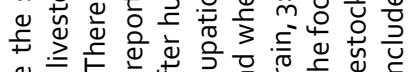
o

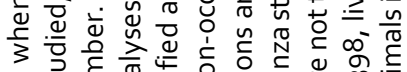

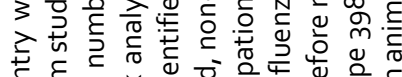

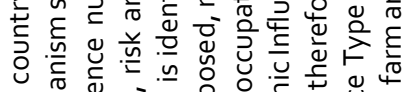

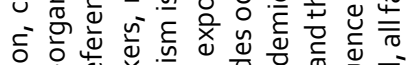

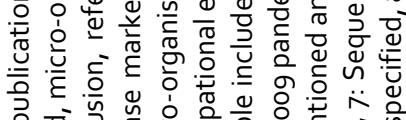

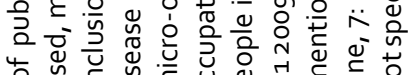

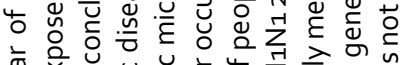

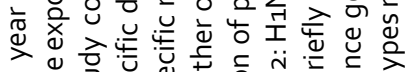

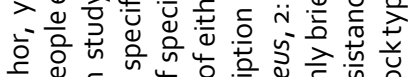

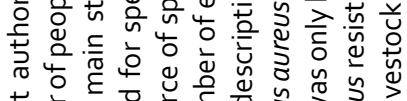
this

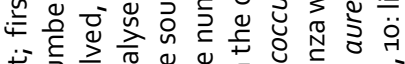
t)

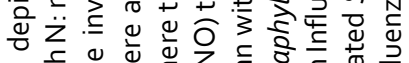

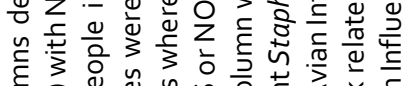

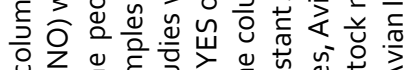
0
0

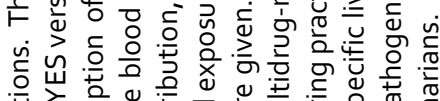
势

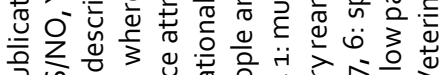
立窟

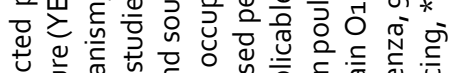

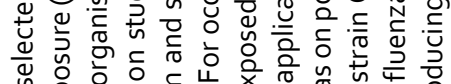

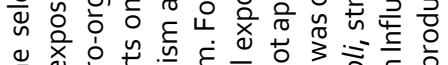

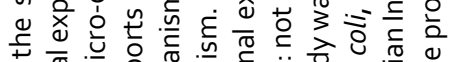

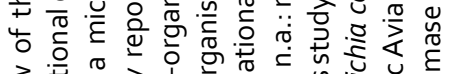

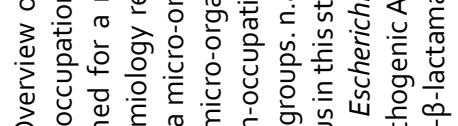

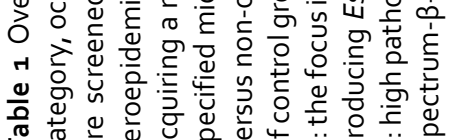

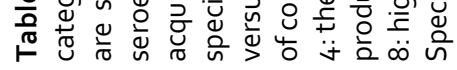

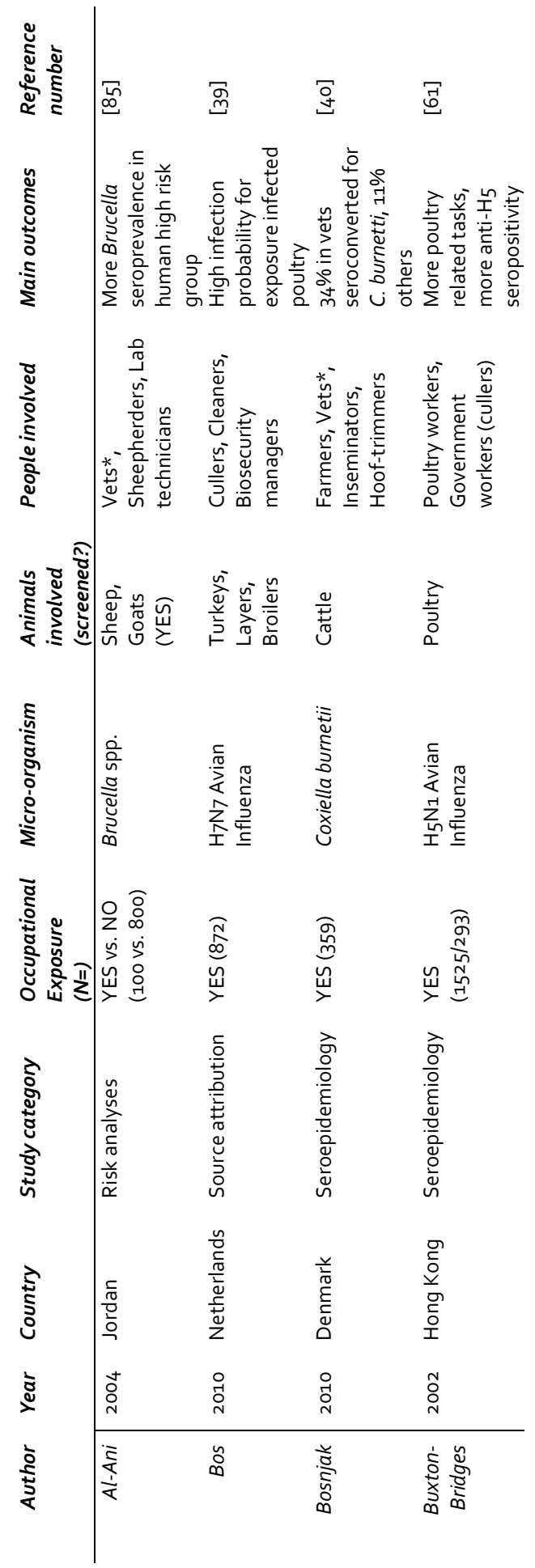




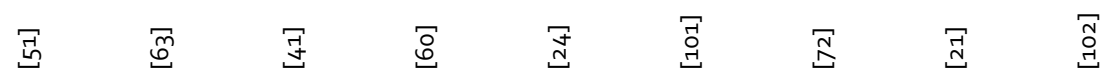

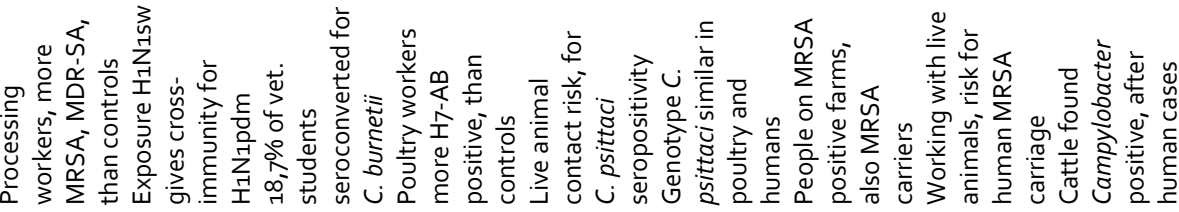

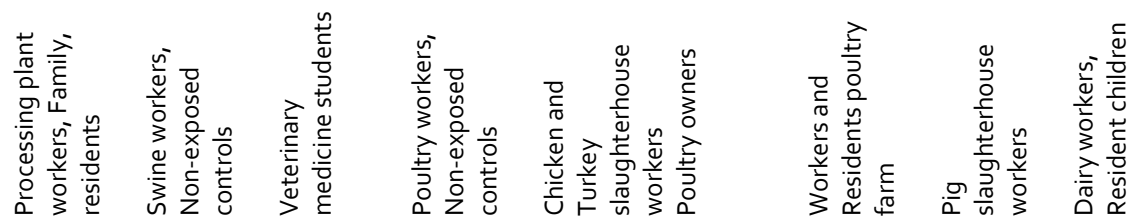

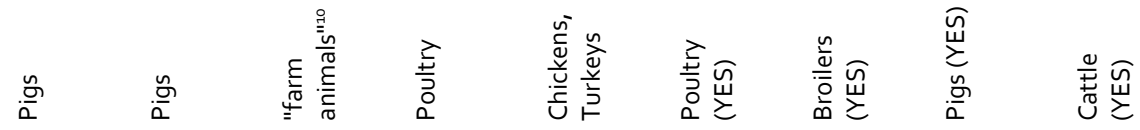

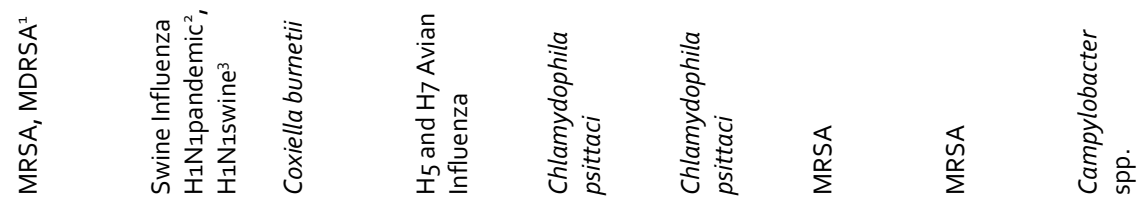

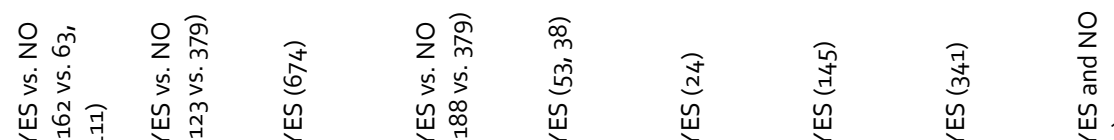

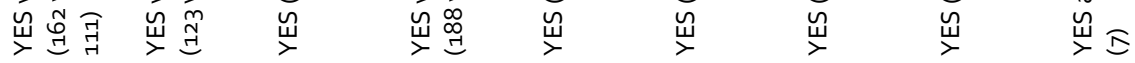

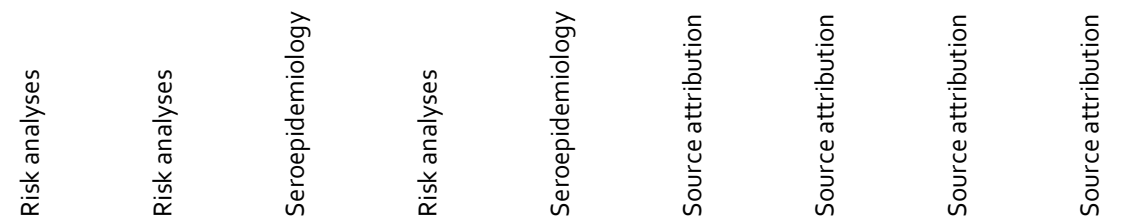

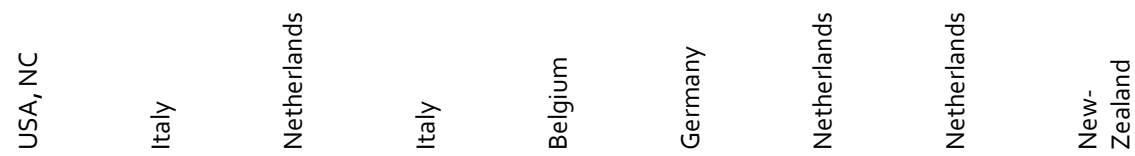

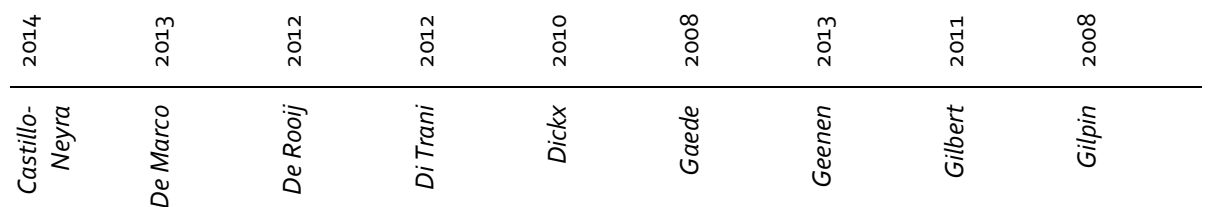




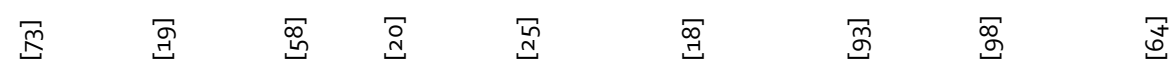

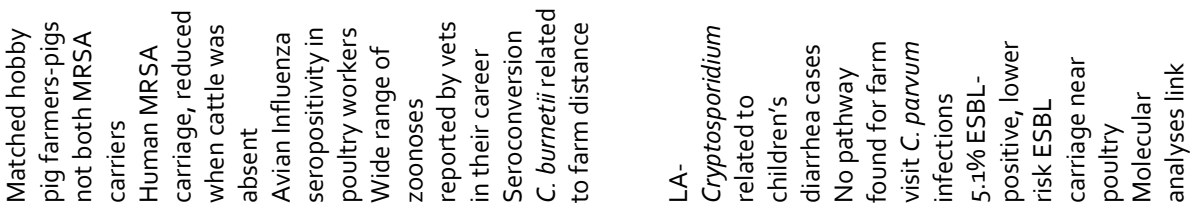

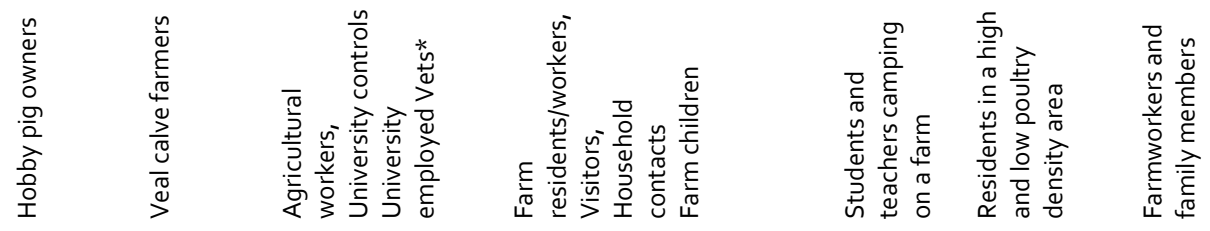

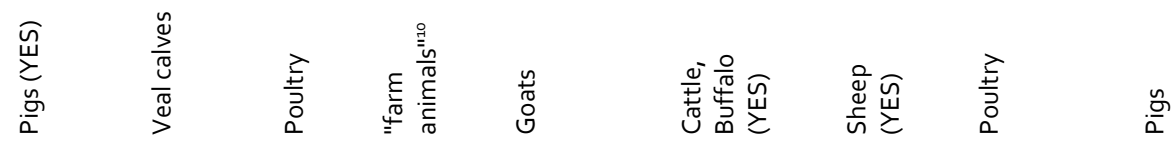

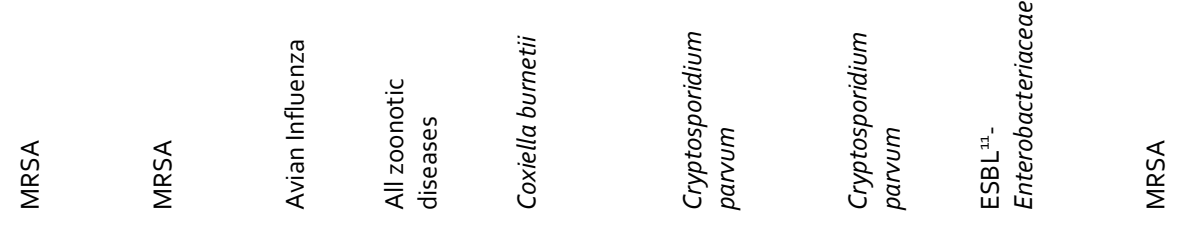

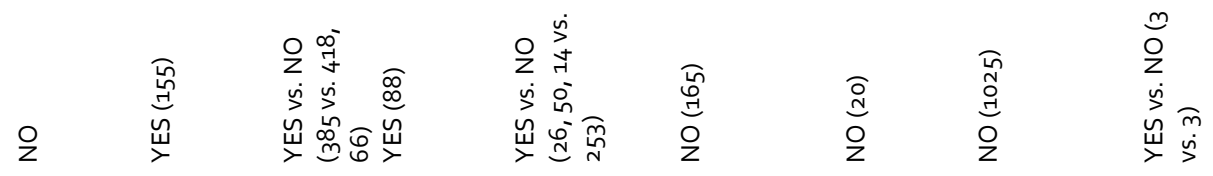

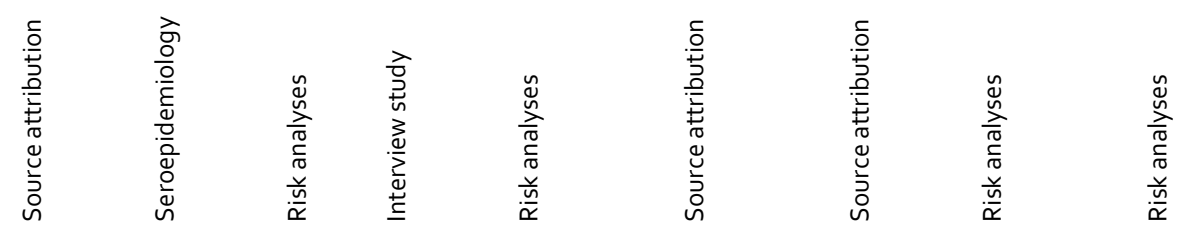

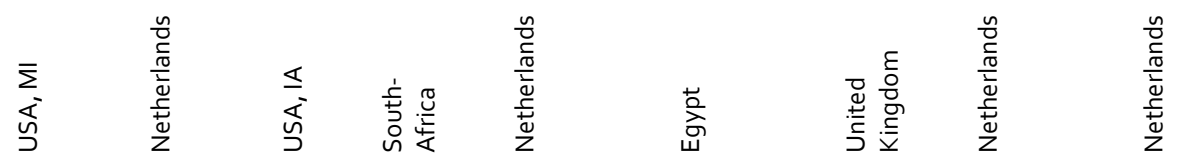

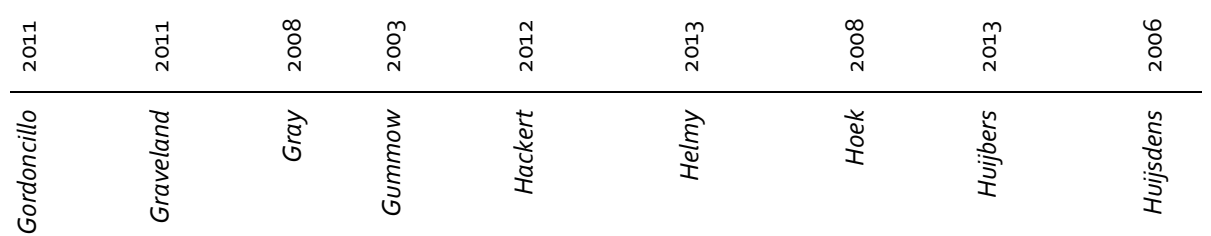




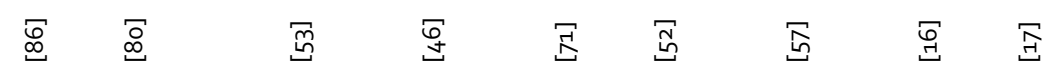

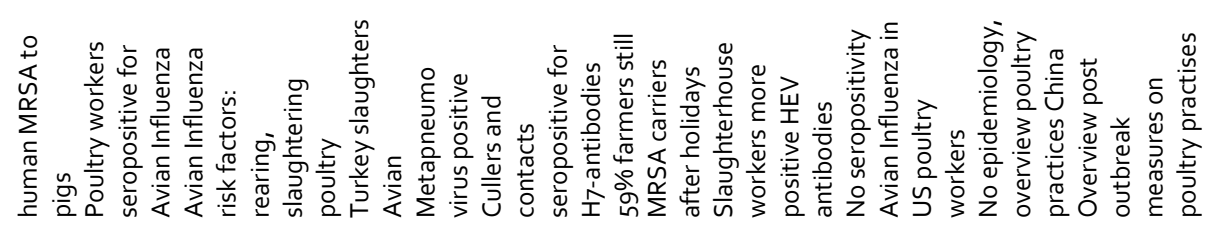

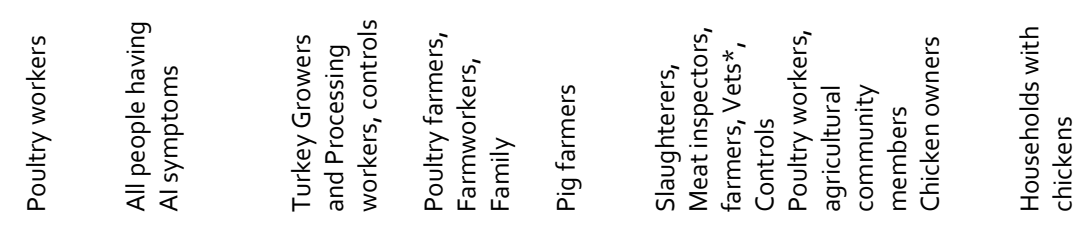

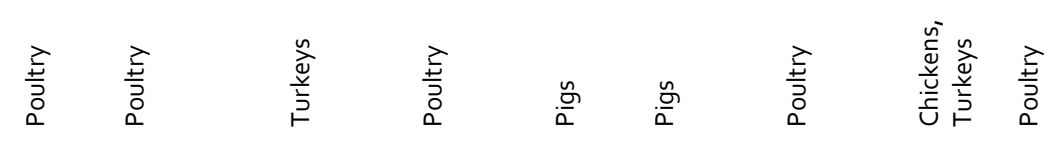

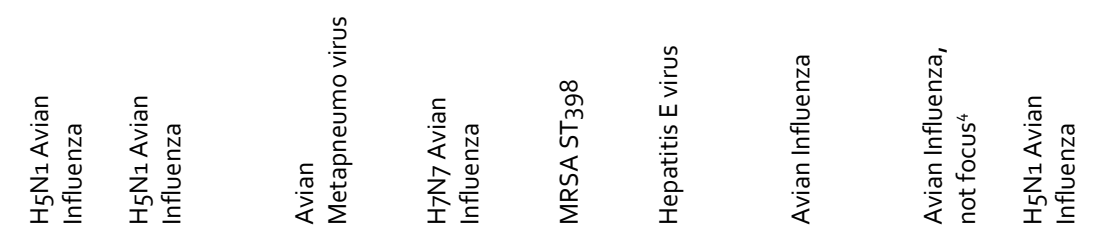

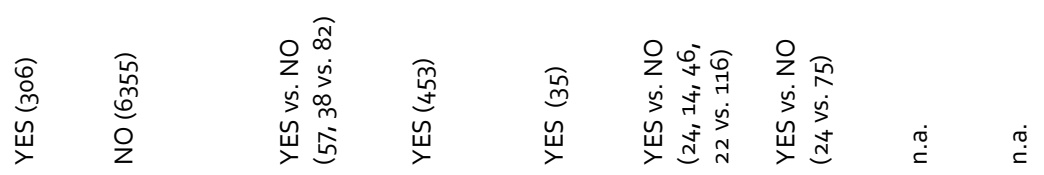

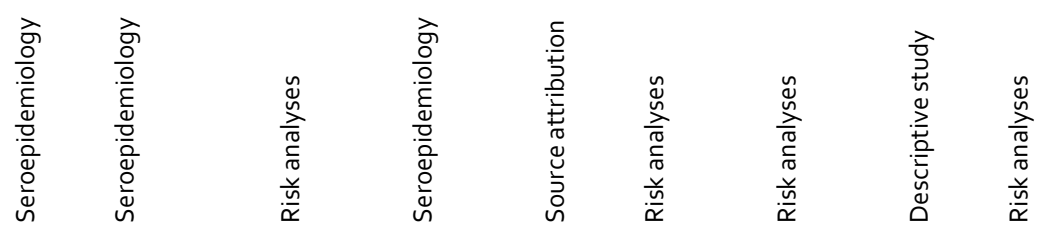

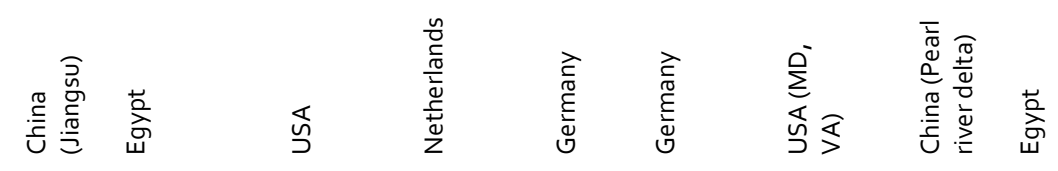

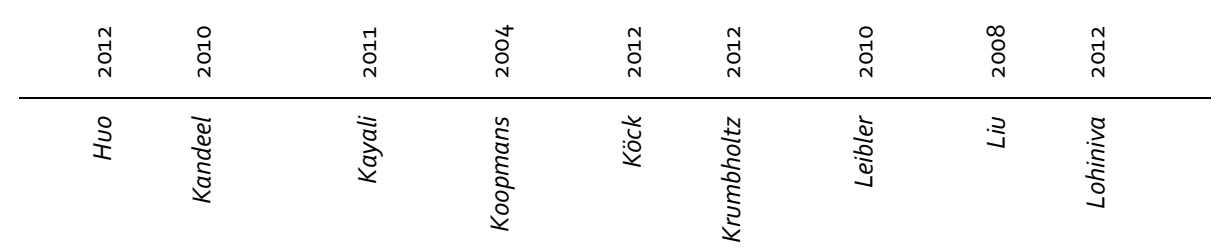




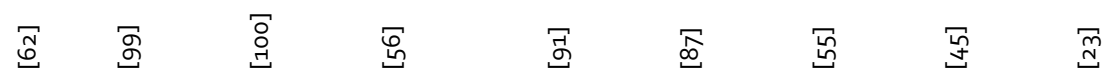

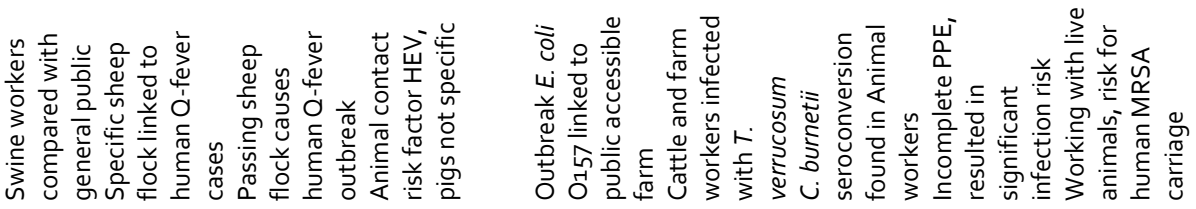

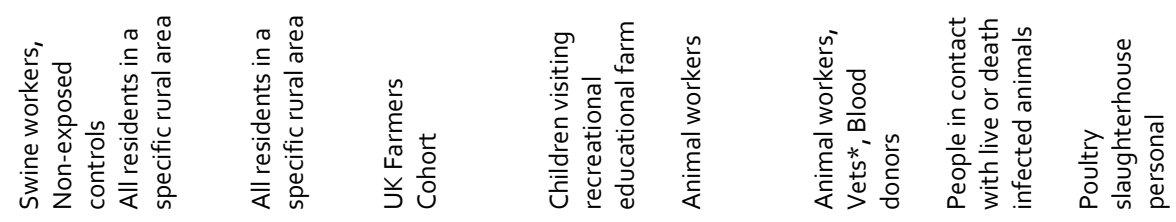

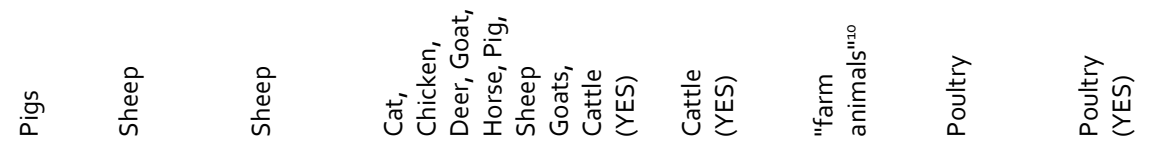

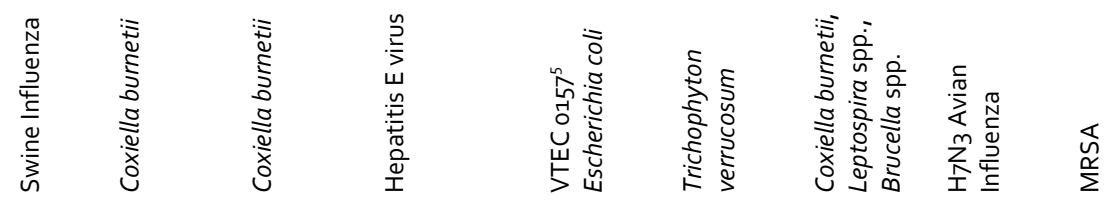

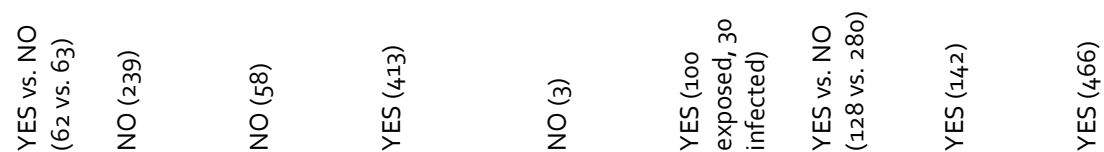

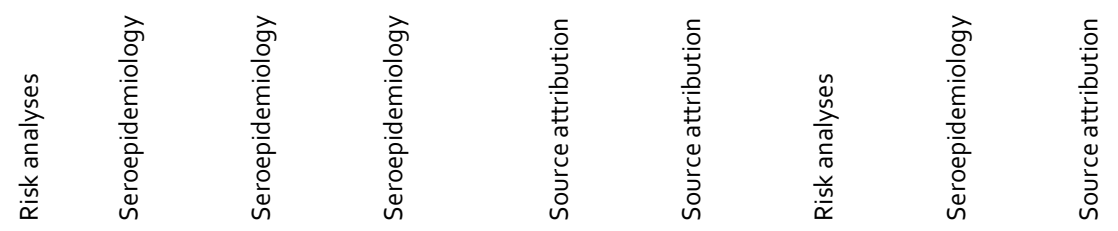

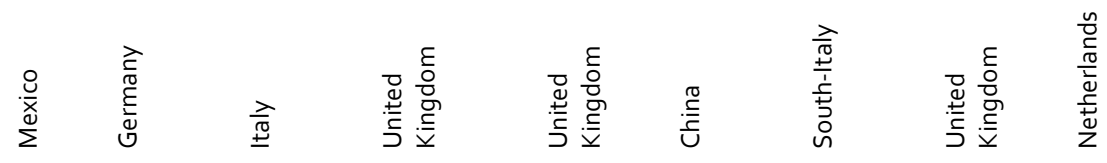

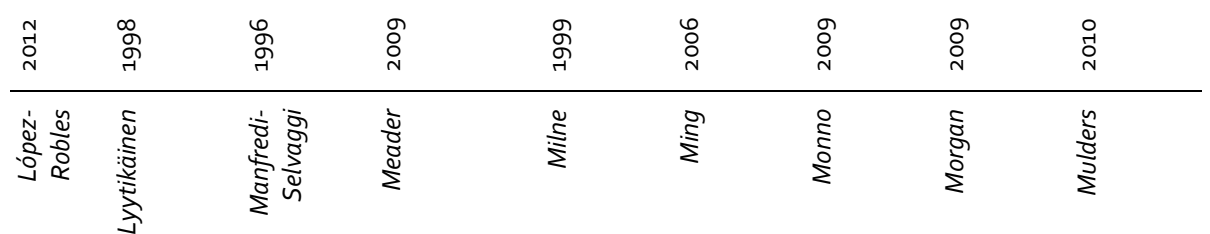




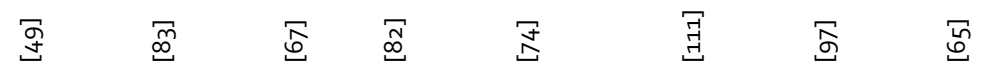

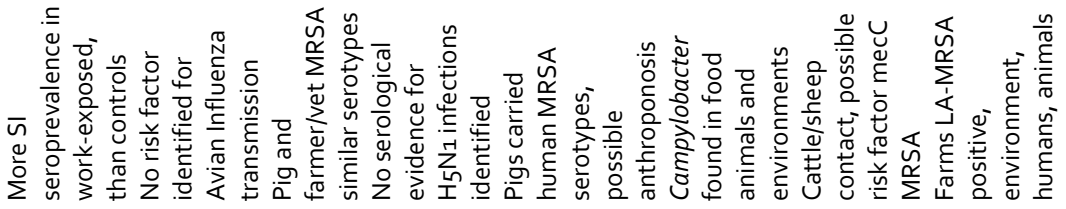

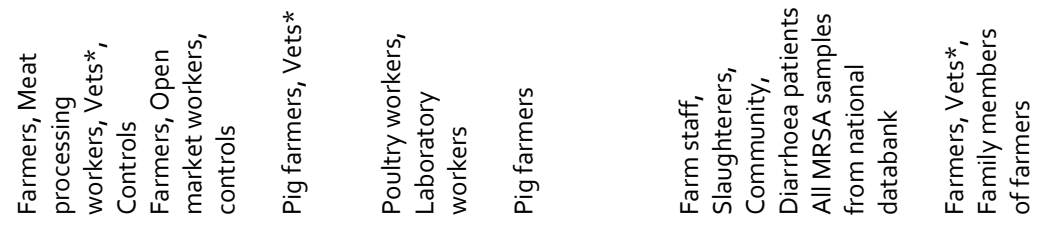

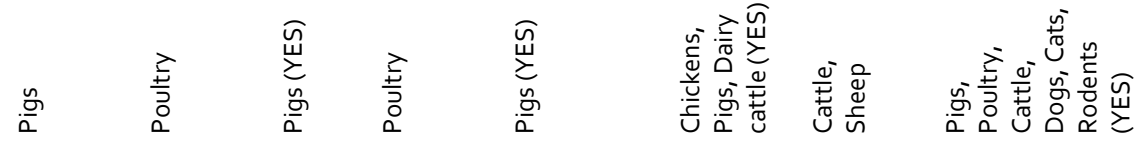

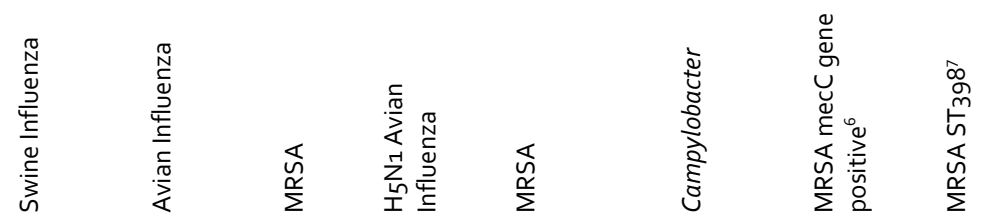

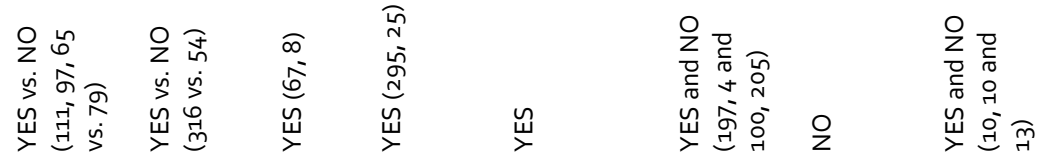

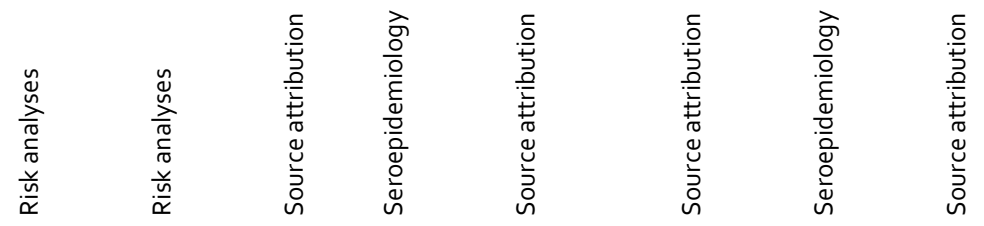

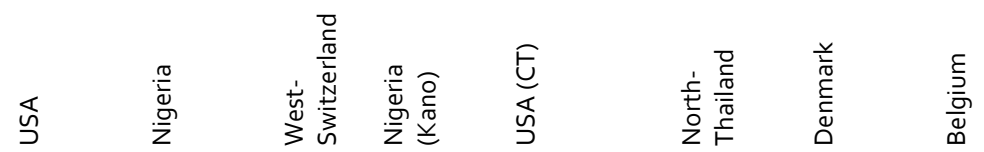

\begin{tabular}{|c|c|c|c|c|c|c|c|}
\hline 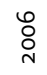 & $\underset{\text { Oे }}{m}$ & त̃ & $\begin{array}{l}\text { : } \\
\stackrel{\sim}{0}\end{array}$ & స̃ & $\begin{array}{l}\tilde{O} \\
\stackrel{N}{N}\end{array}$ & స̃ & సี \\
\hline$\stackrel{n}{\Sigma}$ & $\frac{\tilde{a}}{\partial}$ & 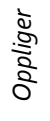 & $\stackrel{N}{ \pm}$ & 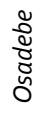 & $\begin{array}{l}7 \\
0 \\
0 \\
5 \\
0 \\
0\end{array}$ & 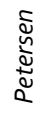 & 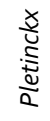 \\
\hline
\end{tabular}




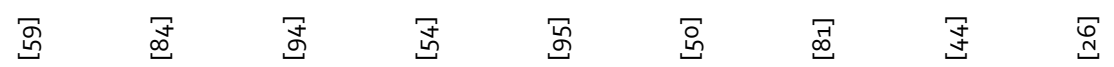

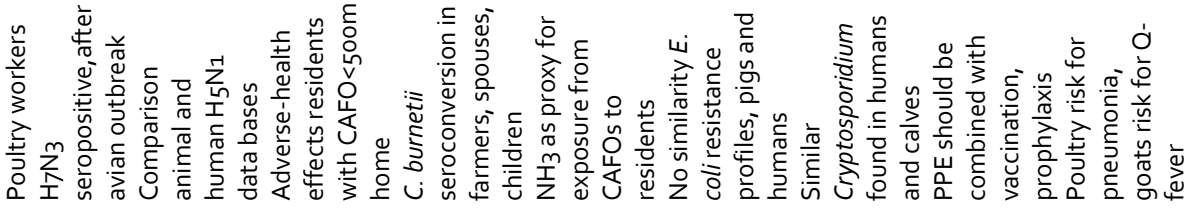

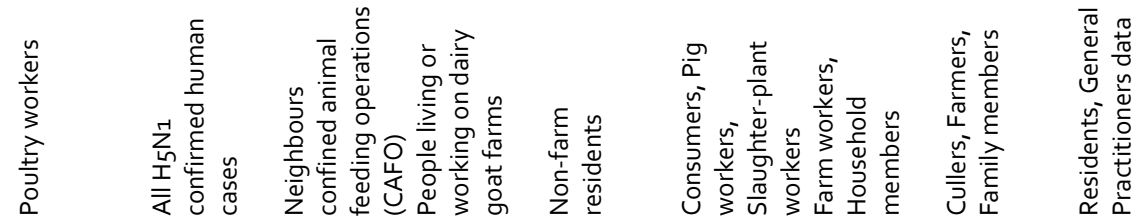

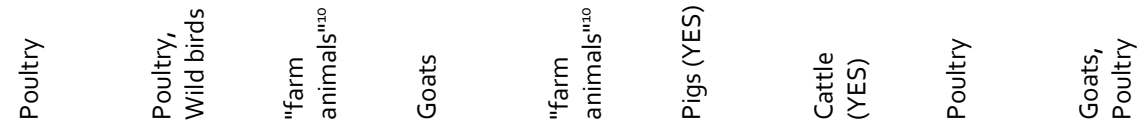

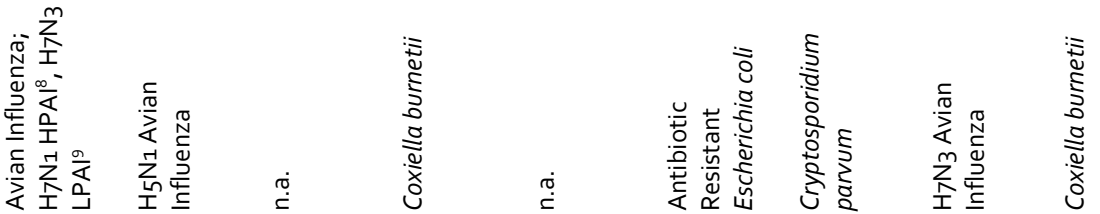

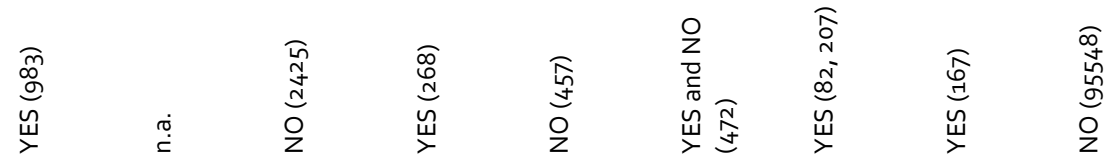

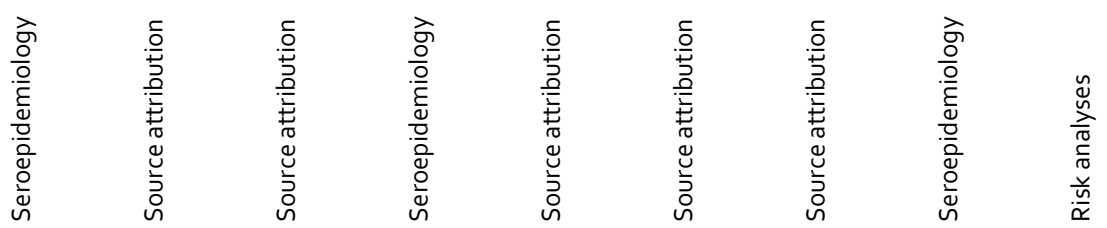

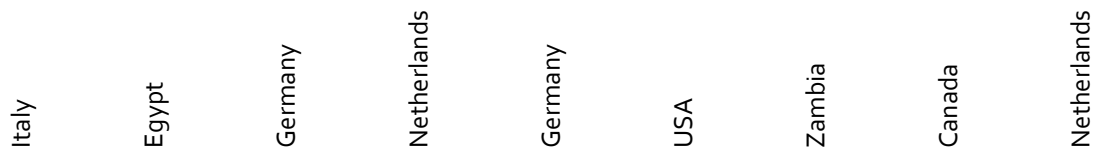

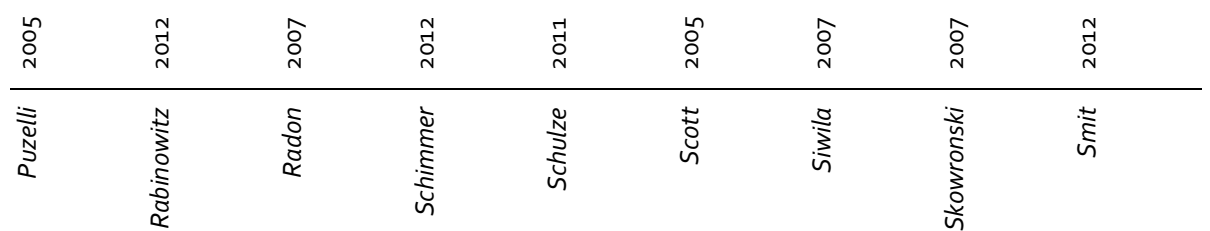




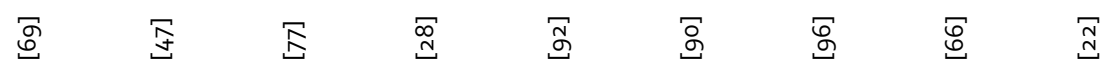

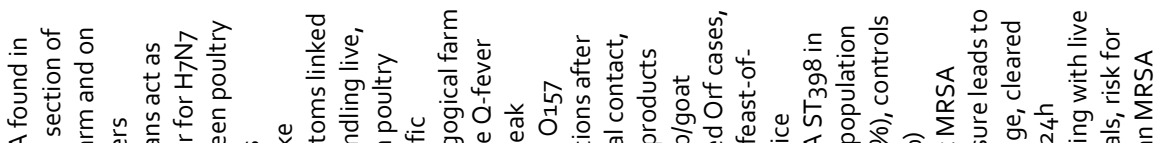

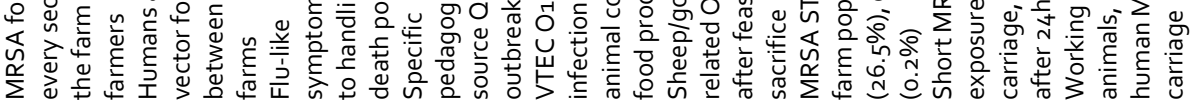

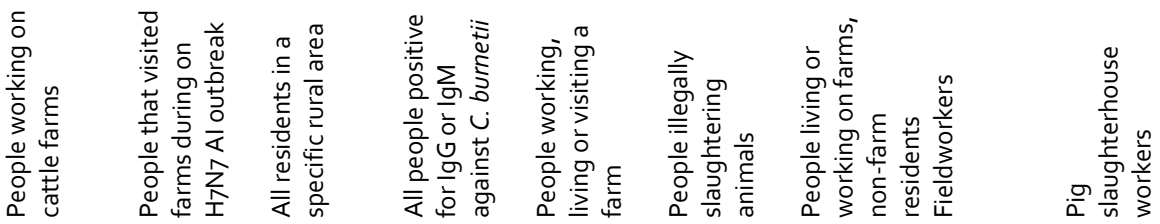

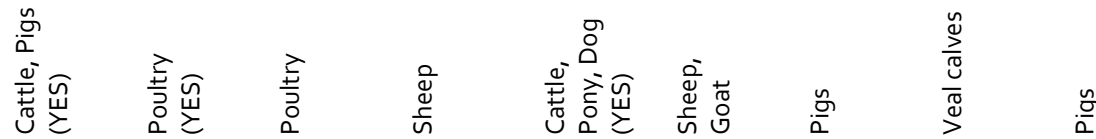

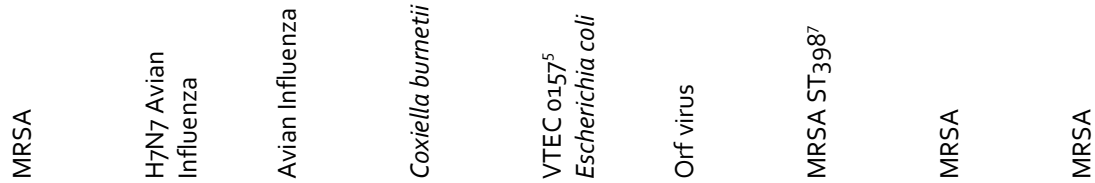

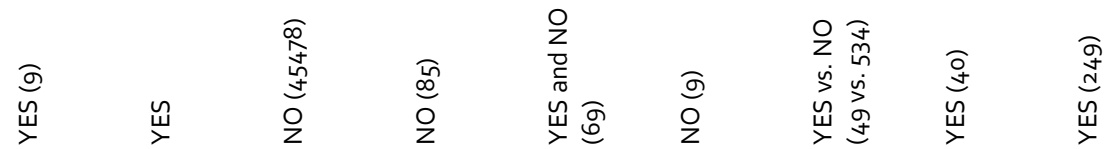

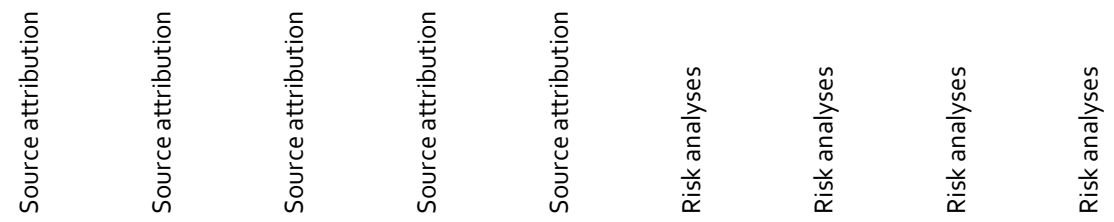

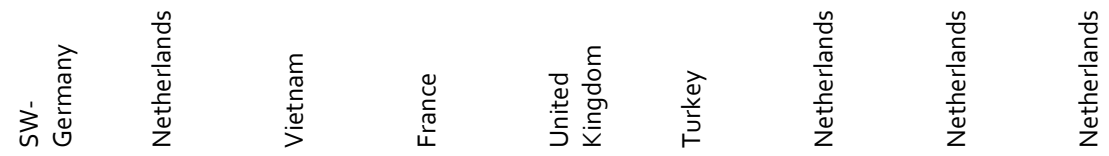

\begin{tabular}{|c|c|c|c|c|c|c|c|c|}
\hline స్ & 몸 & $\begin{array}{l}\text { O } \\
\stackrel{0}{0}\end{array}$ & $\begin{array}{l}\text { n̊ } \\
\stackrel{N}{ }\end{array}$ & ஓ् & $\begin{array}{l}\tilde{O} \\
\stackrel{\circ}{N}\end{array}$ & $\begin{array}{l}\text { Oे } \\
\text { ํ. }\end{array}$ & స్ & 옴 \\
\hline $\begin{array}{l}\text { s } \\
\text { के }\end{array}$ & 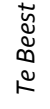 & 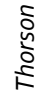 & $\begin{array}{l}\text { 㟧䓂 } \\
\text { 咅 }\end{array}$ & 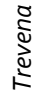 & $\begin{array}{l}\bar{\Xi} \\
\stackrel{\Xi}{~}\end{array}$ & 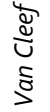 & 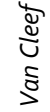 & 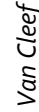 \\
\hline
\end{tabular}




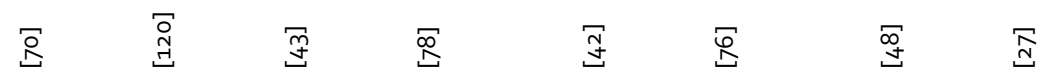

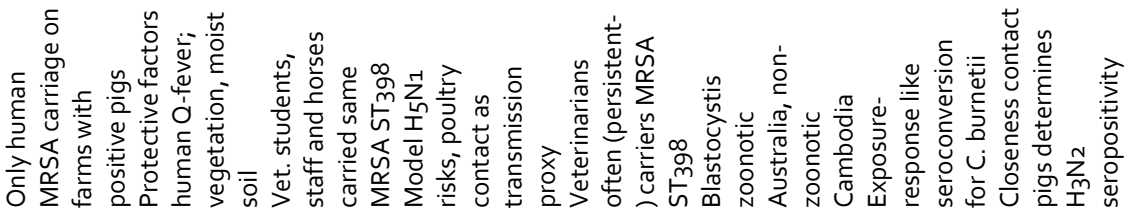

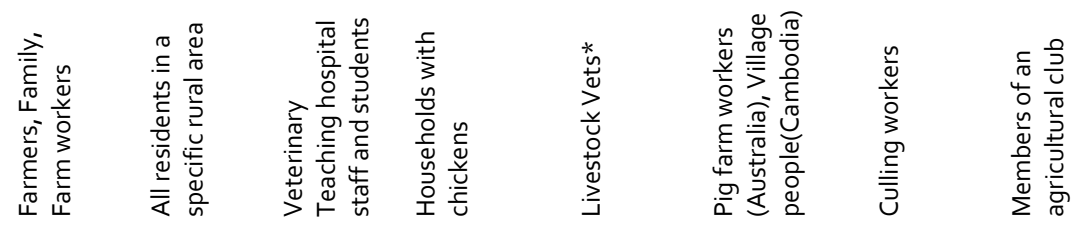

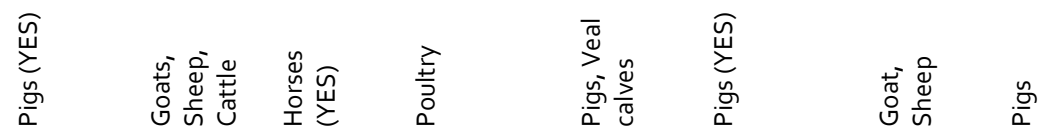

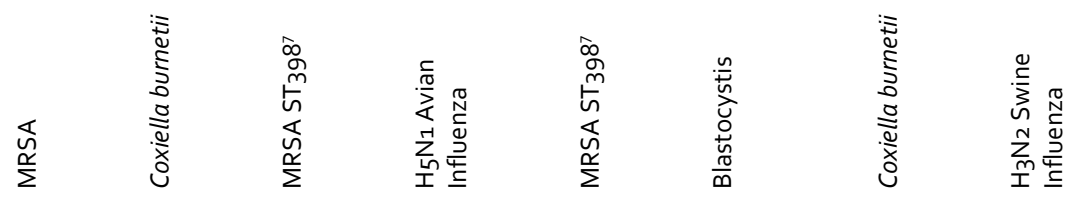

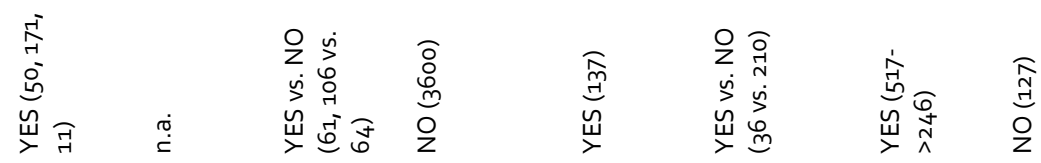

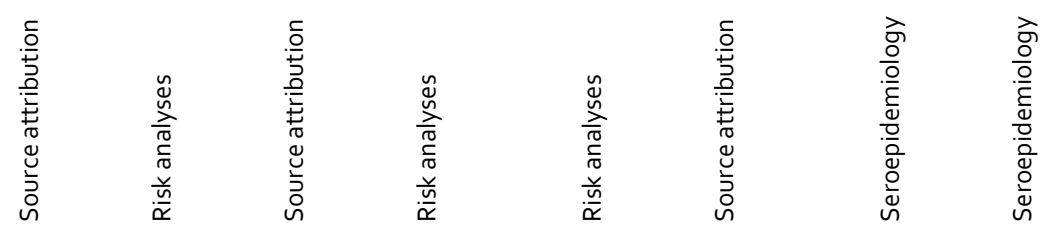

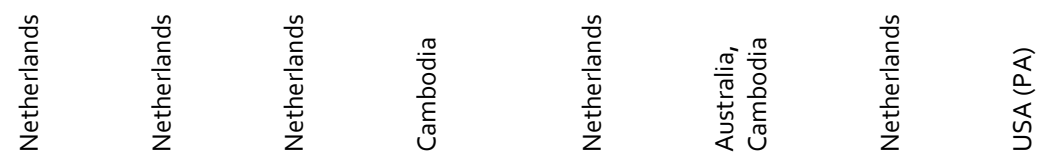

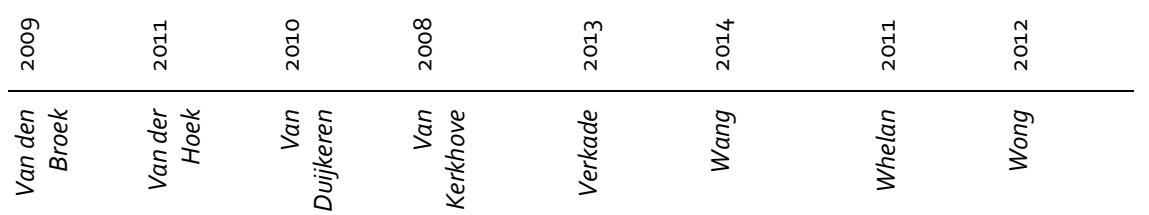


$\stackrel{\infty}{\stackrel{\infty}{\circ}}$

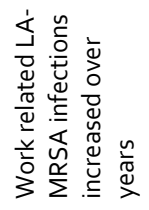

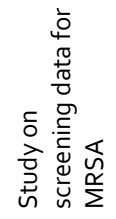

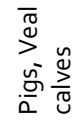

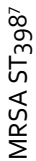

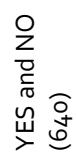

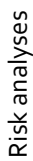

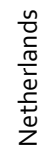

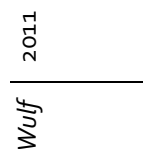

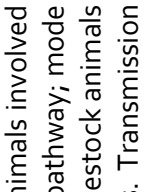

政 它은

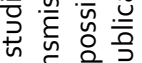

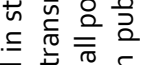

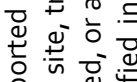

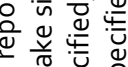
政

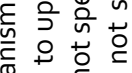

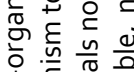

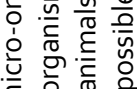
है 일

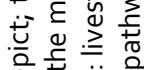

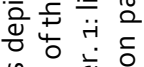

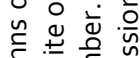

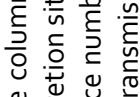

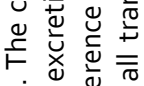

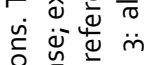

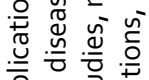

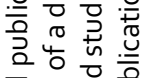

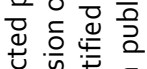
政商

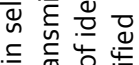
政

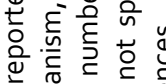

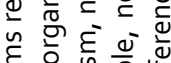
空

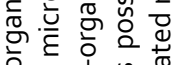

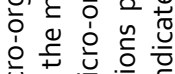

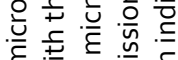
항

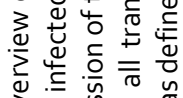

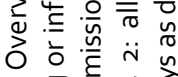
s.

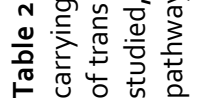
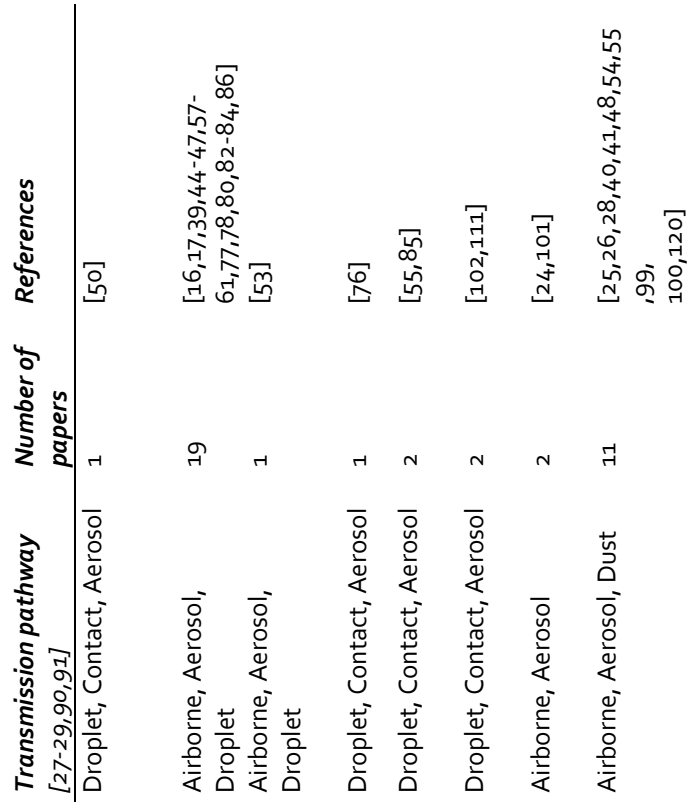


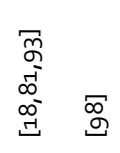

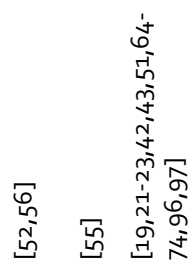

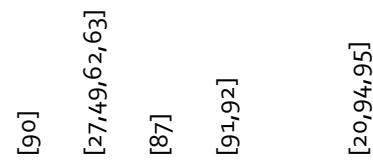

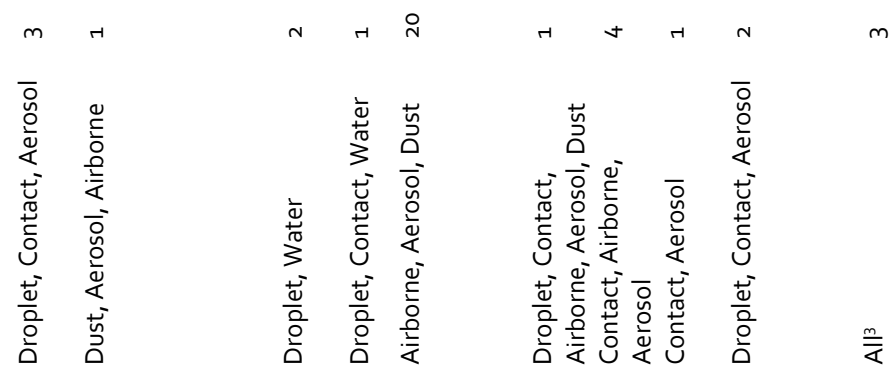

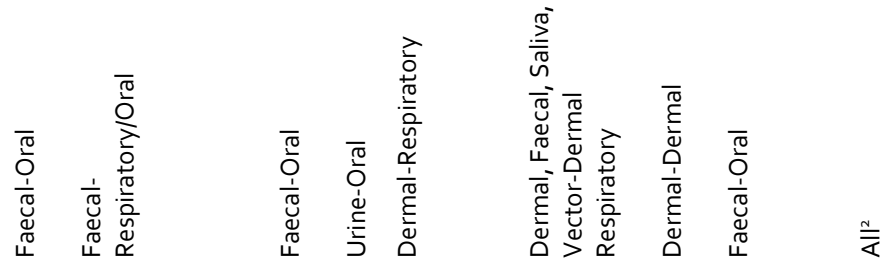

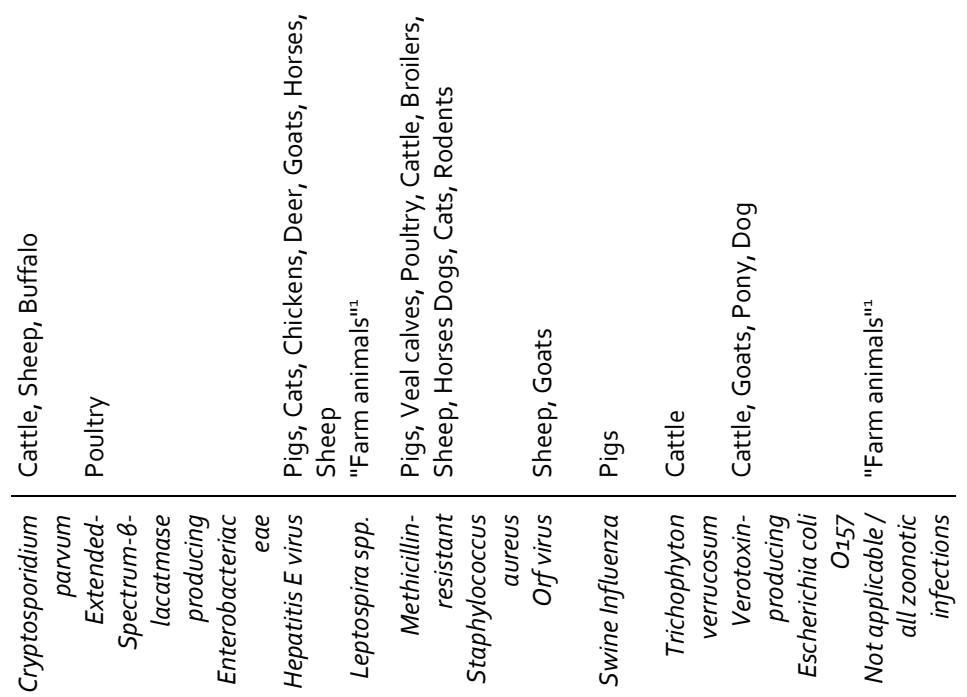




\section{Farmers}

Farmers face daily exposure to LA-micro-organisms in every aspect of their work. Still, it is very hard to determine which activity leads to transmission of micro-organisms. In this group, outbreaks are often investigated in a retrospective way, i.e. by performing serological epidemiology, analysing blood samples for antibodies against specific pathogens. This procedure does not allow to distinguish between past and more recent transmission events.

In the Netherlands, antibodies against C. burnetii were found in $73.5 \%$ of blood samples from farmers keeping dairy goats.[54] In an Italian study, animal workers were checked for blood markers against C. burnetii, Leptospira spp. and Brucella spp. Only for $C$. burnetii a higher sero-prevalence of $73.4 \%$ was found in animal workers, compared with $13.6 \%$ in controls.[55] For the evaluation of Hepatitis E virus, these links were not as clear as for Q-fever: serological epidemiology in a farmer cohort in the United Kingdom showed high Hepatitis E virus sero-positivity, but pig contact was not found to represent a risk factor.[56] In another study from Germany, however, increased Hepatitis E virus positivity in people with contact with pigs was shown, compared to age- and gendermatched controls.[52]

The literature is also inconsistent for Avian Influenza. One study from the US indicated no human antibody sero-positivity of Avian Influenza subtypes prevalent in poultry among poultry workers [57], while other studies from the US and Italy did show similar Avian Influenza subtypes in poultry and poultry workers.[58-60] Evidence from Hong Kong even indicated an exposure-response-like relationship for $\mathrm{H}_{5} \mathrm{~N}_{1}$ Avian Influenza transmission: more anti- $\mathrm{H}_{5}$ antibodies were found in poultry workers with more poultryrelated tasks compared to community controls. Direct contact to poultry and butchering poultry was identified as risk factors carrying the highest infection risk.[61] For Swine Influenza studies are consistent, three studies reported serological antibody presence against swine influenza in pig farmers and workers. $[49,62,63]$ Remarkably, the study of De Marco et al reported cross-protective immunity against the 2009 human pandemic Influenza A in swine workers exposed to pigs and Swine Influenza.[63]

Other research in farmers mainly focussed on antimicrobial-resistant zoonotic organism carriage. These studies often have a different design, utilizing cross-sectional or cohort designs, occasionally with repeated measurements. LA-MRSA [64] can be transmitted between animal species [65] and from animals to humans [65-68], but also from animals to the farm environment, although the host preferences differ.[65,69] One study identified a correlation between the carriage prevalence in pigs and the likelihood of human LA-MRSA carriage.[70] Still, the prevalence of persistent LA-MRSA carriage among farmers is relatively low [71] and most individuals show relatively rapid clearing of LA-MRSA carriage. $[19,66]$ In poultry farms, MRSA positivity was found to be less prevalent compared to veal calf and pig farms. This could explain the limited carriage in poultry workers [72] and among people who keep poultry at home.[73] In addition, the reverse transmission route has also been proposed, with the evidence for a reverse zoonosis/anthroponosis being pigs positive for healthcare associated-MRSA, thus indicating farmer-to-pig MRSA spread.[74] This theory is enhanced by evidence showing that LA-MRSA is less transmissible between people, compared to other MRSA types.[75] 


\section{Non-occupational contact}

Contact to livestock could also occur in non-occupational settings and may lead to transmission or infection with zoonotic micro-organisms. Both direct contact and dispersion through air can account for micro-organism transmission events. In this section 30 publications are discussed, focussing on: Avian Influenza ( $N=9$ papers), $C$. burnetii $(\mathrm{N}=5)$, Cryptosporidium parvum (C. parvum, $\mathrm{N}=3)$, MRSA $(\mathrm{N}=2)$, Verotoxin producing E. coli (VTEC) O157 ( $\mathrm{N}=2)$, Blastocytosis, Brucella spp., Trichophyton verrucosum ( $T$. verricosum), Campylobacter spp., Orf virus, Salmonella spp. and Swine Influenza (all $\mathrm{N}=1$ ).

\section{Developing countries}

Especially in developing countries, transmission of micro-organisms can occur from live animals or via blood products from slaughtering practices within the home setting, but the actual transmission pathways are often unknown. In these countries livestock keeping is common practice for many families and animals are frequently kept in the home backyard for egg, milk or meat production.[16,17,76-80,18,81-85] Backyard poultry keeping has been linked to Avian Influenza transmission on many occasions. This was found by Thornson et al performing interviews in Vietnam, asking for poultry contact and flulike illness [77], modelled by Van Kerkhove et al in Cambodia after interviewing people regarding their poultry contacts [78], and shown among Egyptian women by Kandeel and colleagues performing a risk factor analysis of all suspected Avian Influenza cases in Egypt.[8o]

China knows a broad diversity in livestock farming practices, ranging from poultry farming with people involved in all stages of the production cycle [86], to large industrially managed cattle herds.[87] In both of these situations zoonotic disease transmissions has been described from livestock to humans, Avian Influenza and $T$. verricosum, respectively.[86,87] In summary, literature to date is not informative regarding which livestock-human contact pattern leads to zoonotic disease transmission in developing countries.

\section{Brief contact}

In some instances, very brief exposure may be sufficient for transmission of microorganisms, especially when the infectious dose of a pathogen is very low.[88] This was shown in Germany in a study focussing on LA-MRSA carriage among farmers and residents in an area with a high density of livestock farms. Farmers were mainly at risk when they had pig contact, but the authors also found that regular visits to farms -e.g. to buy eggs or milk- increased the chance of becoming a LA-MRSA carrier among nonfarm residents.[89] In Turkey, preparing freshly slaughtered sheep led to transmission of Orf virus during the feast of sacrifice, an Islamic tradition, among non-occupationally exposed people.[9o] Visits to an agricultural fair in the US resulted in transmission of Swine Influenza between displayed pigs and human visitors.[27] Visitors of a pedagogical farm in France were reported to be infected with Q-fever [28] and gastrointestinal infections with VTEC O157 occurred on a farm open to the public in the UK.[91] VTEC O157 infections were also observed among 'holidaymakers', 'farm visitors', 'farming families' and 'farm workers'.[92] Still, the actual pathway of an 
infection was not specifically ascertained in most papers. This was illustrated by an outbreak of $C$. parvum among children camping on an adventure farm in the UK.[93]

\section{Environmental transmission}

This section summarises reports where people indicated that they had no direct contact to livestock animals, but experienced adverse-health effects due to livestock in their immediate surroundings. These articles indicated that close contact to livestock animals was not necessary for a transmission event to occur, but that already living in close vicinity of livestock could be enough for the occurrence of adverse health effects among residents.

Respiratory health can be affected by many sources, including livestock farming in the vicinity of a residence. In Germany, reduced respiratory health of residents was linked to the presence of Confined Animal Feeding Operations, industrially managed livestock stables, near their home address. Although these studies did not focus on infectious diseases, they did indicate effects of livestock keeping on the health of nearby residents.[94,95] In a Dutch study investigating LA-MRSA presence in a rural population, only direct animal contact was found as a risk factor.[96] When the Danish national human MRSA database was checked for a livestock-associated MecC resistance gene, this was mainly found in samples from people living in rural parts of the country and animal contact was an important risk factor. Still, the gene was also discovered in human MRSA samples from people living in rural areas, but having no livestock contact.[97] An attempt to identify risk factors for Extended-Spectrum BetaLactamase (ESBL) Enterobacteriaceae carriage among people living in high- and lowpoultry density areas in the Netherlands showed no elevated risk between the distance of positive poultry farms from the home and ESBL carriage of residents. [98] For Q-fever, however, the link between living close to infected farms and human cases of the disease is well established.[25,26,88] In the Netherlands, a large outbreak occurred in recent years and an exposure-response-like relationship was found for the number of goats within $5 \mathrm{~km}$ of the home address and human cases.[26] In Germany, a specific flock of sheep could even be identified as the source of a human Q-fever outbreak in a village.[99] In Italy, where in some areas free-range sheep herding is still common practice, the passing of three flocks of infected sheep through a village led to an outbreak of Q-fever.[100]

\section{Discussion}

This review is a first attempt to summarise what is currently known regarding the nature of livestock-human interactions in the transmission of infectious diseases between livestock and humans. We performed a systematic procedure to identify current literature applying predefined criteria regarding livestock-associated zoonoses and tried to distinguish contact patterns between livestock and humans leading up to this zoonosis event. Zoonotic events can be reported in three ways. First, an outbreak is noticed in animals, followed by cases in humans.[101] Second, a cluster of human zoonosis cases appears, after which possible animal sources are identified. $[64,102]$ The third way is retrospective, comparing blood samples from animal-exposed and nonexposed people for infectious disease markers [54], these are mainly cross-sectional studies, which may be subject to selection bias. 
We identified 75 articles discussing micro-organism transmission or infections due to livestock associated micro-organisms. For people with occupational contact with livestock, the risk of acquiring micro-organisms from livestock was especially elevated, since transmission of infections seems to be possible during all phases of the livestock production cycle; from stables until the slaughterhouse.[103] Among the papers discussing occupational exposure to livestock, we found only two studies that assessed livestock contact quantitatively. These papers crudely estimated the number of hours spent amongst infected animals [48], or the number of tasks for handling infected animals.[61] A more detailed exposure assessment tackling concentration, exposure duration and frequency [104], however, is lacking.

Four studies were identified that showed spatial exposure relationships within slaughterhouses,[19-22] and two of these also showed a temporal variability in environmental levels of micro-organisms.[21-24] Although these papers gave an indication of how transmission of micro-organisms from livestock to humans occurred, transmission routes were not specifically mentioned in the studies. The measured exposure proxies and related health effects can therefore not be specified for the potential transmission pathways.

For non-infectious disease studies, a detailed framework has been defined for possible exposure routes.[105] Such a framework is also of potential importance for infectious disease studies because it describes all potential direct and indirect transmission routes. Therefore for LA- substances such as; particulate matter, gases, environmental microorganisms and non-infectious (micro-)organism lysis products called endotoxins [106110], time-weighted averages [106-108], or even task specific levels of endotoxins [110] are available. This enables exposure assessment for these substances within the farm environment.

Unfortunately, comparable sampling methods were not applied in the aforementioned studies on $C$. burnetii and Avian Influenza. $[48,61]$ This could be due to lack of experience with these methods or technical difficulties due to micro-organism features, such as difficulty to catch and culture pathogenic strains. With the rise of molecular techniques, in future outbreaks concentrations of pathogens could be quantified, when combined with information on the duration and frequency of exposure, exposures can be assessed and exposure-response models can be developed for these pathogens.

For people not working in an occupation with livestock, the exposure to zoonotic microorganisms is much lower compared to people with an occupation in the livestock sector. In developing countries it is often impossible to distinguish transmission pathways of micro-organisms since people are exposed to animals in both occupational settings and at home.[16,17,76-80,18,81-84,111]

We found several papers reporting brief exposure to livestock animals that resulted in zoonotic disease transmission to people who were not occupationally exposed to livestock. Remarkably, brief contact in these studies was sufficient to transfer microorganisms to susceptible persons, still the nature of these contacts remain elusive.[27,28,66,90-93] Perhaps the contact moment was not even necessary for disease transmission, but the environmental presence of high levels of micro-organisms surrounding infected animals, shown in other studies [112-119], was sufficient for a transmission event. 
Environmental presence of LA-micro-organisms and other LA-emissions is the explanatory factor for the occurrence of LA-adverse health effects in people that did not have any contact with livestock, but were nevertheless affected by livestock in the vicinity of their home.[25,26,94-97,99,100,120] For both transmission due to brief contact and environmental transmission of micro-organisms, micro-organism transmission pathways are hard to distinguish. Generally, people with adverse health effects from livestock in the vicinity of their homes are residents of rural areas, therefore (brief) livestock-human contact cannot be completely excluded in these studies.

Since there are so many unknown factors in the knowledge about livestock contact and zoonotic micro-organism transmission, it is very hard to optimise interventions, minimising effects of a future outbreak on public health. However, some suggestions on intervention can be given. For the occupational setting: In case of an animal outbreak, Personal Protective Equipment (PPE) use by cullers should be reinforced, especially in case of infectious micro-organisms that can be inhaled.[30] For slaughterhouse workers, PPE appears to be especially relevant for people working on the start of the slaughter line, since they seem to be exposed to the highest levels of zoonotic mircroorganisms.[21-24] Since the protective abilities of PPE have been shown to not always be optimal [30,44-46], vaccination, if available, of cullers and slaughterhouse workers $[44,121]$ may be considered, as well as usage of prophylactic drugs for cullers during their work.[44] For farmers, PPE can be used when they enter the stables, combined with a standardised general on-farm hygiene protocol.[122] When it comes to protecting the general public, in case of zoonotic outbreaks, there is always a risk of spread of micro-organisms from an infected farm to the direct environment[112-119], and farm-emissions are difficult to control.[26,94,95,110] The possible solution to control (infectious-)farm-emmisions is complete closure of stables, combined with effective air filtering or washing systems [123], also manure should be handled with outmost care, since this can contain several micro-organisms. [41,43,80-83]

Additional to the suggested measures regular and close surveillance of farms and both human and livestock health databases for LA-micro-organisms could be implemented to identify a zoonotic disease outbreak as early as possible.

The limitation of our study was that in most reports on zoonotic disease occurrence in humans, the intensity and the type of contacts between livestock and humans leading to the actual disease or micro-organism transmission was only implicitly cited. Therefore, it is virtually impossible to identify specific livestock-human interactions that lead to infectious disease transmission. This makes it very difficult to avert these interactions and even more challenging to design tailor-fit transmission preventive interventions.

\section{Conclusions and future perspectives}

Although, we found a significant body of evidence that described zoonotic transmissions of micro-organisms, little is known about the intensity and type of contact patterns leading to transmission, and thus the exact transmission pathways of microorganisms from livestock to humans usually remains unclear. Human-livestock contacts were merely implicitly cited in the literature, and commonly, contact intensity was 
defined by the occupational status of the person carrying or infected with a LA-microorganism. Studies performed in an occupational setting provided some evidence of exposure response relationships between the intensity of livestock-human contacts and the transmission of micro-organisms. Using methods that are already in place in the exposure assessment sciences [110], exposure to LA-zoonotic micro-organisms through contact patterns between livestock and humans, can be better quantified both in the occupational and the non-occupational setting. This will be crucial in the development of effective interventions to prevent transmission of micro-organisms from livestock to humans.

\section{Authors contribution}

GK, AH, DJJH and RAC designed the study, GK wrote the paper, GK and RAC reviewed the selected papers, AH, DJJH and RAC revised it critically for important intellectual content. All authors approved the submitted version of the article.

\section{Acknowledgments}

Thanks to Daisy de Vries and Romin Pajouheshnia for critically reading the final version of the manuscript. 


\section{References}

Taylor LH, Latham SM, Woolhouse ME. Risk factors for human disease emergence. Philos Trans $R$ Soc Lond B Biol Sci 2001;356:983-9. doi:10.1098/rstb.2001.0888

Beran GW. Disease and destiny-mystery and mastery. Prev Vet Med 2008;86:198-207. doi:10.1016/j.prevetmed.2008.05.001

Pearce-Duvet JMC. The origin of human pathogens: evaluating the role of agriculture and domestic animals in the evolution of human disease. Biol Rev Camb Philos Soc 2006;81:369-82. doi:10.1017/S1464793106007020

Fraser C, Donnelly CA, Cauchemez S, et al. Pandemic potential of a strain of influenza A (H1N1): early findings. Science 2009;324:1557-61. doi:10.1126/science.1176062

Khardori NM. Clinical Aspects of Pandemic 2009 Influenza A (H1N1) Virus Infection. Yearb Med 2010;2010:83-4. doi:10.1016/S0084-3873(10)79684-X

Al-Tawfiq JA., Zumla A, Memish ZA. Travel implications of emerging coronaviruses: SARS and MERS-CoV. Travel Med Infect Dis 2014;12:422-8. doi:10.1016/j.tmaid.2014.06.007

Verbeke W. Consumer Perception of Food Safety: Role and Influencing Factors. New Approaches to Food-Safety Econ 2003;:21-6.

Fitzgerald JR. Livestock-associated Staphylococcus aureus: Origin, evolution and public health threat. Trends Microbiol 2012;20:192-8. doi:10.1016/j.tim.2012.01.006

Chatard-Pannetier A., Rousset S, Bonin D, et al. Nutritional knowledge and concerns about meat of elderly French people in the aftermath of the crises over BSE and foot-and-mouth. Appetite 2004;42:175-83. doi:10.1016/j.appet.2003.11.002

Ogoshi K, Yasunaga H, Obana N, et al. Consumer reactions to risk information on bovine spongiform encephalopathy in Japan. Environ Health Prev Med 2010;15:311-8. doi:10.1007/s12199-010-0144-3

Bennett R, Christiansen K, Clifton-Hadley R. Preliminary estimates of the direct costs associated with endemic diseases of livestock in Great Britain. Prev Vet Med 1999;39:155-71. doi:10.1016/S0167-5877(99)00003-3

Christou L. The global burden of bacterial and viral zoonotic infections. Clin Microbiol Infect 2011;17:326-30. doi:10.1111/j.1469-0691.2010.03441.x Leibler J, Otte J, Silbergeld E. Zoonotic Disease Risks and Socioeconomic Structure of Industrial Poultry Production : Review of the US Experience with Contract Growing. Agriculture 2008;:1-24. Torgerson PR, Macpherson CNL. The socioeconomic burden of parasitic zoonoses: Global trends. Vet Parasitol 2011;182:79-95. doi:10.1016/j.vetpar.2011.07.017 Jones KE, Patel NG, Levy M a, et al. Global trends in emerging infectious diseases. Nature 2008;451:990-3. doi:10.1038/nature06536

6 Liu T. Custom, taste and science: Raising chickens in the Pearl River Delta Region, South China. Anthropol Med 2008;15:7-18. doi:10.1080/13648470801918992

1 Lohiniva AL, Dueger E, Talaat M, et al. Poultry rearing and slaughtering practices in rural Egypt: An exploration of risk factors for H5N1 virus human transmission. Influenza Other Respi Viruses 2013;7:1251-9. doi:10.1111/irv.12023

Helmy YA., Krücken J, Nöckler K, et al. Molecular epidemiology of Cryptosporidium in livestock animals and humans in the Ismailia province of Egypt. Vet Parasitol 2013;193:15-24. doi:10.1016/j.vetpar.2012.12.015

Graveland H, Wagenaar JA., Bergs K, et al. Persistence of livestock associated MRSA CC398 in humans is dependent on intensity of animal contact. PLoS One 2011;6:1-7. doi:10.1371/journal.pone. 0016830

0 Gummow B. A survey of zoonotic diseases contracted by South African veterinarians. J S Afr Vet Assoc 2003;74:72-6. doi:10.4102/jsava.v74i3.514 Gilbert MJ, Bos MEH, Duim B, et al. Livestock-associated MRSA ST398 carriage in pig slaughterhouse workers related to quantitative environmental exposure. Occup Environ Med 2012;69:472-8. doi:10.1136/oemed-2011-100069 Van Cleef BAGL, Broens EM, Voss A, et al. High prevalence of nasal MRSA carriage in slaughterhouse workers in contact with live pigs in The Netherlands. Epidemiol Infect 2010;138:756-63. doi:10.1017/S0950268810000245 

flocks and risk factors for slaughterhouse personnel in The Netherlands. Epidemiol Infect 2010;138:743-55. doi:10.1017/S0950268810000075 chicken and turkey slaughterhouse. J Clin Microbiol 2010;48:3244-50. doi:10.1128/JCM.00698-10 Hackert VH, Van Der Hoek W, Dukers-Muijrers N, et al. Q fever: Single-point source outbreak with high attack rates and massive numbers of undetected infections across an entire region. Clin Infect Dis 2012;55:1591-9. doi:10.1093/cid/cis734

Smit LAM, van der Sman-de Beer F, Opstal-van Winden AWJ, et al. Q fever and pneumonia in an area with a high livestock density: A large population-based study. PLoS One 2012;7.

doi:10.1371/journal.pone.0038843

Wong KK, Greenbaum A, Moll ME, et al. Outbreak of Infl uenza A ( H3N2 ) Variant Virus Infection among Attendees of an Agricultural Fair, Pensylvania, USA, 2011. 2012;18:1-2.

Tissot-Dupont $\mathrm{H}$, Amadei MA, Nezri M, et al. A pedagogical farm as a source of $Q$ fever in a French city. Eur J Epidemiol 2005;20:957-61. doi:10.1007/s10654-005-2336-5

Mims C. Mims' Medical Microbiology. 4th editio. Mosby, Elsevier 2007.

Jones RM, Brosseau LM. Aerosol Transmission of Infectious Disease. J Occup Environ Med 2015;57:501-8. doi:10.1097/JOM.0000000000000448

Lindsley WG, Blachere FM, Thewlis RE, et al. Measurements of airborne influenza virus in aerosol particles from human coughs. PLoS One 2010;5. doi:10.1371/journal.pone.0015100

Papineni RS, Rosenthal FS. The size distribution of droplets in the exhaled breath of healthy human subjects. J Aerosol Med 1997;10:105-16. doi:10.1089/jam.1997.10.105

Chao $\mathrm{CYH}$, Wan MP, Morawska L, et al. Characterization of expiration air jets and droplet size distributions immediately at the mouth opening. J Aerosol Sci 2009;40:122-33.

doi:10.1016/j.jaerosci.2008.10.003 infection: emission of respirable pathogens. J Occup Environ Hyg 2005;2:143-54.

doi:10.1080/15459620590918466

Best EL, Sandoe JAT, Wilcox MH. Potential for aerosolization of Clostridium difficile after flushing toilets: The role of toilet lids in reducing environmental contamination risk. $J$ Hosp Infect 2012;80:1-5. doi:10.1016/j.jhin.2011.08.010 Zinsstag J, Schelling E, Roth F, et al. Human benefits of animal interventions for zoonosis control. Emerg Infect Dis 2007;13:527-31. doi:10.3201/eid1304.060381 

beings during a large outbreak in commercial poultry farms in the Netherlands. Lancet 2004;363:587-93. doi:10.1016/S0140-6736(04)15589-X Te Beest DE, Stegeman J a., Mulder YM, et al. Exposure of Uninfected Poultry Farms to HPA (H7N7) Virus by Professionals During Outbreak Control Activities. Zoonoses Public Health 2011;58:493-9. doi:10.1111/j.1863-2378.2010.01388.x

Whelan J, Schimmer B, Schneeberger P, et al. Q fever among culling workers, the Netherlands, 2009-2010. Emerg Infect Dis 2011;17:1719-23. doi:10.3201/eid1709.110051

Myers KP, Olsen CW, Setterquist SF, et al. Are swine workers in the United States at increased risk of infection with zoonotic influenza virus? Clin Infect Dis 2006;42:14-20. doi:10.1086/498977 Scott HM, Campbell L, Harvey R, et al. Patterns of Antimicrobial Resistance Among Commensal Escherichia coli Isolated from Integrated Multi-site Housing and Worker Cohorts of Humans and Swine. Foodborne Pathog Dis 2005;2:24-37. Neyra RC, Frisancho JA, Rinsky JL, et al. Multidrug-Resistant and Methicillin-Resistant Staphylococcus aures (MRSA) in Hog Slaughter and Processing plant Workers and Their Community in North Carolina (USA). Environ Health Perspect 2014;122:471-7. Krumbholz A, Mohn U, Lange J, et al. Prevalence of hepatitis E virus-specific antibodies in humans with occupational exposure to pigs. Med Microbiol Immunol 2012;201:239-44.

doi:10.1007/s00430-011-0210-5 Among Adults Occupationally Exposed to Turkeys. Vector-Borne Zoonotic Dis 2011;11:1453-8. doi:10.1089/vbz.2011.0637

Schimmer B, Lenferink A, Schneeberger $\mathrm{P}$, et al. Seroprevalence and risk factors for Coxiella burnetii (Q fever) seropositivity in dairy goat farmers' households in the Netherlands, 2009-2010. PLoS One 2012;7:2009-10. doi:10.1371/journal.pone.0042364 Monno R, Fumarola L, Trerotoli P, et al. Seroprevalence of Q fever, Brucellosis, Leptospirosis in farmers and agricultural workers in Bari, Southern Italy. Ann Agric Environ Med 2009;16:205-9. Meader E, Thomas D, Salmon R, et al. Seroprevalence of hepatitis E virus in the UK farming population. Zoonoses Public Health 2010;57:504-9. doi:10.1111/j.1863-2378.2009.01254.x Leibler JH, Silbergeld EK, Pekosz A, et al. No evidence of infection with avian influenza viruses among US poultry workers in the Delmarva Peninsula, Maryland and Virginia, USA. J Agromedicine 2011;16:52-7. doi:10.1080/1059924X.2011.533612 Gray GC, McCarthy T, Capuano AW, et al. Evidence for avian influenza A infections among lowa's agricultural workers. Influenza Other Respi Viruses 2008;2:61-9. doi:10.1111/j.17502659.2008.00041.x Puzelli S, Di Trani L, Fabiani C, et al. Serological analysis of serum samples from humans exposed to avian H7 influenza viruses in Italy between 1999 and 2003. J Infect Dis 2005;192:1318-22. doi:10.1086/444390 Trani L Di, Porru S, Bonfanti L. Serosurvey Against H5 and H7 Avian Influenza Viruses in Italian Poultry Workers. Avian Dis 2012;56:1068-71. doi:10.1637/10184-041012-ResNote.1 Bridges CB, Lim W, Hu-Primmer J, et al. Risk of influenza A (H5N1) infection among poultry workers, Hong Kong, 1997-1998. J Infect Dis 2002;185:1005-10. doi:10.1086/340044 López-Robles G, Montalvo-Corral M, Caire-Juvera G, et al. Seroprevalence and Risk Factors for Swine Influenza Zoonotic Transmission in Swine Workers from Northwestern Mexico. Transbound Emerg Dis 2012;59:183-8. doi:10.1111/j.1865-1682.2011.01250.x De Marco MA., Porru S, Cordioli P, et al. Evidence of Cross-Reactive Immunity to 2009 Pandemic Influenza A Virus in Workers Seropositive to Swine H1N1 Influenza Viruses Circulating in Italy. PLoS One 2013;8. doi:10.1371/journal.pone.0057576 Huijsdens XW, Dijke van BJ, Spalburg E, et al. Community-acquired MRSA and pig-farming. Ann Clin. 2006;5:1-4. doi:10.1186/1476-0711-5-26 Pletinckx L, Verhegghe M, Crombé F, et al. Evidence of possible methicillin-resistant Staphylococcus aureus ST398 spread between pigs and other animals and people residing on the same farm. Prev Vet Med 2013;109:293-303. doi:10.1016/j.prevetmed.2012.10.019 Van Cleef BAGL, Graveland H, Haenen APJ, et al. Persistence of livestock-associated methicillinresistant Staphylococcus aureus in field workers after short-term occupational exposure to pigs and veal calves. J Clin Microbiol 2011;49:1030-3. doi:10.1128/JCM.00493-10 

strains acquired by pig farmers from pigs. Appl Environ Microbiol 2012;78:8010-4.

doi:10.1128/AEM.01902-12

Wulf MWH, Verduin CM, Van Nes A., et al. Infection and colonization with methicillin resistant Staphylococcus aureus ST398 versus other MRSA in an area with a high density of pig farms. Eur J Clin Microbiol Infect Dis 2012;31:61-5. doi:10.1007/s10096-011-1269-z dairy herds in southwest Germany. Zoonoses Public Health 2011;58:252-61. doi:10.1111/j.18632378.2010.01344.x Van den Broek IVF, VAN Cleef BAGL, Haenen a, et al. Methicillin-resistant Staphylococcus aureus in people living and working in pig farms. Epidemiol Infect 2009;137:700-8. doi:10.1017/S0950268808001507 Köck R, Loth B, Köksal M, et al. Persistence of nasal colonization with livestock-associated methicillin-resistant Staphylococcus aureus in pig farmers after holidays from pig exposure. Appl Environ Microbiol 2012;78:4046-7. doi:10.1128/AEM.00212-12 Geenen PL, Graat EAM, Haenen A., et al. Prevalence of livestock-associated MRSA on Dutch broiler farms and in people living and/or working on these farms. Epidemiol Infect 2012;:1-10. doi:10.1017/S0950268812001616 Gordoncillo MJ, Abdujamilova N, Perri M, et al. Detection of Methicillin-Resistant Staphylococcus aureus (MRSA) in Backyard Pigs and Their Owners, Michigan, USA. Zoonoses Public Health 2012;59:212-6. doi:10.1111/j.1863-2378.2011.01437.x Osadebe LU, Hanson B, Smith TC, et al. Prevalence and Characteristics of Staphylococcus aureus in Connecticut Swine and Swine Farmers. Zoonoses Public Health 2013;60:234-43. doi:10.1111/j.1863-2378.2012.01527.x Hetem DJ, Bootsma MCJ, Troelstra A, et al. Transmissibility of livestock-associated methicillinresistant Staphylococcus aureus. Emerg Infect Dis 2013;19:1797-802. doi:10.3201/eid1911.121085 Wang W, Owen H, Traub RJ, et al. Molecular epidemiology of Blastocystis in pigs and their incontact humans in Southeast Queensland, Australia, and Cambodia. Vet Parasitol 2014;203:264-9. doi:10.1016/j.vetpar.2014.04.006 Thorson A, Petzold M, Nguyen TKC, et al. Is Exposure to Sick or Dead Poultry Associated With Flulike Illness? Arch Intern Med 2006;166:119-23. potential risk of H5N1 transmission to humans living in rural Cambodia. Influenza Other Respi Viruses 2008;2:155-63. doi:10.1111/j.1750-2659.2008.00052.x Dione MM, Ikumapayi UN, Saha D, et al. Clonal differences between non-typhoidal Salmonella (NTS) recovered from children and animals living in close contact in the Gambia. PLoS Negl Trop Dis 2011;5:1-7. doi:10.1371/journal.pntd.0001148 Kandeel A, Manoncourt S, el Kareem EA, et al. Zoonotic transmission of avian influenza virus (H5N1), Egypt, 2006-2009. Emerg Infect Dis 2010;16:1101-7. doi:10.3201/eid1607.091695 Siwila J, Phiri IGK, Vercruysse J, et al. Asymptomatic cryptosporidiosis in Zambian dairy farm workers and their household members. Trans R Soc Trop Med Hyg 2007;101:733-4. doi:10.1016/j.trstmh.2007.01.006

Ortiz JR, Katz M a, Mahmoud MN, et al. Lack of evidence of avian-to-human transmission of avian influenza A (H5N1) virus among poultry workers, Kano, Nigeria, 2006. J Infect Dis 2007;196:168591. doi:10.1086/522158

Okoye J, Eze D, Krueger WS, et al. Serologic evidence of avian influenza virus infections among Nigerian agricultural workers. J Med Virol 2013;85:670-6. doi:10.1002/jmv.23520

Rabinowitz PM, Galusha D, Vegso S, et al. Comparison of Human and Animal Surveillance Data for H5N1 Influenza A in Egypt 2006-2011. PLoS One 2012;7:1-10. doi:10.1371/journal.pone.0043851

Al-Ani FK, El-Qaderi S, Hailat NQ, et al. Human and animal brucellosis in Jordan between 1996 and 1998: a study. Rev Sci Tech 2004;23:831-40.

Huo X, Zu R, Qi X, et al. Seroprevalence of avian influenza A (H5N1) virus among poultry workers in Jiangsu Province, China: an observational study. BMC Infect Dis 2012;12:93. doi:10.1186/14712334-12-93

Ming PX, Ti YLX, Bulmer GS. Outbreak of Trichophyton verrucosum in China transmitted from cows to humans. Mycopathologia 2006;161:225-8. doi:10.1007/s11046-005-0223-y

88 Brooke RJ, Kretzschmar ME, Mutters NT, et al. Human dose response relation for airborne exposure to Coxiella burnetii. BMC Infect Dis 2013;13:488. doi:10.1186/1471-2334-13-488 

Uzel M, Sasmaz S, Bakaris S, et al. A viral infection of the hand commonly seen after the feast of sacrifice: human orf (orf of the hand). Epidemiol Infect 2005;133:653-7.

doi:10.1017/S0950268805003778 members of the public. Commun Dis Public Health 1999;2:22-6.

Trevena WB, Willshaw GA, Cheasty T, et al. Transmission of Vero cytotoxin producing Escherichia coli $\mathrm{O} 157$ infection from farm animals to humans in Cornwall and west Devon. Commun Dis Public Health 1999;2:263-8.

Hoek MR, Oliver I, Barlow M, et al. Outbreak of Cryptosporidium parvum among children after a school excursion to an adventure farm, South West England. J Water Health 2008;6:333-8. doi:10.2166/wh.2008.060

94 Radon K, Schulze A, Ehrenstein V, et al. Environmental exposure to confined animal feeding operations and respiratory health of neighboring residents. Epidemiology 2007;18:300-8. doi:10.1097/01.ede.0000259966.62137.84 Schulze A, Römmelt $\mathrm{H}$, Ehrenstein $\mathrm{V}$, et al. Effects on pulmonary health of neighboring residents of concentrated animal feeding operations: exposure assessed using optimized estimation technique. Arch Environ Occup Health 2011;66:146-54. doi:10.1080/19338244.2010.539635 Van Cleef BAGL., Verkade EJM, Wulf MW, et al. Prevalence of livestock-associated MRSA in communities with high pig-densities in the Netherlands. PLoS One 2010;5:8-12. doi:10.1371/journal.pone.0009385 Petersen A., Stegger M, Heltberg O, et al. Epidemiology of methicillin-resistant Staphylococcus aureus carrying the novel mecC gene in Denmark corroborates a zoonotic reservoir with transmission to humans. Clin Microbiol Infect 2013;19. doi:10.1111/1469-0691.12036 Huijbers PMC, de Kraker M, Graat EAM, et al. Prevalence of extended-spectrum $\beta$-lactamaseproducing Enterobacteriaceae in humans living in municipalities with high and low broiler density. Clin Microbiol Infect 2013;19:E256-9. doi:10.1111/1469-0691.12150 Lyytikäinen O, Ziese T, Schwartländer B, et al. An outbreak of Sheep-Associated Q fever in a Rural Community in Germany. Eur J Epidemiol 1998;14:193-9.

100 Manfredi Selvaggi T, Rezza G, Scagnelli M, et al. Investigation of a Q-fever outbreak in northern Italy. Eur J Epidemiol 1996;12:403-8. doi:10.1007/BF00145305

101 Gaede W, Reckling KF, Dresenkamp B, et al. Chlamydophila psittaci infections in humans during an outbreak of psittacosis from poultry in Germany. Zoonoses Public Health 2008;55:184-8. doi:10.1111/j.1863-2378.2008.01108.x

102 Gilpin BJ, Scholes P, Robson B, et al. The transmission of thermotolerant Campylobacter spp. to people living or working on dairy farms in New Zealand. Zoonoses Public Health 2008;55:352-60. doi:10.1111/j.1863-2378.2008.01142.x

103 Hellström S, Laukkanen R, Siekkinen K-M, et al. Listeria monocytogenes contamination in pork can originate from farms. J Food Prot 2010;73:641-8.

104 Baker D, Nieuwenhuizen M. Environmental Epidemiology study methods and application. Oxford University Press 2008.

105 Schneider T, Vermeulen R, Brouwer DH, et al. Conceptual model for assessment of dermal exposure. Occup Environ Med 1999;56:765-

73.http://www.pubmedcentral.nih.gov/articlerender.fcgi?artid=1757678\&tool=pmcentrez\&rende rtype=abstract

106 Van Ransbeeck N, Van Langenhove H, Van Weyenberg S, et al. Typical indoor concentrations and emission rates of particulate matter at building level: A case study to setup a measuring strategy for pig fattening facilities. Biosyst Eng 2012;111:280-9. doi:10.1016/j.biosystemseng.2011.12.004

107 Van Ransbeeck N, Van Langenhove H, Demeyer P. Indoor concentrations and emissions factors of particulate matter, ammonia and greenhouse gases for pig fattening facilities. Biosyst Eng 2013;116:518-28. doi:10.1016/j.biosystemseng.2013.10.010

108 Van Ransbeeck N, Van Langenhove H, Michiels A, et al. Exposure levels of farmers and veterinarians to particulate matter and gases uring operational tasks in pig-fattening houses. Ann Agric Environ Med 2014;21:472-8. doi:10.5604/12321966.1120586

109 Eduard W, Douwes J, Mehl R, et al. Short term exposure to airborne microbial agents during farm work: exposure-response relations with eye and respiratory symptoms. Occup Environ Med 2001;58:113-8. doi:10.1136/oem.58.2.113 

farmers affected by work tasks and stable characteristics. Ann Occup Hyg 2013;57:1005-19. doi:10.1093/annhyg/met029

111 Padungtod P, Kaneene JB. Campylobacter in food animals and humans in northern Thailand. J Food Prot 2005;68:2519-26.

112 Heuvelink AE, Valkenburgh SM, Tilburg JJHC, et al. Public farms: hygiene and zoonotic agents. Epidemiol Infect 2007;135:1174-83. doi:10.1017/\$0950268807008072

113 Gibbs SG, Green CF, Tarwater PM, et al. Airborne antibiotic resistant and nonresistant bacteria and fungi recovered from two swine herd confined animal feeding operations. J Occup Environ Hyg 2004;1:699-706. doi:10.1080/15459620490515824

114 Schulz J, Formosa L, Seedorf J, et al. Measurement of culturable airborne Staphylococci downwind from a naturally ventilated broiler house. Aerobiologia (Bologna) 2011;27:311-8. doi:10.1007/s10453-011-9202-6

115 Schulz J, Friese A, Klees S, et al. Longitudinal study of the contamination of air and of soil surfaces in the vicinity of pig barns by livestock-associated methicillin-resistant Staphylococcus aureus. Appl Environ Microbiol 2012;78:5666-71. doi:10.1128/AEM.00550-12

116 Seedorf J. An emission inventory of livestock-related bioaerosols for Lower Saxony, Germany. Atmos Environ 2004;38:6565-81. doi:10.1016/j.atmosenv.2004.08.023

117 Kersh GJ, Fitzpatrick KA., Self JS, et al. Presence and Persistence of Coxiella burnetii in the environments of goat farms associated with a $\mathrm{Q}$ fever outbreak. Appl Environ Microbiol 2013;79:1697-703. doi:10.1128/AEM.03472-12

118 De Bruin A, van Alphen PT, van der Plaats RQ, et al. Molecular typing of Coxiella burnetii from animal and environmental matrices during $Q$ fever epidemics in the Netherlands. BMC Vet Res 2012;8:165. doi:10.1186/1746-6148-8-165

119 Hogerwerf L, Borlée F, Still K, et al. Detection of Coxiella burnetii DNA in inhalable airborne dust samples from goat farms after mandatory culling. Appl Environ Microbiol 2012;78:5410-2. doi:10.1128/AEM.00677-12

120 Van der Hoek W, Hunink J, Vellema P, et al. Q fever in The Netherlands: the role of local environmental conditions. Int J Environ Health Res 2011;21:441-51.

doi:10.1080/09603123.2011.574270

121 Coetzee N, Edeghere O, Afza M, et al. Limiting worker exposure to highly pathogenic avian influenza a (H5N1): a repeat survey at a rendering plant processing infected poultry carcasses in the UK. BMC Public Health 2011;11:626. doi:10.1186/1471-2458-11-626

122 MacMahon KL, Delaney U, Kullman G, et al. Protecting Poultry Workers from Exposure to Avian Influenza Viruses. Public Health Rep 2008;123:316-22.

123 Melse RW, Timmerman M. Sustainable intensive livestock production demands manure and exhaust air treatment technologies. Bioresour Technol 2009;100:5506-11.

doi:10.1016/j.biortech.2009.03.003 


\section{Appendix Search terms and filter settings}

\section{Search terms}

The following Boolean search statement was used in EMBASE, set to 'search as broadly as possible'; [ (zoonoses'/exp/mj OR 'zoonoses' OR 'zoonosis'/exp/mj OR 'zoonosis' OR 'infectious disease' OR 'human infection' OR 'human case') AND ('livestock'/exp/mj OR 'livestock' OR 'farm animal'/exp/mj OR 'farm animal' OR 'cow'/exp/mj OR 'cow' OR 'cattle'/exp/mj OR 'cattle' OR 'cattle' OR 'chicken'/exp/mj OR 'chicken' OR 'poultry'/exp/mj OR 'poultry' OR 'turkey' OR 'duck'/exp/mj OR 'duck' OR 'sheep'/exp/mj OR 'sheep' OR 'goat'/exp/mj OR 'goat' OR 'ruminants'/exp/mj OR 'ruminants' OR 'small ruminants' OR 'pig'/exp/mj OR 'pig' OR 'pigs' OR 'swine'/exp/mj OR 'swine') AND ('contact' OR 'contact intensity' OR 'bioaerosol' OR 'environmental' OR 'exposure'/exp/mj OR 'exposure' OR 'occupational' OR 'work' OR 'work related' OR 'workers' OR 'culling' OR 'residents' OR 'residential') AND ('transfer' OR 'exchange' OR 'transmission') NOT ('toxicity'/exp/mj OR 'toxicity' OR 'microextraction' OR 'tick'/exp/mj OR 'tick' OR 'rabies'/exp/mj OR 'rabies' OR 'schistosoma'/exp/mj OR 'schistosoma' OR 'transplant')].

\section{Filter settings}

Date preferences were set to $<1966$ to 2014 , so no data restrictions were applied to the search. Filters were set for; study types (human, nonhuman, questionnaire, case report, cross-sectional study, interview, case control study and cohort analysis) and floating subheadings (epidemiology, etiology, prevention, diagnosis, complication, drug resistance and disease management). 


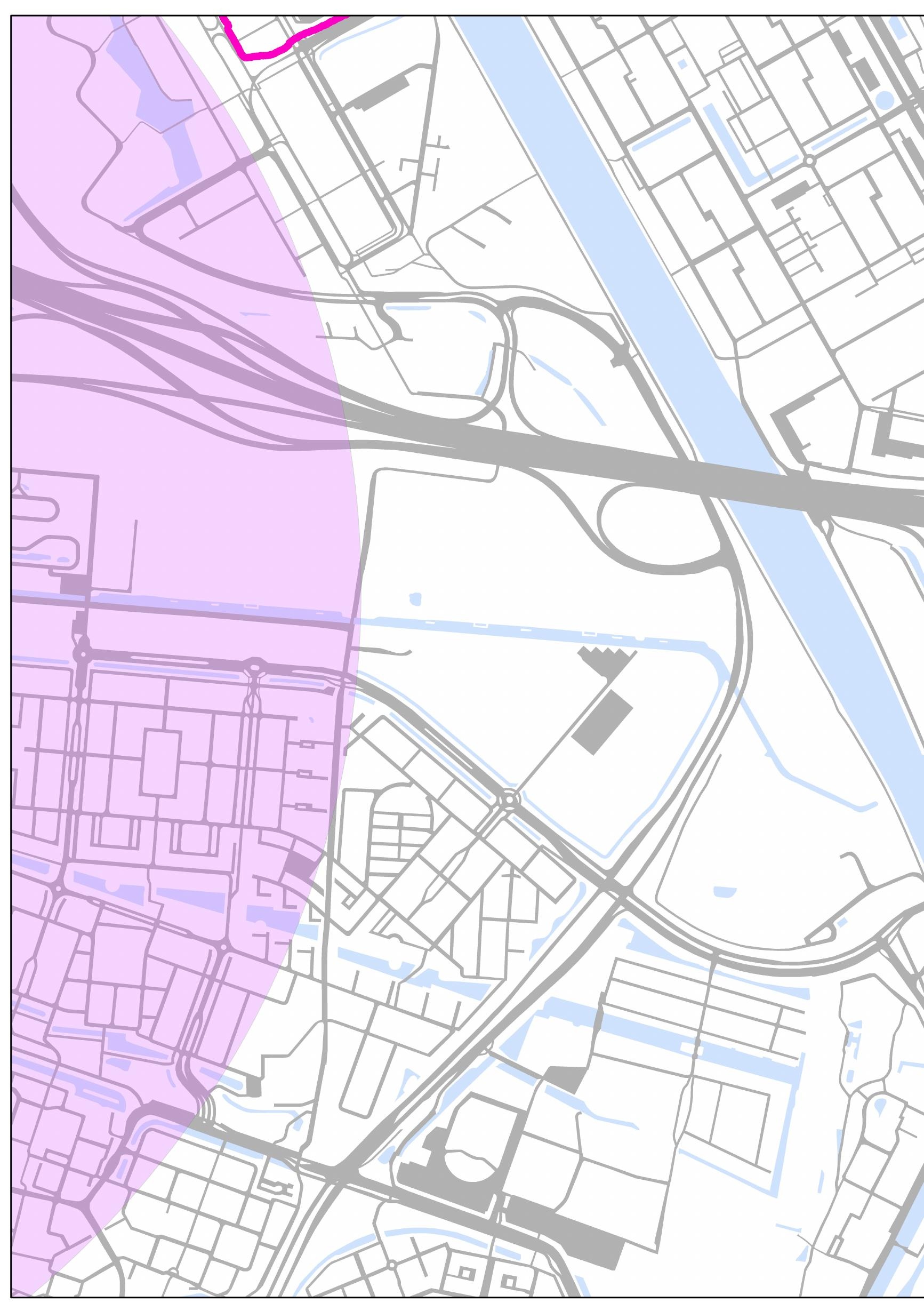


Chapter 3

Mobility assessment of a rural population in the Netherlands using GPS measurements

International Journal of Health Geographics (2017) 16:30 Gijs Klous, Lidwien Smit, Floor Borlée, Roel Coutinho, Mirjam Kretzschmar, Dick Heederik and Anke Huss 


\section{Mobility assessment of a rural population in the Netherlands using GPS measurements}

Background: The home address is a common spatial proxy for exposure assessment in epidemiological studies but mobility may introduce exposure misclassification. Mobility can be assessed using self-reports or objectively measured using GPS logging but selfreports may not assess the same information as measured mobility. We aimed to assess mobility patterns of a rural population in the Netherlands using GPS measurements and self-reports and to compare GPS measured to self-reported data, and to evaluate correlates of differences in mobility patterns.

Method: In total 870 participants filled in a questionnaire regarding their transport modes and carried a GPS-logger for 7 consecutive days. Transport modes were assigned to GPS-tracks based on speed patterns. Correlates of measured mobility data were evaluated using multiple linear regression. We calculated walking, biking and motorised transport durations based on GPS and self-reported data and compared outcomes. We used Cohen's kappa analyses to compare categorised self-reported and GPS measured data for time spent outdoors.

Results: Self-reported time spent walking and biking was strongly overestimated when compared to GPS measurements. Participants estimated their time spent in motorised transport accurately. Several variables were associated with differences in mobility patterns, we found for instance that obese people (BMI >30 $\mathrm{kg} / \mathrm{m}^{2}$ ) spent less time in non-motorised transport (GMR $0.69-0.74$ ) and people with COPD tended to travel longer distances from home in motorised transport (GMR 1.42-1.51).

Conclusions: If time spent walking outdoors and biking is relevant for the exposure to environmental factors, then relying on the home address as a proxy for exposure location may introduce misclassification. In addition, this misclassification is potentially differential, and specific groups of people will show stronger misclassification of exposure than others. Performing GPS measurements and identifying explanatory factors of mobility patterns may assist in regression calibration of self-reports in other studies. 


\section{Introduction}

Environmental epidemiological studies aim at evaluating risks to human health from environmental exposures. Human mobility may affect exposure of persons to different environmental substances, especially if exposure levels display strong spatial, or spatiotemporal variation. Examples of such exposures are ultrafine particles of air pollution [1], electromagnetic fields [2] or livestock-associated exposures, such as zoonotic microorganisms and endotoxins [3-6]. Personal exposure is often approximated by assigning exposure levels on a single location -usually the home address- to study participants, although this may lead to misclassification of exposure. Exposure misclassification can bias risk estimates, and this bias is often towards the null, in particular when misclassification is non-differential [7-10]. This essentially means that health effects from environmental exposures may remain undetected.

In this study we assessed modes of transport, in particular the duration people spent in motorised or non-motorised transport, and the distance from home for these movements. Mobility patterns can be assessed in multiple ways, using e.g. questionnaire data [11-14] or time activity diaries [14,15]. Since the 1990's, Global Positioning Systems (GPS) are available that allow for objective measurement of a persons' movements [16-18]. Measurements with GPS devices and activity diaries are time consuming and thus, questionnaires to assess mobility are often still the method of choice when studying large groups of people. However, self-reports of mobility assessed with questionnaires may be subject to bias and misclassification [11-14], especially if participants answer in a socially desirable way $[19,20]$. In addition, the majority of studies addressing mobility are performed among city dwellers [14]. Living in a rural area is likely associated with different mobility patterns [21] and also with different exposures to area-specific emissions, e.g. from livestock farms in the vicinity (Figure 1). Furthermore, people living in rural areas might spend more time outdoors [21].

In the present study, the main aim was to assess the different modes of transport of a rural population in the Netherlands using GPS measurements. Secondary aims were to explore if we could identify characteristics that explained differences in patterns of transport modes between participants, and to compare self-reported mobility to GPS measured mobility patterns.

\section{Material and methods}

\section{Study population}

The current study was embedded in the Dutch "Livestock Farming and Neighbouring Residents' Health Study" (Dutch acronym; VGO). The VGO study focusses on the health of non-farmer residents living in an area with a high density of livestock farms in the Netherlands. In a population-based cohort of 2494 participants (farmers were excluded a priori) [22], a medical examination was conducted by trained fieldworkers (March 2014 - February 2015) [23] General Practitioners' (GPs) Electronic Medical Records (EMRs) were available for 2426 participants (97\%) via the Netherlands Institute for Health Services Research (NIVEL, see also www.nivel.nl/en), one of the partners in the VGO study. Assessment included a questionnaire (VGO questionnaire) on health, lifestyle factors and the participants' occupational and residential history. NIVEL provided, when 
VGO participants gave permission, information regarding asthma, history of heart diseases and beta-blocker usage. VGO cohort members who agreed to be invited for follow-up research were eligible to participate in the GPS study. Medical Ethical approval was obtained for the VGO study from the Medical Ethical Committee of the University Medical Centre Utrecht (protocol number 13/533).

\section{Study design}

From September 2014 to January 2016, eligible subjects were invited to participate in the GPS study. This means that while some participants used GPS loggers in the winter, others used it in the summer. Our dataset therefore pertains to a whole year sample across all seasons. Participants filled in a questionnaire ( $\mathrm{Q}_{1}$, see supplementary data) that inquired about participants' usual mobility habits regarding different transport modes and time spent outdoors during a regular week. Upon return of $\mathrm{Q}_{1}$, GPS trackers and a second questionnaire $\left(\mathrm{O}_{2}\right)$ were sent to participants, including instructions on how to carry the GPS logger for 7 consecutive days. Participants were asked to put the GPS logger next to their keys, in their bag or jacket, so they would not forget it when they left the house. After the GPS-measurement week, $\mathrm{Q}_{2}$ about study adherence and start and end dates of GPS tracker carriage was filled in and GPS loggers were returned to the study centre.

\section{GPS data}

We used TracKing Key Pro GPS loggers (Land Air Sea systems Woodstock IL, USA). These devices enable continuous logging at 1-second intervals. GPS loggers are equipped with a motion sensor, providing data logging only when a participant is moving, thus reducing battery depletion. We set our measurements to $1 \mathrm{sec}$ measurement intervals, and the median total logging duration was 187h (IOR 143-235 h). Data obtained from GPS loggers were date, time, $X$ and $Y$ coordinate and speed $(\mathrm{km} / \mathrm{h})$. These GPS loggers were previously tested and showed a high positional accuracy when being outdoors [18].

\section{Questionnaire data}

Q1 included items regarding usual duration of time spent outdoors (hours per day) during the week and weekend, occupational status (being employed/self-employed: yes/no), working from home (yes/no), working days (number), having an outdoor occupation (yes/no), number of outdoor working hours (hours per workday) and outdoor activities during leisure time (walking, biking, sports, spending time close to home, other, in hours per week). Furthermore, transport modes for commuting were asked separately for transport during work hours and during leisure time. Transport modes were stratified by spring/summer, autumn/winter and additionally divided into the subcategories public transport, car, moped/motorcycle, electric bike, bicycle, on foot and other transport modes. Duration of these transport times was provided in minutes per day for commuting and work-related transport, and in minutes per week for leisuretime transport, participants could report multiple travel modes per trip, therefore alternating mobility patterns should have been captured (an English translation of $\mathrm{Q}_{1}$ is provided as supplement 11). 


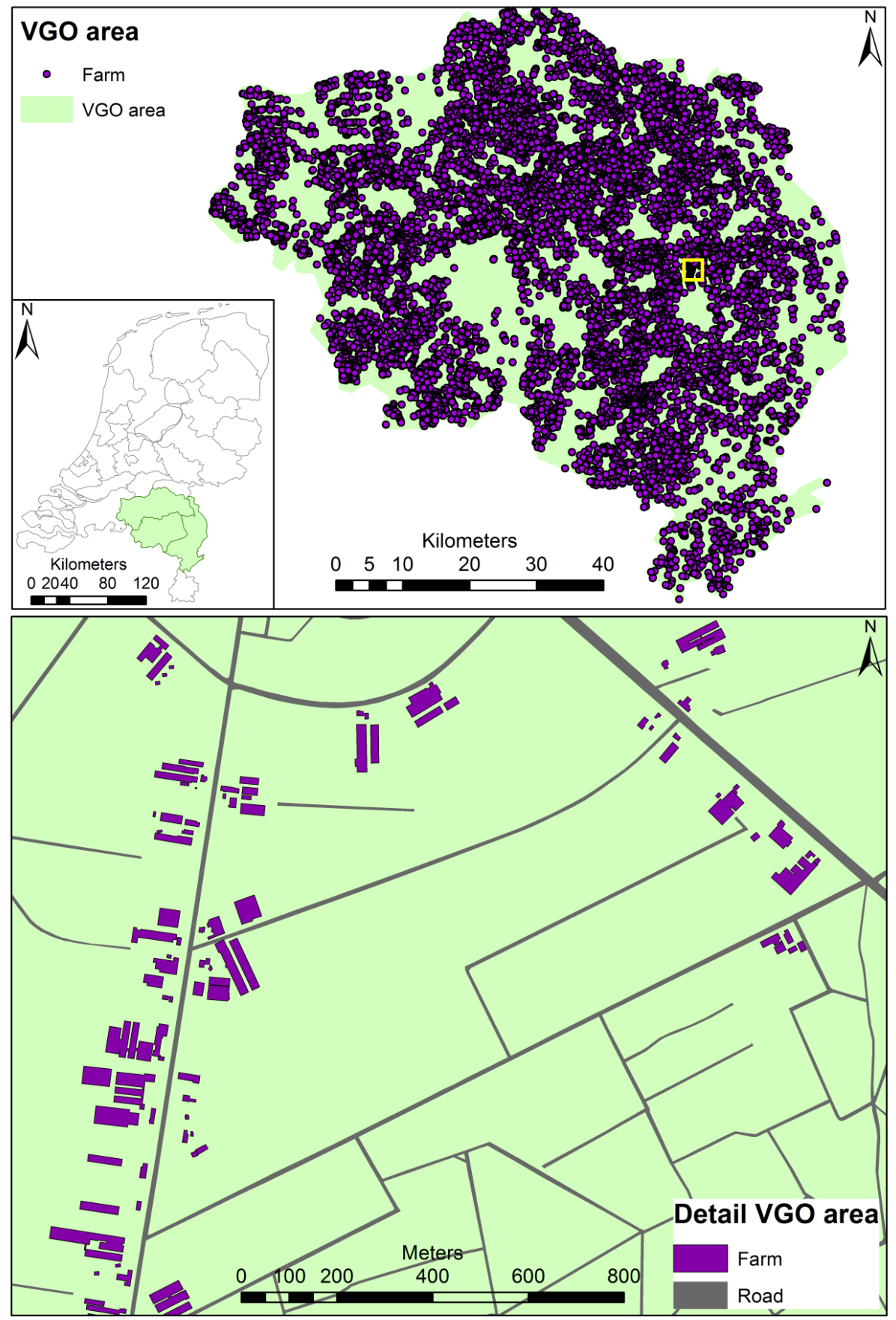

Figure 1. The research area, this map illustrates the rural situation within our research area. Not only are there many farms present in our research area ('VGO area' map) these farms are also very close together, with multiple farms per kilometre close to roads $<50 m$ ('Detail VGO area' map). 
Q2 inquired whether and when participants had left the GPS logger at home during the measuring period and if people had deviated from their normal weekly movement patterns. Additional participant characteristics and potential explanatory factors for differences in mobility patterns (gender, age, educational level, job status, dog and livestock ownership, hay fever, BMI (measured), smoking status, asthma status, COPD status (self-reporting combined with spirometry data from VGO health survey) and cardiovascular health (recent heart attacks, arrhythmia, ill heart functioning and betablocker usage) were obtained from the VGO health assessment and the VGO baseline questionnaire completed at the time of the health assessment (March 2014-February 2015)) $[22,23]$.

\section{Meteorological data}

Meteorological data on precipitation and temperature over the whole measurement period were retrieved from the Royal Netherlands Meteorological Institute. Data from the weather station Eindhoven was used, because this was the most centrally located station of the study area [24]. Percentage of time with rainfall (between 6.ooh and 22.00h) and the average temperature were calculated for the measurement period of each participant.

\section{Data cleaning}

We received GPS files from 940 participants. Of these, 34 had to be excluded due to device failure. Two participants did not adhere to the study protocol in that they either did not carry the GPS or did not fill in Q2. In addition, we applied two exclusion criteria: First we excluded persons who had carried the GPS for less than 24 hours $(\mathrm{N}=19)$ and second, we excluded persons where the self-reported outdoor time exceeded $3 \mathrm{SD}$ of the study population $(\mathrm{N}=16)$. Excluded people reported $>64 \%$ of their time as being outdoors, which we considered as unrealistic extreme values. One person did not return Q2 and was therefore excluded as well (Figure 2).

In addition, if a participant indicated in $\mathrm{Q}_{2}$ that they had not carried the GPS logger for a specific day, this day was removed from the analyses. More detailed information is provided in Figure 3. Note that excluded participants did not differ strongly regarding general characteristics (age, sex, education level), compared to participants who remained in the analyses.

\section{Processing of spatial data}

Home addresses (street, postal code, address) were geocoded using Dutch cadastral data (BAG data). A drawback of GPS-tracking is loss of accuracy when a GPS tracker has no clear view of the sky, especially when being indoors [18] resulting in a point cloud (supplementary Figure 1, supplement 1). Therefore, point clouds around the home were filtered by excluding all coordinates logged within a 6om radius around a home location; this distance was based on visual inspection of point clouds around a range of home addresses. Other GPS measurements were classified as indoors when at least 45 points were located within the outline of a building polygon. These polygons were then supplied with a $20 \mathrm{~m}$ buffer and all points within this buffer were classified as indoors for further analyses. Again, this cut-off was based on visual inspection: Fewer than 45 indoor points were more likely to appear as linearly-ordered 


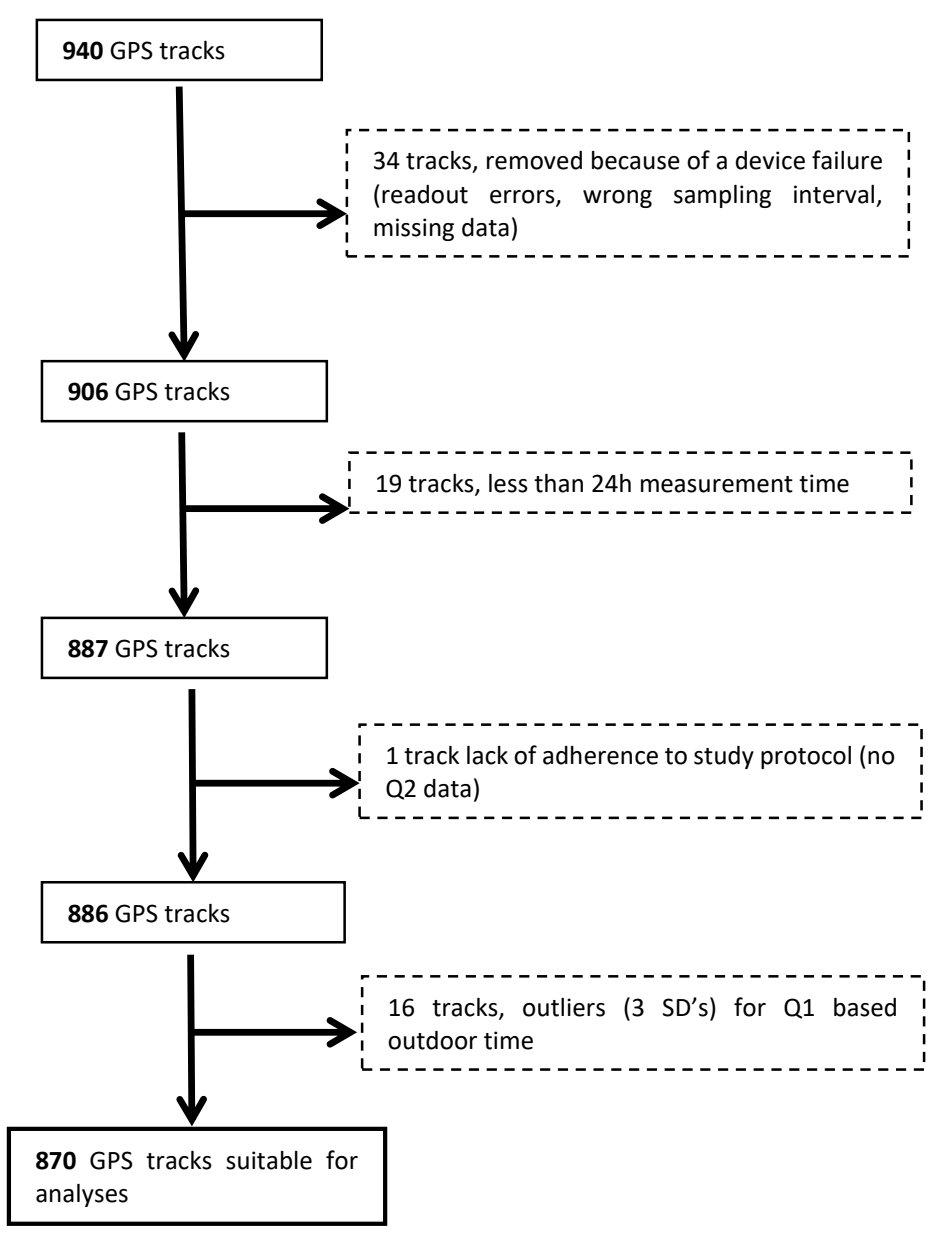

Figure 2 Data cleaning flowchart.

points, indicating smaller spatial inaccuracies when passing a building (supplementary Figure 2, supplement 1), while cloud patterns of coordinates were more likely indicating indoor locations, and were often located in public buildings such as sports facilities or supermarkets.

For every point the time differences with the previous point was calculated, if the difference was more than 1 second or speed was $0 \mathrm{~km} / \mathrm{h}$, then the point was indicated as a stop. These stops were then used to separate individual mobility episodes. The speed profile of each episode was analysed using a previously developed algorithm that assigns type of transport mode to speed patterns, based on a combination of speed, acceleration and deceleration [25]. Three types of transport modes were assigned to speed profiles: walking, biking or motorised transport. For each transport mode, total duration was assessed and was divided by the total tracking time, resulting in the 
percentage of time spent per specific transport mode. We analysed our data on a $24 \mathrm{~h}$ scale, this means we aimed to evaluate on average 168 hours $\left(24^{*} 7\right)$ per participant. Distances from the home address were calculated for each GPS coordinate, by calculating the distance between the GPS coordinate and the border of the 6om buffer around the home address. Figure 3 shows a schematic of GPS processing.

\section{Processing of Questionnaire data}

In $\mathrm{O}_{1}$ we asked for mobility per season (spring/summer and autumn/winter), the reported durations for these seasons were linked to the seasons in which participants performed the GPS measurement, the months October-March were considered as autumn/winter and April-September as spring/summer. We expressed data from $\mathrm{O}_{1}$ pertaining to self-reported transport modes in percentages of time spent per week. Time spent outdoors was calculated by adding the durations for all reported transport modes (commuting, work-related and leisure time) together with time involved in outdoor activities. To compare questionnaire and GPS datasets, time spent outdoors close to home (e.g, gardening, house hold duties, child care, etc.) was subtracted from the total reported time outdoors, as by removing all points within 6om around a place of residence, we were not able to differentiate erroneous GPS locations from time spent outdoors in close proximity to the home.

\section{Statistical analysis}

Participants were first assigned to an outdoors group based on tertiles of time spent outdoors as provided from their $\mathrm{Q}_{1}$ responses and GPS data ('little' (Q1: $\leq 9.5 \%$, GPS: $\leq 2.4 \%$ of time), 'sometimes' (Q1: 9.5-17.5\%, GPS: $2.4-4.2 \%$ of time) and 'often' outdoors (Q1: $>17.5 \%$, GPS: $>4.2 \%$ of time)), see supplement 5 for distributions of time spent outdoors. They were subsequently assigned to an outdoors group based on identical cut-off values using the tertiles derived from GPS measurements. Cohen's kappa analyses were then used to compare self-reported data with GPS measured categories of time spent outdoors.

We evaluated six different models with the following dependent variables: percentage of time spent outdoors, percentage of time spent in non-motorised and in motorised transport, mean distance from home while walking, biking and in motorised transport. We chose these outcome variables because they might be interesting for exposure assessment in future studies and differences in exposure due to walking, biking and motorised transport have been analysed extensively before [57].

The following factors were used in the models as independent variables, these were $a$ priori expected to influence time spent outdoors in active transport modes negatively: Chronic Obstructive Pulmonary Disease (COPD) [27], asthma [28], previous heart diseases [29,30], higher Body Mass Index (BMI) (classified as being overweight (>25-30 $\mathrm{kg} / \mathrm{m}^{2}$ ) or obese $\left(>30 \mathrm{~kg} / \mathrm{m}^{2}\right)$ ) [31-33], current smoking [32] and having any symptom in a broad spectrum of health symptoms (supplementary data Table 1, supplement 2, and explanation of VGO questionnaire B.21, supplement 12), attributed to the presence of livestock in the vicinity [34]. In contrast, we expected former and never smokers and people using beta-blockers to be more physically active, the latter on doctors' advice [35]. We also evaluated whether age (<45yrs, 45-55yrs, 55-65yrs and $>65 y$ rs, see 
GPS data (points)

1-second interval (when moving), Date, Time, $X$ and $Y$ coordinate, Speed

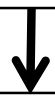

If point falls within $60 \mathrm{~m}$ buffer around home address or $20 \mathrm{~m}$ of other indoor location (building polygon with $>45$ GPS points included), GPS point is considered indoors

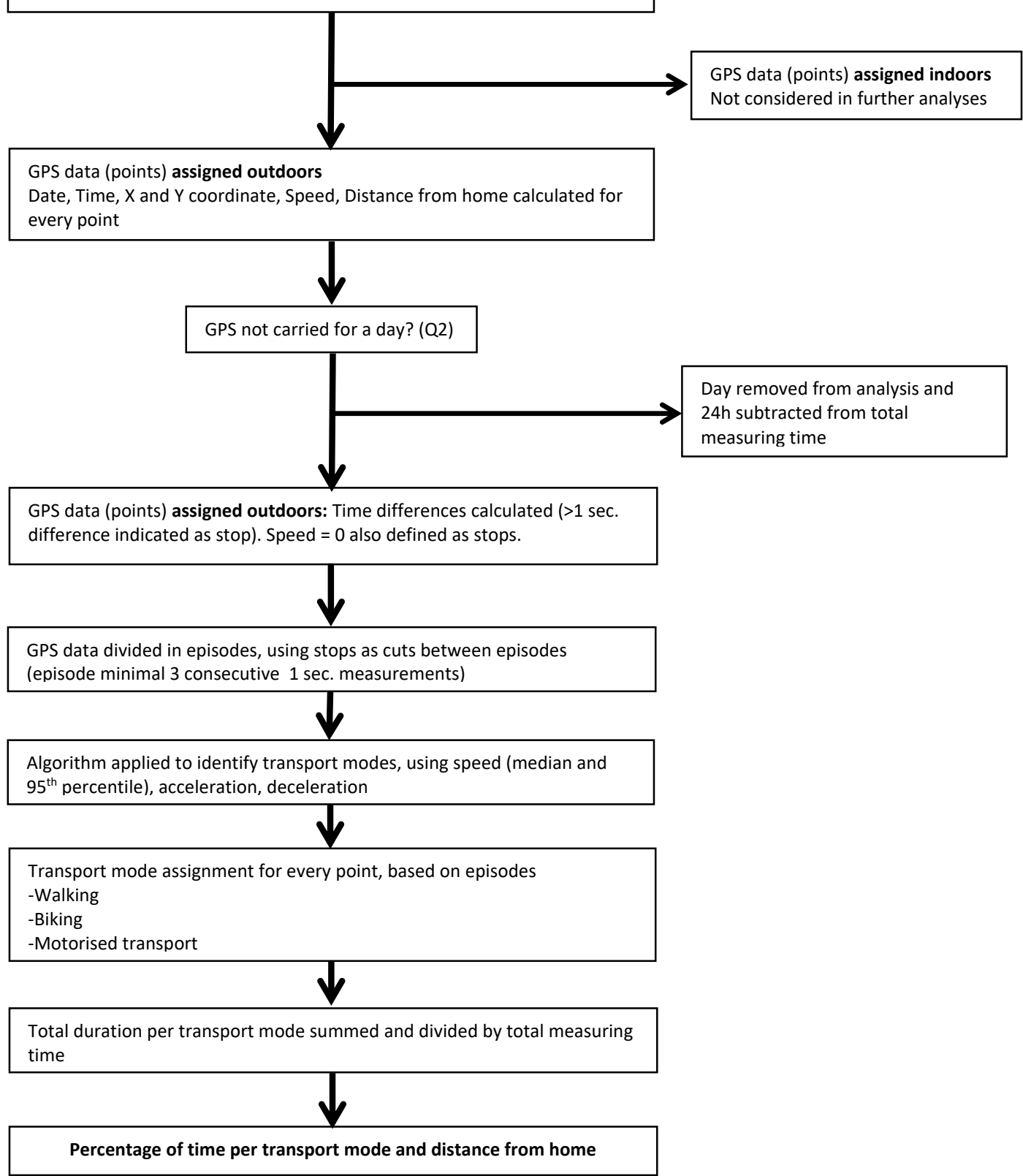

Figure 3. Schematic of GPS processing. 
supplementary Figure 3, supplement 3 for an age distribution), gender, educational level (low, medium, high) [30], working status (job: yes/no), having an outdoors occupation and the number of workdays per week, were associated with mobility patterns [36]. Furthermore, we expected that people were more frequently outdoors if they reported more time spent outdoors close to home (hours per week) [37], owning a dog (yes/no) [38,39] or keeping hobby farm animals (yes/no) [37]. The influence of weather conditions, namely average temperature during the measuring period $(<5,5-10,10-15$ (reference group), $15-20,20-25$, $>25$, all in ${ }^{\circ} \mathrm{C}$, see supplementary Figure 4 , supplement 4, for a temperature distribution) and average rainfall during the measuring period (percentage of time with rainfall between $6.00 \mathrm{~h}$ and $22.00 \mathrm{~h}$, during measurement) were also evaluated.

Univariate linear regression analyses were performed, followed by multiple linear regression with full models that included all possible explanatory factors for differences in time spent outdoors and distances from home, we used log-transformed data, since data was log normally distributed (data not shown). Supervised stepwise backwards selection (SSBS) models, always including age, gender and educational level, were performed in R. Final SSBS models were selected on the basis of the lowest Akaike's Information Criterion (AIC). Supplementary Tables 2 and 3 (supplement 6 and 7) display model outcomes with back transformed coefficients and associated 95\% Confidence Intervals (Cl), which can be interpreted as Geometric Mean Ratios (GMR) [26]. Finally, we performed sensitivity analyses (supplementary data: sensitivity analyses, supplement 8 ) on indoor buffer sizes, using $20 \mathrm{~m}$ instead of 6om buffers around the home address. No substantial differences were observed for measured times spent outdoors (supplementary Table 4) and therefore, the initial 6om buffers were retained for all analyses. In $\mathrm{Q}_{2}$ we asked whether people had deviated from their normal weekly movement patterns since this can affect our SSBS model estimates. We ran a sensitivity analyses of our SSBS models by running the models using only participants that indicated to have had a 'normal week'. Overall we found no material effects on our model estimates (supplementary Table 5 and 6, supplement 9 and 10) and therefore preferred to report on our full study population.

Spatial data was processed using ArcGIS ArcMap 10.2 (ESRI, Redlands, CA, USA), statistical analyses were performed using R 3.2.3. (R Foundation, Vienna, Austria).

\section{Results}

From September 2014 to January 2016, 1517 individuals were invited, 1001 (66.0\%) agreed to participate in the VGO GPS study and were sent a GPS tracker. A total of 940 GPS tracks contributed to the current analyses, since not all GPS trackers were returned, and 870 tracks remained after data cleaning steps (Figure 2). The median total GPS measurement duration of all participants was $187 \mathrm{~h}$ (IQR 143-235h), no movement was detected for median 180h (IQR 136-228h) and movement was registered for median $6 \mathrm{~h}$ (IOR 4-8h).

Mean age of the participants was $57 y$ rs (range $20-72 y r s$ ) $45 \%$ were male and $68 \%$ were employed or self-employed. Characteristics of participants are provided in Table 1. 
Table 1. General characteristics of study population. Data obtained from $\mathrm{Q}_{1}(\mathrm{a})$ and VGO baseline questionnaire $(b)(22,23)$.

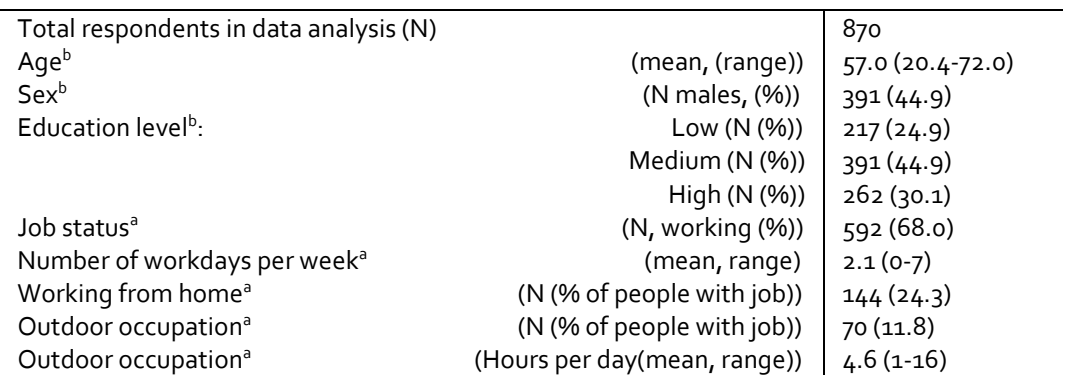

Based on GPS data, participants spent a median of 5.5 hours/week outdoors: 0.3 hours/week walking, 1.1 hours/week biking and 3.0 hours/week in motorised transport. Median distance from home was $2.0 \mathrm{~km}$ for walking (IQR 0.7-7.0), 2.0km for biking (IQR 0.8-4.4) and 7.4km for motorised transport (IQR 4.1-14.3) (Table 2).

The $\left(\mathrm{Q}_{1}\right)$ reported time spent outside was considerably longer compared to GPS measured time spent outside, indicating substantial overestimation (median 4.0 times longer). Especially walking and biking durations were longer based on self-reported compared to GPS measured durations (median 13.7 and 2.8 times overestimated, respectively), while time spent in motorised transport was similar (median 1.2 times higher), see Table 2 and Figure 4. The Cohen's kappa analyses showed a very low agreement between self-reported and measured time spent outdoors (kappa of 0.09 and 0.01 , based on tertiles in GPS and $\mathrm{Q}_{1}$ data, and for using the same cut-off values of GPS data to categorise self-reported data, respectively).

Results of our models evaluating individual characteristics on GPS measured mobility patterns are provided in the supplementary Tables 2 (percentages of time) and 3 (distances from the home address). Given the discrepancy of self-reports and GPSmeasured information, we refrained from evaluating correlates of self-reports.

For the overall percentage of time spent outdoors, cold average temperatures during the measurement period (below $5^{\circ} \mathrm{C}$ ) was associated with spending less time outdoors (GMR 0.80-0.81), women spent less time outdoors compared to men (GMR 0.85-0.87). People owning a dog spent more time outdoors compared to non-dog-owners (GMR 1.15-1.16).

Compared to study participants with a low educational level, participants with medium or high educational level tended to use motorised over non-motorised transport. We found that obese people $\left(\mathrm{BMl}>30 \mathrm{~kg} / \mathrm{m}^{2}\right)$ spent less time in non-motorised transport 
Table 2. Data obtained from the GPS track and Q1. Time values are transformed into hours per week, distances are in $\mathrm{km}$ from the home address, distance values were only available from the GPS measurements. Time outdoors is a combination of time walking, time biking, time in motorised transport and other time outdoors.

\begin{tabular}{|c|c|c|c|}
\hline \multirow[b]{2}{*}{ Variable } & & \multicolumn{2}{|c|}{ Time in hours/week, Distances in km } \\
\hline & & GPS & Questionnaire \\
\hline $\begin{array}{l}\text { Time indoors } \\
\text { Time outdoors } \\
\text { Time walking } \\
\text { Time biking } \\
\text { Time in motorised transport }\end{array}$ & $\begin{array}{l}\text { (Median (IQR)) } \\
\text { (Median (IQR)) } \\
\text { (Median (IQR)) } \\
\text { (Median (IQR)) } \\
\text { (Median (IQR)) }\end{array}$ & $\begin{array}{l}162.5(159.8-164.5) \\
5.5(3.5-8.2) \\
0.3(0.1-0.8) \\
1.1(0.3-2.4) \\
3.0(1.4-5.2)\end{array}$ & $\begin{array}{l}146.0(133.9-154.2) \\
22.0(13.8-34 \cdot 1) \\
4.0(2.0-9.0) \\
3.0(1.0-8.0)\end{array}$ \\
\hline $\begin{array}{l}\text { Distances from home while walking } \\
\text { Distances from home while biking } \\
\text { Distances from home motorised tran }\end{array}$ & $\begin{array}{r}\text { (Median (IQR)) } \\
\text { (Median (IQR)) } \\
\text { (Median (IQR)) }\end{array}$ & $\begin{array}{l}2.0(0.7-7.0) \\
2.0(0.8-4.1) \\
7.4(4.1-14.3)\end{array}$ & \\
\hline
\end{tabular}

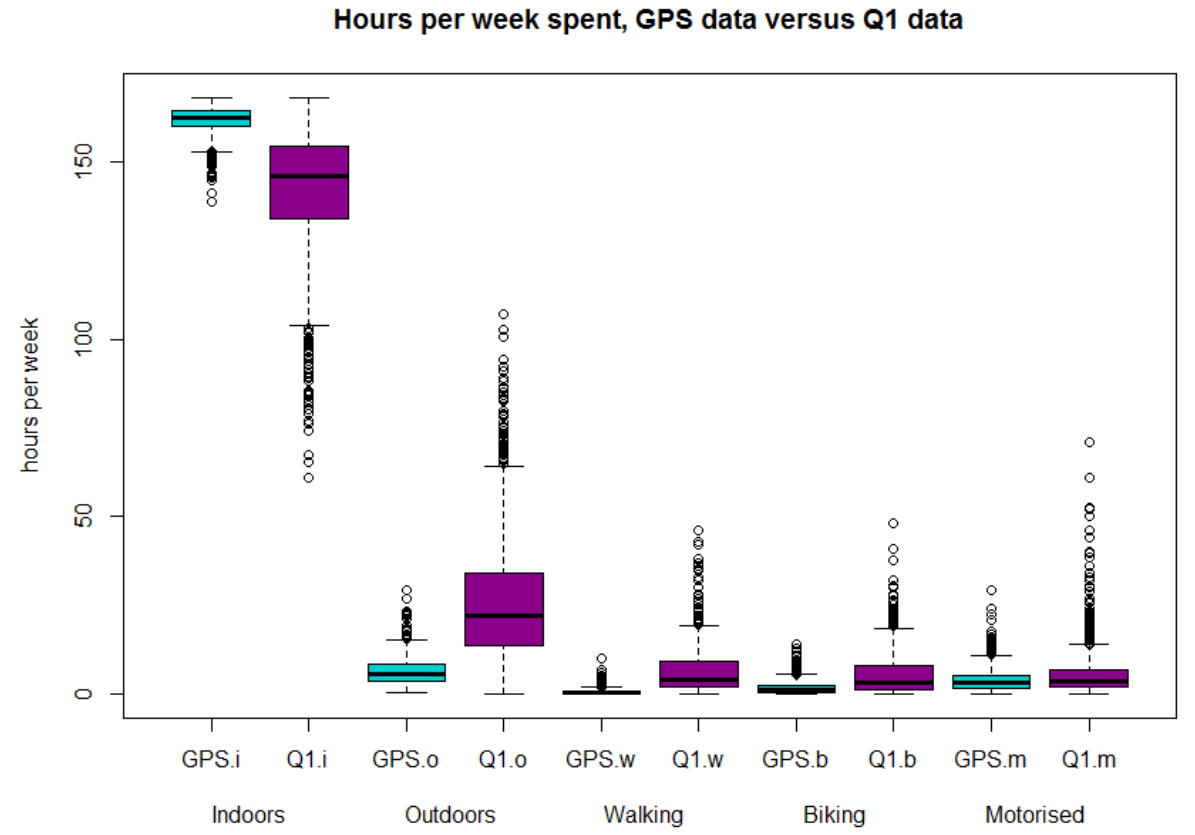

Figure 4. Boxplots for hours per week spent: indoors, outdoors, walking, biking and in motorised transport for GPS (blue) and $\mathrm{Q}_{1}$ (purple) data. Medians and interquartile ranges are provided in Table 2, these boxplots illustrate the great differences between GPS measured and self-reported data. 
(GMR 0.69-0.74) and people with more workdays spent more time in motorised transport (GMR 1.06-1.12). Regarding distances from home while walking we observed that higher educated people tended to walk further away from their home (medium educational level GMR 1.31-1.51, high educational level GMR 1.54-1.93), while owning a dog decreased the distance walked from home (GMR 0.51-0.58).

People using beta-blockers walked and biked less far from home than people not using these drugs (walking GMR 0.60-0.71, biking GMR 0.60-0.63). Dog-owners also remained closer to the home while biking, compared with non-dog-owners (GMR 0.73-0.76).

People with COPD and people with more workdays tended to travel longer distances from home in motorised transport (GMR 1.42-1.51 for people with COPD and GMR 1.061.09 for each workday). Higher outdoor temperatures $\left(20-25^{\circ} \mathrm{C}\right)$ were associated with shorter distances travelled in motorised transport.

\section{Discussion}

We assessed mobility of a rural population of 870 persons in the Netherlands and found that participants significantly overestimated their time spent outdoors in active transport when self-reported data pertaining to "usual mobility patterns" was compared to GPS measured data. In addition, there was low agreement between self-reported and measured categories of low, medium or high amount of time spent outdoors in active transport (kappa of o.09). Finally, we identified a range of (participant) characteristics that were associated with differences in mobility patterns of our study population.

\section{Strengths}

Strengths of our study include the large dataset of GPS-measured as well as selfreported mobility patterns. To the best of our knowledge, there are few previous studies with such extensive datasets. Most studies that focus on GPS measurements included fewer than 300 participants $[14,40]$. Few larger studies with GPS measurements (Schuessler and Axhausen $2008 \mathrm{~N}=4882$ and Bohte and Maat $2009 \mathrm{~N}=1104$ [41,42]), did not evaluate characteristics that explain observed differences in mobility patterns. Our study was embedded in a larger ongoing cohort study, providing additional information for all participants including health data, work and leisure time activities and data about the socio-economic situation of all participants. This extensive dataset enabled us to explore correlates of a range of individual characteristics with mobility patterns of our rural study population.

\section{Limitations}

GPS data has been suggested to add to environmental epidemiological studies, because exposures with a high spatial variability may be more accurately assessed [18]. This is certainly true in the case of GPS logging while in clear view of the sky; in this case, spatial accuracy has been reported to be very high $(\sim 2.5 \mathrm{~m})[18,60]$. However, when a GPS is used indoors, the spatial accuracy of the measurements is strongly reduced [61]. Therefore, we used buffers around indoor locations to assign these points as being indoors. This procedure thus clearly does not capture all aspects of mobility, but mobility close to home may have gone undetected. Note, however, that applying differently sized home buffers to differentiate indoor from outdoor points did not strongly affect our results. We used GPS measurements as a 'gold standard', although 
GPS measured locations can also have errors. However, we knew from previous work that in general, the accuracy is very high $(<10 \mathrm{Om})$ in $85 \%$ of the time even when used in an urban area [18]. Since we performed our study in a rural area, with less high-rise buildings, we expected that GPS positional error would not have a significant effect on our findings. Nevertheless, our inability to correctly differentiate measured locations to being either inside or in close proximity to the home likely misclassifies time spent in gardens as indoors. Other researchers have attempted to avoid this spatial accuracy problem by combining GPS measurements with other measurements, such as temperature [43] or a combination of accelerometer, magnetometers and light and temperature sensors [44]. Such a procedure may however increase problems with study adherence if participants have to carry multiple devices, in addition to generating further data analysis complexity.

Another limitation of our study is that we do not have repeated GPS measurements and that participants were only monitored for one week. Mobility patterns may change over time, and vary especially with season and weather conditions, as found across our study group. However, we were unable to evaluate whether there are individual differences in the adaptation of mobility patterns to weather or season.

Finally, in our study protocol, we inquired about "usual" daily mobility and not about the actual mobility patterns that participants had followed during our measurement week. We tried to improve match of self-reported and measured data by additionally asking whether participants had deviated from their "usual" weekly mobility patterns in Q2. We found no material differences in the correlates of mobility patterns in a sensitivity analysis of participants who had not deviated from a usual week compared to the full population. Nevertheless, this temporal mismatch may have further contributed to observed variance between self-reports and measured values.

\section{Comparison self-reported and GPS measured mobility}

We observed a striking overestimation in self-reported compared to measured time spent outdoors. Total time spent outdoors might be underestimated since we filtered out GPS locations in a $60 \mathrm{~m}$ buffer around the place of residence and $20 \mathrm{~m}$ of other indoor locations. In particular time spent walking was significantly overestimated. While overestimation of self-reported time spent walking as such is in line with previous reports, the amount of overestimation is not [14]. Kelly et al performed a systematic review quantifying differences between self-reported and GPS-measured journey durations. Fourteen publications were included in the meta-analysis and self-reported trip durations were overestimated in all included studies when compared to GPS measurements, overestimations ranged from 9.2-75.4\% [14]. In our analysis we found an overestimation of 13.7 times for walking, 2.8 times for biking and 1.2 times for motorised transport, which means that only overestimation for motorised transport is in line with what was reported by Kelly et al. [14]. There are three underlying reasons that may be driving this strong observed overestimation for time spent walking. First, in our questionnaire, we inquired about walking durations across different activities, but we did not clearly ask for walking that was performed exclusively outdoors, but asked instead for walking that was done "travelling for work". This could have resulted in a conceptual mismatch of self-reported and measured data, especially if a considerable part of daily walking is done indoors, e.g. during shopping for work-related purposes or 
if walking for work indoors (e.g. as a waiter or cleaner) is perceived as "travelling for work". However, the contribution of walking time of this question to overall walking time had a median below $1 \%$, and only $9.2 \%$ of all participants reported any walking for "travelling for work". Second, the algorithm we used to assign transport modes used the $95^{\text {th }}$ percentile of speed, acceleration and deceleration. This algorithm described in Huss et al. 2014 was the best performing algorithm to assign transport modes to GPS data, with a kappa agreement of 0.95 for assigned versus actual mode of transport. The results reported by these authors were based on mobility of 12 participants [25], but speed patterns used to assign mobility in our dataset might have had a wider variation. However, the speed patterns while walking, biking or in motorised transport are so distinct that we still expect the algorithm to be able to assign transport modes correctly in the majority of the cases. In addition, our algorithm assigned "stops" when the GPS device was not moving, if these stops occurred outdoors, transport modes were not assigned, further contributing to an underestimation of measured outdoor time. We checked the cumulative duration of outdoor stops for each participant, and encountered a maximum of 3 minutes over the whole study population. Therefore, we do not expect that the use of the algorithm would have introduced the difference in reported and measured mobility patterns. Third, our rural population walked only very little outdoors, across the whole group we measured a median of just 15 minutes outdoor walking per week. Very short durations, however, are easily misreported and several of our participants also commented that average weekly durations per activity were difficult to estimate. Over-reporting of walking times in our dataset was indeed much less pronounced in persons who walked more (median 4.6 times over-reporting in the highest tertile of walking duration), compared to persons who walked less. Reasons for our rural population to walk so little may be that in general, distances in rural areas tend to be large and many people may thus choose not to walk at all for their mobility needs. Misreporting walking duration may introduce exposure misclassification in studies that attempt to assign outdoor exposures to these durations and/or locations. However, given the very short durations of walking outdoors, the absolute error in exposure assignment may still be limited. Also duration of biking was over-reported by our participants, which highlights that in general, participants overestimate their own amount of active transport outdoors. Motorised transport may be easier to estimate, especially if linked to a fixed schedule in public transport, or if a large part of motorised transport is regular commuting. In studies with a focus on potentially differential concordance/discordance of reported and logged activity locations this disagreement between self-reported and GPS measured spatial data is not present $[58,59]$. However, in the current study our focus was on mobility and activity locations were not evaluated as such.

In several previous studies regarding GPS measurements for assessment of physical activity, the authors have not solely relied on GPS measurements, but have combined these with activity diaries or recall interviews $[14,16-18]$. Oliver et al tested the usage of GPS and accelerometry tools to assess transport-related physical activity (i.e. walking, biking); the comparative standard in this study were questionnaire travel logs. They included 37 participants into their study and concluded that GPS and accelerometry were good tools to assess walking and biking activity, although performance of the questionnaire data was not assessed [19]. Sallis et al. compared interviewer- 
administered and self-reported questionnaires, heart-rate monitors, and accelerometers for activity patterns of fifth graders. Both questionnaire approaches correlated quite well (Pearson's $r=0.76$ ) but correlation between questionnaires and objective measurements (heart-rate monitor and accelerometer) was lower ( $r=\sim 0.50$ and $r=\sim 0.30$, respectively) [45]. These effects can partially be explained with a tendency to answer in a socially desirable way, resulting in over-reporting of activity durations, as shown by Adams et al [20]. This means that regression calibration using measurements (GPS or mobile phone data) performed in a subsample of study participants may represent a way to calibrate self-reports [46], although this approach has not been validated in different populations.

\section{Explanatory variables analyses}

To the best of our knowledge we are the first to identify several correlates of mobility patterns, which may be especially relevant when assessing exposure to agents with a high spatial variability. For example, certain emissions from livestock farms are only detectable at a short distance: detectable levels of viable organisms have been found between $150-160 \mathrm{~m}$ from pig stables [4,47] and at 330m from poultry stables [3]. Even higher spatial variability can be observed for other environmental exposures, such as particulate matter [48] or electromagnetic fields [2]. This means that if mobility is relevant for personal exposure levels, using a general approach such as assigning exposure to the home address, will misclassify specific groups of people more than others. The identified individual explanatory factors for differences in mobility patterns may thus further assist in regression calibration efforts for other studies, or in the interpretation of previous studies that did not take such explanatory factors into account.

\section{Future perspectives}

Until very recently, due to financial, logistic and data management limitations, GPS measurements were only used in a limited way for data collection in mobility assessment. When GPS measurements were collected, this was generally done in small samples of people. Self-reporting with all its disadvantages including recall bias [11-14] was the default method to collect movement data on large cohorts of people [14]. With the increasing capabilities of smartphones [1,49-52], new opportunities exist to gather objectively measured data regarding spatial positions of people. Dewulf et al, illustrated this by combining location data from mobile phone network providers with air pollution data from a monitoring network in Belgium [1]. Using smartphones for location assessment in studies may thus help in reducing the amount of measurement devices a participant has to carry around. It may further assist in upscaling objective measurements to large cohort study collectives. Epidemiological studies relying on selfreports of usual mobility patterns should be aware of possible over-reporting of active transport patterns. Ways to mitigate this include improving temporal matching by using detailed activity diaries instead of asking for "usual" mobility, or possibly to improve reporting by regression calibration methods $[62,63]$. 


\section{Conclusions}

We evaluated mobility of a rural population and found that participants significantly overestimated their time spent outdoors in active transport when self-reported data was compared to GPS measured data. We identified several correlates of mobility patterns, which may be especially relevant when assessing exposure to agents with a high spatial variability. If active transport outdoors is relevant for personal exposure levels, then using a general approach such as assigning exposure to the home address will introduce exposure misclassification that will be stronger in some groups of people than in others. Regression calibration using measurements or these identified explanatory variables may represent a way to calibrate self-reports in future studies.

\section{Declarations}

Medical Ethical approval

All participants signed an informed consent form, medical ethical approval was obtained for the VGO study from the Medical Ethical Committee of the University Medical Centre Utrecht (protocol number 13/533).

\section{Authors contributions}

GK, LAMS and FB collected the data. GK performed the analysis and drafted the first version of the manuscript. RAC, DJJH and $A H$ conceived of the study. All authors contributed to data interpretation and finalising the draft, and read and approved the final manuscript.

\section{Acknowledgements}

We would like to thank all our participants, Lützen Portengen and Astrid Martens for statistical input and Daisy de Vries for textual input. 


\section{References}

1. Dewulf B, Neutens T, Lefebvre W, Seynaeve G, Vanpoucke C, Beckx C, et al. Dynamic assessment of exposure to air pollution using mobile phone data. Int J Health Geogr [Internet]. BioMed Central; 2016;15[1]:14. Available from: http://ijhealthgeographics.biomedcentral.com/articles/10.1186/s12942-016-0042-z

2. Beekhuizen J, Vermeulen R, Kromhout H, Bürgi A, Huss A. Science of the Total Environment Geospatial modelling of electromagnetic fields from mobile phone base stations. Sci Total Environ [Internet]. Elsevier B.V.; 2013;445-446:202-9. Available from: http://dx.doi.org/10.1016/j.scitotenv.2012.12.020

3. Schulz J, Formosa L, Seedorf J, Hartung J. Measurement of culturable airborne staphylococci downwind from a naturally ventilated broiler house. Aerobiologia [Bologna]. 2011;27[4]:311-8.

4. Schulz J, Friese A, Klees S, Tenhagen B a., Fetsch A, Rösler U, et al. Longitudinal study of the contamination of air and of soil surfaces in the vicinity of pig barns by livestock-associated methicillin-resistant Staphylococcus aureus. Appl Environ Microbiol. 2012;78[16]:5666-71.

5. Schulze A, Römmelt $H$, Ehrenstein V, van Strien R, Praml G, Küchenhoff $H$, et al. Effects on pulmonary health of neighboring residents of concentrated animal feeding operations: exposure assessed using optimized estimation technique. Arch Environ Occup Health. 2011;66[3]:146-54.

6. Klous G, Huss A, Heederik DJJ, Coutinho RA. Human - livestock contacts and their relationship to transmission of zoonotic pathogens, a systematic review of literature. ONEHLT [Internet]. The Authors; 2016;2:65-76. Available from: http://dx.doi.org/10.1016/j.onehlt.2016.03.001

7. Kersh GJ, Fitzpatrick K a., Self JS, Priestley R a., Kelly AJ, Ryan Lash R, et al. Presence and Persistence of Coxiella burnetii in the environments of goat farms associated with a $Q$ fever outbreak. Appl Environ Microbiol. 2013;79[5]:1697-703.

8. Perchoux C, Chaix B, Cummins S, Kestens Y. Conceptualization and measurement of environmental exposure in epidemiology: Accounting for activity space related to daily mobility. Heal Place [Internet]. Elsevier; 2013;21:86-93. Available from: http://dx.doi.org/10.1016/j.healthplace.2013.01.005

9. Chaix B, Méline J, Duncan S, Merrien C, Karusisi N, Perchoux C, et al. GPS tracking in neighborhood and health studies: A step forward for environmental exposure assessment, A step backward for causal inference? Heal Place. 2013;21:46-51.

10. Rytkönen MJ. Not all maps are equal: GIS and spatial analysis in epidemiology. Int J Circumpolar Health. 2004;63[1]:9-24.

11. Stalvey BT, Owsley C, Sloane ME, Ball K. The life space questionnaire: a measure of the extent of mobility of older adults. J Appl Gerontol. 1999;18[4]:460-78.

12. O'Brien M, Jones D, Sloan D RM. from the SAGE Social Science Collections . All Rights Reserved . 2016;

13. Meurs H, Haaijer R. Spatial structure and mobility. Transp Res Part D Transp Environ. 2001;6[6]:429-46.

14. Kelly P, Krenn P, Titze S, Stopher P, Foster C. Quantifying the Difference Between Self-Reported and Global Positioning Systems-Measured Journey Durations: A Systematic Review. Transp Rev A Transnatl Transdiscipl J [Internet]. 2013;33[4]:443-59. Available from: http://www.tandfonline.com/doi/abs/10.1080/01441647.2013.815288

15. Deffner V, Kuchenhoff H, Maier V, Pitz M, Cyrys J, Breitner S, et al. Personal exposure to ultrafine particles: Two-level statistical modeling of background exposure and time-activity patterns during three seasons. J Expo Sci Environ Epidemiol [Internet]. 2016;26[1]:17-25. Available from: http://www.ncbi.nlm.nih.gov/pubmed/25407347

16. Elgethun K, Fenske RA, Yost MG, Palcisko GJ. Time-location analysis for exposure assessment studies of children using a novel global positioning system instrument. Environ Health Perspect. 2003;111[1]:115-22.

17. Dias D, Tchepel O. Modelling of human exposure to air pollution in the urban environment: A GPSbased approach. Environ Sci Pollut Res. 2014;21[5]:3558-71.

18. Beekhuizen J, Kromhout H, Huss A, Vermeulen R. Performance of GPS-devices for environmental exposure assessment. J Expo Sci Environ Epidemiol [Internet]. Nature Publishing Group; 2013;23[5]:498-505. Available from: http://www.ncbi.nlm.nih.gov/pubmed/22829049 
19. Oliver M, Badland H, Mavoa S, Duncan MJ, Duncan S. Combining GPS, GIS, and accelerometry: methodological issues in the assessment of location and intensity of travel behaviors. J Phys Act Health. 2010;7[1]:102-8.

20. Adams SA, Matthews CE, Ebbeling CB, Moore CG, Joan E, Fulton J, et al. The Effect of Social Desirability and Social Approval on Self-Reports of Physical Activity. 2005;161[4]:389-98.

21. Matz CJ, Stieb DM, Brion O. Urban-rural differences in daily time-activity patterns, occupational activity and housing characteristics. Environ Health [Internet]. Environmental Health; 2015;14[1]:88. Available from: http://www.ehjournal.net/content/14/1/88

22. Borlée F, Yzermans CJ, Van Dijk CE, Heederik D, Smit LAM. Increased respiratory symptoms in COPD patients living in the vicinity of livestock farms. Eur Respir J [Internet]. 2015;46[6]:1605-14. Available from: http://dx.doi.org/10.1183/13993003.00265-2015

23. Borlée F, Yzermans CJ, Krop E, Aalders B, Rooijackers J, Zock JP, van Dijk CE, Maassen K, Schellevis $F$, Heederik D, Smit LAM. Spirometry, questionnaire and Electronic Medical Record based COPD in a population survey: comparing prevalence, level of agreement and associations with potential risk factors. PLoS One 2017;12:e0171494

24. KNMI website [Internet]. Available from: https://www.knmi.nl/Nederlandnu/klimatologie/uurgegevens Accessed $4^{\text {th }}$ April 2016

25. Huss A, Beekhuizen J, Kromhout H, Vermeulen R. Using GPS-derived speed patterns for recognition of transport modes in adults. Int J Health Geogr [Internet]. 2014;13[1]:40. Available from: http://www.pubmedcentral.nih.gov/articlerender.fcgi?artid=4320483\&tool=pmcentrez\&renderty pe=abstract\nhttp://ij-healthgeographics.biomedcentral.com/articles/10.1186/1476-072X-13-40

26. Kytariolos J, Karalis V, Macheras P, Symillides M. Novel scaled bioequivalence limits with levelingoff properties. Pharm Res. 2006;23[11]:2657-64.

27. Pitta F, Troosters T, Spruit MA, Probst VS, Decramer M, Gosselink R. Characteristics of physical activities in daily life in chronic obstructive pulmonary disease. Am J Respir Crit Care Med. 2005;171[9]:972-7.

28. Williams B, Powell A, Hoskins G, Neville R. Exploring and explaining low participation in physical activity among children and young people with asthma: a review. BMC Fam Pract [Internet]. 2008;9[1]:40. Available from: http://www.biomedcentral.com/1471-2296/9/40

29. Giallauria F, Cirillo P, D'agostino M, Petrillo G, Vitelli A, Pacileo M, et al. Effects of exercise training on high-mobility group box-1 levels after acute myocardial infarction. J Card Fail [Internet]. Elsevier Inc; 2011;17[2]:108-14. Available from: http://www.ncbi.nlm.nih.gov/pubmed/21300299

30. Allman RM, Baker PS, Maisiak RM, Sims R V., Roseman JM. Racial similarities and differences in predictors of mobility change over eighteen months. J Gen Intern Med. 2004;19[11]:1118-26.

31. AM Kytta, AK Broberg MK. Urban Environment and Children's Active Lifestyle: SoftGIS Revealing Children's Behavioral Patterns and Meaningful Places. 2012.

32. Stuck AE, Walthert JM, Nikolaus T, Büla CJ, Hohmann C, Beck JC. Risk factors for functional status decline in community-living elderly people: a systematic literature review. Soc Sci Med. 1999;48[4]:445-69.

33. BMI [Internet]. Available from: http://www.nhlbi.nih.gov/health/educational/lose_wt/BMI/bmim.htm

34. Neuberg SL, Kenrick DT, Schaller M. Human threat management systems: Self-protection and disease avoidance. Neurosci Biobehav Rev [Internet]. Elsevier Ltd; 2011;35[4]:1042-51. Available from: http://dx.doi.org/10.1016/j.neubiorev.2010.08.011

35. Graham I, Atar D, Borch-Johnsen K, Boysen G, Burell G, Cifkova R, et al. European guidelines on cardiovascular disease prevention in clinical practice: executive summary: Fourth Joint Task Force of the European Society of Cardiology and Other Societies on Cardiovascular Disease Prevention in Clinical Practice [Constituted by r. Eur Heart J [Internet]. 2007;28[19]:2375-414. Available from: http://www.ncbi.nlm.nih.gov/pubmed/17726041 \nhttp://eurheartj.oxfordjournals.org/content/2 8/19/2375.short

36. Stopher $\mathrm{P}$, Zhang $\mathrm{Y}$. Is travel behaviour repetitive from day to day? [Internet] http://atrf.info/papers/2010/2010_Stopher_Zhang_B.pdf, 33rd Australasian Transport Research Forum [ATRF] 2010, Canberra, ACT, Australia.

37. Bellows AC, Brown K, Smit J. Health Benefits of Urban Agriculture. Community Food. 2003.

38. Brown JD, Stallknecht DE, Valeika S, Swayne DE. Susceptibility of wood ducks to H5N1 highly pathogenic avian influenza virus. J Wildl Dis. 2007;43[4]:660-7.

39. Cutt H, Giles-Corti B, Knuiman M, Burke V. Dog ownership, health and physical activity: A critical review of the literature. Health Place. 2007;13:261-72. 
40. Chaix B, Kestens Y, Duncan DT, Brondeel R, Méline J, El Aarbaoui T, et al. A GPS-Based Methodology to Analyze Environment-Health Associations at the Trip Level: Case-Crossover Analyses of Built Environments and Walking. Am J Epidemiol [Internet]. 2016;kww071. Available from: http://www.ncbi.nlm.nih.gov/pubmed/27659779

41. Schuessler N, Axhausen KW. Processing Raw Data from Global Positioning Systems Without Additional Information. Transp Res Rec J Transp Res Board. 2009;2105[1]:28-36.

42. Bohte W, Maat K. Deriving and validating trip purposes and travel modes for multi-day GPS-based travel surveys: A large-scale application in the Netherlands. Transp Res Part C Emerg Technol [Internet]. Elsevier Ltd; 2009;17[3]:285-97. Available from:

http://dx.doi.org/10.1016/j.trc.2008.11.004

43. Nethery E, Mallach G, Rainham D, Goldberg MSMS, Wheeler AJAJ. Using Global Positioning Systems [GPS] and temperature data to generate time-activity classifications for estimating personal exposure in air monitoring studies: an automated method. Environ Heal. 2014;13[1]:33.

44. Golding AR, Lesh N. Indoor navigation using a diverse set of cheap, wearable sensors. Wearable Comput 1999 Dig Pap Third Int Symp. 1999;29-36.

45. Sallis J. Validation of interviewer- a self-administered physical activity checklists for fifth grade students. 1996; [July 2016].

46. Matthews CE, Moore C, George SM, Sampson J, Bowles HR. NIH Public Access. 2013;40[3]:118-26.

47. Thorne PS. Industrial Livestock Production Facilities: Airborne Emissions. Encycl Environ Heal [Internet]. 2011;218-26. Available from:

http://www.sciencedirect.com/science/article/pii/B9780444522726004232

48. Li J, Jin M, Xu Z. Spatiotemporal Variability of Remotely Sensed PM 2 . 5 Concentrations in China from 1998 to 2014 Based on a Bayesian Hierarchy Model. 2014;

49. Gonzalez MC, Hidalgo CA, Barabasi A-L. Understanding individual human mobility patterns. Nature [Internet]. 2008;453[7196]:779-82. Available from:

http://antonioneme.googlepages.com/understanding_individual_human_mobil.pdf \nhttp://arxiv. org/pdf/0806.1256; \nhttp://antonioneme.googlepages.com/understanding_individual_human_m obil.pdf

50. Ahas R, Silm S, Järv O, Saluveer E, Tiru M. Using Mobile Positioning Data to Model Locations Meaningful to Users of Mobile Phones. J Urban Technol. 2010;17[1]:3-27.

51. Glasgow ML, Rudra CB, Yoo E-H, Demirbas M, Merriman J, Nayak P, et al. Using smartphones to collect time-activity data for long-term personal-level air pollution exposure assessment. J Expo Sci Environ Epidemiol [Internet]. Nature Publishing Group; 2014;26[September]:1-9. Available from: http://www.nature.com/doifinder/10.1038/jes.2014.78

52. Palmer JRB, Espenshade TJ. New Approaches to Human Mobility : Using Mobile Phones for Demographic Research. 2013;1105-28.

53. Quanjer PH, Stanojevic S, Cole TJ, Baur X, Hall GL, Culver BH, et al. Multi-ethnic reference values for spirometry for the 3-95-yr age range: The global lung function 2012 equations. Eur Respir J. 2012;40[6]:1324-43.

54. The European Respiratory Health Survey. Respiratory Health Survey li. 2007;1-65. Available from: http://www.ecrhs.org/Quests/ECRHSIImainquestionnaire.pdf

55. Yzermans J, Baliatsas C, van Dulmen S, Van Kamp I. Assessing non-specific symptoms in epidemiological studies: Development and validation of the Symptoms and Perceptions [SaP] questionnaire. Int J Hyg Environ Health [Internet]. Elsevier GmbH.; 2016;219[1]:53-65. Available from: http://dx.doi.org/10.1016/j.ijheh.2015.08.006

56. NCEE [Internet]. Available from: www.ncee.org

57. De Hartog JJ, Boogaard H, Nijland H and Hoek G. Do the health benefits of cycling outweigh the risks? Environ Health Perspect. 2010;118[8]:1109-1116.

58. Shareck M, Kestens $Y$, Gauvin L. Examining the spatial congruence between data obtained with novel activity location questionnaire, continuos GPS tracking, and prompted recall surveys. Int J Health Geogr [Internet]. BioMed Central; 2013;12[1]:40. Available from: https://ijhealthgeographics.biomedcentral.com/articles/10.1186/1476-072X-12-40

59. Paz-Soldan VA, Reiner RC, Morrison AC, Stoddard ST, et al. Strenghts and weaknesses of Global Positioning System [GPS] data-loggers and semi-structured interviews for capturing fine-scale human mobility: findings from Iquitos, Peru. PLoS Negl Trop Dis 2014;8[6]:e2888

60. Krenn PJ, Titze S, Oja P, Jones A and Ogilvie D. Use of Global Positioning Systems to Study Physical Activity and the Environment A Systematic Review. American Journal of Preventive Medicine 2011 41[5]: 508-515 
61. Kerr J, Duncan S and Schipperjin J. Using Global Positioning Systems in Health Research A Practical Approach to Data Collection and Processing. American Journal of Preventive Medicine 2011 41[5]: 532-540

62 Lim S, Wyker B, Bartley K and Eisenhower D. Measurement error of self-reported physical activity in New York City: assessement and correction. Am J Epidemiol 2015 181[9]:648-655

63 Saint-Maurice PF, Welk GJ, Beyler NK, Bartee RT and Heelan KA. Calibration of self-report tools for physical activity research: the Physical Activity Questionnaire [PAQ]. BMC Public Health 2014

14:461 


\section{Supplementary data}

1. Example pictures for the spatial analyses, 6om home buffer (Supp. figure 1) and other indoor points (Supp. figure 2).

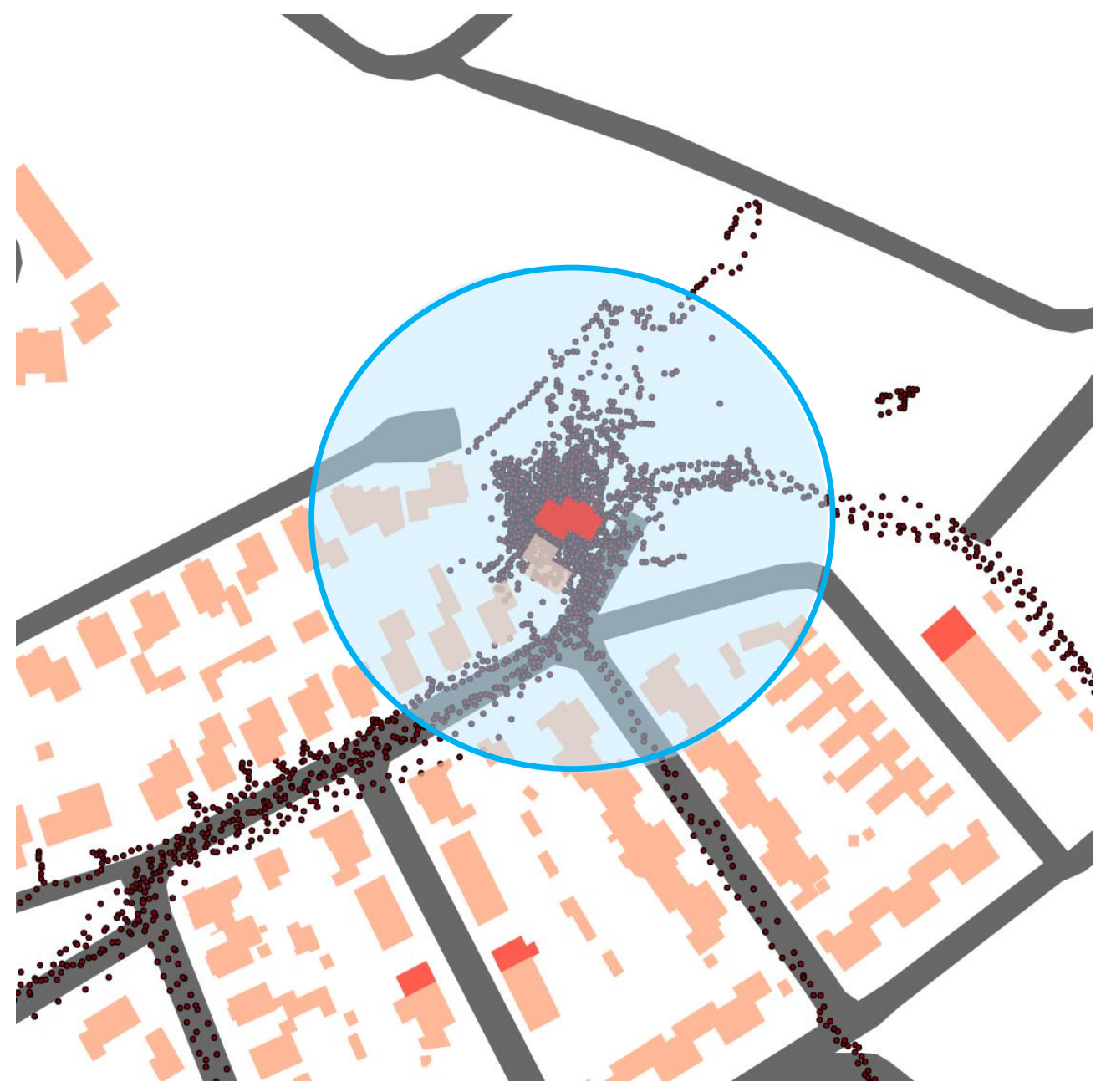

Supp. Figure 1. A typical GPS point cloud around a home address (red polygon), this was resolved by using a 6 om buffer around the home address (light blue), all GPS points within this buffer were indicated as being 'indoors', all points outside this buffer and additional indoor buffers, were indicated as 'outdoors' and used in the analyses. 


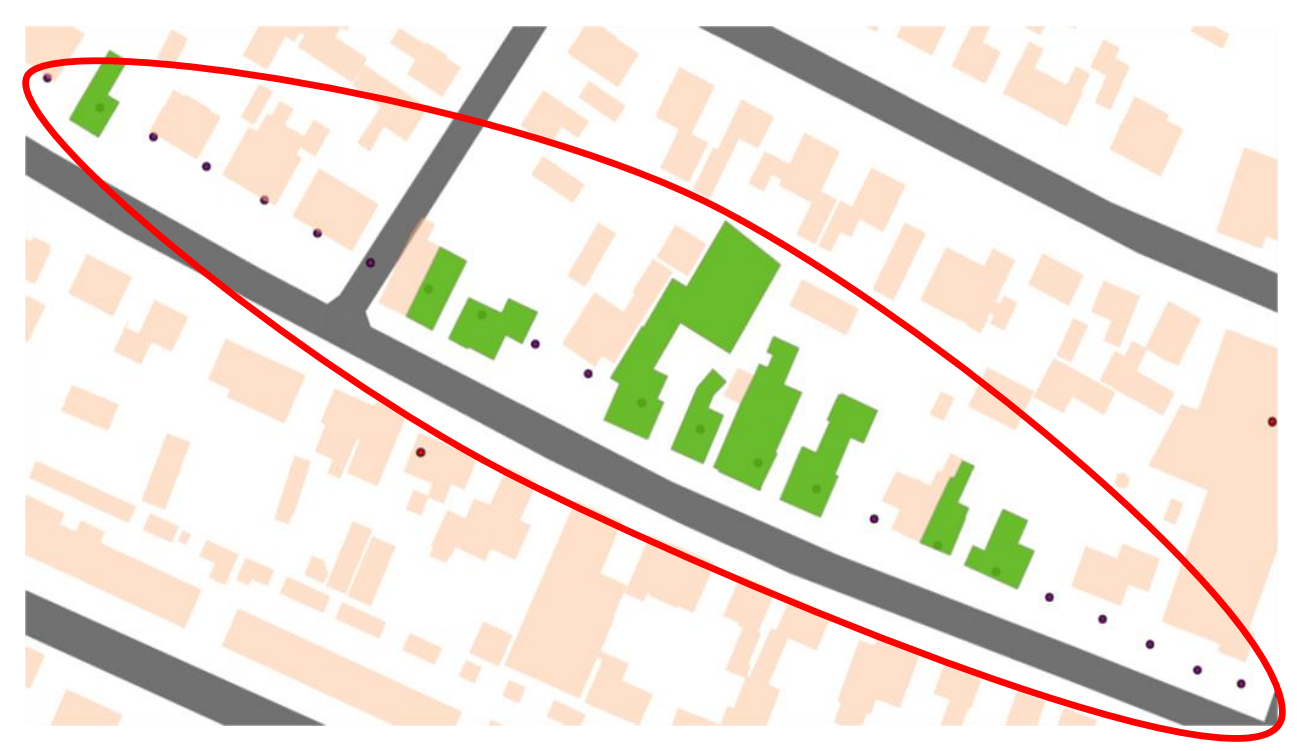

Supp. Figure 2. Measurement error in a GPS track (within the red line), based on the shape of the GPS track, this person was driving in a car on the major road (grey), due to the GPS measuring error some of the GPS points fell within building polygons (green, for those with a point included, pink for building polygons without a GPS point inside). GPS points, outside the home buffer, were only assigned as 'indoors' if more than 45 points were located within a building polygon. If this was the case a $20 \mathrm{~m}$ buffer was used around the specified building to assign those points as 'indoors' using a similar approach as with the home buffer (see Supp. Figure 1). 


\section{Data used for explanatory variable analyses}

Supp. Table 1. Data used for specific explanatory variables.

\begin{tabular}{|c|c|c|}
\hline Explanatory variable & $\begin{array}{l}\text { Prevalence }(\mathrm{N} \\
(\%))\end{array}$ & Data used \\
\hline $\begin{array}{l}\text { COPD, from } \mathrm{VGO} \\
\text { questionnaire }\end{array}$ & $78(9 \%)$ & $\begin{array}{l}\text { Self-reported: 'Have you ever been told by a doctor that } \\
\text { you had chronic obstructive pulmonary disease or } \\
\text { emphysema?' } \\
\text { Based on spirometry: } \\
\text { - Post-BD measurement of FEV1/FVC below the lower } \\
\text { limits of normal (LLN was calculated with GLI- } \\
\text { reference values based on age, gender and height) } \\
\text { AND/OR } \\
\text { - Post-BD measurement of FEV1/FVC <0.70 (GOLD). LLN } \\
\text { was calculated with GLI-reference values based on age, } \\
\text { gender and height (53) }\end{array}$ \\
\hline $\begin{array}{l}\text { Asthma, from } \mathrm{VGO} \\
\text { questionnaire }\end{array}$ & $46(5 \%)$ & $\begin{array}{l}\text { Self-reported: "did you ever have asthma, and was this } \\
\text { confirmed by a doctor?" }\end{array}$ \\
\hline $\begin{array}{l}\text { Heart diseases, from } \\
\text { VGO questionnaire }\end{array}$ & $27(3 \%)$ & $\begin{array}{l}\text { Self-reported: "Are you treated for heart arrhythmia by a } \\
\text { cardiologist?" "have you experienced a heart attack in the } \\
\text { recent } 3 \text { months?" } \\
\text { "do you have a poorly functioning heart?" } \\
\text { grouped as 'any self-reported heart problems' }\end{array}$ \\
\hline $\begin{array}{l}\text { People perceiving health } \\
\text { complaints from } \\
\text { livestock farms, from } \\
\text { VGO questionnaire }\end{array}$ & $67(8 \%)$ & $\begin{array}{l}\text { Self-reported: "do you think the health complaints you } \\
\text { selected, are possibly linked to livestock farms in your } \\
\text { home vicinity?" }\end{array}$ \\
\hline $\begin{array}{l}\text { Outdoors occupation, } \\
\text { from } \mathrm{Q}_{1}\end{array}$ & $70(8 \%)$ & $\begin{array}{l}\text { Self-reported, people agreed on the following: "most } \\
\text { work-activities are outdoors, and work takes place } \\
\text { outdoors for several hours per day" }\end{array}$ \\
\hline
\end{tabular}


3. Age distribution of participants in VGO GPS study

\section{Age distribution VGO GPS study}

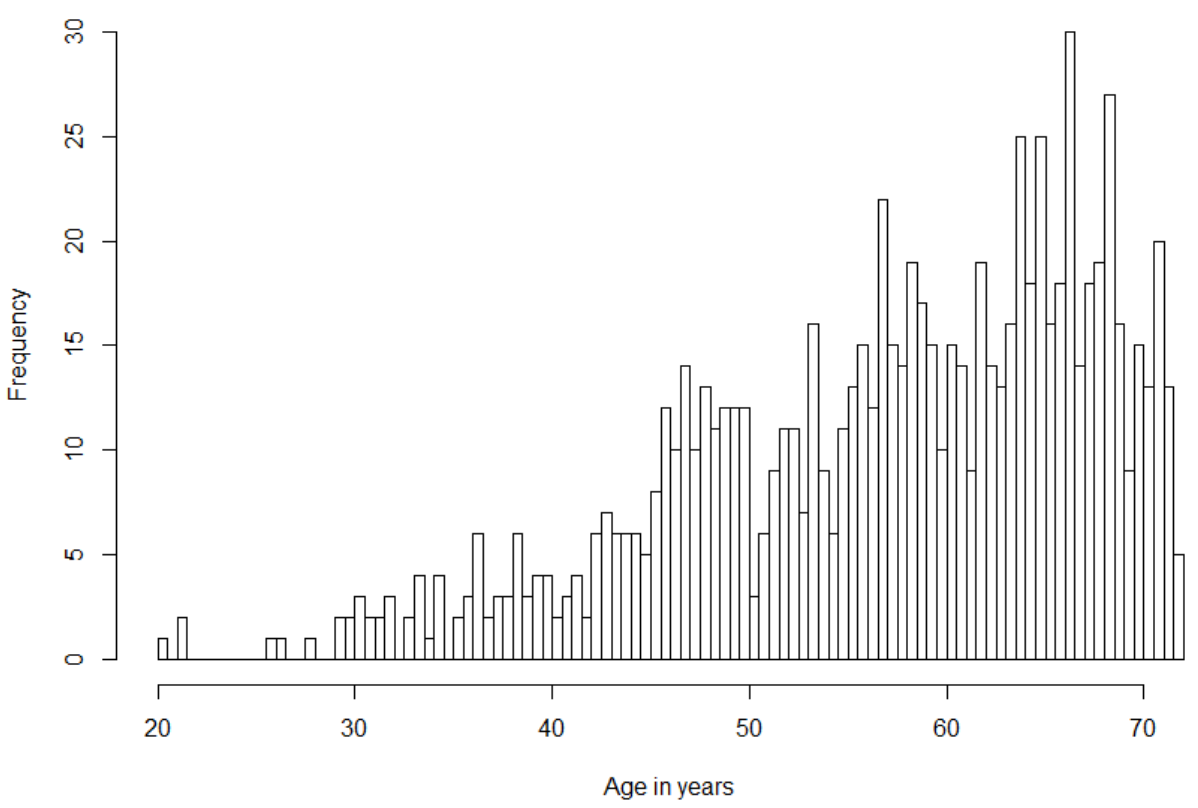

Supp. Figure 3. Distribution of age of participants in the VGO GPS study, based on this distribution four age categories were assigned (<45yrs, 45-55yrs, 55-65yrs, $>65 y r s)$, these categories were used in the explanatory variables analyses. 
4. Distribution of avarage temperature during GPS measuring period

\section{Distribution of average temperature during GPS measuring period}

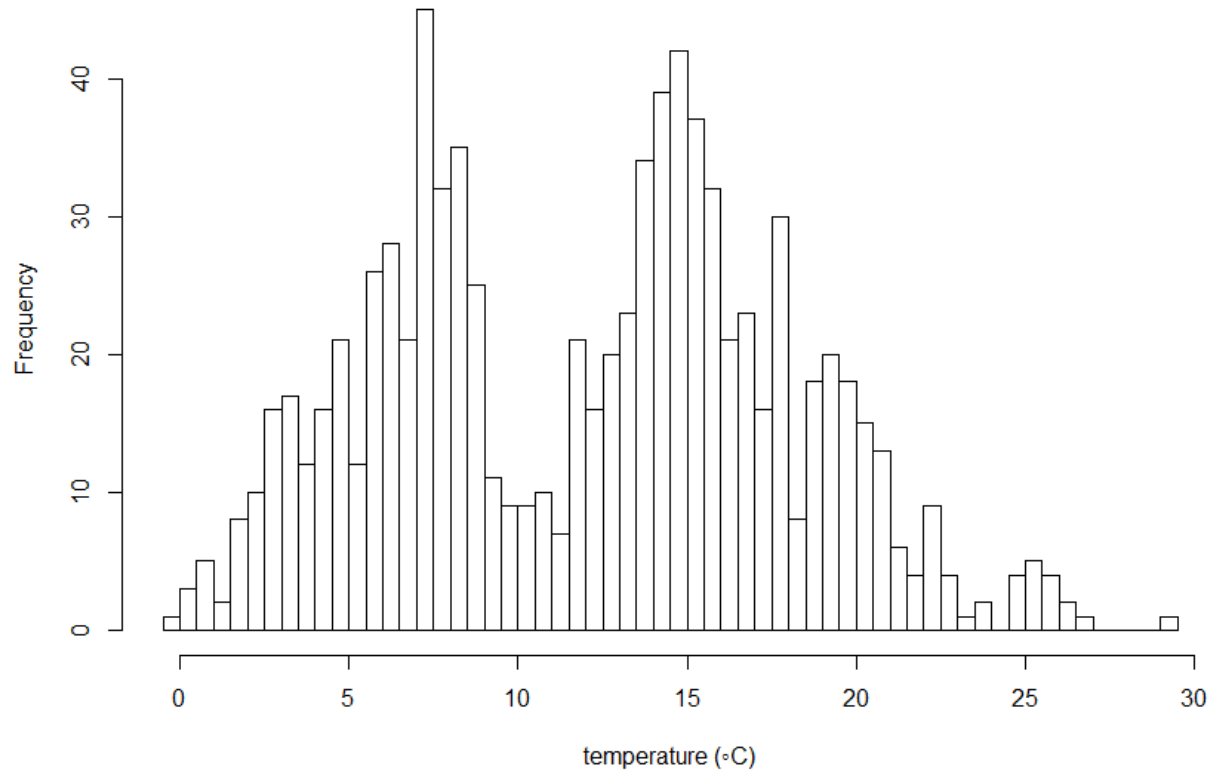

Supp. Figure 4. Distribution of average temperature during the GPS measurement. The following categories were assigned $\left(<5^{\circ} \mathrm{C}, 5-10^{\circ} \mathrm{C}, 10-15^{\circ} \mathrm{C}, 15-20^{\circ} \mathrm{C}, 20-25^{\circ} \mathrm{C},>25^{\circ} \mathrm{C}\right)$ the category $10-15^{\circ} \mathrm{C}$ was chosen as reference category, because this category included both the median $\left(12.9^{\circ} \mathrm{C}\right)$ and mean $\left(12.1^{\circ} \mathrm{C}\right)$ temperature. 
5. Percentages of time spent outdoors A. self-reported, B. GPS measured, with cut-offs used in kappa analysis.
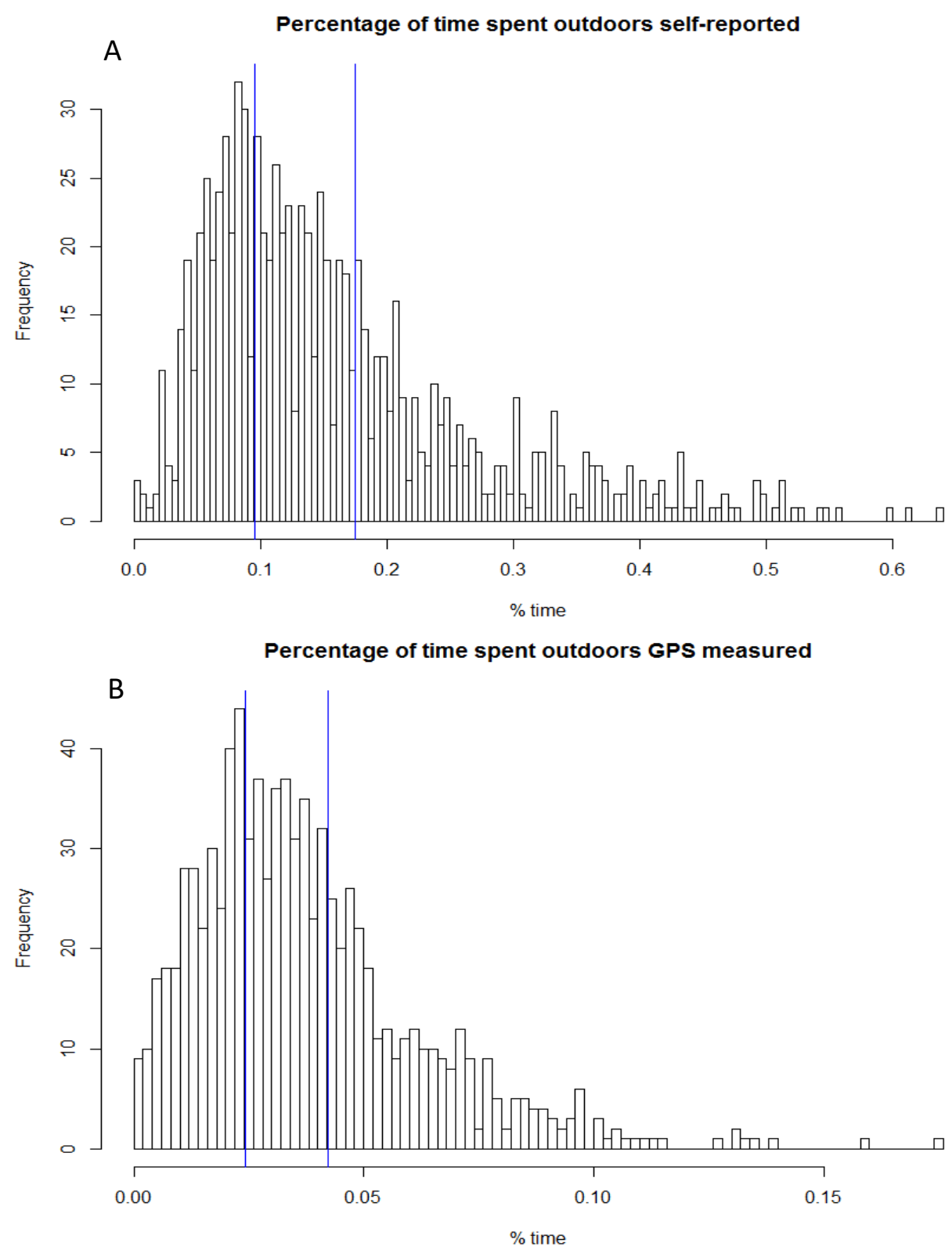

Supp.Figure 5 A and B. Distributions of percentages of time spent outside, measured with $Q_{1}(A)$ and GPS (B). The tertiles of the distributions (in blue Q1: 0.095 and 0.175 , GPS: 0.024 and 0.042 ) of these figures provided the cut-off values for the assignment of the outdoors groups used in the Cohen's kappa analyses. 


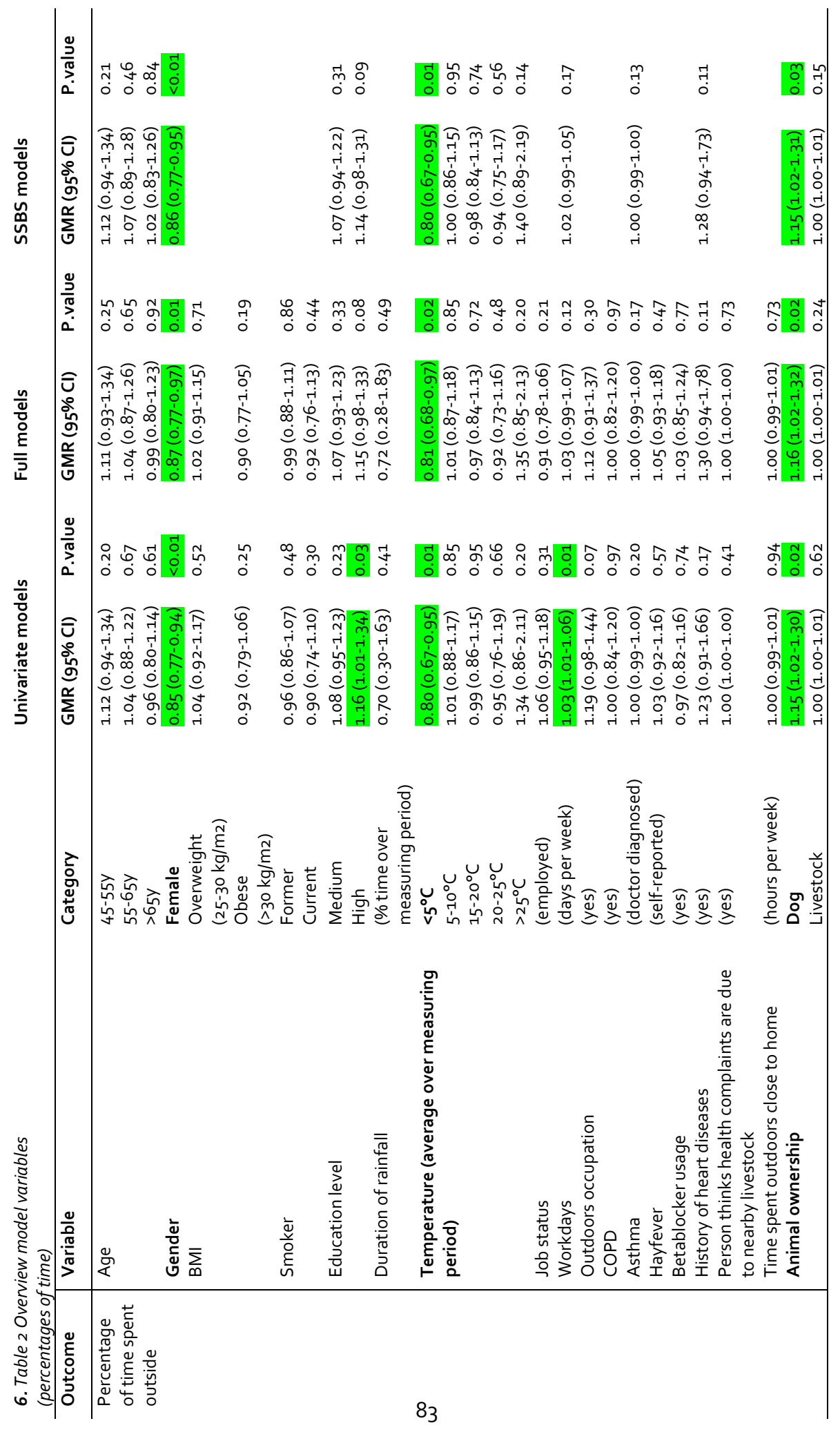




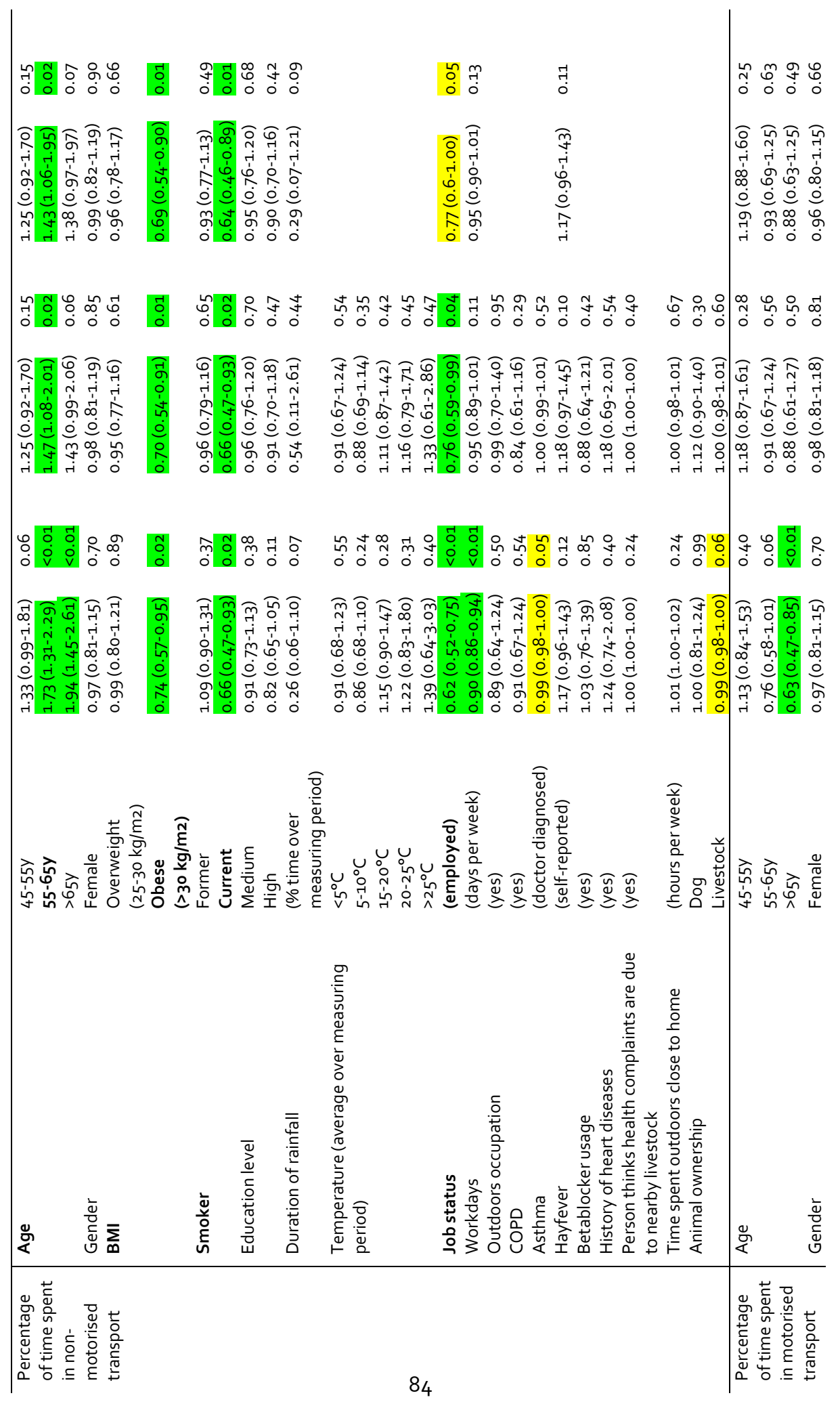



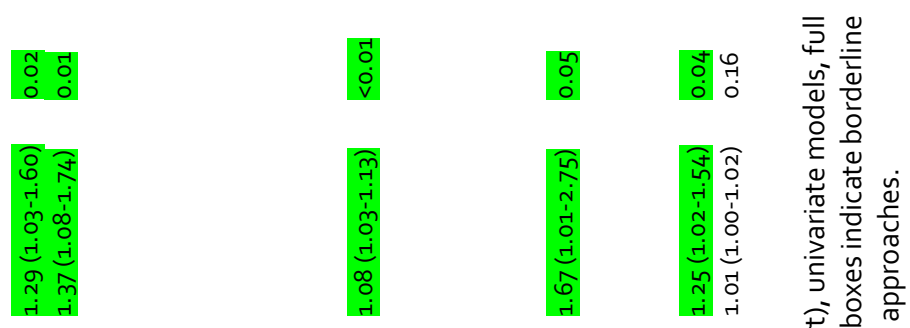

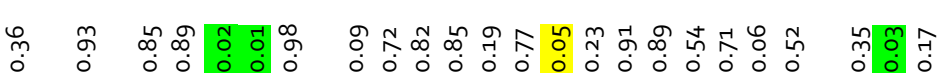

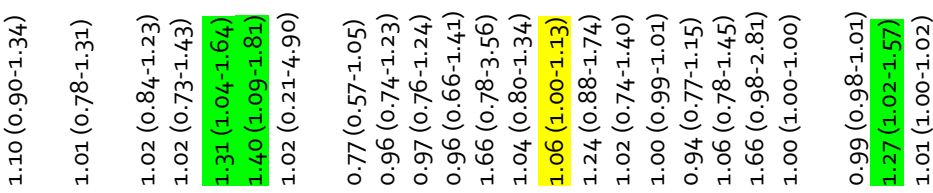

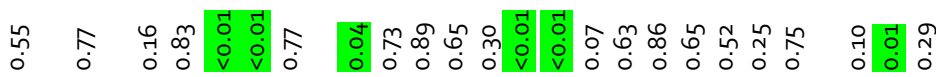
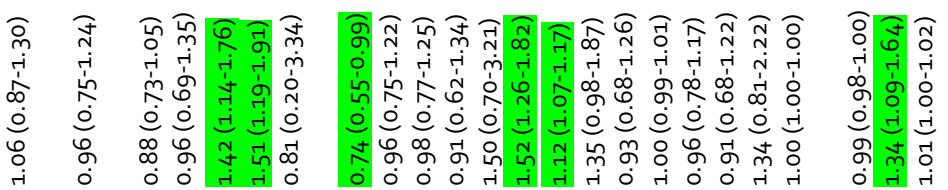

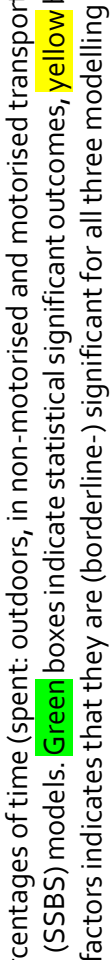

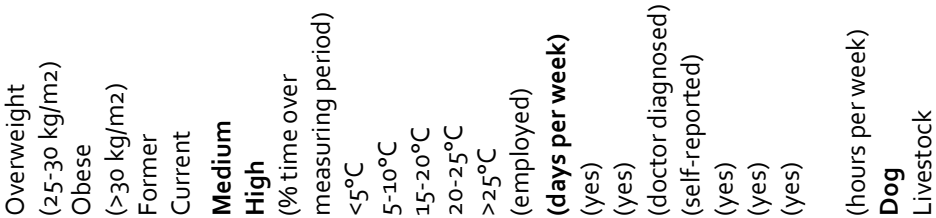
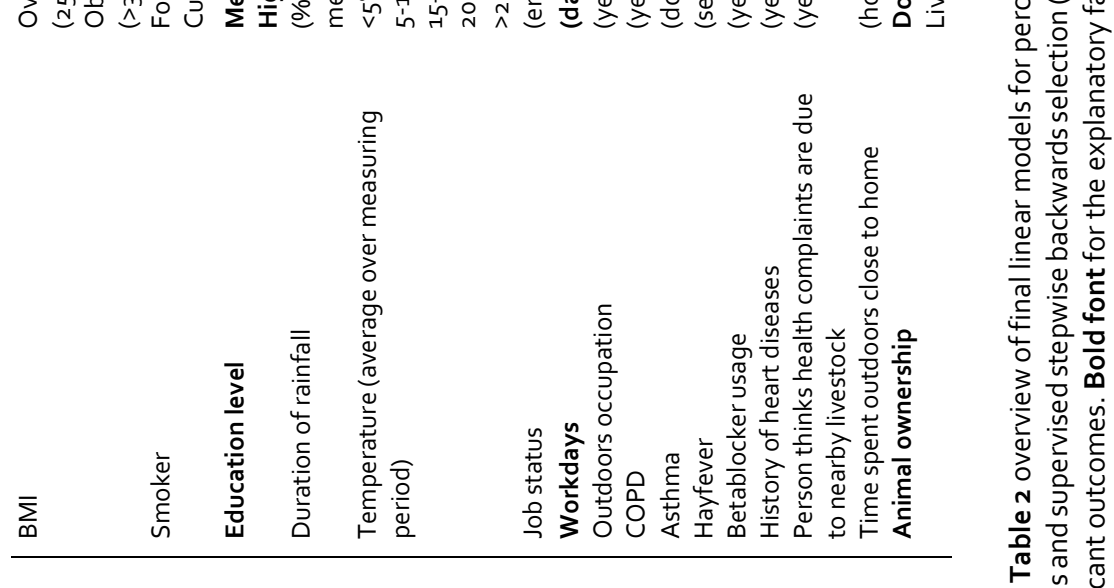

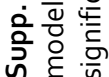




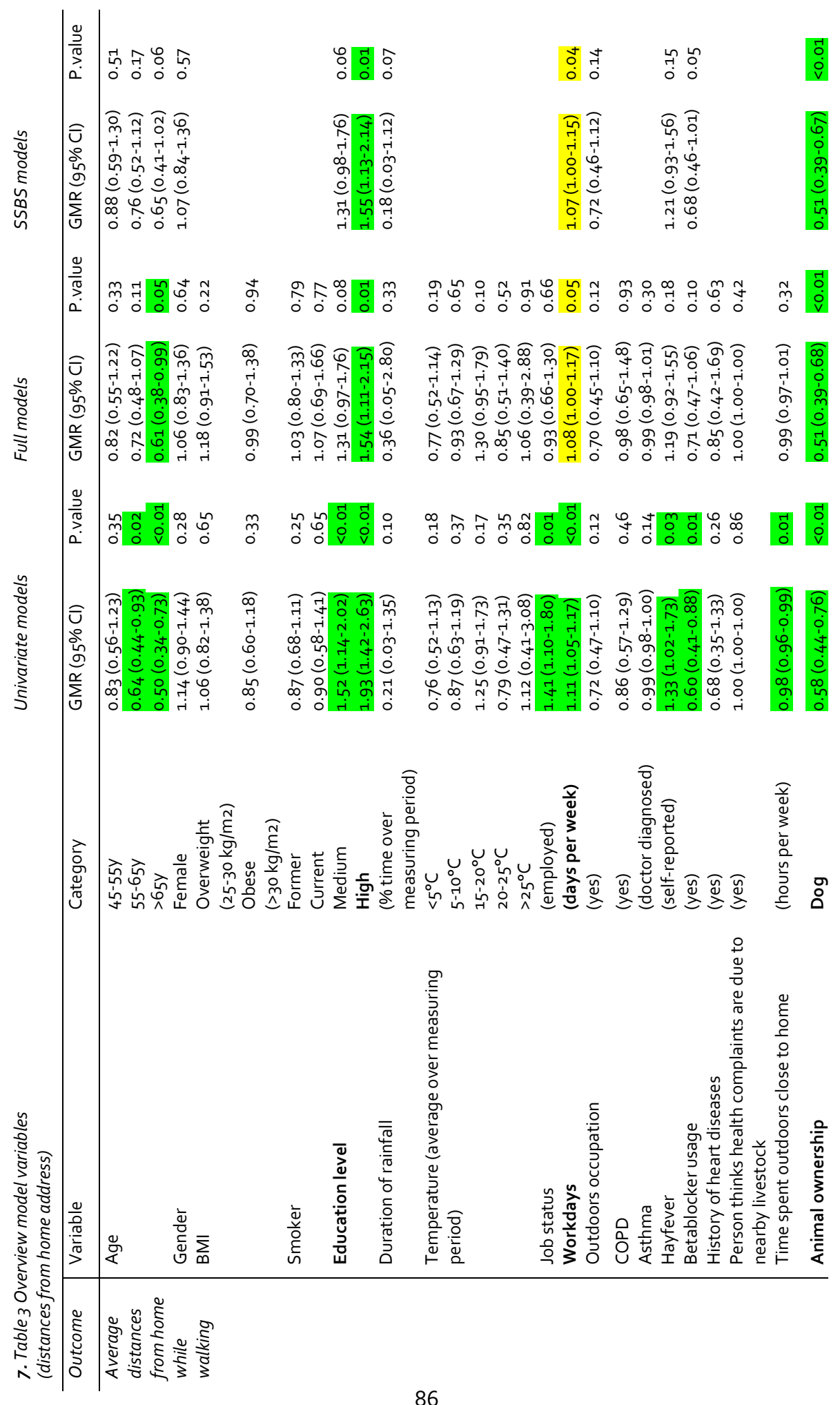




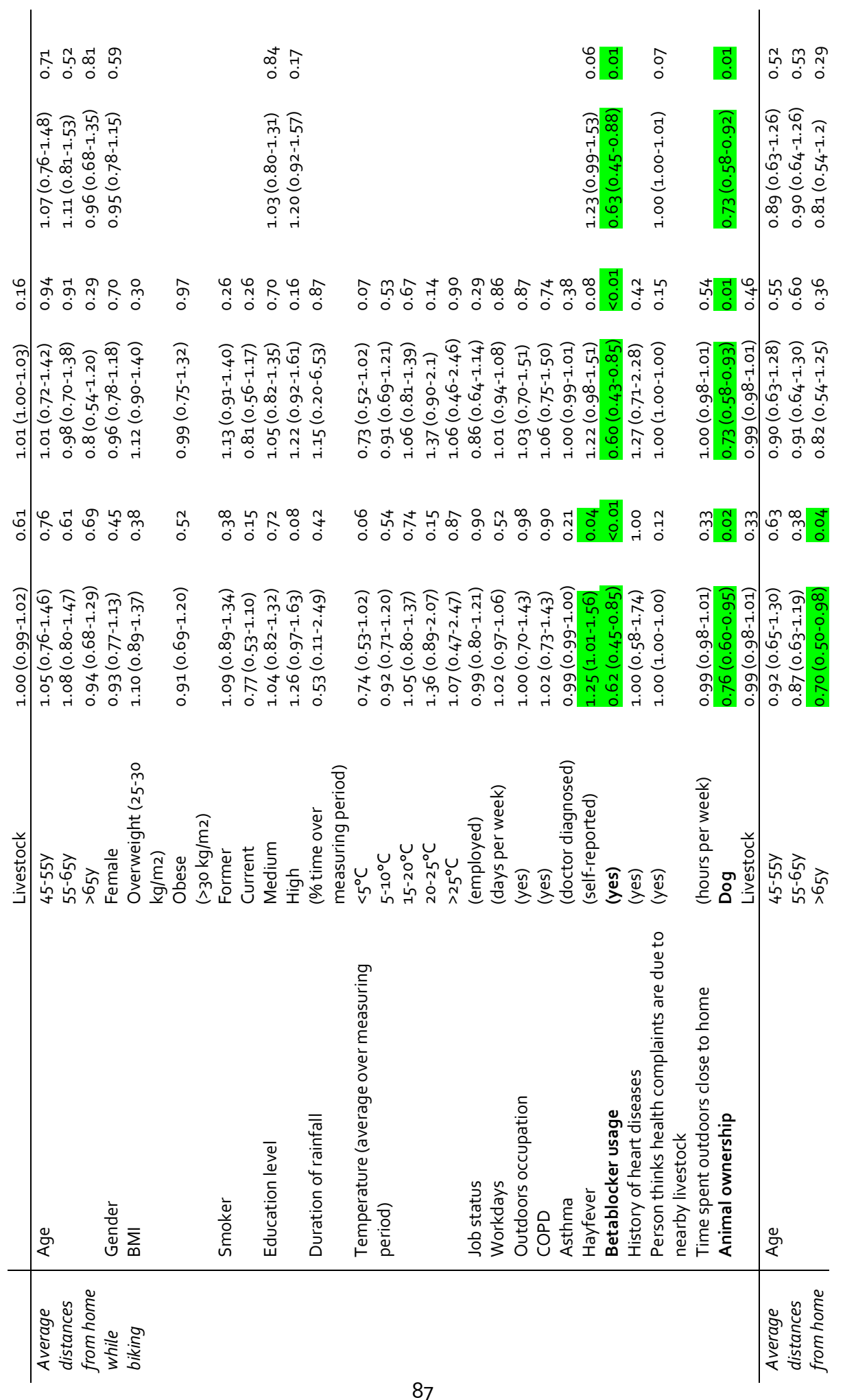




\begin{tabular}{|c|c|c|c|c|c|c|}
\hline & $\underset{0}{N} \underset{0}{N}{ }_{0}^{2}$ & 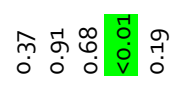 & ô & $\begin{array}{ll}2 & -1 \\
0 & 0 \\
0 & 0\end{array}$ & Õ & $\begin{array}{l}\stackrel{n}{0} \\
0 \\
0\end{array}$ \\
\hline & 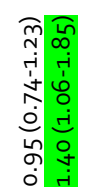 & 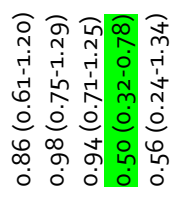 & 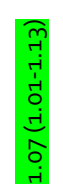 & 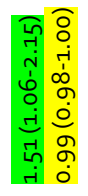 & 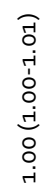 & 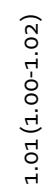 \\
\hline
\end{tabular}

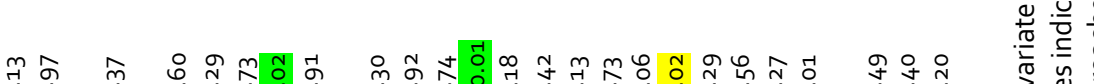

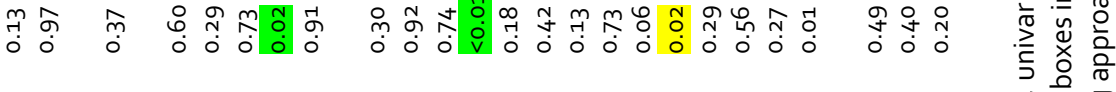

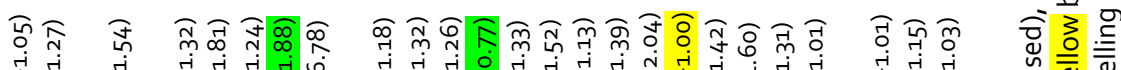

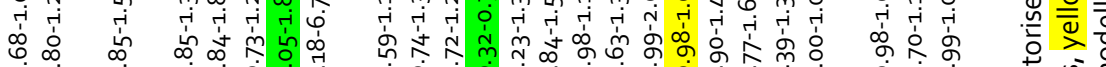

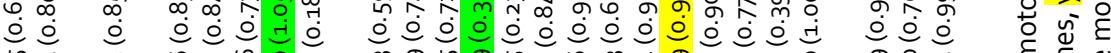

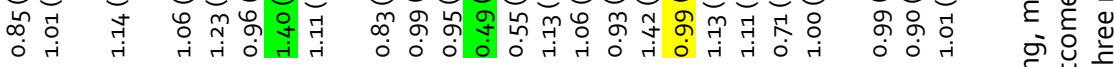
青 ஜ

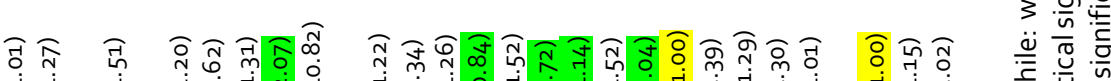

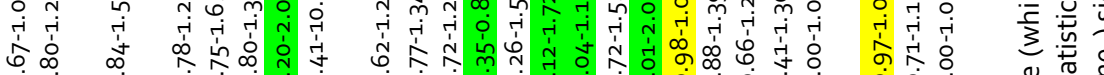
ఏ

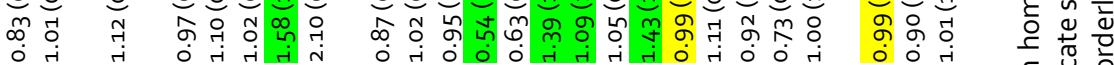
등

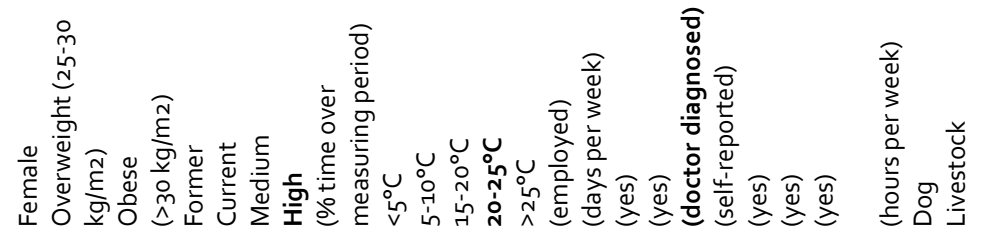

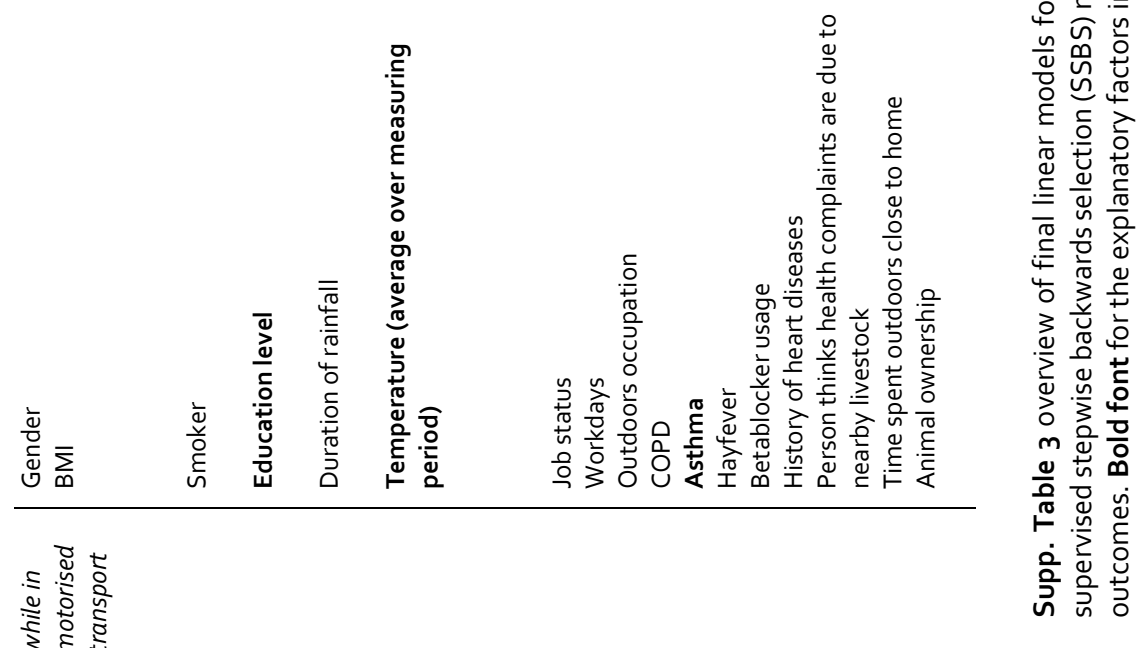




\section{Sensitivity analyses}

8. Buffer sizes around the home address, 6om buffer versus $20 m$ buffer.

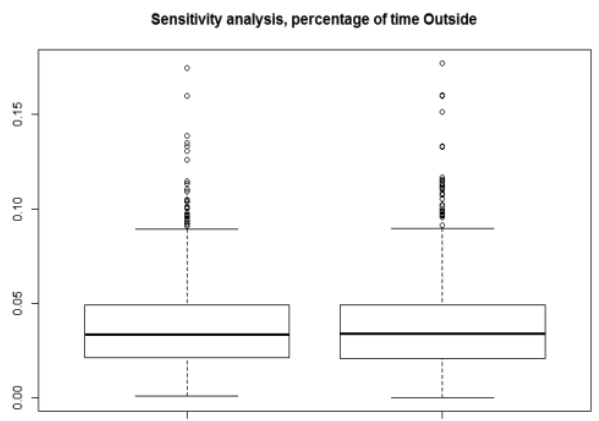

$60 \mathrm{mbuffer}$

Sensitivity analysis, percentage of time Biking

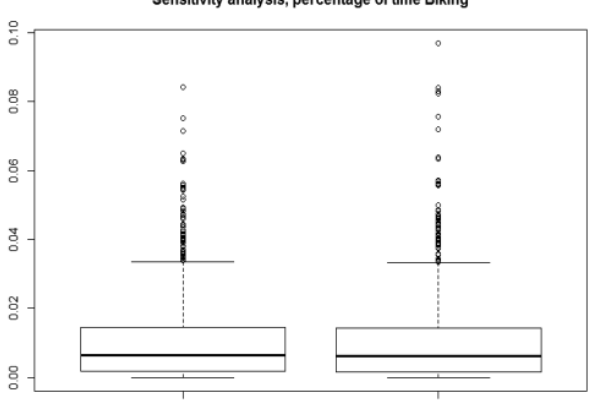

$60 \mathrm{~m}$ buffer

$20 \mathrm{mbuffer}$

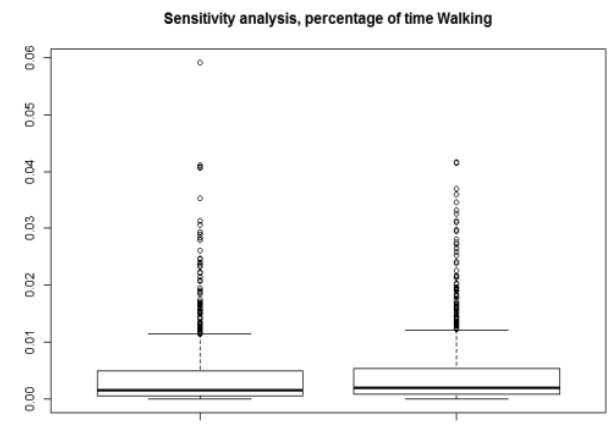

$60 \mathrm{mbuffer}$

$20 \mathrm{mbuffer}$

Sensitivity analysis, percentage of time in Motorised transport

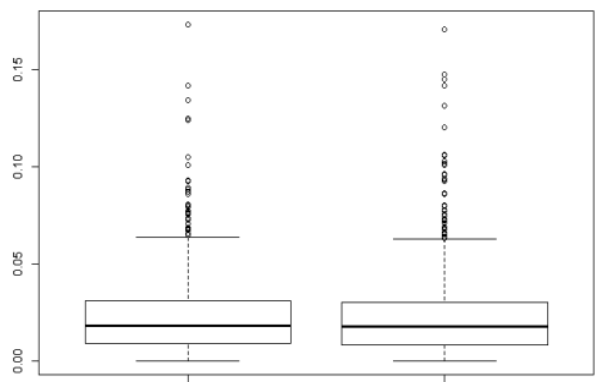

combutfer

20 miffer

Supp. Figure 6 Boxplots, GPS data is used to compare the influence of buffer sizes on percentages of time spent: A. outside, B. walking, C. biking, D. in motorised transport, after assignment of indoor/outdoor and to the specific transport modes.

Supp. Table 4 Overview of T-test outcomes for the comparison of buffer sizes on percentages of time spent: outside, walking, biking, in motorised transport, after assignment of indoor/outdoor and to the specific transport modes. No statistical significant differences in percentages of time spent were identified between the two buffer sizes, therefore we decided to work with the previously assigned 6 om buffers for all analyses.

\begin{tabular}{l|lll}
\multicolumn{1}{l}{ Outcome } & \multicolumn{1}{l}{ Mean of the difference $(95 \% \mathrm{Cl})$} & $T$-value & $P$-value \\
\hline Percentage of time Outside & $-3.33^{*} 10^{-4}\left(-2.49^{*} 10^{-3}, 1.82 * 10^{-3}\right)$ & -0.30 & 0.76 \\
Percentage of time Walking & $-4.02 * 10^{-4}\left(-9.44^{*} 10^{-4}, 1.40^{*} 10^{-4}\right)$ & -1.46 & 0.15 \\
Percentage of time Biking & $-1.53^{*} 10^{-4}\left(-1.23^{*} 10^{-3}, 9.24^{*} 10^{-4}\right)$ & -0.28 & 0.78 \\
Percentage of time Motorised & $2.39^{*} 10^{-4}\left(-1.58^{*} 10^{-3}, 2.06 * 10^{-3}\right)$ & 0.26 & 0.80
\end{tabular}


9. Table 5 Sensitivity analyses SSBS models

Full dataset versus dataset people reporting a 'normal week' (percentages of time)
SSBS models

(Full dataset $\mathrm{N}=870$ )
SSBS models, only if not deviated from normal week $(\mathrm{N}=635)$

\begin{tabular}{|c|c|c|c|c|c|c|}
\hline Outcome & Variable & Category & GMR $(95 \% \mathrm{Cl})$ & P-value & GMR $(95 \% \mathrm{Cl})$ & P-value \\
\hline $\begin{array}{l}\text { Percentage of } \\
\text { time } \\
\text { spent outside }\end{array}$ & $\begin{array}{l}\text { Age } \\
\text { Gender } \\
\text { Education level } \\
\text { Temperature } \\
\text { (average over } \\
\text { measuring period) } \\
\\
\text { Workdays } \\
\text { Asthma } \\
\text { History of heart } \\
\text { diseases } \\
\text { Animal ownership }\end{array}$ & $\begin{array}{l}45-55 y \\
55-65 y \\
>65 y \\
\text { Female } \\
\text { Medium } \\
\text { High } \\
<5^{\circ} \mathrm{C} \\
5-10^{\circ} \mathrm{C} \\
15-20^{\circ} \mathrm{C} \\
20-25^{\circ} \mathrm{C} \\
>25^{\circ} \mathrm{C} \\
\text { (days per week) } \\
\text { (doctor diagnosed) } \\
\text { (yes) } \\
\text { Dog } \\
\text { Livestock } \\
\end{array}$ & $\begin{array}{l}1.12(0.94-1.34) \\
1.07(0.89-1.28) \\
1.02(0.83-1.26) \\
0.86(0.77-0.95) \\
1.07(0.94-1.22) \\
1.14(0.98-1.31) \\
0.80(0.67-0.95) \\
1.00(0.86-1.15) \\
0.98(0.84-1.13) \\
0.94(0.75-1.17) \\
1.40(0.89-2.19) \\
1.02(0.99-1.05) \\
1.00(0.99-1.00) \\
1.28(0.94-1.73) \\
1.15(1.02-1.31) \\
1.00(1.00-1.01) \\
\end{array}$ & $\begin{array}{l}0.21 \\
0.46 \\
0.84 \\
<0.01 \\
0.31 \\
0.09 \\
0.01 \\
0.95 \\
0.74 \\
0.56 \\
0.14 \\
0.17 \\
0.13 \\
0.11 \\
0.03 \\
0.15 \\
\end{array}$ & $\begin{array}{l}1.15(0.93-1.43) \\
1.07(0.86-1.33) \\
1.19(0.92-1.54) \\
0.86(0.75-0.98) \\
1.09(0.93-1.28) \\
1.17(0.98-1.40) \\
0.80(0.64-0.99) \\
0.96(0.81-1.14) \\
0.97(0.82-1.15) \\
0.84(0.63-1.13) \\
1.58(0.89-2.78) \\
1.03(1.00-1.07) \\
1.00(0.99-1.00) \\
1.07(0.75-1.51) \\
1.22(1.05-1.42) \\
1.00(1.00-1.01) \\
\end{array}$ & \begin{tabular}{l|}
0.20 \\
0.54 \\
0.19 \\
0.02 \\
0.28 \\
0.08 \\
0.04 \\
0.66 \\
0.74 \\
0.25 \\
0.12 \\
0.06 \\
0.12 \\
0.72 \\
\\
0.01 \\
0.37 \\
\end{tabular} \\
\hline $\begin{array}{l}\text { Percentage of } \\
\text { Time spent in } \\
\text { non-motorised } \\
\text { transport }\end{array}$ & $\begin{array}{l}\text { Age } \\
\text { Gender } \\
\text { BMI } \\
\text { Smoker } \\
\text { Education level } \\
\text { Duration of rainfall } \\
\text { Job status } \\
\text { Workdays } \\
\text { Hayfever }\end{array}$ & $\begin{array}{l}45-55 y \\
55-65 y \\
>65 y \\
\text { Female } \\
\text { Overweight }(25-30 \\
\mathrm{kg} / \mathrm{m} 2) \\
\text { Obese (>30 kg/m2) } \\
\text { Former } \\
\text { Current } \\
\text { Medium } \\
\text { High } \\
\text { (\% time over } \\
\text { measuring period) } \\
\text { (employed) } \\
\text { (days per week) } \\
\text { (self-reported) }\end{array}$ & $\begin{array}{l}1.25(0.92-1.70) \\
1.43(1.06-1.95) \\
1.38(0.97-1.97) \\
0.99(0.82-1.19) \\
0.96(0.78-1.17) \\
0.69(0.54-0.90) \\
0.93(0.77-1.13) \\
0.64(0.46-0.89) \\
0.95(0.76-1.20) \\
0.90(0.70-1.16) \\
0.29(0.07-1.21) \\
0.77(0.60-1.00) \\
0.95(0.90-1.01) \\
1.17(0.96-1.43)\end{array}$ & $\begin{array}{l}0.15 \\
0.02 \\
0.07 \\
0.9 \\
0.66 \\
\\
0.01 \\
0.49 \\
0.01 \\
0.68 \\
0.42 \\
0.09 \\
\\
0.05 \\
0.13 \\
0.11 \\
\end{array}$ & $\begin{array}{l}1.29(0.91-1.83) \\
1.32(0.92-1.88) \\
1.46(0.96-2.21) \\
0.98(0.79-1.21) \\
1.03(0.82-1.30) \\
0.81(0.60-1.09) \\
0.95(0.76-1.19) \\
0.60(0.41-0.86) \\
0.99(0.77-1.29) \\
0.92(0.68-1.23) \\
0.38(0.07-2.01) \\
0.83(0.61-1.13) \\
0.92(0.86-0.99) \\
1.07(0.85-1.35)\end{array}$ & $\begin{array}{l}0.15 \\
0.13 \\
0.08 \\
0.82 \\
0.81 \\
\\
0.16 \\
0.65 \\
0.01 \\
0.96 \\
0.57 \\
0.25 \\
\\
0.23 \\
0.02 \\
0.54 \\
\end{array}$ \\
\hline $\begin{array}{l}\text { Percentage of } \\
\text { Time spent in } \\
\text { motorised } \\
\text { transport }\end{array}$ & $\begin{array}{l}\text { Age } \\
\text { Gender } \\
\text { Education level } \\
\text { Workdays } \\
\text { History of heart } \\
\text { diseases } \\
\text { Animal ownership }\end{array}$ & $\begin{array}{l}45-55 y \\
55-65 y \\
>65 y \\
\text { Female } \\
\text { Medium } \\
\text { High } \\
\text { (days per week) } \\
\text { (yes) } \\
\text { Dog } \\
\text { Livestock }\end{array}$ & $\begin{array}{l}1.19(0.88-1.60) \\
0.93(0.69-1.25) \\
0.88(0.63-1.25) \\
0.96(0.80-1.15) \\
1.29(1.03-1.60) \\
1.37(1.08-1.74) \\
1.08(1.03-1.13) \\
1.67(1.01-2.75)\end{array}$ & $\begin{array}{l}0.25 \\
0.63 \\
0.49 \\
0.66 \\
0.02 \\
0.01 \\
<0.01 \\
0.05\end{array}$ & $\begin{array}{l}1.25(0.89-1.77) \\
1.06(0.75-1.49) \\
0.99(0.65-1.49) \\
0.92(0.74-1.13) \\
1.34(1.04-1.73) \\
1.42(1.07-1.89) \\
1.11(1.05-1.17) \\
1.44(0.82-2.51) \\
1.35(1.06-1.72) \\
1.01(0.99-1.02)\end{array}$ & $\begin{array}{l}0.20 \\
0.73 \\
0.95 \\
0.42 \\
0.02 \\
0.02 \\
<0.01 \\
0.20 \\
\\
0.01 \\
0.37\end{array}$ \\
\hline
\end{tabular}

Supp. Table 5 Sensitivity analyses for percentages of time (spent: outdoors, in non-motorised and motorised transport) for people indicating to have had a 'normal week'. In questionnaire $2\left(\mathrm{O}_{2}\right)$, regarding study adherence, we inquired whether people had had a 'normal week'. Of our participants $73 \%$ indicated to have had a 'normal week', we reanalysed our supervised stepwise backwards selection (SSBS) models with this subpopulation and overall found no material effects on our estimates. 
10. Table 6 Sensitivity analyses SSBS models Full dataset versus dataset people reporting a 'normal week' (distances from home address)

\begin{tabular}{|c|c|c|c|c|c|c|}
\hline Outcome & Variable & Category & GMR(95\% Cl) & P-value & GMR $(95 \% \mathrm{Cl})$ & P-value \\
\hline \multirow{12}{*}{$\begin{array}{l}\text { Average } \\
\text { distance from } \\
\text { home while } \\
\text { walking }\end{array}$} & \multirow[t]{3}{*}{ Age } & $45-55 y$ & $0.88(0.59-1.30)$ & 0.51 & $0.88(0.53-1.46)$ & 0.62 \\
\hline & & $55-65 y$ & $0.76(0.52-1.12)$ & 0.17 & $0.75(0.45-1.25)$ & 0.27 \\
\hline & & $>65 y$ & $0.65(0.41-1.02)$ & 0.06 & $0.84(0.46-1.55)$ & 0.58 \\
\hline & Gender & Female & $1.07(0.84-1.36)$ & 0.57 & $1.18(0.86-1.63)$ & 0.31 \\
\hline & \multirow[t]{2}{*}{ Education level } & Medium & $1.31(0.98-1.76)$ & 0.06 & $1.35(0.92-1.96)$ & 0.12 \\
\hline & & High & $1.55(1.13-2.14)$ & 0.01 & $1.82(1.18-2.80)$ & 0.01 \\
\hline & Duration of rainfall & $\begin{array}{l}\text { (\% time over } \\
\text { measuring period) }\end{array}$ & $0.18(0.03-1.12)$ & 0.07 & $\begin{array}{l}1.55 \quad\left(0.14^{-}\right. \\
17.48)\end{array}$ & 0.72 \\
\hline & Workdays & (days per week) & $1.07(1.00-1.15)$ & 0.04 & $1.12(1.02-1.22)$ & 0.02 \\
\hline & $\begin{array}{l}\text { Outdoors } \\
\text { occupation }\end{array}$ & (yes) & $0.72(0.46-1.12)$ & 0.14 & $0.98(0.56-1.71)$ & 0.93 \\
\hline & Hayfever & (self-reported) & $1.21(0.93-1.56)$ & 0.15 & $1.27(0.90-1.77)$ & 0.17 \\
\hline & Betablocker usage & (yes) & $0.68(0.46-1.01)$ & 0.05 & $0.77(0.46-1.30)$ & 0.33 \\
\hline & Animal ownership & Dog & $0.51(0.39-0.67)$ & $<0.01$ & $0.51(0.35-0.72)$ & $<0.01$ \\
\hline \multirow{10}{*}{$\begin{array}{l}\text { Average } \\
\text { distance from } \\
\text { home while } \\
\text { biking }\end{array}$} & \multirow[t]{3}{*}{ Age } & $45-55 y$ & $1.07(0.76-1.48)$ & 0.71 & $1.13(0.77-1.65)$ & 0.54 \\
\hline & & $55-65 y$ & $1.11(0.81-1.53)$ & 0.52 & $1.04(0.72-1.50)$ & 0.83 \\
\hline & & $>65 y$ & $0.96(0.68-1.35)$ & 0.81 & $1.04(0.69-1.56)$ & 0.86 \\
\hline & & Female & $0.95(0.78-1.15)$ & 0.59 & $0.86(0.68-1.08)$ & 0.20 \\
\hline & \multirow[t]{2}{*}{ Education level } & Medium & $1.03(0.80-1.31)$ & 0.84 & $0.94(0.71-1.24)$ & 0.66 \\
\hline & & High & $1.20(0.92-1.57)$ & 0.17 & $1.08(0.79-1.48)$ & 0.61 \\
\hline & Hayfever & (self-reported) & $1.23(0.99-1.53)$ & 0.06 & $1.25(0.97-1.61)$ & 0.08 \\
\hline & Betablocker usage & (yes) & $0.63(0.45-0.88)$ & 0.01 & $0.62(0.42-0.90)$ & 0.01 \\
\hline & $\begin{array}{l}\text { Person thinks } \\
\text { health complaints } \\
\text { are due to nearby } \\
\text { livestock }\end{array}$ & (yes) & $1.00(1.00-1.01)$ & 0.07 & $1.00(1.00-1.01)$ & 0.15 \\
\hline & Animal ownership & Dog & $0.73(0.58-0.92)$ & 0.01 & $0.79(0.61-1.03)$ & 0.08 \\
\hline \multirow{16}{*}{$\begin{array}{l}\text { Average } \\
\text { distance from } \\
\text { home while in } \\
\text { motorised } \\
\text { transport }\end{array}$} & \multirow[t]{3}{*}{ Age } & $45-55 y$ & $0.89(0.63-1.26)$ & 0.52 & $0.96(0.65-1.42)$ & 0.84 \\
\hline & & $55-65 y$ & $0.90(0.64-1.26)$ & 0.53 & $0.92(0.63-1.36)$ & 0.69 \\
\hline & & $>65 y$ & $0.81(0.54-1.20)$ & 0.29 & $1.06(0.67-1.67)$ & 0.81 \\
\hline & Gender & Female & $0.88(0.71-1.08)$ & 0.21 & $0.88(0.69-1.12)$ & 0.29 \\
\hline & \multirow[t]{2}{*}{ Education level } & Medium & $0.95(0.74-1.23)$ & 0.72 & $1.07(0.80-1.43)$ & 0.64 \\
\hline & & High & $1.40(1.06-1.85)$ & 0.02 & $1.64(1.19-2.25)$ & $<0.01$ \\
\hline & \multirow{5}{*}{$\begin{array}{l}\text { Temperature } \\
\text { (average over } \\
\text { measuring period) }\end{array}$} & $<5^{\circ} \mathrm{C}$ & $0.86(0.61-1.20)$ & 0.37 & $1.17(0.78-1.74)$ & 0.45 \\
\hline & & $5-10^{\circ} \mathrm{C}$ & $0.98(0.75-1.29)$ & 0.91 & $1.03(0.76-1.40)$ & 0.85 \\
\hline & & $15-20^{\circ} \mathrm{C}$ & $0.94(0.71-1.25)$ & 0.68 & $0.89(0.65-1.21)$ & 0.46 \\
\hline & & $20-25^{\circ} \mathrm{C}$ & $0.50(0.32-0.78)$ & $<0.01$ & $0.56(0.33-0.96)$ & 0.03 \\
\hline & & $>25^{\circ} \mathrm{C}$ & $0.56(0.24-1.34)$ & 0.19 & $0.56(0.20-1.57)$ & 0.27 \\
\hline & Workdays & (days per week) & $1.07(1.01-1.13)$ & 0.02 & $1.11(1.04-1.19)$ & $<0.01$ \\
\hline & COPD & (yes) & $1.51(1.06-2.15)$ & 0.02 & $1.38(0.93-2.05)$ & 0.11 \\
\hline & Asthma & (doctor diagnosed) & $0.99(0.98-1.00)$ & 0.01 & $0.99(0.98-1.00)$ & 0.01 \\
\hline & $\begin{array}{l}\text { Person thinks } \\
\text { health complaints } \\
\text { are due to nearby } \\
\text { livestock }\end{array}$ & (yes) & $1.00(1.00-1.01)$ & 0.02 & $1.00(1.00-1.01)$ & 0.29 \\
\hline & Animal ownership & Livestock & $1.01(1.00-1.02)$ & 0.05 & $1.01(1.00-1.03)$ & 0.10 \\
\hline
\end{tabular}

SSBS models (Full dataset $\mathrm{N}=870$ )
SSBS models, only if not deviated from normal week $(\mathrm{N}=635)$

Supp. Table 6 Sensitivity analyses for average distances from home (while: walking, biking, motorised) for people indicating to have had a 'normal week'. In questionnaire 2 ( $\left.\mathrm{O}_{2}\right)$, regarding study adherence, we inquired whether people had had a 'normal week'. Of our participants $73 \%$ indicated to have had a 'normal week', we reanalysed our supervised stepwise backwards selection (SSBS) models with this subpopulation and overall found no material effects on our estimates with the possible exception of duration of rainfall. 
11. Questionnaire questions used in this study, originating from $Q_{1}$ and VGO questionnaire $(22,23)$

Translated from Dutch to English, highlighted text indicates comment by GK.

VGO GPS study

to GPS carrying)

Questionnaire 1 (filled in prior

This questionnaire includes 10 questions, among which 8 multiple-choice questions.

Please indicate what is applicable to your situation by filling in the boxes $(\bullet)$.

If you make a mistake, please indicate this with a cross trough the mistake $\rightarrow$ and afterwards fill in the right answer $(\bullet)$.

For some questions we ask you to estimate durations of specific travel modes, can you please estimate durations for a normal week and can you be as specific as possible?

\section{General questions}

1. What is the average amount of hours per day you spend outdoors?

Weekdays (Monday-Friday)

Weekend (Saturday and Sunday) hours hours

2. Are your currently employed (either a paid or an unpaid voluntary position)?
O Yes
O No

$\rightarrow$ (please continue with question 8)

\section{Workdays}

The following questions apply to the days on which you do your main work activities.

3. Please keep an average workday in mind, do you mainly work at home?
O Yes
$\rightarrow$ ( please continue with question 8)
O No 
4. How many days per week do you commute to work?

(for either a paid or an unpaid voluntary position)
1 day per week
O 2 days per week
O 3 days per week
O 4 days per week
O 5 days per week
O 6 days per week
O 7 days per week

5. Please keep an ordinary workday in mind, how many hours per day, do you commute using the following travel modes?

(please indicate what is applicable to your situation, multiple answers are allowed, please estimate durations)

\begin{tabular}{|l|c|cr|} 
Transport mode & autumn / winter & spring / summer \\
\hline $\begin{array}{l}\text { Train and Bus (Public } \\
\text { transport) }\end{array}$ & hours minutes & hours minutes \\
\hline Car & hours minutes & hours & minutes \\
\hline Moped, scooter, motorbike & hours minutes & hours minutes \\
\hline E-bike & hours minutes & hours minutes \\
\hline Bicycle & hours minutes & hours minutes \\
\hline On foot & hours minutes & hours minutes \\
\hline $\begin{array}{l}\text { Other transport mode, } \\
\text { (Namely): }\end{array}$ & hours minutes & hours minutes \\
\hline
\end{tabular}

6. Do you have an "outdoors" occupation? (your work activities are mainly situated outdoors, you are multiple hours per day outdoors carrying out your work activities)
O No
O Yes, I am hours per day outdoors to do my work 
7. Please keep an ordinary workday in mind, how many hours per day, do you spend traveling for work purposes, using the following travel modes?

(please indicate what is applicable to your situation, multiple answers are allowed, please estimate durations)

\begin{tabular}{|l|l|lr|} 
Transport mode & autumn / winter & spring/summer \\
\hline None & n.a & n.a & \\
\hline $\begin{array}{l}\text { Train and Bus (Public } \\
\text { transport) }\end{array}$ & hours minutes & hours minutes \\
\hline Car & hours minutes & hours minutes \\
\hline Moped, scooter, motorbike & hours minutes & hours minutes & hours minutes \\
\hline E-bike & hours minutes & hours minutes \\
\hline Bicycle & hours minutes & hours minutes \\
\hline On foot & hours minutes & hours minutes \\
\hline $\begin{array}{l}\text { Other transport mode, } \\
\text { (Namely): }\end{array}$ & & & \\
\hline
\end{tabular}

\section{Leisure time}

The following questions apply to periods when you are not working, or commuting to work, for instance during the weekends or at night.

8. Which of the following outdoor leisure time activities are in your normal week schedule?

(please indicate what is applicable to your situation, multiple answers are allowed, please estimate durations)

\begin{tabular}{|l|c|c|} 
Activity & autumn / winter & spring / summer \\
\hline $\begin{array}{l}\text { Walking (e.g. while shopping, hiking, } \\
\text { walking the dog) }\end{array}$ & Hours per week & Hours per week \\
\hline $\begin{array}{l}\text { Bicycle riding (e.g. from and to shops, } \\
\text { bicycle tours) }\end{array}$ & Hours per week & Hours per week \\
\hline $\begin{array}{l}\text { Outdoor sports (e.g. running, tennis, } \\
\text { football) }\end{array}$ & Hours per week & Hours per week \\
\hline $\begin{array}{l}\text { Spending time close to home (e.g. Time } \\
\text { spent outdoors close to home, taking care of } \\
\text { animals, do-it-yourself work, relaxing in the } \\
\text { garden) }\end{array}$ & Hours per week & Hours per week \\
\hline $\begin{array}{l}\text { Other outdoors activities (e.g. visiting a } \\
\text { playground, angling) }\end{array}$ & Hours per week & Hours per week \\
\hline
\end{tabular}


9. How often do you use the following transport modes per week during leisure time and what are the average durations per week you use them?

(please indicate what is applicable to your situation, multiple answers are allowed, please estimate durations)

\begin{tabular}{|l|c|cc|} 
Transport mode & autumn/winter & spring / summer \\
\hline $\begin{array}{l}\text { Train and Bus (Public } \\
\text { transport) }\end{array}$ & hours minutes & hours minutes \\
\hline Car & hours minutes & hours & minutes \\
\hline Moped, scooter, motorbike & hours minutes & hours minutes \\
\hline E-bike & hours minutes & hours minutes \\
\hline Bicycle & hours minutes & hours minutes \\
\hline On foot & hours minutes & hours minutes \\
\hline $\begin{array}{l}\text { Other transport mode, } \\
\text { (Namely): }\end{array}$ & hours minutes & hours minutes \\
\hline
\end{tabular}

\section{Closure}

10.Please indicate below if you have any other remarks. 
12. Items from VGO study questionnaire, selected for present analysis (VGO, questionnaire health study, 22,23,55,56)

The answers to these questions were used as explanatory variables in the multiple linear regression analyses.

A.2 Please indicate your gender

o Male

o Female

A.3 Please indicate your date of birth

Day Month Year

A.4 What is your birth country?

o the Nederlands

o Another country, namely

B.4 Have you ever had asthma?

oYes oNo

B.5 Was your asthma confirmed by a doctor?

o No

o Yes, it was confirmed in - - - - (year)

B.12 Are you sensitive or allergic to the following substances?
A. House dust
B. Food items
C. Animals
D. Plants or pollen
E. Other substances, namely

Question B.21 was a table indicating a range of health complaints: exhaustion, gastrointestinal complaints, nausea, diarrhoea, congestion, bloody/slimy excrements, being sick, fever, eye irritation, ear complaints, palpitations, neck or shoulder complaints, back complaints, chest pain, hand/wrist/elbow/arm complaints, leg/hip/knee/foot complaints, myalgia, headache, dizziness, anxious/nervous/tense feeling, feeling depressed, sudden stress or crisis, irritable/angry mood, sleeping problems, increased 
usage of alcohol/cigarettes/drugs/prescribed drugs, distress/shortness of breath while resting (without additional physical activity), sore throat, coughing, nasal complaints(e.g. often sneezing, irritated or stuffy nose, skin problems (itches, rash, red areas), urinary problems, changes in body weight. If any of these complaints were reported, follow-up question B.22 was also filled in.(55)

B.22 Do you think that the health complaints you indicated, are possibly linked to the presence of livestock farms in the vicinity of your home?

o Yes o No (if no, please continue with part $\mathrm{C}$ of the questionnaire)

C.1 What is the highest level of education you completed (56)?

o None, did not complete any education

o Primary school

o Lower pre-vocational secondary school (LTS, LEAO, LHNO, VMBO)

o Medium pre-vocational secondary school (MAVO, MULO, MBO-2/3yrs, VMBO-t)

o Senior secondary vocational education and training (MBO-4yrs, MTS, MEAO, BOL, BBS, INAS)

o Senior secondary education / university preparatory education (HAVO, VWO,

Atheneum, Gymnasium, HBS, MMS)

o University of professional education (HBO, HTS, HEAO)

o University

D.2 Did you live on a livestock farm during your childhood (until age 18yrs)?

o No

o Yes, from....(years of age), until.....(years of age)

D.15 Which pets did you keep during the past 5 years?

No, not in the past

5 years

Cat

Dog

Bird

Rabbit, hamster,

Guinea pig

Mouse or rat

Fish

Turtle
Yes, I currently Yes, I kept it during the last keep this pet
5 years, but not currently

0

o

o

0

0

0

o
0

0

0

0

0

0

o
0

0

0

o

0

0

0 
D.17 Which hobby farm animals did you keep during the past 5 years?

\begin{tabular}{|c|c|c|c|}
\hline No, not in the past & \multicolumn{2}{|c|}{ Yes, I currently } & Yes, I kept it during $t$ \\
\hline 5 years & keep this animal & 5 years, $b$ & but not currently \\
\hline Pig & 0 & 0 & 0 \\
\hline Cow & 0 & 0 & 0 \\
\hline Sheep & 0 & 0 & 0 \\
\hline Goat & 0 & 0 & 0 \\
\hline $\begin{array}{l}\text { Chicken, turkey, } \\
\text { duck, goose }\end{array}$ & 0 & 0 & 0 \\
\hline Horse, pony, donkey & 0 & 0 & 0 \\
\hline
\end{tabular}

E.1 Did you (ever) smoke cigarettes, cigars, and/or pipe tobacco? (yes, indicates at least 20 packages in total or 1 year of at least 1 cigarette per day)

o No

o Yes, used to smoke, but quit ......years ago.

oYes, I currently smoke 

Chapter 4

Pneumonia risk of people living close to goat and poultry farms - Taking GPS derived mobility patterns into account 


\section{Pneumonia risk of people living close to goat and poultry farms - taking GPS derived mobility patterns into account}

Background: We previously observed an increased incidence of pneumonia in persons living near goat and poultry farms, using animal presence around the home to define exposure. However, it is unclear to what extent individual mobility and time spent outdoors close to home contributes to this increased risk. Therefore, the aim of the current study was to investigate the role of mobility patterns and time spent outdoors in the vicinity of goat or poultry farms in relation to pneumonia risk.

Method: In a rural Dutch cohort, 941 members logged their mobility using GPS trackers for 7 days. Pneumonia was diagnosed in 83 subjects (participants reported that pneumonia had been diagnosed by a medical doctor, or recorded in EMR from general practitioners, 2011-2014). We used logistic regression to evaluate pneumonia-risk by presence of goat farms within 500 and $1000 \mathrm{~m}$ around the home and around GPS-tracks (only non-motorised mobility), also we evaluated whether more time spent outdoors increased pneumonia-risks.

Results: We observed a clearly increased risk of pneumonia among people living in close proximity to goat farms, ORs increased with closer distances of homes to farms (500m: $6.2(95 \% \mathrm{Cl} 2.2-16.5) 1000 \mathrm{~m}: 2.5(1.4-4.3))$ The risk increased for individuals who spent more time outdoors close to home, but only if homes were close to goat farms (within 50om and often outdoors: $12.7(3.6-45.4)$ less often: $2.0(0.3-9.2)$, no goat farms and often outdoors: 1.0 (0.6-1.6)). For poultry we found no increased risks.

Conclusions: Pneumonia-risks increased when people lived near goat farms, especially when they spent more time outdoors, mobility does not seem to add to these risks. 


\section{Introduction}

The Netherlands is a densely populated country with a land surface of $41.500 \mathrm{~km}^{2}$ [1] and a population of approximately 17 million people.[2] Intensive farming in the Netherlands is an important economic activity and the country has a large livestock population of approximately 124 million animals (data from 2016: 0.5 million goats, 0.8 million sheep, 4.3 million cattle, 12.5 million pigs, 105.5 million poultry)[3], clustered in specific areas (Figure 1). Associations between livestock animals and the potential for zoonotic disease transmissions has come to attention globally.[45] Given the close proximity of people and livestock, the Netherlands is considered to be at high risk for the emergence of livestock-associated zoonotic diseases.[4] This was illustrated in the past decade by the presence of antibiotic resistant bacteria in livestock animals with spill-over to humans $[5,6]$ and the largest reported Q-fever outbreak to date, originating from infected pregnant goats.[7] These events have renewed interest into the potential effects of livestock production on human health, which led to the start of the large "Farming and Neighbouring Residents' Health" study in 2012 (Dutch acronym: VGO). The main goal of this study is to investigate whether living in the vicinity of livestock farms has an impact on the health of residents. [8]

The main findings of the VGO study include a significantly increased incidence of pneumonia among people living close to goat and poultry farms (odds ratios 4.4 and 2.0 for persons living within $500 \mathrm{~m}$ and $1000 \mathrm{~m}$ of a goat farm and 1.3 and 1.7 for living within $500 \mathrm{~m}$ and $1000 \mathrm{~m}$ of a poultry farm). However, this increased risk was not observed for other farms such as cattle and pig farms.[9,10] Freidl et al used the home address as a proxy of exposure. However, people are mobile which might also be relevant for their exposure. We recently assessed the daily mobility [11] of a representative subsample (Supp. Table 1, $[8,9,12]$ ) of the VGO cohort study to enable exploring differences in exposure to livestock based on the home address and on mobility patterns.

The aim of the current study was to investigate the role of mobility patterns and time spent outdoors in the vicinity of goat or poultry farms in relation to pneumonia risk.

\section{Methods}

\section{Population and health data}

Participants in the VGO cohort $(\mathrm{N}=2,494)$ were living in a rural area in the south-eastern part of the Netherlands (Figure 1). Farmers and people living or working on farms were excluded a priori, since the focus was on the health of residents living in the vicinity of farms. VGO cohort members underwent a medical examination (lung function measurements, blood, nasal- and buccal-epithelia collection, stool sample) in a field study that took place between March 2014 and February 2015. During this medical examination, participants also filled in a baseline questionnaire (VGO questionnaire), including questions about personal characteristics, health and lifestyle. $[8,9]$

Additional health information for 2,426 out of the 2,494 (97\%) participants was obtained from electronic medical records (EMR) of 27 participating general practitioners (GPs). In the Netherlands, every citizen is obliged to register with a general practitioner who acts as gatekeeper to specialised care. EMR data was used in the study if permission was granted from participants and specific quality criteria for registering were met by GPs. The quality requirements to be met be GPs are broadly as follows: 1) GPs were required 
to register health data in the EMR using the codes defined in the International Classification of Primary Care (ICPC) [15]; 2) ICPC codes had to be assigned to at least $50 \%$ of the records in the EMR; and 3) GP practices recorded consultations for more than 6 months during a year.[8,13,14] Sixty-eight of the 2,494 VGO participants were excluded from analysis because either EMR access was refused or EMR data was not available. Therefore, the final population of the VGO study was 2,426 individuals [9], of which 2,370 (98\%) provided consent to be contacted for subsequent research. Subsequent to the VGO study, multiple follow-up studies were initiated(ESBL screening, COPD follow-up). If people were not invited for these other studies, they were invited for the current (GPS) study. Participants of the COPD follow-up were afterwards also invited to participate in the GPS study. Therefore, from the VGO population, 1517 participants were invited for the GPS study and a total of 1014 invitees (66.8\%) agreed to participate.[11] Medical Ethical approval was obtained for the VGO study from the Medical Ethical Committee of the University Medical Centre Utrecht (protocol number 13/533).

\section{Pneumonia case definition}

People were considered to be diagnosed with pneumonia if they reported a physiciandiagnosed pneumonia in the past three years in the VGO questionnaire. In addition, EMRs were reviewed for a GPs registration of pneumonia within the last three years (ICPC code R81) [15]. If participants did not report a pneumonia in the VGO questionnaire, but R81 was registered in their EMR between 2011 and 2015, these participants were also considered as pneumonia cases.

Global Positioning System (GPS) data and self-reported time spent outdoors, data collection and cleaning

The procedures of the VGO GPS study are described in more detail in Klous et al 2017.[11] In brief, between September 2014 and January 2016, 1014 volunteers logged their movements by carrying a GPS logger for 7 consecutive days. GPS devices were set to a one-second interval and only logged when the devices were moved. A total of 941 GPS tracks were available for the current analyses. The main reasons for exclusion were primarily device configuration errors ( $5 \mathrm{sec}$ instead of $1 \mathrm{sec}$ sampling interval, $\mathrm{N}=13$ ), GPS device failure $(\mathrm{N}=14)$, or postal errors, an overview is given in Figure 2. Based on GPS measured speed patterns, transport modes were assigned to GPS points that were located outdoors. $[11,16]$ Indoors/outdoors assignment of GPS locations was done using the participants' home address coordinates using cadastral data from the Netherlands (BAG data 2015) (see Figure 3 for an overview of GPS data processing). Assigned transport modes were walking, biking, or motorised transport.

Before GPS logging, participants filled in a questionnaire ( $\mathrm{Q}_{1}$ ) containing questions on the number of hours per week they spent outdoors close to their homes ("in a usual week how many hours do you spend outdoors close to home e.g. gardening, care for animals, do-it-yourself activities, sitting in the garden").[11] As we used a 6om buffer around the home address to assign a GPS point as being indoors or outdoors [11], time spent outdoors while remaining close to home could not be determined solely using 

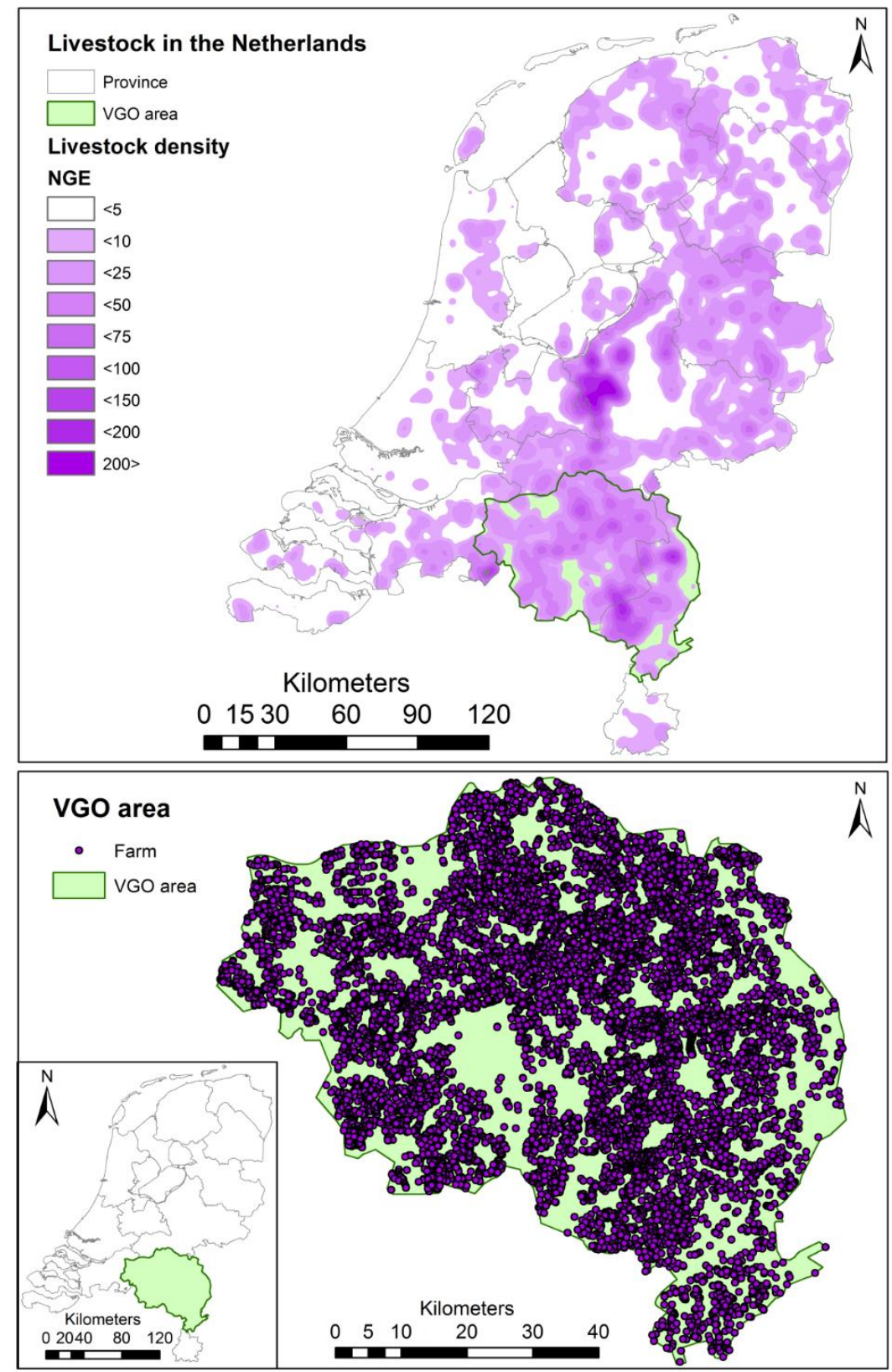

Figure 1. Livestock in the Netherlands and the rural situation in the research area, all forms of livestock keeping practices are shown in both maps. Top panel, 'Livestock in the Netherlands': darker shades of purple indicate higher densities of livestock keeping farms. Livestock farms are clustered in specific areas. [43] Within our research area, bottom panel, 'VGO area', you find a very dense, diverse [44] livestock population. 
1014 people agreed to participate

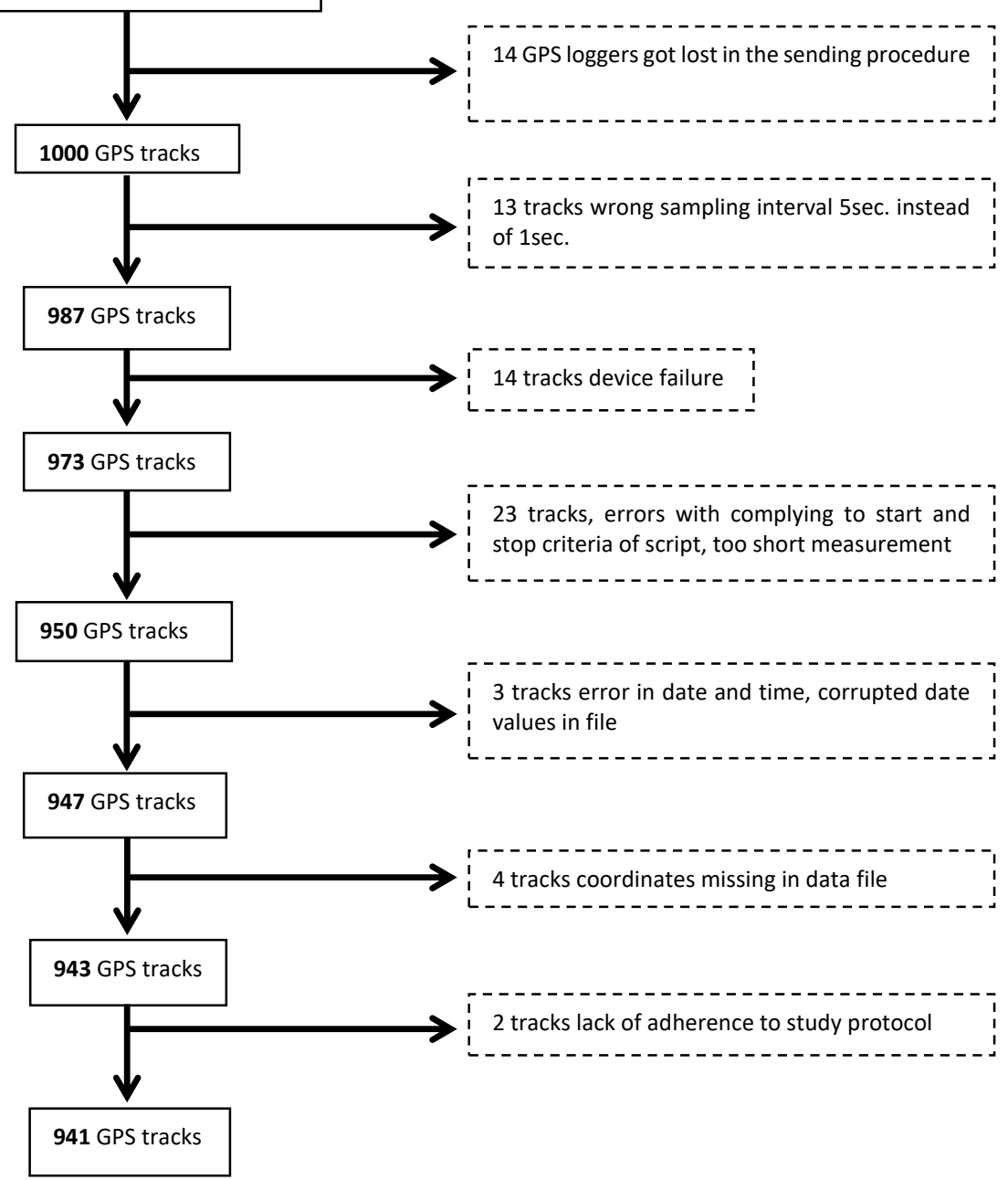

Figure 2. Data cleaning flowchart.

GPS measurements. Therefore, we used answers to the question about time spent outdoors while close to home to specify these durations.

Geographic Information System (GIS) analyses

1) Animals in the vicinity of the home address and GPS-measured mobility.

In line with the previous analysis by Freidl et al 2017 [9], we used the database of livestock-keeping companies (Dutch abbreviation: BVB-database) 2015 to assess how many goats and poultry were registered within 500m and 1000m distances around home addresses. The BVB registry includes permit registrations for farms, with information 
pertaining to location of the farm, and types and numbers of animals. $[17,18]$ In concordance with Freidl et al, to evaluate the presence or absence of goats or poultry in the vicinity of the homes for our main analysis, we required a minimum of 50 goats or 250 chickens in our distance categories of 500 and 1000m.[9] The number of animals required for a farm to be officially registered as such. Note that according to Statistics Netherlands, more than $98 \%$ of animals registered as 'poultry' are chicken therefore we assume that all records of poultry refer to chicken. $[3,19]$

Of all participants' location coordinates measured with GPS, we only evaluated those that related to active transport modes (outdoor points grouped as 'walking' or 'biking'), as these were assumed to be relevant for exposure to the outdoor environment. Any GPS coordinate that fell within 500 m or 1000 m of any goat or poultry farm was classified as "exposed". We then summarised per person the amount of time spent outdoors in "exposed" locations, or if all GPS locations could be grouped as "unexposed".

2) Self-reported time spent outdoors close to home.

We used questionnaire data about time spent outdoors to assign the duration of time spent outdoors close to home. Based on the median duration (3.5h/week) that participants reported to spend outdoors close to home (e.g. gardening, care for animals, do-it-yourself activities, sitting in the garden), this variable was dichotomised (o3.5 h/week versus >3.5-62.5 h/week).

\section{Statistical analyses}

We evaluated pneumonia risk related to the presence of goat and poultry farms within 500 or 1000 m of either the home address, GPS track (GPS-measured "exposed" active mobility: walking or biking), or both. We further evaluated whether time spent outdoors close to home while living close to farms had an effect on pneumonia risk. We used logistic regression to evaluate pneumonia risk, adjusted for age, sex, educational level (low, medium, high) and smoking status (current, ever, never). Some people might be exposed to both goats and poultry, and the corresponding Spearman's correlation coefficients for number of registered goats and chicken within 500 and $1000 \mathrm{~m}$ were 0.37 and 0.31 , respectively. We therefore adjusted our main analysis also for presence or absence of the respective other animal type near home.

\section{Sensitivity analyses}

We performed several sensitivity analyses.

(A) Animal intensity: In our main analysis we considered 50 goats or 250 chickens as cutoff to indicate farms. This implies that some participants may be categorised as unexposed, while they could have been exposed to lower numbers of animals in the vicinity of their homes. Therefore, we performed sensitivity analyses on the number of animals registered within the 500 or $1000 \mathrm{~m}$ distance buffer around participants' homes. In this analysis, we assigned "low" animal intensity category to persons living within 500 or 1000m from farms with 1-49 goats or 1-249 chickens. We additionally categorised animal intensity as "medium" or "high", by applying the cut-off at the median of registered animal numbers (1,659 and 384 goats within 500 and $1000 \mathrm{~m}$, respectively and 
GPS data (points)

1-second interval (when moving), Date, Time, $\mathrm{X}$ and $\mathrm{Y}$ coordinate, Speed

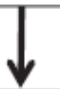

If point falls within $60 \mathrm{~m}$ buffer around home address or $20 \mathrm{~m}$ of other indoor location (building polygon with $>45$ GPS points included), GPS point is considered indoors
GPS data (points) assigned indoors

Not considered in further analyses
GPS data (points) assigned outdoors

Date, Time, $\mathrm{X}$ and $\mathrm{Y}$ coordinate, Speed, Distance from home calculated for every point

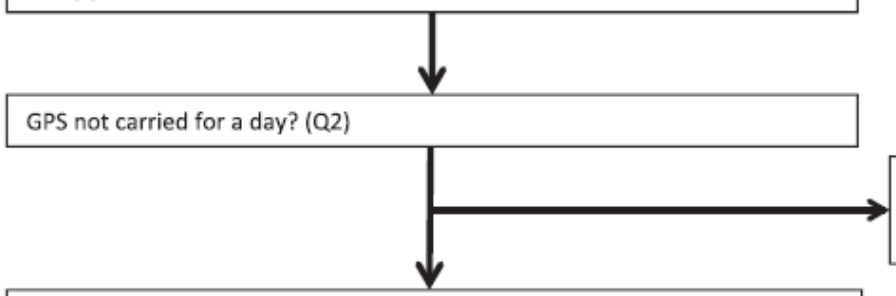

GPS data (points) assigned outdoors: Time differences calculated ( $>1 \mathrm{sec}$. difference indicated as stop). Speed $=0$ also defined as stops.
Day removed from analysis and $24 \mathrm{~h}$ subtracted from total measuring time

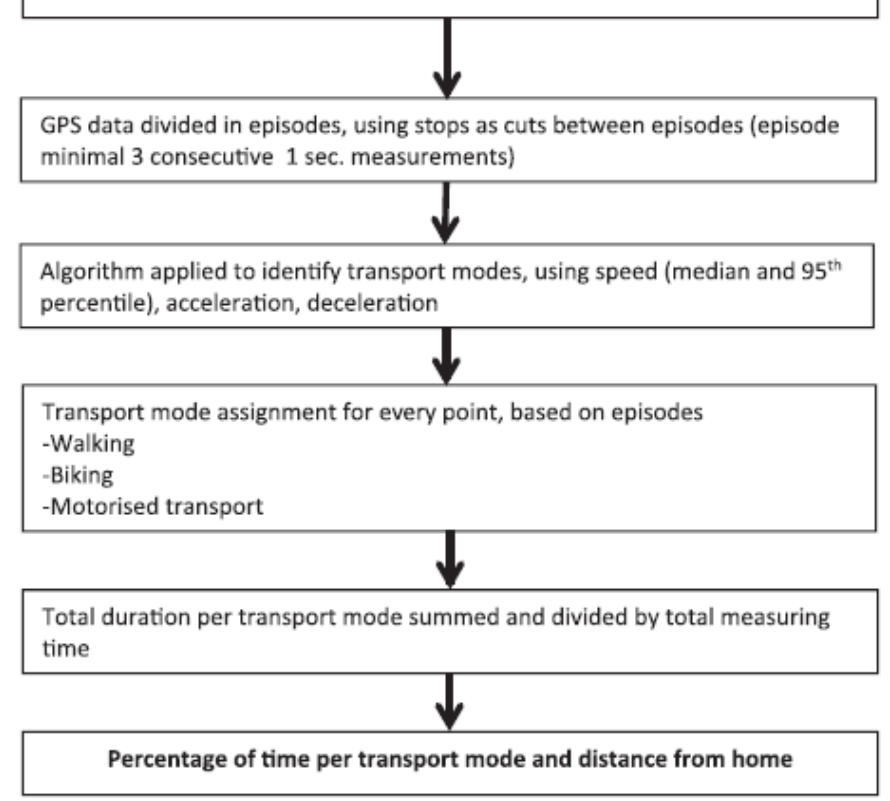

Figure 3 Schematic of GPS data processing 
13,480 and 37,160 chickens within 500 and 1000 m, respectively). This means we assigned "medium" animal intensity for the residential presence of goats and poultry if participants lived within 500 or 1000 of $50-1,658$ or $50-383$ goats or $250-13,479$ or 250 - 37,159 chickens, or "high" for living within 500 or $1000 \mathrm{~m}$ from $\geq 1,659-3,250$ goats or $\geq 384-5,015$ goats, or $\geq 13,480-290,600$ chickens or $\geq 37,160-694,900$ chickens, respectively. See Supp. Table 2 for a summary of the used cut-offs.

(B) Case definition: We restricted our pneumonia cases to participants with an R81 registration (pneumonia) in their GPs electronic medical records $(N=55,66 \%$ of cases based on the original case definition).

(C) Spline analysis: We explored the shape of the association between pneumonia risk and total time spent outdoors in the vicinity of goat or poultry farms using penalised regression splines applying the (default) 'thin plate' basis of the R package mgcv (mixed generalised additive model computation vehicle). For these analyses, all 'goat-exposed time' was combined, so GPS-measured 'exposed' active mobility (walking, biking) was added to self-reported 'exposed' time spent outdoors close to home, thus accumulating into one 'exposed time variable'. This was done separately for the different buffer sizes (500 or $1000 \mathrm{~m})$. We also performed the same analysis for exposure to poultry farms.

(D) Full VGO cohort: We repeated our main analysis in the full VGO cohort using the VGO baseline questionnaire to extract information on time spent outdoors close to home. In this analysis, the same case definition was applied as for the GPS study.

(E) Invitation selection and non-responder analyses, we compared invited and noninvited VGO cohort members and participants and invited non-responders for: outcome category, age, gender, educational level, smoking status and goat and poultry exposure.

All statistical analyses were performed using $R$ (3.2.3), and all GIS analyses were performed with ArcGIS ArcMap 10.2 (ESRI, Redlands, CA, USA) and automated using Python 2.7.

\section{Results}

The average age of the 941 participants was 57 years (range $20-72$ years) and $55 \%$ of the participants were women. A total of, $26(3 \%)$ participants lived within $500 \mathrm{~m}$ of a goat farm, $116(12 \%)$ within $1000 m$ of a goat farm and 151 (16\%) and $416(44 \%)$ within 50om and 1000m of a poultry farm, respectively. Overall, 83 participants (8.8\%) reported a pneumonia diagnosis in the past three years (2011-2015) or reported to have been diagnosed by their GP with pneumonia (of which 55 [66\% of total cases] had an R81 registration in the EMR). Of cases, $65 \%$ were female $(\mathrm{N}=54)$ and their average age was 60 years (range 31-72 years), see Table 1 . The subsample of individuals with GPS tracks did not differ significantly in terms of age, sex educational level and smoking habits from the total VGO cohort. There was however a difference in exposure categories, this is mainly explained by differences in sizes of the non-exposed groups (Supplementary Table 1). Between invited and non-invited VGO cohort members we observed a 
Table 1 General characteristics of study population

Variable

Pneumonia cases controls

\begin{tabular}{|c|c|c|c|}
\hline Number of participants $(\mathrm{N}=)$ & & 83 & 858 \\
\hline Age (mean (range)) & & $60(31-72)$ & $57(20-72)$ \\
\hline Gender (females (\%)) & & $54(65 \%)$ & $464(54 \%)$ \\
\hline Education $(\mathrm{N}=(\%))$ & Low & $30(36 \%)$ & $202(24 \%)$ \\
\hline & Medium & $32(39 \%)$ & $392(46 \%)$ \\
\hline & High & $21(25 \%)$ & $264(31 \%)$ \\
\hline Smoking $(\mathrm{N}=(\%))$ & Never & $25(30 \%)$ & $352(41 \%)$ \\
\hline & Former & $52(63 \%)$ & $435(51 \%)$ \\
\hline & Current & $6(7 \%)$ & $68(8 \%)$ \\
\hline & No data & & $3(0.3 \%)$ \\
\hline Time spent outdoors close to home & (hours/week (median, IQR)) & $4.0(2.0-7.0)$ & $3.5(1.5-7.5)$ \\
\hline Time walking & (min/week (median IQR)) & $19.8(8.4-40.2)$ & $19.7(7.8-55.2)$ \\
\hline Time biking & (min/week (median IQR)) & $76.3(17.4-140.1)$ & $59.9(15.9-147.6)$ \\
\hline
\end{tabular}

significant difference in group sizes of exposed participants (Supplementary Table 10). There was only a minor difference observed for age and smoking status between participants and non-responders of the VGO GPS study (Supplementary Table 11).

\section{Goats}

We found a distance-related increased risk for pneumonia associated with the presence of goats (see Table 2, unadjusted results are shown in Supp. Table 3). If people lived within $500 \mathrm{~m}$ of a farm with at least 50 goats, they had 6.2 times higher odds to be diagnosed with pneumonia (OR $6.2(95 \% \mathrm{Cl} 2.2-16.5)$ and for a farm with at least 50 goats within $1000 m$ of the home the OR was $2.5(95 \% \mathrm{Cl} 1.4-4.3)$. If the number of animals was categorised into "low", "medium" and "high" categories (using farms with $\geq 50$ animals and the median as cut-offs) an exposure-response trend was observed with an increasing risk for pneumonia with increasing categories of animal intensity (OR 1.o for "low" and 2.5 for "high" goat intensity, there were no pneumonia cases within the "median" category (Supp. Table 3)). This relationship could only be observed for farms with goats within 1000m of the home, since a similar analysis was not possible for goats within 50om around the home because there were too few cases in the "low" and "medium" groups (1-49, 50-median). Only a marginal change in the goat-associated risk for pneumonia was observed when mobility was taken into account (using $500 \mathrm{~m}$ buffers, OR 6.21 [95\% Cl 2.2-16.9] for animals close to the home address plus mobility versus OR 6.15 [95\% Cl 2.2-16.5] for animals close to the home address only). When we calculated the risk for pneumonia in relation to active mobility only (based on GPS monitoring), we found an OR of 1.03 ( $95 \% \mathrm{Cl} 0.6-1.7)$. However, when time spent outdoors in the vicinity of the home (i.e. primarily gardening) was taken into account, we observed increasing risks of pneumonia when people were living within $500 \mathrm{~m}$ and $1000 \mathrm{~m}$ of goat farms. 
Table 2 Pneumonia risk and presence of goats (50 goats or more) within 500 and $1000 \mathrm{~m}$ of the home, within 500 and $1000 \mathrm{~m}$ of the GPS track when walking or biking and within 500 and $1000 \mathrm{~m}$ of the home while being outdoors (gardening).

\begin{tabular}{|c|c|c|c|c|c|c|c|}
\hline \multicolumn{2}{|l|}{ Goats } & \multicolumn{3}{|c|}{500 meter buffer } & \multicolumn{3}{|c|}{1000 meter buffer } \\
\hline & & $\begin{array}{l}\text { Cases } \\
\mathrm{N}=83\end{array}$ & $\begin{array}{r}\text { Controls } \\
\mathrm{N}=85^{8}\end{array}$ & $\begin{array}{r}\text { Adj OR } \\
(95 \% \mathrm{Cl}) \\
\end{array}$ & $\begin{array}{l}\text { Cases } \\
\mathrm{N}=83\end{array}$ & $\begin{array}{r}\text { Controls } \\
\mathrm{N}=858\end{array}$ & $\begin{array}{r}\text { Adj OR } \\
(95 \% \mathrm{Cl})\end{array}$ \\
\hline \multirow{2}{*}{$\begin{array}{r}\text { Home } \\
\text { buffers } \\
\text { only }\end{array}$} & $\begin{array}{l}\text { Goats in vicinity of } \\
\text { home }\end{array}$ & 9 & 17 & $\begin{array}{r}6.2 \\
(2.2-16.5)\end{array}$ & 23 & 119 & $\begin{array}{r}2.5 \\
(1.4-4 \cdot 3)\end{array}$ \\
\hline & $\begin{array}{l}\text { No Goats in } \\
\text { vicinity of home }\end{array}$ & 74 & 841 & Ref. & 60 & 739 & Ref. \\
\hline \multirow{3}{*}{$\begin{array}{c}\text { Animals } \\
\text { close to } \\
\text { home + } \\
\text { while in } \\
\text { transport }\end{array}$} & $\begin{array}{l}\text { Goats in vicinity of } \\
\text { home and GPS } \\
\text { track }\end{array}$ & 9 & 17 & $\begin{array}{r}6.2 \\
(2.2-16.9)\end{array}$ & 22 & 118 & $\begin{array}{r}2.5 \\
(1.3-4.7)\end{array}$ \\
\hline & $\begin{array}{l}\text { Only goats in } \\
\text { vicinity GPS track }\end{array}$ & 21 & 219 & $\begin{array}{r}1.0 \\
(0.6-1.7)\end{array}$ & 30 & 330 & $\begin{array}{r}1.1 \\
(0.6-1.9)\end{array}$ \\
\hline & $\begin{array}{l}\text { No goats in vicinity } \\
\text { of home and GPS } \\
\text { track }\end{array}$ & 53 & 622 & Ref. & 30 & 409 & Ref. \\
\hline \multirow[t]{4}{*}{$\begin{array}{r}\text { Outdoor } \\
\text { s close to } \\
\text { home }\end{array}$} & $\begin{array}{l}\text { Goats in vicinity of } \\
\text { home, long period } \\
\text { outdoors }\end{array}$ & 7 & 7 & $\begin{array}{r}12.7 \\
(3.6-45.4)\end{array}$ & 14 & 56 & $\begin{array}{r}3.0 \\
(1.4-6.2)\end{array}$ \\
\hline & $\begin{array}{l}\text { Goats in vicinity of } \\
\text { home, short period } \\
\text { outdoors }\end{array}$ & 2 & 10 & $\begin{array}{r}2.0 \\
(0.3-9.2)\end{array}$ & 9 & 63 & $\begin{array}{r}1.9 \\
(0.8-4.1)\end{array}$ \\
\hline & $\begin{array}{l}\text { No goats in vicinity } \\
\text { of home, long } \\
\text { period outdoors }\end{array}$ & 37 & 407 & $\begin{array}{r}1.0 \\
(0.6-1.6)\end{array}$ & 30 & 358 & $\begin{array}{r}1.0 \\
(0.6-1.7)\end{array}$ \\
\hline & $\begin{array}{l}\text { No goats in vicinity } \\
\text { of home, short } \\
\text { period outdoors }\end{array}$ & 37 & 434 & Ref. & 30 & 381 & Ref. \\
\hline
\end{tabular}

ORs and $95 \% \mathrm{Cl}^{\prime}$ s are provided for animal presence categories in the different models, ORs are adjusted for age, sex, educational status, smoking and presence of poultry in the vicinity of the home within the distance used in the analysis. We used the non-exposure category for all analyses as reference category. This means we used "No goats in vicinity of home and GPS track" as reference for the analysis "Animals close to home + while in transport", because this enabled comparison of all separate categories. For the analysis "Outdoors close to home", we used "No goats in vicinity of home, short period outdoors" as reference, again to enable comparison of all separate categories in the analyses.

*One case and 1 control were removed from the analysis using 100om buffers because of power limitations, these fell within the category "Goats in vicinity of home, no goats in vicinity of GPS track".

People living within $500 \mathrm{~m}$ of a goat farm who spent long periods in their garden had an OR of $12.7\left(95 \% \mathrm{Cl}_{3} .6-45.4\right)$, based on 7 cases and 7 controls, which was larger than that observed for people who spent shorter periods in their garden (OR 2.0 [ $95 \% \mathrm{Cl} 0.3-9.2]$, based on 2 cases, 10 controls). No increased risks were observed for people who spent long periods in their gardens in unexposed locations, ORs were 1.0 for both $500(95 \% \mathrm{Cl}$ 0.6-1.6) and $1000 \mathrm{~m}$ ( $95 \% \mathrm{Cl}$ 0.6-1.7) distance categories. For people living within $1000 \mathrm{~m}$ of a goat farm similar effects were observed. When people spent longer periods outdoors the OR was higher (OR $3.0[95 \% \mathrm{Cl}$ 1.4-6.2] versus $\mathrm{OR} 1.9[95 \% \mathrm{Cl}$ 0.8-4.1]). Similar patterns were observed when we restricted our cases to pneumonia cases registered in the GP electronic medical records (Supp. Table 5) or when we analysed the complete VGO population (Supp. Table 7). 


\section{Poultry}

No statistically significantly increased pneumonia risks were observed for people living close to farms with 250 or more chickens in the vicinity of their home, (OR $1.1[95 \% \mathrm{Cl}$ 0.6-2.1] for poultry within 500m, OR 1.1 [95\% Cl 0.7-1.8] for poultry within $1000 \mathrm{~m}$ ) (see Table 3 and Supp. Table 4). ORs were above unity but not statistically significant for participants exposed at home and during active mobility. More time spent on mobility in exposed locations resulted in an OR of $1.5(95 \% \mathrm{Cl}$ o.8-3.2) for a poultry farm within 500 of a GPS track, for farms within 1000m of the GPS track no such effect was observed. When we analysed re-categorised poultry density categories, based on number of chickens, we did not observe an exposure-response increase in pneumonia risk for higher chicken density (see Supp. Table 4). In addition, risk estimates for pneumonia from the presence or absence of poultry were attenuated when we adjusted for the presence of goats.

Table 3 Pneumonia risk and presence of poultry (250 chickens or more) within 500 and $1000 \mathrm{~m}$ of the home, within 500 and 1000 of the GPS track when walking or biking and within 500 and $1000 \mathrm{~m}$ of the home while being outdoors (gardening).

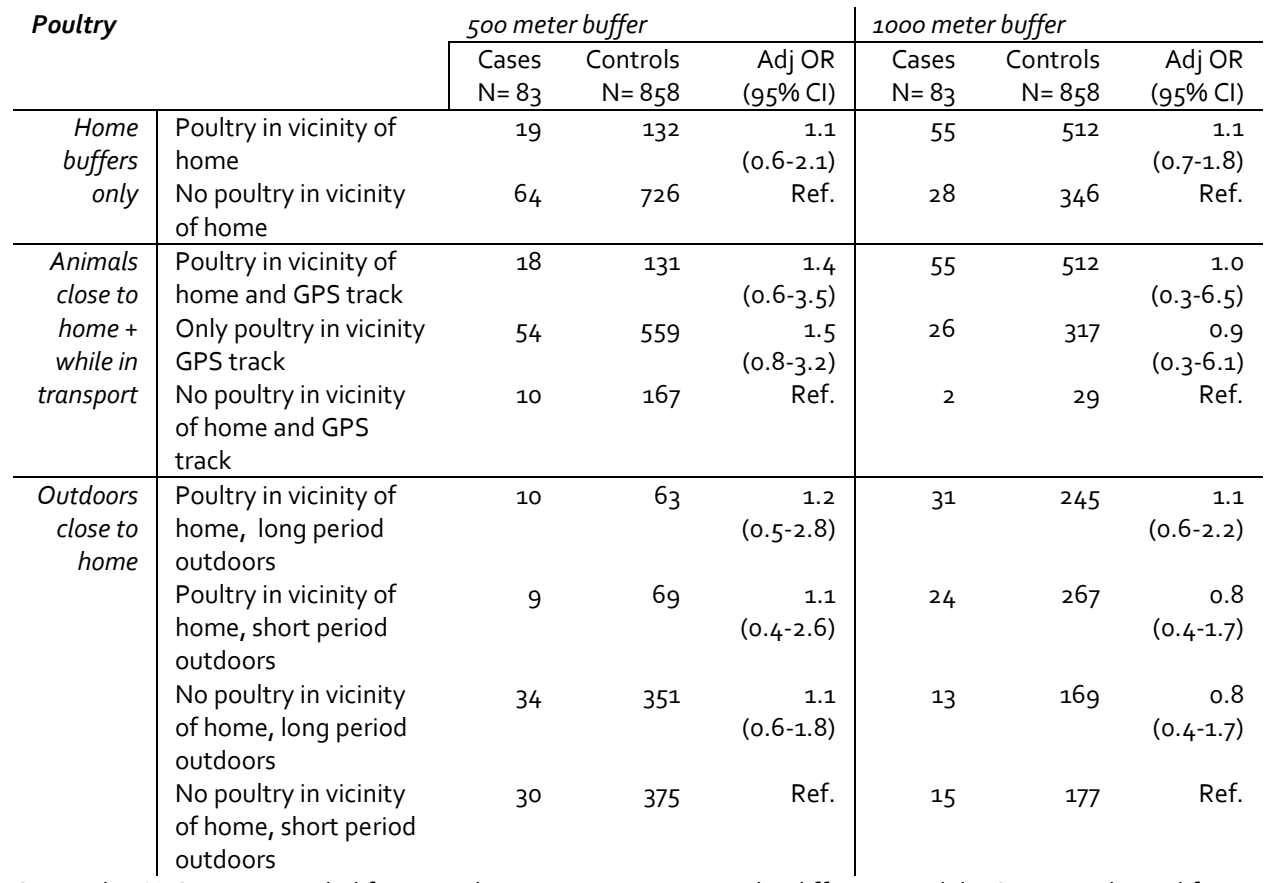

ORs and $95 \% \mathrm{Cl}^{\prime} \mathrm{s}$ are provided for animal presence categories in the different models, ORs are adjusted for age, sex, educational status, smoking and presence of goats in the vicinity of the home within the distance used in the analysis. We used the non-exposure category for all analyses as reference category. This means we used "No poultry in vicinity of home and GPS track" as reference for the analysis "Animals close to home + while in transport", because this enabled comparison of all separate categories. For the analysis "Outdoors close to home", we used "No poultry in vicinity of home, short period outdoors" as reference, again to enable comparison of all separate categories in the analyses. * One case and 1 control were removed from the analysis using $500 \mathrm{~m}$ buffers because of power limitations, these fell within the category "Poultry in vicinity of home, no poultry in vicinity of GPS track". 

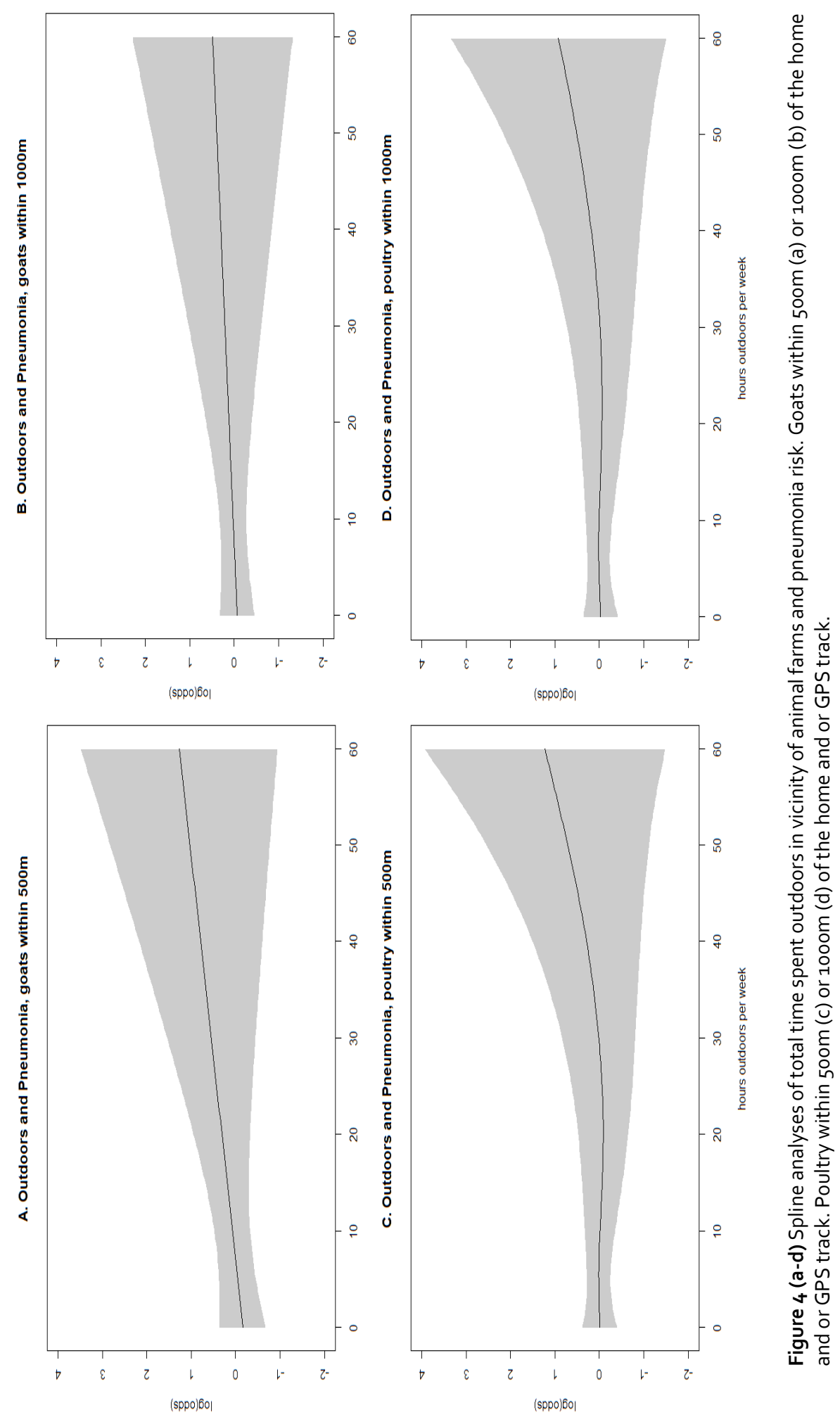


\section{Spline analyses}

Spline analyses suggested a linear association between total time spent outdoors in the vicinity of goat farms (both within 500 and $1000 \mathrm{~m}$ ) and increased risks for pneumonia. This relationship again was stronger for the presence of goat farms within 50om of the home when more time was spent outdoors. However, the confidence intervals of the splines were very wide, especially for those participants who spent the most time outdoors (Figure $4 \mathrm{a}$ and $4 \mathrm{~b}$ ). For poultry, these relationships were not observed, in line with the outcomes of the logistic regression analyses (Figure $4 \mathrm{C}$ and $4 \mathrm{~d}$ ).

\section{Discussion}

We observed an increased risk of pneumonia in people living in close proximity to goat farms. ORs increased with closer distances of homes to farms and with increasing categories of animal intensity. Active mobility in the vicinity of goat farms only marginally added to pneumonia risk. However, the risk was increased for individuals who spent more time outdoors close to their home, but only if their homes were located in close proximity (i.e. within 500 or $1000 \mathrm{~m}$ ) to goat farms. Pneumonia risks for poultry farms in the vicinity of homes, during active mobility or for time spent outside was above unity but not statistically significantly elevated.

The observed increased risk of pneumonia in persons living close to goat farms is in line with the observation from Freidl et al [9], which is reassuring given that we analysed a subgroup of the VGO study. A few years before this study, between 2007 and 2009, the area had experienced the largest described Q-fever epidemic to date.[7] It has been suggested that previous infection with Coxiella burnetii (the causative agent of Q-fever) may add an increased sensitivity to other infectious agents.[20-26] It is relevant to note that at the time of our study, O-fever incidence had dropped again to pre-epidemic levels.[9] Moreover, all study participants underwent serological testing for antibodies against $C$. burnetii, as part of the health assessment of the VGO study.[12] In line with previous research [9], we re-evaluated Q-fever serology and did not observe different levels of $C$. burnetii antibodies between people who had experienced pneumonia in the past three years and those who had not. This means that it is unlikely that a present or past Q-fever epidemic is underlying the increased pneumonia risk observed in our study. Few indications exist for other zoonoses that originate from goats. Rodolakis (2014) reviewed zoonoses from goats and identified two other agents that can potentially cause pneumonia in humans; Chlamydia abortus and Pasteurella multocida.[27] C. abortus is mainly a risk for pregnant women and has previously only been reported once in the Netherlands.[28] P. multocida can cause pneumonia, but is more often isolated from skin lesions [29] and has, to the best of our knowledge, so far never been isolated in the Netherlands. Overall, we were limited in our ability to explore the potential for these or other agents (e.g. viruses [30,31], fungi [32] originating from the straw that is used inside stables [33], or thermophile fungi or bacteria originating from manure applied to the surrounding land [34]) as the underlying cause of pneumonia, given the lack of data regarding presence or absence of these agents.

We observed that active mobility close to goat or poultry farms did not strongly affect risk estimates and risk estimates were mainly driven by living close to goat farms. This might be due to the fact that total time in active transport was rather limited (20 min/week walking, 1h/week biking) as was the time while in close distance to a farm 
while in active transport (Supp. Table 8), compared to time spent gardening (median 3.5h/week).

Risks were more pronounced for people living close to goat farms who spent more time outdoors close to home (primarily on gardening), however the number of cases and controls in this group was very limited. Still, time spent outdoors in locations that were not close to goat farms did not translate into increased risks, which suggests that gardening as such is not a risk factor. The spline analyses we performed also showed that more time spent outdoors in the vicinity of goat farms seemed to be associated with an increasing pneumonia risk (Figure $4 \mathrm{a}$ and $4 \mathrm{~b}$ ). The association between time spent outdoors close to home in the vicinity of goat farms and pneumonia risk also remained present when we performed this analysis in the full VGO cohort $(\mathrm{N}=2426)$. We observed similar patterns (Supp. Table 7), strengthening the notion that pneumonia risks were associated with time spent outdoors in locations close to goat farms.

For poultry in the vicinity of homes we observed a small, statistically non-significant increase of risk for pneumonia. Observed risks are in line with an earlier analysis among more than 100,000 individuals using EMR data in the same region.[10] The authors speculated that dust and endotoxin emissions from poultry might explain this excess risk [10], since fine dust is a known causative agent for pneumonia [35] and other lung diseases.[36] According to a recent national report [37], goat farms emit much lower levels of fine dust compared to poultry farms (Supp. Table 9). This means that fine dust exposure from animal keeping is less likely to explain excess risk for pneumonia from goat farms than it is for poultry farms. In summary, we have no explanation for the underlying causative agent responsible for the increased pneumonia risk related to goat farms in our study.

\section{Strengths and limitations}

A strength of our study is that we had measured mobility data of a relatively large cohort $(\mathrm{N}=941)$ [11]. In addition, the cohort included self-reported information about time spent outdoors. Furthermore, we had information about participants' health and lifestyle, age, gender, education level, smoking status and whether they lived in the vicinity of goats and/or poultry. Although nearly $9 \%$ of our participants had had a pneumonia in recent years and we have an extensive dataset for our study population, the overall population size $(\mathrm{N}=941)$ might be too small to observe minor increases in risk for pneumonia.

Mobility patterns may change over time and this may not be well captured in our data. Still, we tracked 941 study participants during the time frame of over one year. Therefore, misclassification on the individual level may be present in our study, but the data should also reflect a representative picture of mobility patterns in our population. Active mobility contributed only a limited amount to the total time spent outdoors because the majority of time spent outdoors was spent in the vicinity of the home.

Another limitation of our study relates to using GP electronic patient records where we do not know which diagnostic procedure was underlying the pneumonia diagnosis. The occurrence of pneumonia was relatively high (nearly $9 \%$ ) in our study population. We considered people as cases if they had had a pneumonia in the last 3 years. This increased pneumonia incidence in our study area, compared to the whole of the Netherlands, is an ongoing trend since 2007. Van Dijk et al studied pneumonia 
prevalence in our study area and found an increased pneumonia risk over the years (average prevalence 2007-2013 16.3/1000 patients) when compared to a control rural area with a lower livestock density (average prevalence 2007-2013 11.9/1000 patients).[14] Given the recent Q-fever epidemic, it is conceivable that doctors were more prone to diagnose a pneumonia in our rural study area. Therefore, we cannot exclude that information bias might have contributed to the observed increased risks of pneumonia, especially when GPs were aware about the location of their patients' homes and the location of farms in the residential area. However, a nation-wide analysis of hospital admissions for pneumonia over the years 2012-2014 suggests clustering of pneumonia admissions in livestock-dense regions.[38] Furthermore, information bias does not explain the strong increase in pneumonia risk for people spending more time outdoors close to home, since this is not evaluated in pneumonia diagnosis.

We also classified participants as "cases" if they reported a doctor-diagnosed pneumonia that was not corroborated by the GP records. If participants misinterpreted their GPs diagnosis of e.g. an acute bronchitis or upper respiratory tract infection as pneumonia, and if these participants lived closer to goat farms, then this could have further contributed to differential misclassification. It might also be that for the questionnaire-based pneumonia cases, participants did not remember correctly the time of the diagnosis. However, in the analysis on the full cohort, excluding pneumonia cases if they were not confirmed by GP records had no material effect on risk estimates.[9] Within our subgroup of the VGO population, $33 \%(\mathrm{~N}=28)$ of the cases were assigned based on their questionnaire answers only, $66 \%(\mathrm{~N}=55)$ of cases had either an EMR R81 notification or were assigned as cases based on questionnaire data and EMR data. When we performed our analyses assigning cases only based on an EMR R81 notification, the results of our analyses also remained materially unchanged (Supplementary data, Supp. Table 5 and 6).

The invitation method we applied might have had an effect on our study, we observed a significant difference in group sizes of exposed participants between invited and noninvited VGO cohort members. An explanation might be that the non-invited group also included people invited to the COPD follow-up, previous work in the VGO study showed that participants with COPD lived less often in the vicinity of farms [8].

With regards to the spatial analyses, we found no significant differences between invited participants with and without usable GPS tracks, concerning outcome and exposure. In order to increase our power for the statistical analyses, we included people with goats/poultry within 50om of the house also to the analyses with animals within 1000 of the house. Which may lead to effect modification to some extent. However, when we performed the analyses with mutual exclusion we still observed a significantly increased OR for goats within 0-500m (OR 6.7, 95\% Cl 2.4-18.1) and a non-statistically significant increased OR for having goats within 500-100om of the home (OR 1.8, 95\% Cl 0.9-3.4). For poultry within $500 \mathrm{~m}$ or $1000 \mathrm{~m}$, ORs where still above unity, but not statistically significant.

\section{Future research}

It is unclear what is underlying the observed increased pneumonia risks associated with proximity to goat farms and spending time outdoors close to goat farms. Additional research is required to identify the underlying cause of these increased risks. First, a 
veterinary survey would be informative to evaluate whether and which infectious agents are circulating among goats by applying molecular diagnostics such as whole genome sequencing and proteomics on samples obtained from animals.[39-41] Second, if an infectious agent was identified among livestock, air samples could be taken in goat stables and their surroundings to check whether the agent is emitted to the environment. These environmental samples could then be analysed using more specific molecular techniques such as PCR.[33] In a third step, samples obtained from human pneumonia cases and controls should be analysed using similar techniques. [42] If the infectious agent is found in each step, the relationship between the animal-origin pathogen, environmental transmission and human infections can be confirmed and the pathway clarified, providing opportunities for prevention.

\section{Conclusions}

Pneumonia risk in our study was increased if people lived within 500 or $1000 \mathrm{~m}$ of a goat farm. Mobility outdoors in the vicinity of goat farms did not markedly change risk estimates, but this could be expected given that the time spent outside was relatively limited. Time spent outdoors close to home in the presence of goat farms translated into a significantly increased pneumonia risk. As it is unknown which specific agent or mechanism is underlying the observed increased risk, this needs further study.

\section{Acknowledgements}

We like to thank all the participants, Myrna de Rooij for statistical input, Daisy de Vries for textual input and George Downward for a final language edit of the manuscript. 


\section{References}

1. www.cbs.nl. landsurface Netherlands [Internet]. Available from: http://statline.cbs.nl/Statweb/publication/?DM=SLNL\&PA=70262ned\&D1=0-2\&D2=0-4\&D3=3$7 \& \mathrm{VW}=\mathrm{T}$

2. www.cbs.nl. population Netherlands [Internet]. Available from: http://statline.cbs.nl/Statweb/publication/?DM=SLNL\&PA=37296ned\&D1=0-2,19-28,52$58,68 \& D 2=0,10,20,30,40,50,(1-1)-1 \& V W=T$

3. www.cbs.nl. livestock Netherlands [Internet]. Available from: http://statline.cbs.nl/Statweb/publication/?DM=SLNL\&PA=81302NED\&D1=387536\&D2 $=0,5,10,13-16 \& H D R=G 1 \& S T B=T \& V W=T /$

4. Jones KE, Patel NG, Levy MA, Storeygard A, Balk D, Gittleman JL, et al. Global trends in emerging infectious diseases. Nature. 2008;451(7181):990-3.

5. Graveland H, Wagenaar J a., Bergs K, Heesterbeek H, Heederik D. Persistence of livestock associated MRSA CC398 in humans is dependent on intensity of animal contact. PLoS One. 2011;6(2):1-7.

6. Wielders $\mathrm{CCH}$, van Hoek AHAM, Hengeveld PD, Veenman C, Dierikx CM, Zomer TP, et al. Extendedspectrum $\beta$-lactamase- and $\mathrm{PAmpC}$-producing Enterobacteriaceae among the general population in a livestock-dense area. Clin Microbiol Infect [Internet]. Elsevier Ltd; 2017;23(2):120.e1-120.e8. Available from: http://dx.doi.org/10.1016/j.cmi.2016.10.013

7. Hoek W Van Der, Morroy G, Renders NHM, Wever PC, Hermans MHA, Leenders ACAP, et al. Coxiella burnetii: Recent Advances and New Perspectives in Research of the Q Fever Bacterium [Internet]. 2012. 329-364 p. Available from: http://link.springer.com/10.1007/978-94-007-4315-1

8. Borlée F, Yzermans CJ, Van Dijk CE, Heederik D, Smit LAM. Increased respiratory symptoms in COPD patients living in the vicinity of livestock farms. Eur Respir J [Internet]. 2015;46(6):1605-14. Available from: http://dx.doi.org/10.1183/13993003.00265-2015

9. Freidl GS, Spruijt IT, Borlée F, Smit LAM, Van Gageldonk-Lafeber AB, Heederik DJJ, et al. Livestockassociated risk factors for pneumonia in an area of intensive animal farming in the Netherlands. PLoS One. 2017;12(3):1-16.

10. Smit LAM, Boender GJ, de Steenhuijsen Piters WAA, Hagenaars TJ, Huijskens EGW, Rossen JWA, et al. Increased risk of pneumonia in residents living near poultry farms: does the upper respiratory tract microbiota play a role? Pneumonia [Internet]. 2017;9(1):3. Available from: http://pneumonia.biomedcentral.com/articles/10.1186/s41479-017-0027-0

11. Klous G, Smit LAM, Borlée F, Coutinho RA, Kretzschmar MEE, Heederik DJJ, et al. Mobility assessment of a rural population in the Netherlands using GPS measurements. Int J Health Geogr [Internet]. BioMed Central; 2017;16(1):30. Available from: http://ijhealthgeographics.biomedcentral.com/articles/10.1186/s12942-017-0103-y

12. Borlée F, Yzermans CJ, Krop E, Aalders B, Rooijackers J, Zock JP, et al. Spirometry, questionnaire and electronic medical record based COPD in a population survey: Comparing prevalence, level of agreement and associations with potential risk factors. PLoS One. 2017;12(3):1-16.

13. Smit LAM, van der Sman-de Beer F, Opstal-van Winden AWJ, Hooiveld M, Beekhuizen J, Wouters IM, et al. Q fever and pneumonia in an area with a high livestock density: A large population-based study. PLoS One. 2012;7(6).

14. van Dijk CE, Zock JP, Baliatsas C, Smit LAM, Borlée F, Spreeuwenberg P, et al. Health conditions in rural areas with high livestock density: Analysis of seven consecutive years. Environ Pollut. 2017;222:374-82.

15. Lamberts H, Wood M. International Classification of Primary Care. Oxford University Press; 1987.

16. Huss A, Beekhuizen J, Kromhout H, Vermeulen R. Using GPS-derived speed patterns for recognition of transport modes in adults. Int J Health Geogr [Internet]. 2014;13(1):40. Available from: http://www.pubmedcentral.nih.gov/articlerender.fcgi?artid=4320483\&tool=pmcentrez\&renderty pe=abstract \nhttp://ij-healthgeographics.biomedcentral.com/articles/10.1186/1476-072X-13-40

17. Noord-Brabant. BVB Brabant [Internet]. Available from: http://bvb.brabant.nl/

18. Limburg. BVB Limburg. Available from: http://www.limburg.nl/

19. www.wur.nl. Poultry sector Netherlands [Internet]. Available from: http://www.wur.nl/nl/artikel/Kort-overzicht-economisch-belang-Nederlandse-pluimveesector.htm

20. Hussain-Yusuf H, Islam A, Healy B, Lockhart M, Nguyen C, Sukocheva O, et al. An analysis of Q fever patients 6 years after an outbreak in Newport, Wales, UK. Qjm. 2012;105(11):1067-73. 
21. Marmion BP, Sukocheva O, Storm PA, Lockhart M, Turra M, Kok T, et al. Q fever: Persistence of antigenic non-viable cell residues of Coxiella burnetii in the host - Implications for post $Q$ fever infection fatigue syndrome and other chronic sequelae. Qjm. 2009;102(10):673-84.

22. Raoult D, Marrie TJ, Mege JL. Natural history and pathophysiology of Q fever. Lancet Infect Dis. 2005;5(4):219-26.

23. Waag DM. Coxiella burnetii: Host and bacterial responses to infection. Vaccine. 2007;25(42):728895.

24. Keijmel SP, Raijmakers RPH, Bleeker-Rovers CP, van der Meer JWM, Netea MG, Schoffelen T, et al. Altered interferon- $\gamma$ response in patients with Q-fever fatigue syndrome. J Infect [Internet]. Elsevier Ltd; 2016;72(4):478-85. Available from: http://dx.doi.org/10.1016/j.jinf.2016.01.004

25. Hatchette TF, Hayes M, Merry H, Schlech WF, Marrie TJ. The effect of $C$. burnetii infection on the quality of life of patients following an outbreak of $Q$ fever. Epidemiol Infect [Internet]. 2003;130(3):491-5. Available from:

http://www.pubmedcentral.nih.gov/articlerender.fcgi?artid=2869986\&tool=pmcentrez\&renderty pe $=$ abstract

26. Morroy G, Peters JB, Van Nieuwenhof M, Hj Bor H, Hautvast J La, Van Der Hoek W, et al. The health status of Q-fever patients after long- term follow-up. BMC Infect Dis [Internet]. BioMed Central Ltd; 2011;11(1):97. Available from: http://www.biomedcentral.com/1471-2334/11/97

27. Rodolakis A. Zoonoses in goats: How to control them. Small Rumin Res [Internet]. Elsevier B.V.; 2014;121(1):12-20. Available from: http://dx.doi.org/10.1016/j.smallrumres.2014.01.007

28. Meijer A, Brandenburg A, De Vries J, Beentjes J, Roholl P, Dercksen D. Chlamydophila abortus infection in a pregnant woman associated with indirect contact with infected goats. Eur J Clin Microbiol Infect Dis. 2004;23(6):487-90.

29. Mohamed RA, Abdelsalam EB. A Review on Pneumonic Pasteurellosis (Respiratory Mannheimiosis) With Emphasis on Pathogenesis, Virulence Mechanisms and Predisposing Factors. Bulg J Vet Med. 2008;11(3):139-60.

30. Kallio-Kokko H, Uzcategui N, Vapalahti O, Vaheri A. Viral zoonoses in Europe. FEMS Microbiol Rev. 2005;29(5):1051-77.

31. Li W, Mao L, Cheng S, Wang Q, Huang J, Deng J, et al. A novel parainfluenza virus type 3 (PIV3) identified from goat herds with respiratory diseases in eastern China. Vet Microbiol [Internet]. Elsevier B.V.; 2014;174(1-2):100-6. Available from: http://dx.doi.org/10.1016/j.vetmic.2014.08.027

32. Libshitz I. Aspergillosisand Mucormycosis : Two Types of Opportunistic Fungal. 1981;301-6.

33. Hogerwerf L, Borlée F, Still K, Heederik D, van Rotterdam B, de Bruin A, et al. Detection of Coxiella burnetii DNA in inhalable airborne dust samples from goat farms after mandatory culling. Appl Environ Microbiol. 2012;78(15):5410-2.

34. van den Brom R, Schimmer B, Schneeberger PM, Swart W a., van der Hoek W, Vellema P. Seroepidemiological Survey for Coxiella burnetii Antibodies and Associated Risk Factors in Dutch Livestock Veterinarians. PLoS One. 2013;8(1):1-5.

35. Cheng MF, Ho SC, Chiu HF, Wu TN, Chen PS, Yang CY. Consequences of exposure to Asian dust storm events on daily pneumonia hospital admissions in Taipei, Taiwan. J Toxicol Environ Heal Part A Curr Issues. 2008;71(19):1295-9.

36. Brauer M, Hoek G, Van Vliet P, Meliefste K, Fischer PH, Wijga A, et al. Air pollution from traffic and the development of respiratory infections and asthmatic and allergic symptoms in children. Am J Respir Crit Care Med. 2002;166(8):1092-8.

37. Netherlands Government. Livestock finedust [Internet]. Available from: https://www.rijksoverheid.nl/onderwerpen/luchtkwaliteit/documenten/publicaties/2017/03/15/e missiefactoren-fijn-stof-voor-veehouderij-2017

38. Benincà E, Van Boven M, Hagenaars T, Van Der Hoek W. Space-time analysis of pneumonia hospitalisations in the Netherlands. PLoS One. 2017;12(7):1-14.

39. Cirulli ET, Goldstein DB. Uncovering the roles of rare variants in common disease through wholegenome sequencing. Nat Rev Genet [Internet]. Nature Publishing Group; 2010;11(6):415-25. Available from: http://www.nature.com/doifinder/10.1038/nrg2779

40. Köser CU, Ellington MJ, Cartwright EJP, Gillespie SH, Brown NM, Farrington M, et al. Routine Use of Microbial Whole Genome Sequencing in Diagnostic and Public Health Microbiology. PLoS Pathog. $2012 ; 8(8)$. 
41. Ray S, Reddy PJ, Jain R, Gollapalli K, Moiyadi A, Srivastava S. Proteomic technologies for the identification of disease biomarkers in serum: Advances and challenges ahead. Proteomics. 2011;11(11):2139-61.

42. Zhang Z, Kermekchiev MB, Barnes WM. Direct DNA Amplification from Crude Clinical Samples Using a PCR Enhancer Cocktail and Novel Mutants of Taq. J Mol Diagnostics [Internet]. American Society for Investigative Pathology and Association for Molecular Pathology; 2010;12(2):152-61. Available from: http://linkinghub.elsevier.com/retrieve/pii/S1525157810600438

43. Bieleman J. Boeren in Nederland, geschiedenis van de landbouw 1500-2000. Amsterdam; 2008.

44. de Rooij MMT, Heederik DJJ, Borlée F, Hoek G, Wouters IM. Spatial and temporal variation in endotoxin and PM10 concentrations in ambient air in a livestock dense area. Environ Res [Internet]. Elsevier; 2017;153(September 2016):161-70. Available from:

http://dx.doi.org/10.1016/j.envres.2016.12.004

45. Klous G, Huss A, Heederik DJJ and Coutinho RA. Human-livestock contacts and their relationship to transmission of zoonotic pathogens, a systematic review of literature. One Health 2 (2016) 65-76. Available from: http://dx.doi.org/10.1016/j.onehlt.2016.03.001 


\section{Supplementary data}

Supp. Table 1 Comparison study population VGO GPS study versus the full VGO study population.

\begin{tabular}{|c|c|c|c|c|}
\hline Variable & & VGO GPS study & VGO study & P-value \\
\hline Number of participants $(\mathrm{N}=)$ & & 941 & 2426 & n.a. \\
\hline Pneumonia cases $(\mathrm{N}=(\%))$ & & $83(9 \%)$ & $186(8 \%)$ & 0.30 \\
\hline Age (years) (mean (range)) & & $57(20-72)$ & $57(20-72)$ & 0.09 \\
\hline Gender (females (\%)) & & $518(55 \%)$ & $1314(54 \%)$ & 0.67 \\
\hline \multirow[t]{3}{*}{ Education $(\mathrm{N}=(\%))$} & Low & $232(25 \%)$ & $629(26 \%)$ & 0.75 \\
\hline & Medium & $424(45 \%)$ & $1075(44 \%)$ & \\
\hline & High & $285(30 \%)$ & $722(30 \%)$ & \\
\hline \multirow[t]{4}{*}{ Smoking $(\mathrm{N}=(\%))$} & Never & $377(40 \%)$ & $1016(42 \%)$ & 0.13 \\
\hline & Former & $487(52 \%)$ & $1168(48 \%)$ & \\
\hline & Current & $74(8 \%)$ & $224(9 \%)$ & \\
\hline & No data & $3(0.3 \%)$ & $18(0.7 \%)$ & \\
\hline \multirow[t]{3}{*}{ Goats near home $(\mathrm{N}=(\%))$} & Within 50om & $26(3 \%)$ & $42(2 \%)$ & $<0.01$ \\
\hline & Within 100om & $116(12 \%)$ & $223(9 \%)$ & \\
\hline & No goats & $799(85 \%)$ & $2161(89 \%)$ & \\
\hline \multirow[t]{3}{*}{ Poultry near home $(\mathrm{N}=(\%))$} & Within 50om & $151(16 \%)$ & $354(15 \%)$ & 0.03 \\
\hline & Within 100om & $416(44 \%)$ & $986(41 \%)$ & \\
\hline & No poultry & $374(39 \%)$ & $1086(45 \%)$ & \\
\hline
\end{tabular}

$\mathrm{P}$-value were calculated with t-test for age, and Chi-squared tests of independence for all other variables.

Supp. Table 2 Animal numbers used as cut-off for sensitivity analyses based on animal intensity. Cut-off for 'low' category is based on the cut-off we applied in the main analyses, where 50 goats or 250 poultry were used as animal numbers to indicate farms, for this analysis we also wanted to include lower animal numbers as exposure sources. 'Medium' category is based on the previous cut-off and the median animal numbers where people were exposed to in the analyses. 'High' is the category that includes median to maximum number of animals where people were exposed to. This method was applied to specific animal species and distances, therefore cut-off-values for the medium and high category vary between the different animal species and distances.

\begin{tabular}{l|lllll}
\multicolumn{2}{l}{ Goats } & \multicolumn{4}{l}{ Poultry } \\
\hline Category & $\begin{array}{l}\text { Within 50om of } \\
\text { home address }\end{array}$ & $\begin{array}{l}\text { Within 1000m of } \\
\text { home address }\end{array}$ & $\begin{array}{l}\text { Within 50om of } \\
\text { home address }\end{array}$ & $\begin{array}{l}\text { Within 1000m of } \\
\text { home address }\end{array}$ \\
\hline Reference & 0 & 0 & 0 & 0 \\
Low & $1-49$ & $1-49$ & $1-249$ & $1-249$ \\
Medium & $50-1,658$ & $50-383$ & $250-13,479$ & $250-37,159$ \\
High & $>1,659$ & $>384$ & $>13,480$ & $>37,160$ \\
& $(\max 3,250)$ & $(\max 5,015)$ & $(\max .290,600)$ & $($ max. 694,900)
\end{tabular}




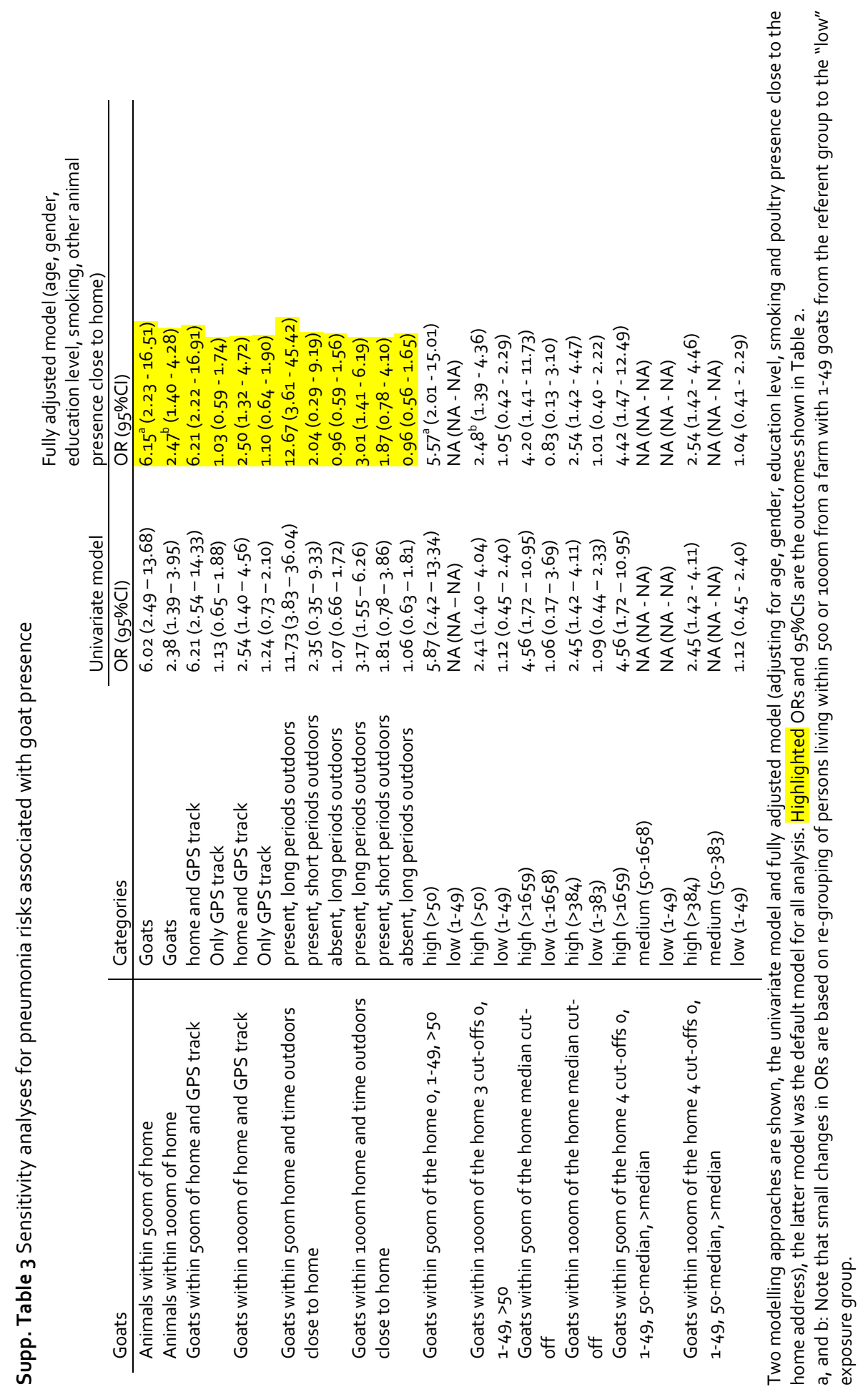




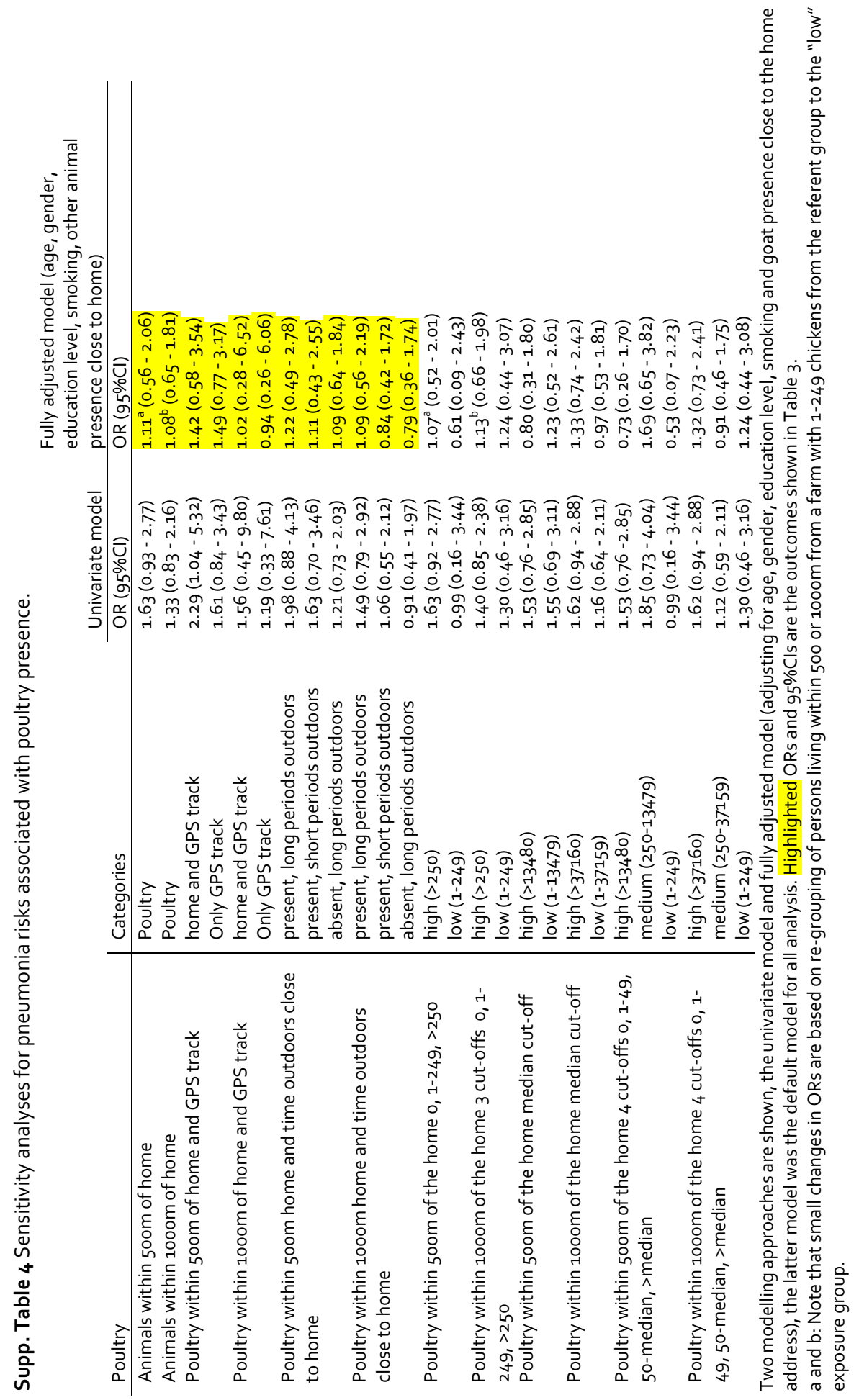



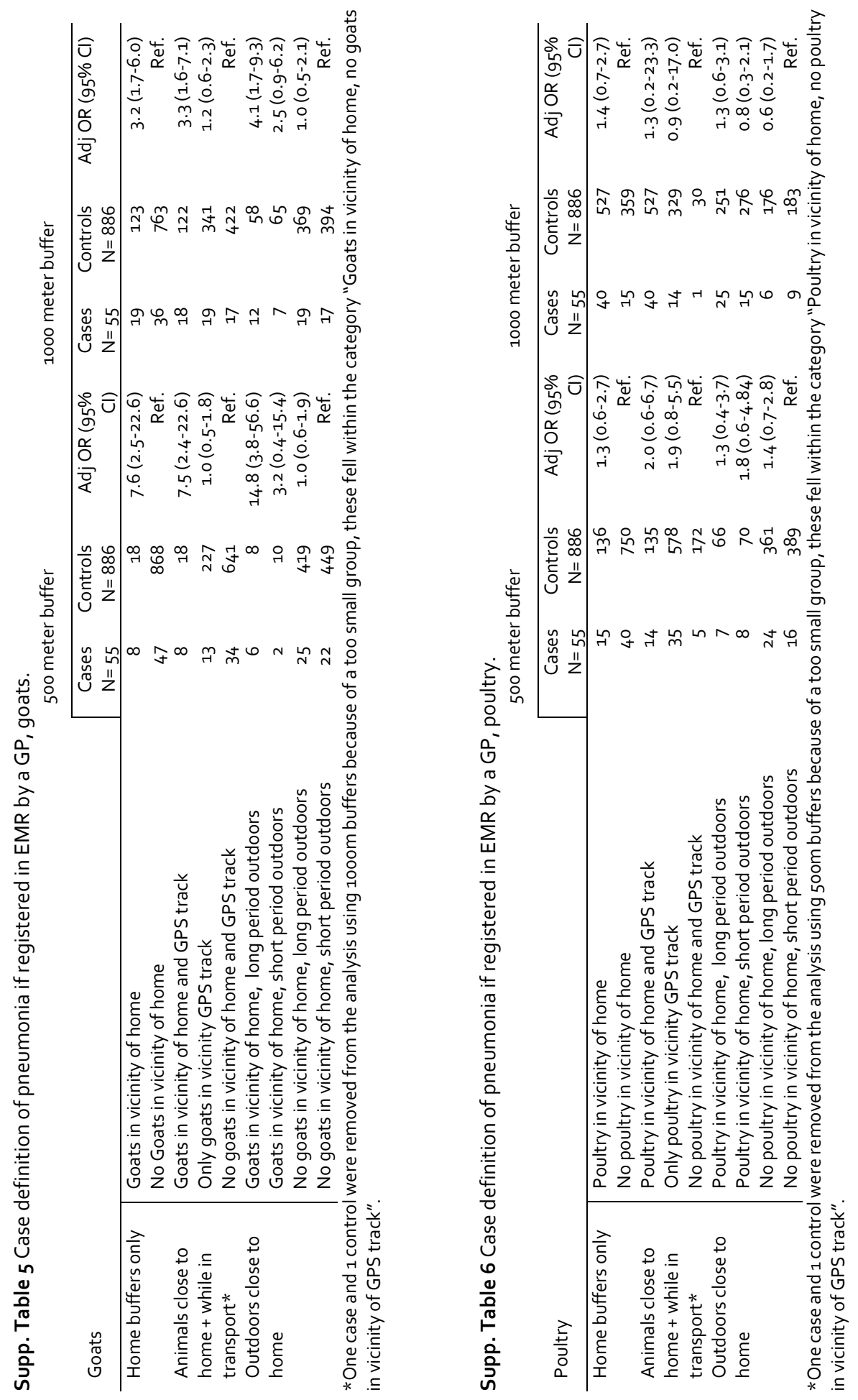


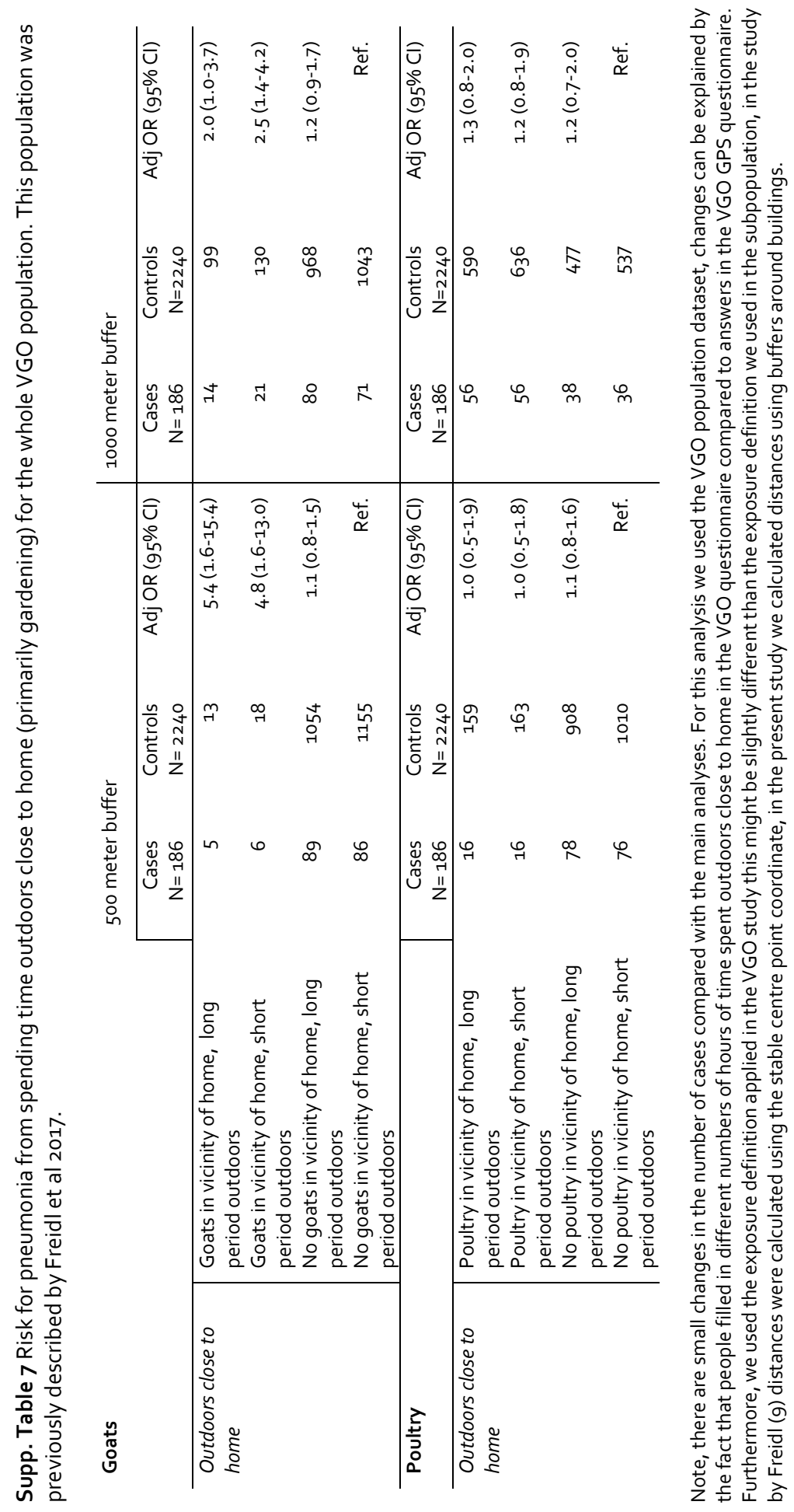


Supp. Table 8 Durations of time spent in active transport with animals within close distance.

\begin{tabular}{l|l}
\multicolumn{1}{l}{ Animals within distance } & \multicolumn{1}{l}{$\begin{array}{l}\text { Mean (range) hours per week exposed while in active } \\
\text { transport (walking, biking combined) }\end{array}$} \\
\hline Goats 500m of GPS track & $0.1(0-2.0)$ \\
Goats 100om of GPS track & $0.4(0-9.6)$ \\
Poultry 50om of GPS track & $0.5(0-6.6)$ \\
Poultry 1000m of GPS track & $1.4(0-36.7)$
\end{tabular}

Supp. Table 9 average dust emissions for farms within the research area with specific animal types.

\begin{tabular}{lllll}
$\begin{array}{l}\text { Animals } \\
\text { type }\end{array}$ & $\begin{array}{l}\text { Used variable } \\
\text { (Table } \\
\text { government) }\end{array}$ & $\begin{array}{l}\text { Dust emission per } \\
\text { animal (g/animal/year) }\end{array}$ & $\begin{array}{l}\text { Average farm } \\
\text { size in research } \\
\text { area }\end{array}$ & $\begin{array}{l}\text { Average dust } \\
\text { emission in research } \\
\text { area (kg/farm/year) }\end{array}$ \\
\hline Goat & C 1.100 & 19 & 653 goats & 12.4 \\
Poultry & E 5.100 & 22 & 41270 poultry & 907.9 \\
Cattle & A 1.2 .2 & 148 & 183 cattle & 27.1 \\
Pigs & D 1.2.100 & 160 & 2375 pigs & 380.0
\end{tabular}

Supp. Table 10 Comparison people invited to the VGO GPS study versus VGO participants that were not invited.

\begin{tabular}{|c|c|c|c|c|}
\hline Variable & & $\begin{array}{l}\text { Invitees } \\
\text { VGO GPS study }\end{array}$ & Non-invitees & P-value \\
\hline Number of participants $(\mathrm{N}=)$ & & 1517 & 909 & n.a. \\
\hline Pneumonia cases $(\mathrm{N}=(\%))$ & & $128(8 \%)$ & $58(6 \%)$ & 0.08 \\
\hline Age (years) (mean (range)) & & $57(20-72)$ & $57(21-72)$ & 0.83 \\
\hline Gender (females (\%)) & & $823(54 \%)$ & $491(54 \%)$ & 0.94 \\
\hline \multirow[t]{3}{*}{ Education $(\mathrm{N}=(\%))$} & Low & $386(25 \%)$ & $243(27 \%)$ & 0.60 \\
\hline & Medium & $684(45 \%)$ & $391(43 \%)$ & \\
\hline & High & $447(29 \%)$ & $275(30 \%)$ & \\
\hline \multirow[t]{4}{*}{ Smoking $(N=(\%))$} & Never & $636(42 \%)$ & $380(42 \%)$ & 0.75 \\
\hline & Former & $736(49 \%)$ & $432(48 \%)$ & \\
\hline & Current & $133(9 \%)$ & $91(10 \%)$ & \\
\hline & No data & $12(0.7 \%)$ & $6(0.7 \%)$ & \\
\hline \multirow[t]{3}{*}{ Goats near home $(\mathrm{N}=(\%))$} & Within $500 \mathrm{~m}$ & $37(2 \%)$ & $5(0.6 \%)$ & $<0.01$ \\
\hline & Within 100om & $178(12 \%)$ & $45(5 \%)$ & \\
\hline & No goats & $1302(86 \%)$ & $859(94 \%)$ & \\
\hline \multirow[t]{3}{*}{ Poultry near home $(\mathrm{N}=(\%))$} & Within 50om & $225(15 \%)$ & $120(13 \%)$ & $<0.01$ \\
\hline & Within 100om & $658(43 \%)$ & $328(36 \%)$ & \\
\hline & No poultry & $632(42 \%)$ & $454(50 \%)$ & \\
\hline
\end{tabular}

P-value were calculated with t-test for age, and Chi-squared tests of independence for all other variables.

The general characteristics and numbers of cases and controls did not differ significantly between the invited and the non-invited part of the VGO cohort. However, there is a significant difference in group sizes of exposed participants. The group of non-invited people also included people that were invited to the COPD follow-up study. Borlée et al (2015) previously showed that VGO cohort members with COPD complaints lived less often in the vicinity of farms [8], this might be the explanation for this observed difference. 
Supp. Table 11 non-responder analysis.

\begin{tabular}{|c|c|c|c|c|}
\hline \multicolumn{2}{|l|}{ Variable } & Participant & Non-responder & P-value \\
\hline \multicolumn{2}{|l|}{ Number of participants $(\mathrm{N}=)$} & 1014 & 503 & n.a. \\
\hline \multicolumn{2}{|l|}{ Pneumonia cases $(\mathrm{N}=(\%))$} & $89(9 \%)$ & $39(8 \%)$ & 0.56 \\
\hline \multicolumn{2}{|l|}{ Age (years) (mean (range)) } & $57(20-72)$ & $55(20-72)$ & 0.01 \\
\hline \multicolumn{2}{|l|}{ Gender (females (\%)) } & $554(55 \%)$ & $269(53 \%)$ & 0.71 \\
\hline \multirow[t]{3}{*}{ Education $(\mathrm{N}=(\%))$} & Low & $254(25 \%)$ & $132(26 \%)$ & 0.68 \\
\hline & Medium & $454(45 \%)$ & $230(46 \%)$ & \\
\hline & High & $306(30 \%)$ & $141(28 \%)$ & \\
\hline \multirow[t]{4}{*}{ Smoking $(N=(\%))$} & Never & $413(41 \%)$ & $223(44 \%)$ & 0.02 \\
\hline & Former & $516(51 \%)$ & $220(44 \%)$ & \\
\hline & Current & $79(8 \%)$ & $54(11 \%)$ & \\
\hline & No data & $6(<0.01 \%)$ & $6(0.01 \%)$ & \\
\hline \multirow[t]{3}{*}{ Goats near home $(\mathrm{N}=(\%))$} & Within 50om & $27(3 \%)$ & $10(2 \%)$ & 0.48 \\
\hline & Within $1000 \mathrm{~m}$ & $124(12 \%)$ & $54(11 \%)$ & \\
\hline & No goats & $863(85 \%)$ & $439(87 \%)$ & \\
\hline \multirow[t]{3}{*}{ Poultry near home $(\mathrm{N}=(\%))$} & Within 50om & $156(15 \%)$ & $69(14 \%)$ & 0.18 \\
\hline & Within 100om & $451(44 \%)$ & $207(41 \%)$ & \\
\hline & No poultry & $405(40 \%)$ & $227(45 \%)$ & \\
\hline \multicolumn{5}{|c|}{ P-value were calculated with t-test for age, and Chi-squared tests of independence for all other variables. } \\
\hline
\end{tabular}



Chapter 5

Prediction of human active mobility in rural areas: development and validity tests of three different approaches

Journal of Exposure Science and Environmental Epidemiology (2019) Gijs Klous, Mirjam Kretzschmar, Roel Coutinho, Dick Heederik en Anke Huss 


\section{Prediction of human active mobility in rural areas: development and validity tests of three different approaches}

Background: Active mobility may play a relevant role in the assessment of environmental exposures (e.g. traffic-related air pollution, livestock emissions), but data about actual mobility patterns are work intensive to collect, especially in large study populations, therefore estimation methods for active mobility may be relevant for exposure assessment in different types of studies. We previously collected mobility patterns in a group of 941 participants in a rural setting in the Netherlands, using weeklong GPS tracking. We had information regarding personal characteristics, self-reported data regarding weekly mobility patterns and spatial characteristics. The goal of this study was to develop versatile estimates of active mobility, test their accuracy using GPS measurements and explore the implications for exposure assessment studies.

Method: We estimated hours/week spent on active mobility based on personal characteristics (e.g. age, sex, pre-existing conditions), self-reported data (e.g. hours spent commuting per bike) or spatial predictors such as home and work address. Estimated hours/week spent on active mobility were compared with GPS measured hours/week, using linear regression and kappa statistics.

Results: Estimated and measured hours/week spent on active mobility had low correspondence, even the best predicting estimation method based on self-reported data, resulted in a $\mathrm{R}^{2}$ of 0.09 and Cohen's kappa of 0.07. A visual check indicated that, although predicted routes to work appeared to match GPS-measured tracks, only a small proportion of active mobility was captured in this way, thus resulting in a low validity of overall predicted active mobility.

Conclusions: We were unable to develop a method that could accurately estimate active mobility, the best performing method was based on detailed self-reported information but still resulted in low correspondence. For future studies aiming to evaluate the contribution of home-work traffic to exposure, applying spatial predictors may be appropriate. Measurements still represent the best possible tool to evaluate mobility patterns. 


\section{Introduction}

Environmental epidemiological studies aim at evaluating risks to human health from environmental exposures [1], examples of environmental exposures are for instance; ultrafine particles of air pollution [2], electromagnetic fields [3] or livestock-associated emissions.[4] Personal exposure in environmental health studies is often approximated by assigning or measuring exposure levels at a single location, usually the home address. The fact that people are mobile is often ignored. Active mobility, using only physical activity for locomotion (in this study walking and biking), may affect exposure of persons to different environmental substances, especially if exposure levels display strong spatial, or spatio-temporal variation.[5-9] Examples include: exposure to traffic related air pollution near roads [10], but also exposure expected to be beneficial to health, such as time near urban green space during daily mobility.[11] Ignoring (active-) mobility may therefore increase misclassification of exposure and thus change measures of association.[12] In general, misclassification usually biases risk estimates towards the null, in particular when misclassification is non-differential, meaning that true effects may remain unobserved.[13]

Detailed self-reported data on (active-) mobility has been infrequently collected in previous studies, partly because collecting this type of information is laborious for participants, especially when using activity diaries.[14] Furthermore, data quality, in particular responder bias, is an issue of concern. In a previous study we found that study participants strongly overestimated their time spent on active mobility when compared with GPS-measured data.[15] Collecting outdoor activity data using GPS loggers or mobile phones is only sometimes performed, or performed in smaller subpopulations, due to associated costs and work time. $[7,8,10,11,14,16-24]$ Several studies have reported that underlying general characteristics of study participants may explain part of observed variability in mobility patterns. $[15,25-27)$

Because measuring mobility patterns is challenging, other methods have been based on location information using Geographic Information Systems (GIS). Such GIS based methods have been used for example to assess exposure experienced during commutes on commonly used routes (e.g. home to work, home to school). $[10,11,16,20,21]$ When GIS based methods were applied, the predicted routes can be validated using GPS logging. Such validation efforts were generally performed in smaller study populations ( $\max N=175)[10,11,16,20,21]$ and results of these analyses vary in the sense that estimated and measured exposure may [16], or may not show correspondence. $[10,11,20,21]$

The goal of this study was to design different methods to estimate active mobility based on available data in a study cohort, namely general characteristics, self-reported data and location information. All data was available from the VGO GPS study and in a second step we validate our approaches using GPS measurements originating from this study. Finally, we discuss the implications of these approaches for exposure assessment studies. 


\section{Methods}

\section{Study population}

In 2012 the "Farming and Neighbouring Residents' Health" study (Dutch acronym: VGO study) was initiated. The focus of the VGO study was on the health of non-farming resident's living in an area with a high density of livestock farms (Supp. Figure 1). For this study 2494 people volunteered to undergo a medical examination (lung function measurements, blood, nasal- and buccal-epithelia collection, stool sample) in a field study that took place in between March 2014 and February 2015. Participants were also asked to fill in a baseline questionnaire (VGO questionnaire), including questions about participant characteristics, health and lifestyle.[28,29] Farmers and people living on farms were excluded a priori from the VGO study, since the focus was on health of nonfarming residents.

From the VGO population a representative subgroup [30] was recruited to take part in the VGO GPS study. Initially 1517 VGO cohort members were invited, 67\% participated in the GPS study, resulting in 1014 logged GPS tracks. After GPS data cleaning, 941 usable GPS tracks remained for further analysis, with a median of 186 hours of GPS data logged.[30] Participants in the VGO GPS study filled in a mobility baseline questionnaire (Q1). For each VGO GPS study participant information was available on employment status, the nature of work activities and the home and work address (if applicable) from the VGO questionnaire. Medical Ethical approval was obtained for the VGO study from the Medical Ethical Committee of the University Medical Centre Utrecht (protocol number 13/533), and all participants provided informed consent.

\section{Estimation method development}

We developed three estimation methods to predict time spent in active mobility, all based on different types of determinants. We predicted the number of hours/week spent on active mobility and compared intra-individually with GPS measured hours/week spent on active mobility. The aim of our first estimation method (Estimation method 1) was to develop a regression model that could be broadly applied in environmental epidemiology. In order to predict active mobility, we used individual general characteristics of study participants. The method makes use of previously identified determinants of GPS measured movement patterns in the VGO GPS study population.[15] The following determinants were identified: age group ( $<45 \mathrm{y}, 45-55 \mathrm{y}$, $55-65 y$ and $>65 y$ ), BMl (normal weight $\left[<25 \mathrm{~kg} / \mathrm{m}^{2}\right]$, overweight $\left[25-30 \mathrm{~kg} / \mathrm{m}^{2}\right]$, obese $\left[>30 \mathrm{~kg} / \mathrm{m}^{2}\right]$ ), smoking status (never, former, current), working status (job yes/no), hay fever (yes/no) and number of workdays (N/week from $\mathrm{Q}_{1}$ ). Using these determinants, we calculated per participant (see supp. table 1) the expected hours/week spent on active mobility. For an overview of the applied calculations and formulas see supplementary data (Estimation method 1).

For our second estimation method (Estimation method 2) we used adjusted selfreported data regarding mobility patterns from questionnaire data of the VGO GPS study. In this questionnaire, participants were asked to report weekly mobility. Items in this questionnaire included time spent for commuting, during work hours, during leisure time and as outdoor activity (see supplement Estimation method 2 for an overview of used questions as input for this method). Walking and biking were assessed separately 
and subsequently added, resulting in a total of hours/week spent biking and walking. From our previous study we knew that VGO GPS study participants strongly overestimated their time spent on mobility (walking, biking and motorised).[15] We therefore adjusted the calculated weekly hours walking by $1 / 13.7$ and weekly hours biking by $1 / 2.8$, since these numbers represented the amount of overestimation of walking and biking, respectively.[15]

The third estimation method (Estimation method 3) made use of location information to predict weekly active mobility. For these type of estimations data regarding commonly visited locations (e.g. home, work, school) were necessary, which enabled calculation of commonly used routes. For every participant the home address and, if applicable, the work address was available. Addresses were geo-coded using cadastral data from the Netherlands (BAG data 2015). Information about supermarkets was obtained from the national information system on work locations (Dutch acronym: LISA, [31] 2017). Addresses and coordinates of all locations selling groceries within the research area were obtained and the closest shop was assigned to every individual home address.[32] Distance calculations were based on the road network from topographical maps (TOP10NL, [33] 2017).[34] For every participant the home address, assigned closest supermarket, and, if available, work address were selected and the shortest, road based, route was calculated in $\mathrm{km}$ (see Supp. Figure 1 for a visual example of the analysis).[35] Based on these distances, most likely transport modes were assigned using a recent representative survey from the Netherlands Ministry of Infrastructure and the Environment.[36] This survey reports distances travelled using specific transport modes. We used reported median distances, to indicate whether a used route was most likely travelled walking, (E-)biking or using motorised transport. In a next step, we calculated approximate durations spent in active transport using reported average speeds for these travel modes (see Supp. Table 2 for an overview of distance cut-offs and used average speeds). Since calculated routes were one-way, all estimated distances were multiplied by 2 . We assumed that people went to the supermarket once a week and for the route to work we multiplied with the number of workdays participants reported to work, see Supplementary Table 3 for an overview of this process.

Estimation methods compared with GPS measured hours/week spent on active mobility Processing of our GPS data has been described in detail previously.[15] In brief, we used an algorithm that assigned every logged point as either an indoors or outdoors point. Points assigned outdoors were grouped into episodes and for every episode a transport mode was assigned based on acceleration, deceleration and the 95th percentile of the maximum speed.[15,37] Each GPS coordinate was thus categorised into walking, biking or motorised transport and time spent per specific transport mode was extracted as hours/week.[15] The GPS measured times were here considered as 'gold-standard' and reference data.

\section{Statistical analysis}

For all estimation methods, we compared intra-individually whether GPS measured hours/week of active transport (e.g. hours/week walking and biking) correlated with the 
hours/week of active transport predicted for that specific participant. Linear regression was used to compare estimated hours/week with GPS measured hours/week.

Next to linear regression we compared GPS measured and predicted hours/week spent on active mobility on a categorical level using Cohen's kappa-analyses. Participants were indicated as 'high-', 'medium-' or 'low-' actively mobile based on tertiles for both estimated and GPS measured hours/week spent on active mobility.

\section{Sensitivity analyses}

We applied two sensitivity analyses to check for differences in specific groups. First, we reran the analyses, but stratified the dataset by age categories ( $<45 y, 45-55 y, 55-65 y$ and $>65 y$ [15]), since age is related to occupational status [38] and life situation [39] what might be related to differences in daily mobility. In the second sensitivity analysis we stratified based on reporting of a work address (Yes/No), since having a work address may explain the majority of weekly mobility, because of daily commuting and this is one of two driving factors in Estimation method 3.

All statistical analyses were performed using $\mathrm{R}$ (3.4.3.) and all GIS analyses were performed in ArcGIS ArcMap 10.5.1 (ESRI, Redlands, CA, USA) and automated using Python 2.7.

\section{Results}

Due to incomplete data (missing information for Estimation method 1, e.g. age, BMI, smoking status), data from 7 individuals was removed from the original 941 usable datasets. Therefore, analyses were performed with data of 934 people in the VGO GPS population. The average age of participants was 57 years (range 20-72 years) and $55 \%$ of participants were women, hay fever was reported by $18 \%$ of participants $(\mathrm{N}=163)$. Of participants, 33\% were of normal weight (BMI <25), 49\% overweight (BMI 25-30) and $19 \%$ were obese $(\mathrm{BMI}>30)$. Most participants were former smokers $(52 \%)$, a minority was a current smoker (8\%) and $40 \%$ had never smoked. Work participation was high, $68 \%$ indicated having a job, and the median number of workdays was 2 days/week (range 0-5 days/week) see Table 1 for an overview of population characteristics.

Table 1 Population characteristics

\begin{tabular}{|c|c|c|}
\hline \multicolumn{2}{|l|}{ Variable } & Variable \\
\hline \multicolumn{2}{|c|}{ Age, years (mean (range)) } & $57.3(20.4-72.0)$ \\
\hline \multicolumn{2}{|c|}{ Gender, female $(\mathrm{N},(\%))$} & $513(55.0 \%)$ \\
\hline \multirow[t]{3}{*}{ BMI } & Normal weight $\left[<25 \mathrm{~kg} / \mathrm{m}^{2}\right](\mathrm{N},(\%))$ & $305(32.7 \%)$ \\
\hline & Overweight $\left[25-30 \mathrm{~kg} / \mathrm{m}^{2}\right](\mathrm{N},(\%))$ & $455(48.8 \%)$ \\
\hline & Obese $\left[>30 \mathrm{~kg} / \mathrm{m}^{2}\right](\mathrm{N},(\%))$ & $173(18.5 \%)$ \\
\hline \multirow[t]{4}{*}{ Smoking } & $\operatorname{Never}\left(N_{1}(\%)\right)$ & $373(40.0 \%)$ \\
\hline & Former $(\mathrm{N},(\%))$ & $484(51.8 \%)$ \\
\hline & Current $(\mathrm{N},(\%))$ & $74(7.9 \%)$ \\
\hline & No data $(\mathrm{N},(\%))$ & $3(0.3 \%)$ \\
\hline \multicolumn{2}{|c|}{ Hayfever, yes $(\mathrm{N},(\%))$} & $163(17.5 \%)$ \\
\hline \multicolumn{2}{|c|}{ Work, yes $(\mathrm{N},(\%))$} & $631(67.5 \%)$ \\
\hline \multicolumn{2}{|c|}{ Workdays*, number (median (range)) } & $2(0-5)$ \\
\hline
\end{tabular}

*Information is provided for the whole study population and therefore does include zero values for those not working. 
Comparisons predicted versus GPS measured hours/week spent on active mobility Figure 1, shows boxplots of GPS measured and estimated hours/week spent on active mobility. Figures 2a-d display more detailed distributions of hours/week spent on active mobility, Figure 2b-d show the predictions from Estimation methods 1-3, respectively, Figure $2 a$ pertains to GPS measured hours/week spent on active mobility. From these distributions we observe that only Estimation method 2 (Figure 1 and Figure 2c) shows variation and a range in observed values that is similar to the GPS measured hours/week (Figure 1 and Figure 2a). The distributions of Estimation methods 1 and 3 (Figure $2 b$ and 2d) are not in line with the GPS measured spread and range of hours/week spent on active mobility (Figure 1 and Figure 2a). When we compared estimated and measured hours/week spent on active mobility using linear regression, the predicted and measured hours/week for Estimation method 2 showed low agreement $\left(R^{2}=0.09\right)$ (Figure 3). In line with the distribution plots, estimated hours/week spent on active mobility from Estimation methods 1 and 3 had a low agreement with GPS measured hours/week in the linear regression analyses, with $\mathrm{R}^{2}$ values of: 0.05 for Estimation method 1 (Figure 3) and $<0.01$ for Estimation method 3 (Figure 3). An overview of $\mathrm{R}^{2}$ values of the linear regression analyses and descriptions of the used input for the Estimation methods and the reference are provided in Table 2.

\section{GPS measured and estimated hours/week spent on active mobility}

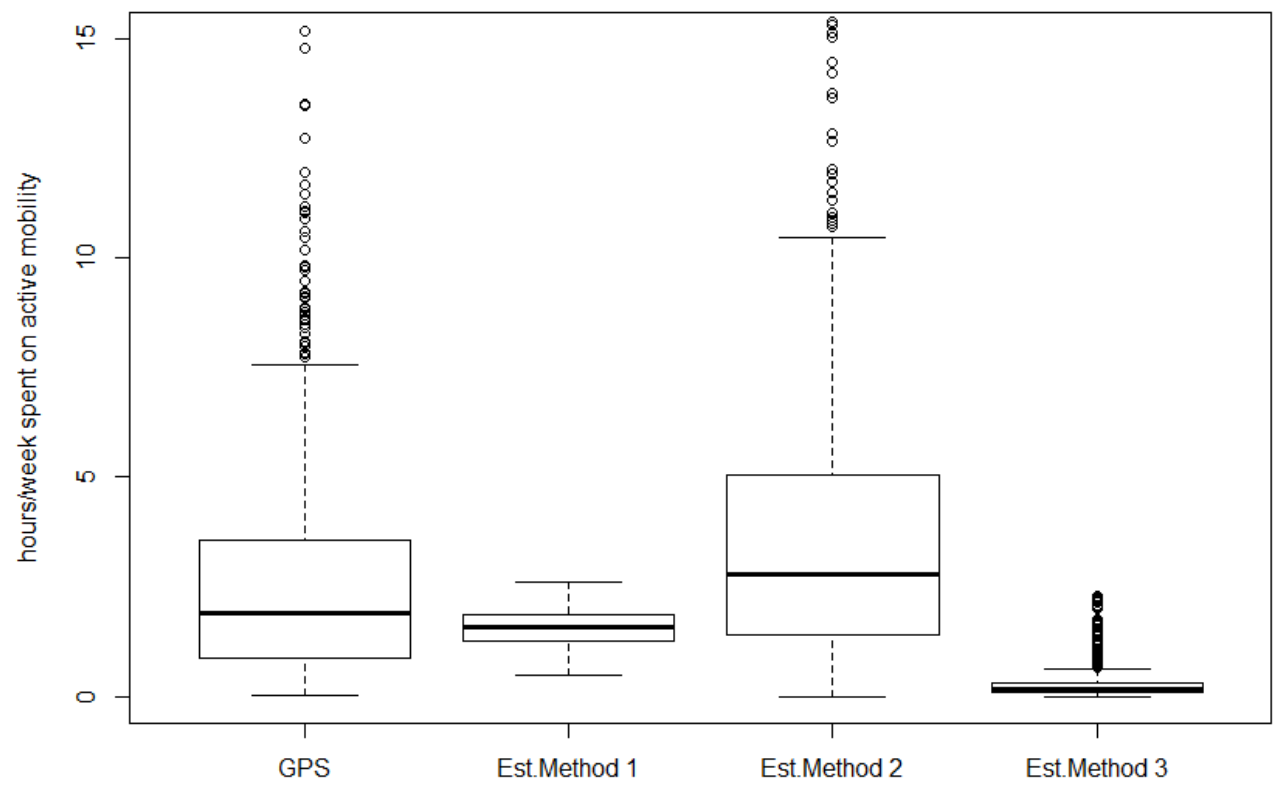

Figure 1. Boxplots of GPS measured and estimated hours/week spent on active mobility. Est. Method 1 is Estimation method 1, Est.Method 2 is Estimation method 2 and Est. Method 3 is Estimation method 3. We set the maximum Y-value to 15 hours/week to allow for a better visual comparison, therefore, outliers $>15$ hours/week are not visible in this plot. A boxplot with all outliers visible is available in Supp. Figure 2. 
Table 2 Description of input data for Estimation methods, GPS reference and $\mathrm{R}^{2}$ values

\begin{tabular}{|c|c|c|c|}
\hline Method & Input data & Reference & $\mathrm{R}^{2}$ \\
\hline 1 & $\begin{array}{l}\text { GMRs of explanatory variables from [15], for } \\
\text { non-motorised transport (age [categorical], BMI } \\
\text { [categorical], smoking status, working status, } \\
\text { hay fever, workdays [N/week]), estimates in } \\
\text { hours/week }\end{array}$ & \multirow[t]{3}{*}{$\begin{array}{l}\text { Combined GPS data of active } \\
\text { mobility: data assigned as } \\
\text { 'walking' and 'biking' by way of } \\
\text { an algorithm [15,37], outcomes } \\
\text { in hours/week }\end{array}$} & 0.05 \\
\hline 2 & $\begin{array}{l}\text { Adjusted reported data from } \mathrm{Q}_{1} \text {, correction } \\
\text { based on calculated overestimation from [15], } \\
\text { estimates in hours/week }\end{array}$ & & 0.09 \\
\hline 3 & $\begin{array}{l}\text { GIS network analyses of weekly time spent in } \\
\text { active transport, calculated using commuting } \\
\text { route and/or route to closest supermarket, } \\
\text { estimates in hours/week }\end{array}$ & & $<0.01$ \\
\hline
\end{tabular}

\section{Kappa analyses}

Cohen's kappa analyses showed a very low agreement between estimated and GPS measured hours/week spent on active mobility when participants were categorised into low, medium or high groups of active mobility, again the highest agreement was observed for Estimation method 2 (0.07). An overview of the used cut-offs and kappa statistics are given in Table 3.

Table 3 Kappa analysis of estimated and measured outcomes Cut-offs

\begin{tabular}{|c|c|c|c|c|c|}
\hline \multirow{2}{*}{$\begin{array}{l}\text { Estimation } \\
\text { Method }\end{array}$} & \multicolumn{2}{|l|}{ Estimation } & \multicolumn{2}{|c|}{ GPS Reference } & \multirow{2}{*}{$\begin{array}{l}\text { Kappa } \\
0.05\end{array}$} \\
\hline & $1^{\text {st }}$ Quantile & $3^{\text {rd }}$ Quantile & $1^{\text {st }}$ Quantile & $3^{\text {rd }}$ Quantile & \\
\hline 1 & $1.265 \mathrm{~h}$ & $1.87 \mathrm{oh}$ & \multirow{3}{*}{$0.877 \mathrm{~h}$} & \multirow{3}{*}{$3.567 \mathrm{~h}$} & 0.09 \\
\hline 2 & $1.387 \mathrm{~h}$ & $4.905 \mathrm{~h}$ & & & $<0.01$ \\
\hline 3 & o.ogoh & $0.329 \mathrm{~h}$ & & & 0.05 \\
\hline
\end{tabular}

\section{Sensitivity analyses}

We repeated all Estimation methods stratified for reported work address (yes and no) and for different previously determined age categories ( $\langle 45 y, 45-55 y, 55-65 y, 65 y\rangle)$. The stratified analyses did not result in material differences between the strata and were similar to calculations in the whole population. The stratified estimated hours/week spent on active mobility were in the same range as the estimated hours/week of the whole population and we observed a low agreement between estimated and measured values for both linear comparisons and kappa analyses. An overview of hours/week spent on active mobility of sensitivity analyses is provided in Supplementary Table 4.

\section{Discussion}

Active mobility may play a relevant role in exposure to spatially variable environmental substances, therefore, active mobility should be included in environmental exposure assessment models. Collecting active mobility data however, is challenging especially in large study populations. Therefore, to include active mobility data in exposure assessment in large populations, we developed estimation methods for active mobility 

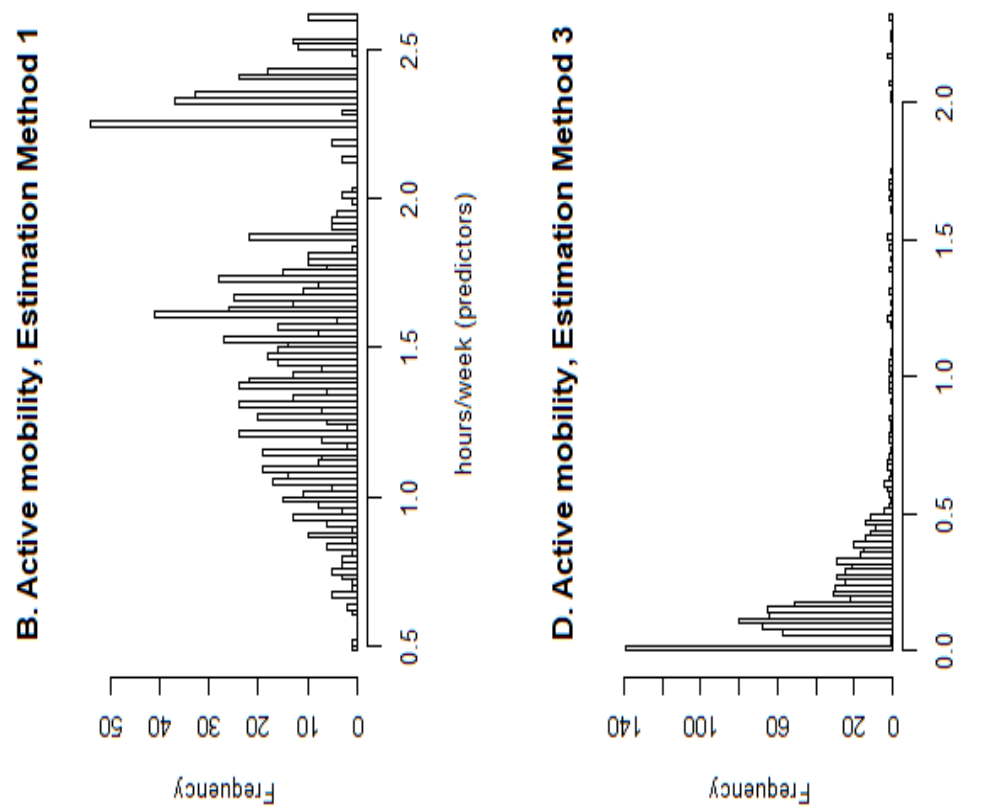

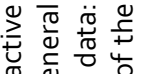
ᄃ 등으융 은도 둔 $\checkmark \stackrel{4}{0}$ ¿ उ을 ㄴ जั้ 으 흠 궁

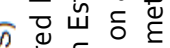
ए) जे ह 웡 『 ह ผ 의 훙 प $\frac{E}{0}$ 3 논 온 을 ह 힌ㄷㄴ 운든 ㄷํㅇ ํㅣㄹ ข) 认

월 은 鬲究 운 주오 응 خ记

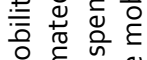
है
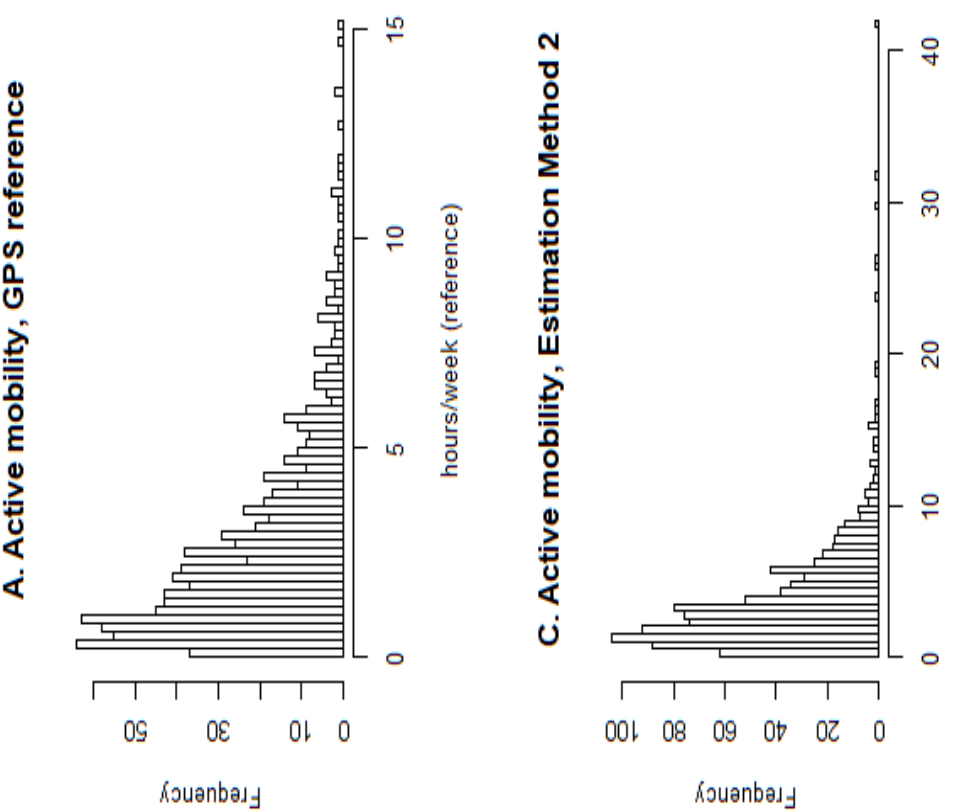

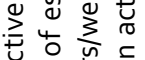
范 ㄷํㅇ 오 눙 $+\frac{1}{2}$ 这 ป ठ

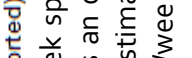
范皆这 这范

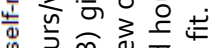
ต วิ 도 v $\frac{1}{0}+\frac{1}{0}$ ข 药 을 웅

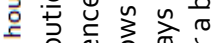
는 은 $\frac{0}{\circ}$ 는 入ิ 드의

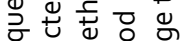

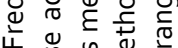

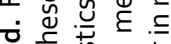

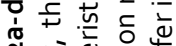

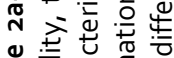

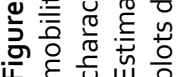




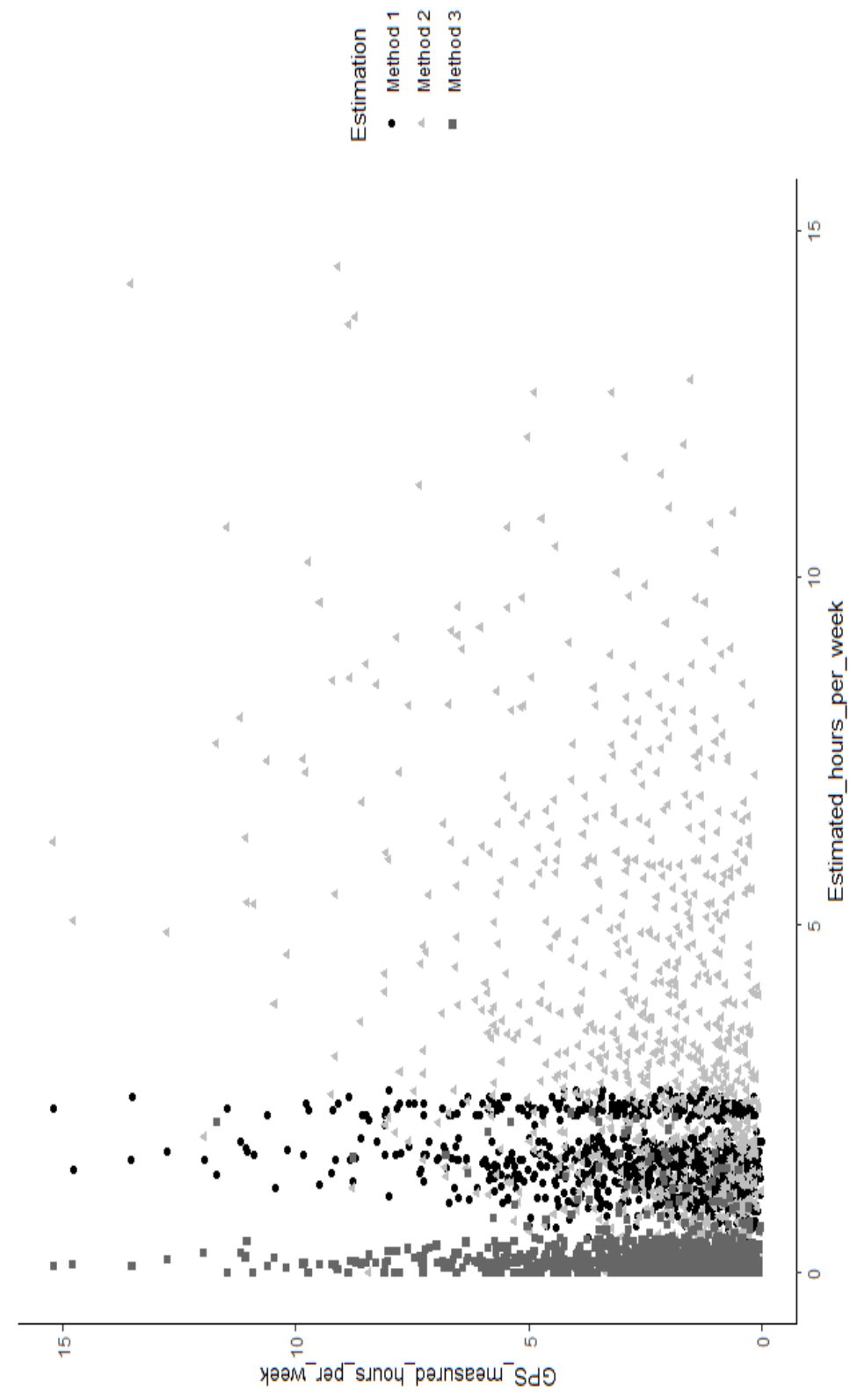

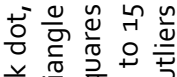

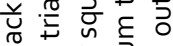

잉 खे

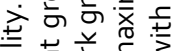

言节竞 ह

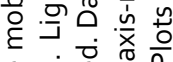

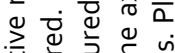

䓀

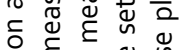

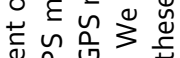

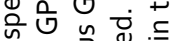

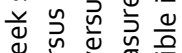

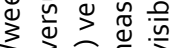

जे

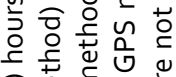

त $\varepsilon$ ज

×

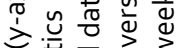

먼 혼 क्ष

屯웡

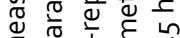

$\varepsilon$ 㛡

ñ

บ

둰

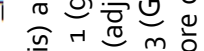

뭉

メ艺 울

ठ $\varepsilon$ \&

들 든 으음

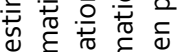

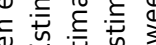

㟧出出

خ

인 인 운

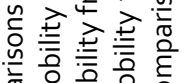

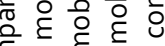

है

U.

రण

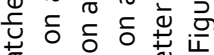

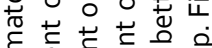

पे केष

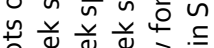

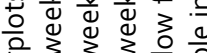

के

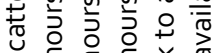

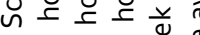

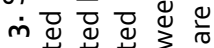

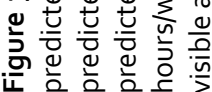


based on general characteristics, self-reported data and location information such as home and work address. Estimated hours/week spent on active mobility were compared with individually measured matching GPS data. We observed low agreement between estimated and GPS measured hours/week spent on active mobility for all three approaches.

\section{Estimation method 1, based on individual general characteristics}

Studies with a focus on mobility assessment often identify general characteristics that partially explain variability in mobility patterns. $[15,23,25-27]$ Therefore, we explored a method based on previously identified general characteristics (e.g. age, BMI, smoking status, workdays/week) related to variability in active mobility patterns in the VGO GPS study.[15] The spread and range of estimated hours/week spent on active mobility was not in line with GPS measured hours/week. This method showed low agreement between estimated and GPS measured hours/week spent on active mobility $\left(R^{2}=0.05\right.$, kappa $=0.05$ ). Although the factors used in Estimation method 1 explained some of the variation in mobility patterns, other factors such as transport mode preferences [26] and distances to often visited locations $[23,27]$, were not considered in our previous analysis.[15] The limited spread and range of the estimated hours/week are most likely an effect of the limited explained variability of the used determinants. Note that our estimation method likely overestimated explained variability, as the development and validation data set were identical.

\section{Estimation method 2, based on adjusted self-reported data}

The method based on adjusted self-reported data about active mobility represented the best estimate of hours/week spent on active mobility, when compared with GPS measured hours/week. Still, when compared intra-individually using linear regression and kappa analyses, we saw a low agreement between estimated and GPS measured hours/week spent on active mobility.

Self-reported data has long been considered as a standard method to obtain information about mobility in a population $[40,41]$ and has for example also been applied to improve exposure estimates to air pollution.[6] The information available from the mobility baseline questionnaire ( $\mathrm{Q}_{1}$ ) of the VGO GPS study, was relatively extensive. From 934 participants we had detailed self-reported mobility data and a GPS dataset.[30] Essential for this method is reliable questionnaire data regarding active mobility, however, correctly estimating time spent on mobility is difficult for participants leading to reporting errors. $[14,15,19,42]$ We tried to adjust reporting error by applying a correction factor based on previous research, to correct for the previously observed overestimation [15], but this adjustment did not materially improve agreement between self-reports and measurements.

Recently, a new approach was tested, namely map-based questionnaires (MBQ's) which seem to provide a new, possibly inexpensive method to assess mobility in large study populations. MBQ's showed high agreement between GPS measured and MBO indicated activity locations.[24] So far, it remains unclear if assessment of activity locations can be expanded to evaluate time spent in active transport in a valid way. 


\section{Estimation method 3, GIS based approach}

More recent attempts target location-based GIS analyses to include mobility data in exposure assessment approaches.[10,11,16] Our GIS based method used the residential address, the location of the closest supermarket, and, if available, the work address to calculate the shortest routes between these locations. Based on route lengths, people were assigned to a likely mobility mode and duration of time spent in active transport was calculated.[37,43] Several underlying reasons may contribute to the poor performance of this approach:

Firstly, we used specific route length cut-offs (<0.5km: walking, $0.5-2.5 \mathrm{~km}$ : bike, 2.5 $3.7 \mathrm{~km}$ : E-bike, adapted from [36]), to assign most likely mobility modes. Misclassification may occur by performing this step. Median travel distances for mobility modes were based on a recent survey, which were used as cut-offs in our analyses. When we repeated our analysis using the $75^{\text {th }}$-percentile instead of medians, this did not improve the fit of the estimation (data not shown).

Secondly, this last method was developed using only the residential address, closest supermarket, and, if available, the work address. GIS can be used to estimate shortest routes between locations, and GIS calculated routes tend to estimate travelling distance correctly when compared to actual-(GPS-) measured-routes. $[10,20,21]$ This was indeed what we observed when we visually compared a sample of estimated commuting routes with matching GPS tracks. What also followed from this check was that peoples' activities display a larger spatial distribution than can be estimated using these three locations. Clearly, people also spend time with their family, are involved in sports activities, go to other shops than supermarkets, or visit (nature-) parks or beaches.

\section{Study implications for exposure assessment studies}

This study was performed in residents of a rural area in the Netherlands and results from this study may be not generalizable to other settings. Our estimation methods were unable to predict active mobility; this means that these methods are unlikely to improve exposure assessment. Still, active mobility is not the only situation where people are exposed to environmental emissions. One may also be exposed while travelling in motorised transport [44], but this was not the focus of our study. In a previous analysis we observed that self-reported time spent outdoors in the vicinity of the home was associated with pneumonia risk in people living in the vicinity of goat farms, but active mobility appeared not to be associated to this increased risk.[30] The contribution of active mobility to health relevant levels of environmental exposures will likely depend on spatial and spatio-temporal distributions of the respective exposure of interest.

\section{Conclusions}

Our main objective was to test different approaches to predict active mobility based on accessible data in a study cohort, since data regarding active mobility is challenging to obtain in large cohorts. Our estimation methods based on general characteristics, selfreported data and location-based information were equally unable to accurately predict active mobility. Estimated commuting routes did to some degree match GPS tracks, so if the goal is to analyse the contribution of home-work traffic to an exposure, using a GIS-based method may be applicable but requires further study. Overall, measurements still represent the best possible tool to evaluate mobility patterns. $[11,18,19,21,45,46]$ 


\section{Acknowledgements}

We like to thank all the participants, Lützen Portengen and Myrna de Rooij for statistical input and Daisy de Vries for textual input. The VGO GPS Study is funded by UMC Utrecht, publications fees for this article were available from IRAS. The Livestock Farming and Neighboring Residents' Health (VGO) study was funded by the Ministry of Health, Welfare and Sports and the Ministry of Economic Affairs of the Netherlands, and supported by a grant from the Lung Foundation Netherlands (Grant number: 3.2.11.022). 


\section{References}

1. Nieuwenhuijsen MJ (editor) et al., 2015 Exposure assessment in environmental epidemiology, second edition. Oxford University Press. ISBN 9780199378784

2. Janssen NAH, Hoek G, Simic-lawson M, Fischer P, Bree L Van, Brink $H$, et al. Black carbon and health effects of airborne particles compared with PM10 and PM2.5 12. Environ Health Perspect [Internet] 119:1691-1699 (2011). Available from: http://dx.doi.org/10.1289/ehp.1003369

3. Beekhuizen J, Vermeulen R, Kromhout H, Bürgi A, Huss A. Geospatial modelling of electromagnetic fields from mobile phone base stations. Sci Total Environ [Internet]. 2013;445-446:202-9. Available from: http://dx.doi.org/10.1016/j.scitotenv.2012.12.020

4. de Rooij MMT, Heederik DJJ, Borlée F, Hoek G, Wouters IM. Spatial and temporal variation in endotoxin and PM10 concentrations in ambient air in a livestock dense area. Environ Res [Internet]. 2017;153(September 2016):161-70. Available from: http://dx.doi.org/10.1016/j.envres.2016.12.004

5. Nyhan M, Grauwin S, Britter R, Misstear B, McNabola A, Laden F, et al. "exposure track" - The impact of mobile-device-based mobility patterns on quantifying population exposure to air pollution. Environ Sci Technol. 2016;50(17):9671-81.

6. Smith JD, Mitsakou C, Kitwiroon N, Barratt BM, Walton HA, Taylor JG, et al. London Hybrid Exposure Model: Improving Human Exposure Estimates to NO 2 and PM 2.5 in an Urban Setting. Environ Sci Technol. 2016;50(21):11760-8.

7. Breen MS, Long TC, Schultz BD, Crooks J, Breen M, Langstaff JE, et al. assessments : Model evaluation in central North Carolina. J Expo Sci Environ Epidemiol. 2014 July; 24(4): 412-420. doi:10.1038/jes.2014.13.

8. Gerharz LE, Pebesma E. Using geostatistical simulation to disaggregate air quality model results for individual exposure estimation on GPS tracks. Stoch Environ Res Risk Assess. 2013;27(1):223-34.

9. Mueller N, Rojas-Rueda D, Cole-Hunter T, de Nazelle A, Dons E, Gerike R, et al. Health impact assessment of active transportation: A systematic review. Prev Med (Baltim) [Internet]. 2015;76:103-14. Available from: http://dx.doi.org/10.1016/j.ypmed.2015.04.010

10. Harrison F, Burgoine T, Corder K, van Sluijs EMF, Jones A. How well do modelled routes to school record the environments children are exposed to?: A cross-sectional comparison of GIS-modelled and GPS-measured routes to school. Int J Health Geogr. 2014;13.

11. Vich G, Marquet O, Miralles-Guasch C. Green exposure of walking routes and residential areas using smartphone tracking data and GIS in a Mediterranean city. Urban For Urban Green [Internet]. 2018;(July):1-11. Available from: https://doi.org/10.1016/j.ufug.2018.08.008

12. Park YM, Kwan MP. Individual exposure estimates may be erroneous when spatiotemporal variability of air pollution and human mobility are ignored. Heal Place [Internet]. 2017;43(October 2016):85-94. Available from: http://dx.doi.org/10.1016/j.healthplace.2016.10.002

13. Armstrong BG. Effect of measurement error on epidemiological studies of environmental and occupational exposures. Occup Environ Med. 1998;55(10):651-6.

14. Kelly P, Krenn P, Titze S, Stopher P, Foster C, Kelly P, et al. Quantifying the Difference Between SelfReported and Global Positioning Systems-Measured Journey Durations : A Systematic Review [Internet] Transport Reviews, 33:4, 443-459, DOI:10.1080/01441647.2013.815288 Available from: https://doi.org/10.1080/01441647.2013.815288

15. Klous G, Smit LAM, Borlée F, Coutinho RA, Kretzschmar MEE, Heederik DJJ, et al. Mobility assessment of a rural population in the Netherlands using GPS measurements. Int J Health Geogr. 2017;16(1).

16. Burgoine T, Jones AP, Namenek Brouwer RJ, Benjamin Neelon SE. Associations between BMI and home, school and route environmental exposures estimated using GPS and GIS: Do we see evidence of selective daily mobility bias in children? Int J Health Geogr. 2015;14(1):1-12.

17. De Nazelle A, Seto E, Donaire-Gonzalez D, Mendez M, Matamala J, Nieuwenhuijsen MJ, et al. Improving estimates of air pollution exposure through ubiquitous sensing technologies. Environ Pollut [Internet]. 2013;176:92-9. Available from: http://dx.doi.org/10.1016/j.envpol.2012.12.032

18. Dons E, Van Poppel M, Kochan B, Wets G, Int Panis L. Implementation and validation of a modeling framework to assess personal exposure to black carbon. Environ Int [Internet]. 2014;62:64-71. Available from: http://dx.doi.org/10.1016/j.envint.2013.10.003 
19. Fillekes MP, Röcke C, Katana M, Weibel R. Self-reported versus GPS-derived indicators of daily mobility in a sample of healthy older adults. Soc Sci Med [Internet]. 2019;220(November):193202. Available from: https://doi.org/10.1016/j.socscimed.2018.11.010

20. Duncan MJ, Badland HM, Mummery WK. Applying GPS to enhance understanding of transportrelated physical activity Am J Prev Med 2007;33(1):51-53

21. Dalton AM, Jones AP, Panter J, Ogilvie D. Are GIS-modelled routes a useful proxy for the actual routes followed by commuters? J Transp Heal [Internet]. 2014;2(2):219-29. Available from: http://dx.doi.org/10.1016/j.jth.2014.10.001

22. Davies G, Whyatt D. A least-cost approach to personal exposure reduction. Trans GIS. 2009;13(2):229-46.

23. Pooley C, Whyatt D, Walker M, Davies G, Coulton P, Bamford W. Understanding the school journey: Integrating data on travel and environment. Environ Plan A. 2010;42(4):948-65.

24. Kestens $Y$, Thierry B, Shareck M, Steinmetz-Wood M, Chaix B. Integrating activity spaces in health research: Comparing the VERITAS activity space questionnaire with 7-day GPS tracking and prompted recall. Spat Spatiotemporal Epidemiol [Internet]. 2018;25:1-9. Available from: https://doi.org/10.1016/j.sste.2017.12.003

25. Bringolf-Isler B, Grize L, Mäder U, Ruch N, Sennhauser FH, Braun-Fahrländer C. Personal and environmental factors associated with active commuting to school in Switzerland. Prev Med (Baltim). 2008;46(1):67-73.

26. Jansen M, Ettema D, Pierik F, Dijst M. Sports facilities, shopping centers or homes: What locations are important for adults' physical activity? A cross-sectional study. Int J Environ Res Public Health. 2016;13(3).

27. Ulfarsson GF, Shankar VN. Children's travel to school: Discrete choice modeling of correlated motorized and nonmotorized transportation modes using covariance heterogeneity. Environ Plan B Plan Des. 2008;35(2):195-206.

28. Freidl GS, Spruijt IT, Borlée F, Smit LAM, Van Gageldonk-Lafeber AB, Heederik DJJ, et al. Livestockassociated risk factors for pneumonia in an area of intensive animal farming in the Netherlands. PLoS One. 2017;12(3):1-16.

29. Borlée F, Yzermans CJ, van Dijk CE, Heederik D, Smit LAM. Increased respiratory symptoms in COPD patients living in the vicinity of livestock farms. Eur Respir J [Internet]. 2015;46(6):1605-14. Available from: http://dx.doi.org/10.1183/13993003.00265-2015

30. Klous G, Smit LAM, Freidl GS, Borlée F, van der Hoek W, IJzermans CJ, et al. Pneumonia risk of people living close to goat and poultry farms - Taking GPS derived mobility patterns into account. Environ Int. 2018;115.

31. [Internet] www.lisa.nl

32. Esri/near_analysis [Internet]. Available from: http://pro.arcgis.com/en/pro-app/toolreference/analysis/near.htm

33. [Internet] www.kadaster.nl

34. Esri/network_analysis [Internet]. Available from: http://pro.arcgis.com/en/pro-app/toolreference/network-analyst/an-overview-of-the-network-analyst-toolbox.htm

35. Esri/find-closest-facilities [Internet]. Available from: http://pro.arcgis.com/en/pro-app/toolreference/ready-to-use/find-closest-facilities.htm

36. Schaap N, Harms L, Kansen M, Wust H. Cycling and Walking: the grease in our mobility chain. 2016; Available from: http://english.kimnet.nl

37. Huss A, Beekhuizen J, Kromhout H, Vermeulen R. Using GPS-derived speed patterns for recognition of transport modes in adults. International Journal of Health Geographics 2014, 13:40 doi:10.1186/1476-072X-13-40

38. Https://www.cbs.nl/nl-nl/achtergrond/2016/20/beroepsbevolking. No Title [Internet]. Available from: https://www.cbs.nl/nl-nl/achtergrond/2016/20/beroepsbevolking

39. Scheiner J, Holz-Rau C. Travel mode choice: affected by objective or subjective determinants? Transportation 2007 34:487-511 doi: 10.1007/s11116-007-9112-1

40. Axhausen K, Zimmermann A, Schönfelder S, Rindsfüser... G. Observing the rhythms of daily life: a six-week travel diary Elektronische Daten. Transportation 2002, 29: 95-124. Available from: http://en.scientificcommons.org/831369

41. Flamm M, Kaufmann V. The Concept of Network of Usual Places as a Tool for Analyzing Human Activity Spaces: An Exploration Based on the Mobidrive Large Scale Travel Diary Data Set. 11th World Conf Transp Res [Internet]. 2007;(April). Available from:

http://trid.trb.org/view.aspx?id=878244 
42. Vanwolleghem G, Schipperijn J, Gheysen F, Cardon G, De Bourdeaudhuij I, Van Dyck D. Children's GPS-determined versus self-reported transport in leisure time and associations with parental perceptions of the neighborhood environment. Int J Health Geogr. 2016;15(1):1-12.

43. Vlakveld WP, Twisk D, Christoph M, Boele M, Sikkema R, Remy R, et al. Speed choice and mental workload of elderly cyclists on e-bikes in simple and complex traffic situations: A field experiment. Accid Anal Prev [Internet]. 2015;74:97-106. Available from:

http://dx.doi.org/10.1016/j.aap.2014.10.018

44. Zuurbier M, Hoek G, Hazel P Van Den, Brunekreef B. Minute ventilation of cyclists, car and bus passengers: An experimental study. Environ Heal A Glob Access Sci Source. 2009;8(1):1-10.

45. Chaix B, Méline J, Duncan S, Merrien C, Karusisi N, Perchoux C, et al. GPS tracking in neighborhood and health studies: A step forward for environmental exposure assessment, A step backward for causal inference? Heal Place. 2013;21:46-51.

46. Su JG, Jerrett M, Meng YY, Pickett M, Ritz B. Integrating smart-phone based momentary location tracking with fixed site air quality monitoring for personal exposure assessment. Sci Total Environ [Internet]. 2015;506-507:518-26. Available from:

http://dx.doi.org/10.1016/j.scitotenv.2014.11.022 


\section{Supplementary data}

\section{Estimation method 1}

The following formulas were used in the calculations for Estimation method 1:

1. $e^{-4.524}$ * $\mathrm{GMR}_{\text {age }}$ * $\mathrm{GMR}_{\mathrm{BMI}}$ * $\mathrm{GMR}_{\text {smoking }}$ * $\mathrm{GMR}_{\text {work }}$ * GMR $\mathrm{M}_{\text {hayfever }}$ * $\mathrm{GMR}^{\mathrm{N} \text {, workdays }}$ $=$ Geometric Mean (GM)

In formula $1, e^{-4.524}$ is the exponent of the intercept calculated in the explanatory variable analysis for non-motorised transport from Klous et al 2017, in this study we calculated Geometric Mean Ratios (GMR) for the following factors: GMR age is the GMR for age category, GMR $\mathrm{BMI}_{\mathrm{I}}$ is the GMR for BMI category, GMR $\mathrm{R}_{\text {smoking }}$ is the GMR for smoking status, GMR work $_{\text {is }}$ the GMR for work status, GMR hayfever is the GMR for hayfever

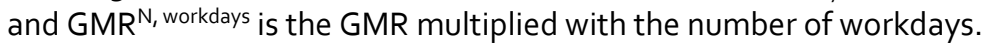

In order to appropriately estimate the hours per week spent in active transport the GM was back calculated to an Arithmetic Mean (AM, formula 2). In formula 2, GSD stands for Geometric Standard Deviation (GSD=1,068726), this is the standard deviation of the residuals of the explanatory variable analysis applied in Klous et al 2017. The AM represented the percentage of time per week spent in active mobility. By multiplying the AM with 168 (number of total hours per week, formula 3), the number of hours per week spent in active mobility was calculated.

2. $\mathrm{GM} * e^{\left(\log (G S D)^{2} / 2\right)}=\mathrm{AM}$

3. $A M * 168=$ hours/week spent on active mobility

Supplementary Table 1 GMRs used in calculation of Estimation method 1 from Klous 2017 [15]

\begin{tabular}{l|l|l} 
Factor & Category & \multicolumn{1}{l}{ GMR (95\% Confidence Interval) } \\
\hline age & $<45$ years & 1.00 (reference) \\
& $45-55$ years & $1.25(0.92-1.70)$ \\
& $55-65$ years & $1.43(1.06-1.95)$ \\
BMI & $>65$ ears & 1.00 (reference) \\
& Normal weight $\left(<25 \mathrm{~kg} / \mathrm{m}^{2}\right)$ & $0.96(0.78-1.17)$ \\
Smoking status & Overweight $\left(25-30 \mathrm{~kg} / \mathrm{m}^{2}\right)$ & $0.69(0.54-0.90)$ \\
& Obese $\left(>30 \mathrm{~kg} / \mathrm{m}^{2}\right)$ & $1.00($ reference) \\
Work status & Never & $0.93(0.77-1.13)$ \\
Workdays & Former & $0.64(0.46-0.89)$ \\
Hayfever & Current & 1.00 (reference) \\
& (un-employed) & $0.77(0.60-1.00)$ \\
& (employed) & $0.95(0.90-1.01)$ \\
& (days per week) & 1.00 (reference) \\
& (self-reported) No & 1.17 (0.96-1.43)
\end{tabular}




\section{Estimation method 2}

The following questions were used to calculate the time in active mobility for Estimation method 2, these questions are translated from Dutch, see Klous et al 2017 for an overview of the complete questionnaire.[15]

\section{VGO GPS study} to GPS carrying)

\section{Questionnaire 1 (filled in prior}

This questionnaire includes 10 questions, among which 8 multiple-choice questions.

Please indicate what is applicable to your situation by filling in the boxes ( ).

If you make a mistake, please indicate this with a cross trough the mistake $\rightarrow$ and afterwards fill in the right answer $(\bullet)$.

For some questions we ask you to estimate durations of specific travel modes, can you please estimate durations for a normal week and can you be as specific as possible?

\section{Workdays}

The following questions apply to the days on which you do your main work activities.

Please keep an ordinary workday in mind, how many hours per day, do you commute using the following travel modes?

(please indicate what is applicable to your situation, multiple answers are allowed, please estimate durations)

\begin{tabular}{|l|c|cc|} 
Transport mode & autumn/winter & spring / summer \\
\hline $\begin{array}{l}\text { Train and Bus (Public } \\
\text { transport) }\end{array}$ & hours minutes & hours minutes \\
\hline Car & hours minutes & hours & minutes \\
\hline Moped, scooter, motorbike & hours minutes & hours minutes \\
\hline E-bike & hours minutes & hours minutes \\
\hline Bicycle & hours minutes & hours minutes \\
\hline On foot & hours minutes & hours minutes \\
\hline $\begin{array}{l}\text { Other transport mode, } \\
\text { (Namely): }\end{array}$ & hours minutes & hours minutes \\
\hline
\end{tabular}


Please keep an ordinary workday in mind, how many hours per day, do you spend traveling for work purposes, using the following travel modes?

(please indicate what is applicable to your situation, multiple answers are allowed, please estimate durations)

\begin{tabular}{|c|c|c|c|c|}
\hline Transport mode & \multicolumn{2}{|c|}{ autumn / winter } & \multicolumn{2}{|c|}{ spring / summer } \\
\hline None & n.a & & n.a & \\
\hline $\begin{array}{l}\text { Train and Bus (Public } \\
\text { transport) }\end{array}$ & hours & minutes & hours & minutes \\
\hline Car & hours & minutes & hours & minutes \\
\hline Moped, scooter, motorbike & hours & minutes & hours & minutes \\
\hline E-bike & hours & minutes & hours & minutes \\
\hline Bicycle & hours & minutes & hours & minutes \\
\hline On foot & hours & minutes & hours & minutes \\
\hline $\begin{array}{l}\text { Other transport mode, } \\
\text { (Namely): }\end{array}$ & hours & minutes & hours & minutes \\
\hline
\end{tabular}

\section{Leisure time}

The following questions apply to periods when you are not working, or commuting to work, for instance during the weekends or at night.

Which of the following outdoor leisure time activities are in your normal week schedule?

(please indicate what is applicable to your situation, multiple answers are allowed, please estimate durations)

\begin{tabular}{|l|c|c|} 
Activity & autumn / winter & spring / summer \\
\hline $\begin{array}{l}\text { Walking (e.g. while shopping, hiking, } \\
\text { walking the dog) }\end{array}$ & Hours per week & Hours per week \\
\hline $\begin{array}{l}\text { Bicycle riding (e.g. from and to shops, } \\
\text { bicycle tours) }\end{array}$ & Hours per week & Hours per week \\
\hline $\begin{array}{l}\text { Outdoor sports (e.g. running, tennis, } \\
\text { football) }\end{array}$ & Hours per week & Hours per week \\
\hline $\begin{array}{l}\text { Spending time close to home (e.g. Time } \\
\text { spent outdoors close to home, taking care of } \\
\text { animals, do-it-yourself work, relaxing in the } \\
\text { garden) }\end{array}$ & Hours per week & Hours per week \\
\hline $\begin{array}{l}\text { Other outdoors activities (e.g. visiting a } \\
\text { playground, angling) }\end{array}$ & Hours per week & Hours per week \\
\hline
\end{tabular}


How often do you use the following transport modes per week during leisure time and what are the average durations per week you use them?

(please indicate what is applicable to your situation, multiple answers are allowed, please estimate durations)

\begin{tabular}{|l|c|cr|} 
Transport mode & autumn / winter & spring/summer \\
\hline $\begin{array}{l}\text { Train and Bus (Public } \\
\text { transport) }\end{array}$ & hours minutes & hours minutes \\
\hline Car & hours minutes & hours & minutes \\
\hline Moped, scooter, motorbike & hours minutes & hours & minutes \\
\hline E-bike & hours minutes & hours minutes \\
\hline Bicycle & hours minutes & hours minutes \\
\hline On foot & hours minutes & hours minutes \\
\hline $\begin{array}{l}\text { Other transport mode, } \\
\text { (Namely): }\end{array}$ & hours minutes & hours minutes \\
\hline
\end{tabular}




\section{Estimation method 3}

Overview of cut-offs and average speeds used to calculate time spent in active transport in Estimation method 3.

Supplementary Table 2 Distance cut-offs and average speeds used in calculation of Estimation method 3

\begin{tabular}{l|lll}
\multicolumn{1}{l}{ Travel purpose } & Transport mode & Distance cut-off $(\mathrm{km})[35]$ & Average speed $(\mathrm{km} / \mathrm{h})$ \\
\hline Commuting & Walking & $0.5 \mathrm{~km}$ & $2 \mathrm{~km} / \mathrm{h}^{*, 1}$ \\
& Bike & $2.5 \mathrm{~km}$ & $14.9 \mathrm{~km} / \mathrm{h}^{*, 1,2}$ \\
\multirow{3}{*}{ Shopping } & E-bike & $3.7 \mathrm{~km}$ & $16.6 \mathrm{~km} / \mathrm{h}^{*, 2}$ \\
& Walking & $0.5 \mathrm{~km}$ & $2 \mathrm{~km} / \mathrm{h}^{*, 1}$ \\
& Bike & $2.5 \mathrm{~km}$ & $14.9 \mathrm{~km} / \mathrm{h}^{*, 1,2}$ \\
& E-bike & $2.5 \mathrm{~km}$ & $16.6 \mathrm{~km} / \mathrm{h}^{*, 2}$
\end{tabular}

*Note that these speed values include stops (e.g. at traffic light), 1: [37], 2: [43]

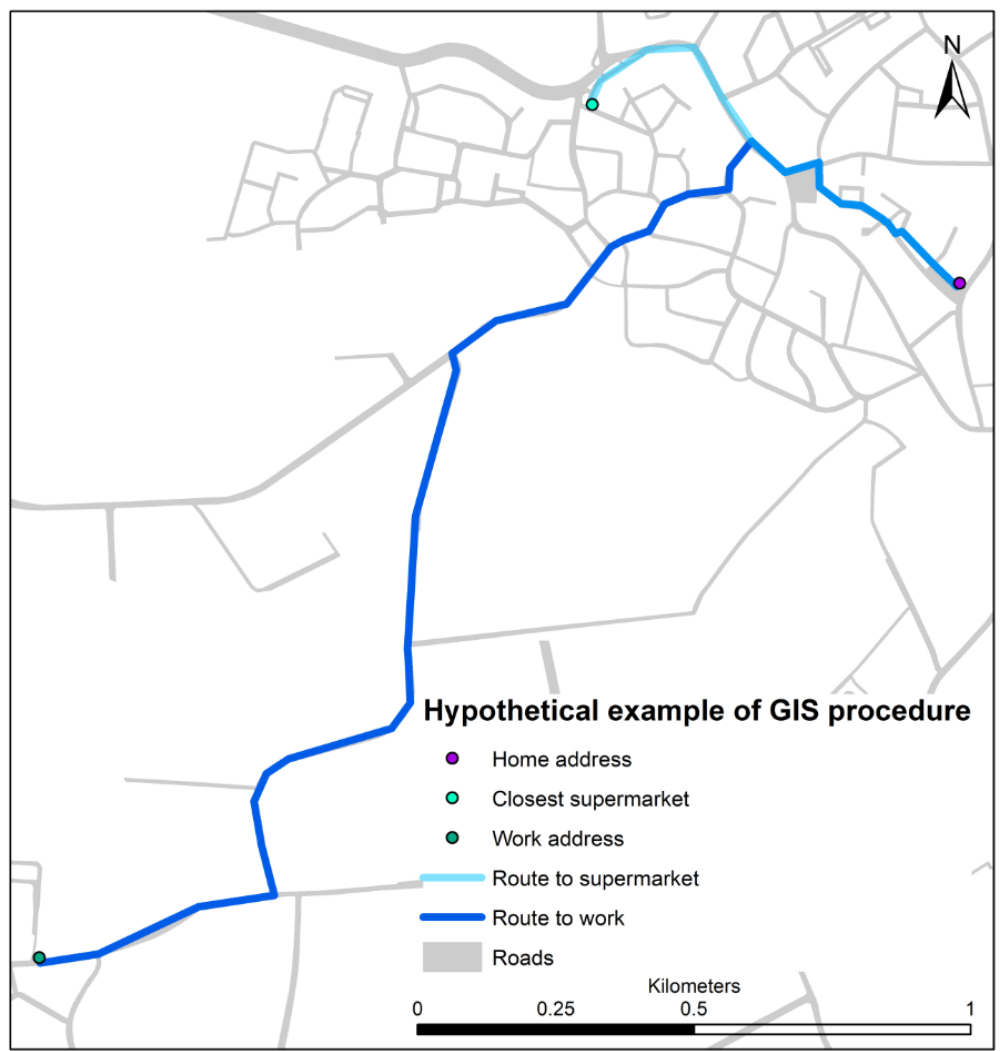

Supplementary Figure 1. Hypothetical example of the GIS procedure. For every participant we had information available about the home address (purple dot), location of the closest supermarket (light blue dot), and, if available, the work address (green dot). These dots were combined with a road map (grey lines) and using this road map the shortest routes to the supermarket (light blue line), and, if available, work address (dark blue line) were drawn. The route lengths were than used to assign a mobility mode based on a set of cut-offs (Supp. Table 2) the combination of mobility mode and route length were than further used to calculate travel durations. 
In the VGO questionnaire there was one question regarding daily activities, from this question we assigned the number of workdays for each participant. Translated to English this question was: "What are your main activities?"

This was a multiple-choice question with multiple answers allowed. The following answers were provided: Working (less than 19 hours/week), Working (more than 19 hours/week), Housekeeping, Unemployed, Studying, Incapacitated, Retired and Volunteer.

Supplementary Table 3 Questionnaire answers (VGO questionnaire) used to indicate workdays for Estimation method 3

\begin{tabular}{|c|c|}
\hline Number of workdays & Answer (combination) \\
\hline o & $\begin{array}{l}\text { No answer, Retired, Incapacitated, Housekeeping, Unemployed, Retired \& } \\
\text { Incapacitated, Retired \& Unemployed, Retired \& Housekeeping, Retired \& } \\
\text { Incapacitated \& Housekeeping, Incapacitated \& Unemployed, } \\
\text { Incapacitated \& Housekeeping, Incapacitated \& Housekeeping \& } \\
\text { Unemployed, Housekeeping \& Unemployed }\end{array}$ \\
\hline 1 & Incapacitated, Housekeeping, Unemployed, Volunteer \\
\hline 2 & $\begin{array}{l}\text { Volunteer, Working <19h, Retired \& Volunteer, Retired \& Incapacitated \& } \\
\text { Volunteer, Retired \& Housekeeping \& Volunteer, Retired \& Working <19h, } \\
\text { Retired \& Housekeeping \& Working <19h, Incapacitated \& Volunteer, } \\
\text { Incapacitated \& Housekeeping \& Volunteer, Incapacitated \& Working <19h, } \\
\text { Incapacitated \& Housekeeping \& Working <19h, Housekeeping \& } \\
\text { Unemployed \& Volunteer, Housekeeping \& Volunteer, Housekeeping \& } \\
\text { Studying, Housekeeping \& Working <19h, Unemployed \& Volunteer }\end{array}$ \\
\hline 3 & $\begin{array}{l}\text { Retired \& Housekeeping \& Volunteer \& Studying, Retired \& Volunteer \& } \\
\text { Working <19h, Retired \& Housekeeping \& Volunteer \& Working }<19 \text {, } \\
\text { Retired \& Working }>19 h, \text { Retired \& Housekeeping \& Working }>19 h, \text { Retired } \\
\text { \& Volunteer \& Working }>19 h, \text { Incapacitated \& Volunteer \& Work }<19 \text {, } \\
\text { Incapacitated \& Housekeeping \& Volunteer \& Work <19h, Incapacitated \& } \\
\text { Housekeeping \& Working }>19 h \text {, Incapacitated \& Working >19h, } \\
\text { Housekeeping \& Volunteer \& Working <19h, Housekeeping \& } \\
\text { Incapacitated \& Unemployed \& Volunteer \& Studying, Housekeeping \& } \\
\text { Volunteer \& Studying, Volunteer \& Working <19h, Working <19h \& } \\
\text { Working >19h }\end{array}$ \\
\hline 4 & $\begin{array}{l}\text { Retired \& Housekeeping \& Volunteer \& Working }>19 u \text {, Incapacitated \& } \\
\text { Housekeeping \& Studying \& Working }<19 \text { h, Incapacitated \& Housekeeping } \\
\text { \& Volunteer \& Working }>19 h \text {, Incapacitated \& Housekeeping \& Volunteer } \\
\text { \& Studying \& Working }>19 h, \text { Housekeeping \& Studying \& Working }<19 h \text {, } \\
\text { Housekeeping \& Volunteer \& Studying \& Working }<19 h \text {, Housekeeping \& } \\
\text { Working }>19 h, \text { Housekeeping \& Volunteer \& Working }>19 h\end{array}$ \\
\hline 5 & $\begin{array}{l}\text { Studying, Working >19h, Housekeeping \& Studying \& Working >19h, } \\
\text { Housekeeping \& Volunteer \& Studying \& Working >19h, Unemployed \& } \\
\text { Studying, Working <19h \& Studying, Working >19h \& Volunteer, Working } \\
>19 h \text { \& Studying, Working >19h \& Volunteer \& Studying }\end{array}$ \\
\hline
\end{tabular}




\section{Sensitivity analyses}

We ran the estimation methods stratified for work (yes and no) and for different previously determined age categories $(<45 y, 45-55 y, 55-65 y, 65 y\rangle$, based on the age distribution within the study population [15]). For the linear regression we overall observed statistical significant difference between all estimated outcomes and their reference values. The kappa analyses, in agreement with outcomes of the whole study population, showed a very low agreement between estimated and GPS measured hours/week in active mobility.

Supplementary Table 4 Description of sensitivity analysis, linear regression and kappa analysis

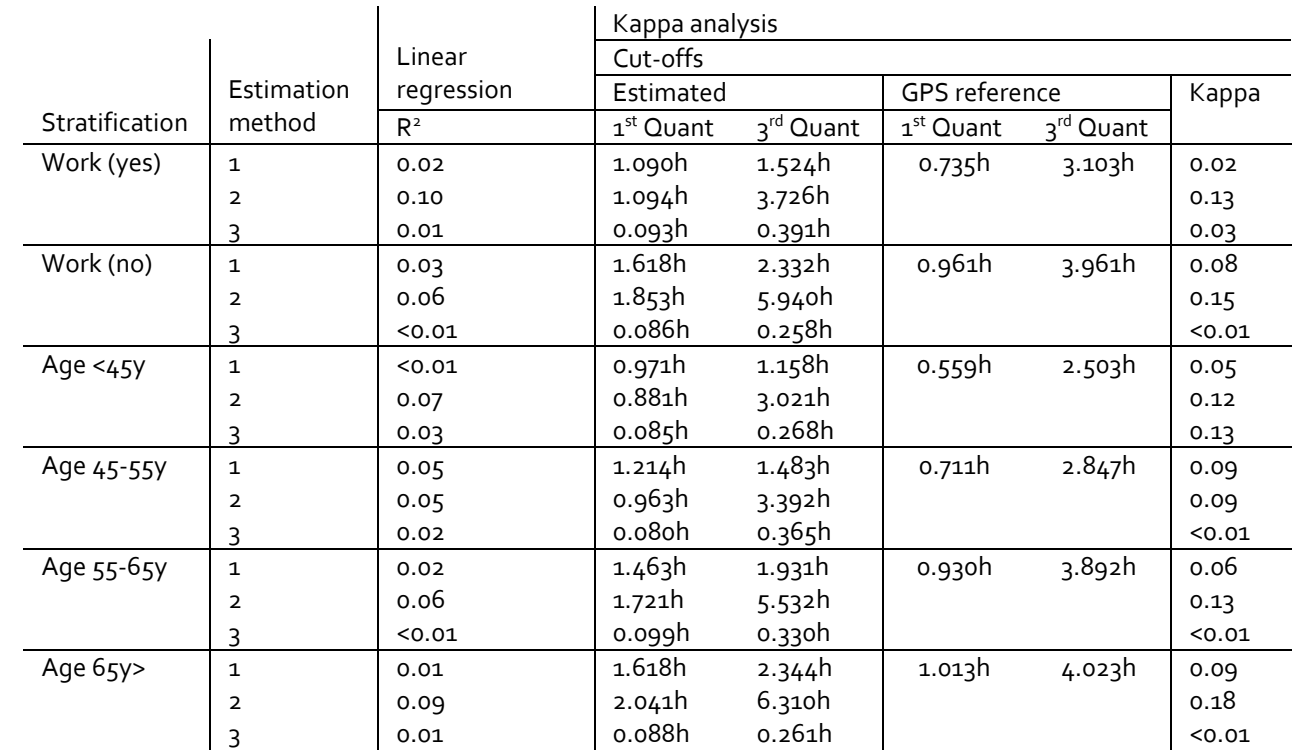


Figure 1 and 3 with all outliers visible

GPS measured and estimated hours/week spent on active mobility

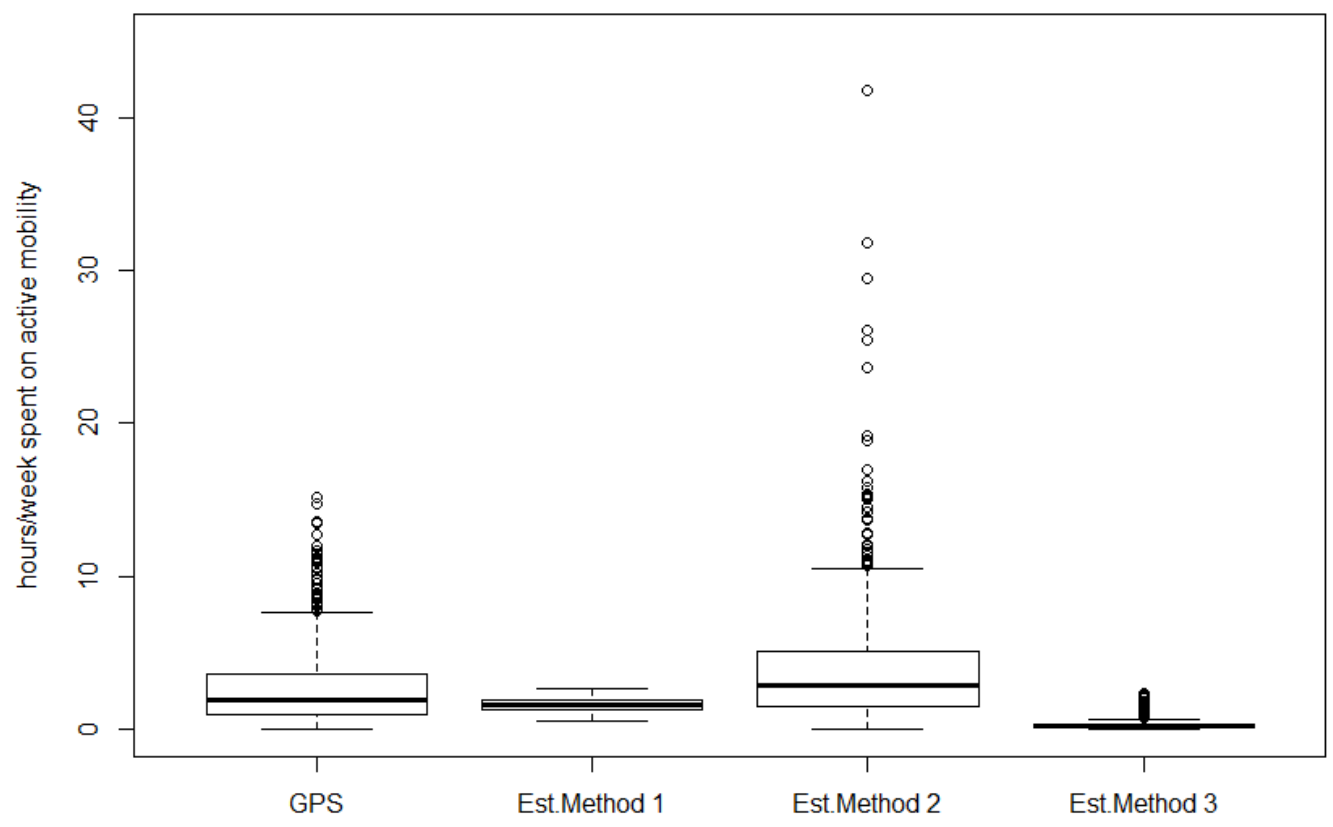

Supplementary Figure 2. Boxplot comparisons of GPS measured and estimated hours/week spent on active mobility. Est.Method 1 is Estimation method 1, Est. Method 2 is Estimation method 2 and Est.Method 3 is Estimation method 3. Note, that the maximum Y-value is now 45 hours/week, thus including all outliers. 


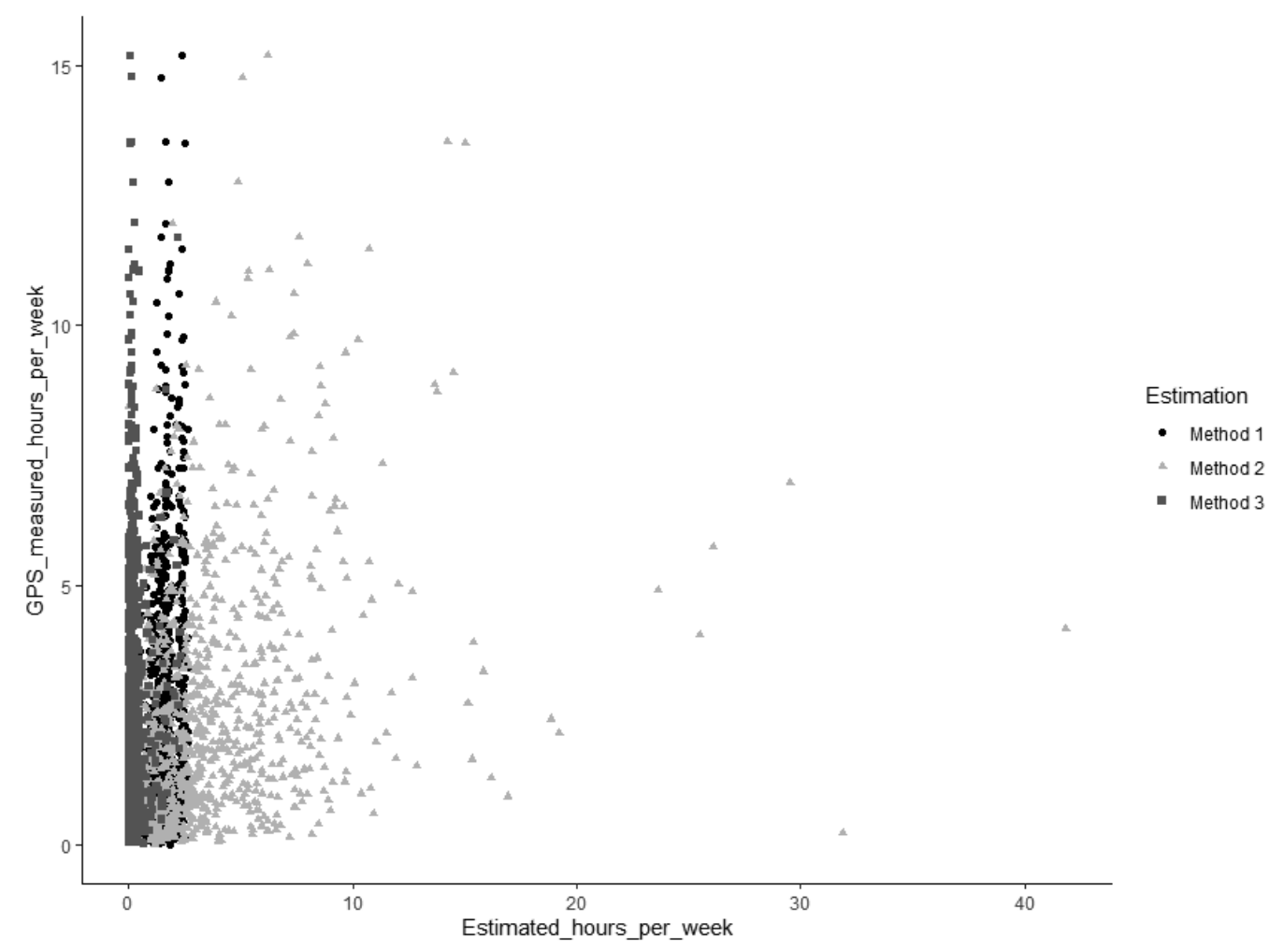

Supplementary Figure 3. Scatterplots of matched comparisons between estimated ( $x$-axis) and GPS measured (y-axis) hours/week spent on active mobility. Black dot: estimated hours/week spent on active mobility from Estimation method 1 (general characteristics method) versus GPS measured. Light grey triangle: estimated hours/week spent on active mobility from Estimation method 2 (adjusted self-reported data method) versus GPS measured. Dark grey squares: estimated hours/week spent on active mobility from Estimation method 3 (GIS based method) versus GPS measured. Note, that in the figure the $\mathrm{x}$-axis maximum is set to 45 hours/week, thus including all outliers. 


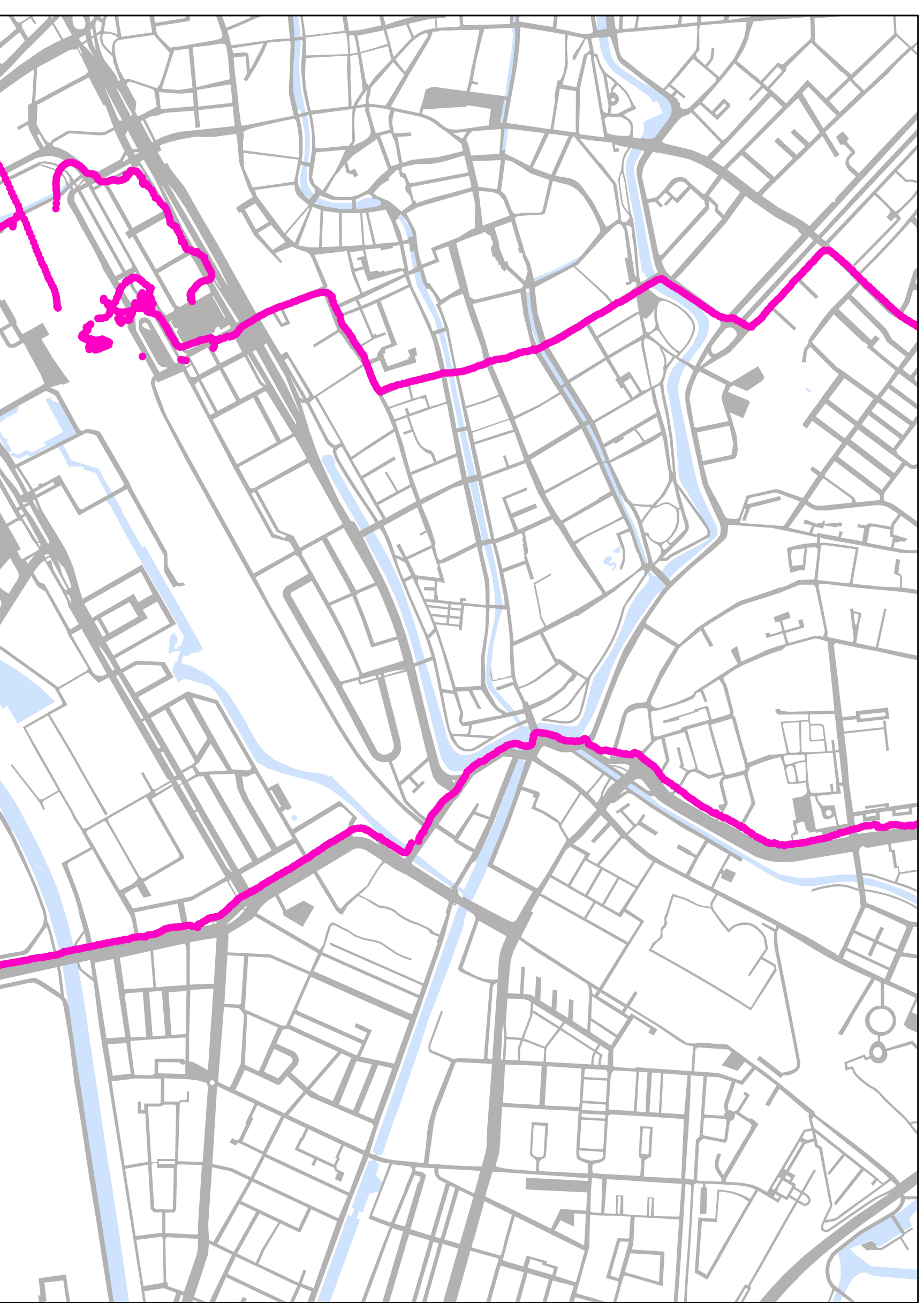


Chapter 6

Relationship between Coxiella burnetii ( $Q$ fever) antibody serology and time spent outdoors

Journal of Infection (2020) 81(1) 90-97 Gijs Klous, Lidwien Smit, Wim van der Hoek, Mirjam Kretzschmar, Piet Vellema, Roel Coutinho, Dick Heederik and Anke Huss 


\section{Relationship between Coxiella burnetii ( $Q$ fever) antibody serology and time spent outdoors}

Background: From 2007 through 2010, the Netherlands experienced the largest recorded $\mathrm{Q}$ fever outbreak to date. People living closer to Coxiella burnetii infected goat farms were at increased risk for acute $Q$ fever. Time spent outdoors near infected farms may have contributed to exposure to $C$. burnetii. The aim of this study was to retrospectively evaluate whether hours/week spent outdoors, in the vicinity of previously $C$. burnetii infected goat farms, was associated with presence of antibodies against $C$. burnetii in residents of a rural area in the Netherlands.

Method: Between 2014-2015, we collected C. burnetii antibody serology and selfreported data about habitual hours/week spent outdoors near the home from 2494 adults. From a subgroup we collected 941 GPS tracks, enabling analyses of active mobility in the outbreak region. Participants were categorised as exposed if they spent time within specified distances (500m, 1000m, 2000m, or 4000m) of C. burnetii infected goat farms. We evaluated whether time spent near these farms was associated with positive $C$. burnetii serology using spline analyses and logistic regression.

Results: People that spent more hours/week outdoors near infected farms had a significantly increased risk for positive $C$. burnetii serology (time spent within 2000m of a C. burnetii abortion-wave positive farm, OR 3.6 (1.2-10.6)), compared to people spending less hours/week outdoors.

Conclusions: Outdoor exposure contributed to the risk of becoming C. burnetii serology positive. These associations were stronger if people spent more time near $C$. burnetii infected farms. Outdoor exposure should, if feasible, be included in outbreak investigations. 


\section{Introduction}

In the years 2007 through 2010, the Netherlands experienced the largest outbreak of $Q$ fever reported to date[1-3]. Over 4000 human cases were identified [4,5] predominantly in the south-eastern part of the country[3], a region with a high density of livestock farming $[6,7]$. The primary sources of Coxiella burnetii infections were abortion-waves in dairy goats, which in the Netherlands are kept in intensive livestock systems[4]. When human $\mathrm{Q}$ fever incidence was combined with data about $C$. burnetii status of farms, spatial relationships were identified: with increasing distance from $C$. burnetii positive farms, decreasing human $Q$ fever incidence was observed $[8,9]$. This relationship has been thoroughly investigated in the past, focussing on environmental conditions[10,11], meteorological conditions[12], and mapping cases in relation to $C$. burnetii positive farms $[2,13]$ as recently reviewed by De Rooij et al[5].

The outbreak was contained by at first, voluntary and later, obligatory vaccination of dairy goats [14,15], introducing mandatory bulk milk checks for $C$. burnetii presence[16] and culling of pregnant goats on bulk milk tank positive farms[17]. Still, in the affected area residual effects remain present to date, with several hundred people still suffering from chronic $Q$ fever after the outbreak[18]. The $Q$ fever outbreak contributed to the interest into the potential effects of livestock production on human health and led to the start of the large "Livestock Farming and Neighbouring Residents' Health" study in 2012 (Dutch acronym: VGO). The main goal of the VGO study is to investigate whether living in the vicinity of livestock farms has an impact on the health of residents[19]. In the VGO study and all previous $\mathrm{Q}$ fever analyses, personal exposure was approximated by assigning exposure levels to the home address and for the $\mathrm{Q}$ fever analyses both abortion waves and/or bulk milk positivity for $C$. burnettii were used to assign a stable as being $C$. burnetii positive $[2,4,10,12,13,9,20]$. These approaches are disregarding whether time spent outdoors in close proximity of $C$. burnetii positive farms poses additional risks. Especially, time spent outdoors and active human mobility near $C$. burnetii emitting goat farms, may have affected exposure to $C$. burnetii during the outbreak $[2,5,12]$. Therefore, as an additional study to the VGO study, the VGO GPS study was initiated in 2014. In this study, participants were asked to log their mobility with a GPS tracker during a whole week. The VGO GPS study took place in the same area where the $\mathrm{Q}$ fever outbreak occurred and has provided us with detailed information of residents' daily mobility and average weekly time spent outdoors near the home[7,21].

For the current study, we aimed at evaluating whether hours/week spent outdoors, an aggregate of self-reported hours/week spent outdoors near the home and GPS measured active mobility in the vicinity of goat farms was associated with the risk of positive $C$. burnetii antibody serology. Furthermore, we assessed whether either selfreported hours/week spent outdoors near the home, or GPS measured active mobility were associated with the risk for positive $C$. burnetii antibody serology.

\section{Methods}

\section{Study population: VGO cohort}

Study participants of the VGO cohort $(\mathrm{N}=2494)$ lived in a rural area in the Netherlands[19]. Farmers and people living on farms were excluded a priori, since the 
focus was on health of non-occupationally exposed neighbouring residents. All cohort members underwent a medical examination in a field study that took place in 20142015. During the examination, blood samples were taken and participants were asked to fill in a baseline questionnaire (VGO questionnaire), including questions about demographics, health and lifestyle[19,22]. From the VGO questionnaire, information was available about the home address of participants and the hours/week people spend outdoors near their home.

\section{Study population: GPS group}

VGO cohort members that indicated they could be contacted for follow-up research were recruited as participants for the GPS study. We invited 1517 VGO participants to take part in the GPS study and 1014 agreed to participate. All 1014 consenting participants were sent a GPS logger (TracKing Pro Land Air Sea systems Woodstock IL, USA) and were asked to always take it with them during one week before returning it to the study centre. GPS loggers were sent in sixteen batches between September 2014 and February 2016. Included in the package was a questionnaire regarding study adherence and whether participants had logged a 'normal week'. GPSs were set to a logging interval of one second and were equipped with a motion sensor to prevent battery depletion. After data cleaning[7], 941 usable GPS tracks were available (38\% of the total VGO cohort), and overall participants had a median of 186 hours of data logged. We used a 6om buffer around the home to assign every logged GPS coordinate as being 'indoors' or 'outdoors', transport modes (walking, biking or motorised transport) were assigned to 'outdoors' coordinates using a previously developed algorithm[21,23]. The 6 om buffer around the home, minimizes the chance that time spent outdoors around the home was included to the mobility measurement[21]. Figure 1 shows a flowchart of the recruitment, data collection and data cleaning process.

\section{Exposure assignment}

Since infected goat farms were previously identified as sources in the Dutch $\mathrm{Q}$ fever outbreak[1,2,8], we performed analyses with buffers of 500m, 1000m, 2000m, and $4000 \mathrm{~m}$ around goat farms, in order to test for distance-response relationships. For comparability reasons, we initially evaluated if using a 500om buffer[8] was feasible, there were however limitations with applying these buffers: using the smaller buffers (50om and 1000m) resulted in too few people exposed to goat farms and using the largest buffers ( $4000 \mathrm{~m}$ and $5000 \mathrm{~m}$ ) resulted in too few people unexposed to farms. We therefore decided not to use the $5000 \mathrm{~m}$ buffer, but used the $4000 \mathrm{~m}$ buffer as maximum distance and preferred to show the results of the analyses with the 2000m buffers as primary outcomes. See Table 1 for an overview of applied exposure variables and Supplementary Table 1 for an overview of group sizes for the analyses with 500m, $1000 \mathrm{~m}, 2000 \mathrm{~m}$ and $4000 \mathrm{~m}$ buffers, an overview of the spatial distribution of the home addresses of participants and the applied buffers, is given in Supp. Figure 1. For comparability with previous studies and to evaluate whether farm status ('C. burnetii positive' or 'negative') influenced the outcomes, four different definitions were used to describe the $C$. burnetii status of a goat farm: 


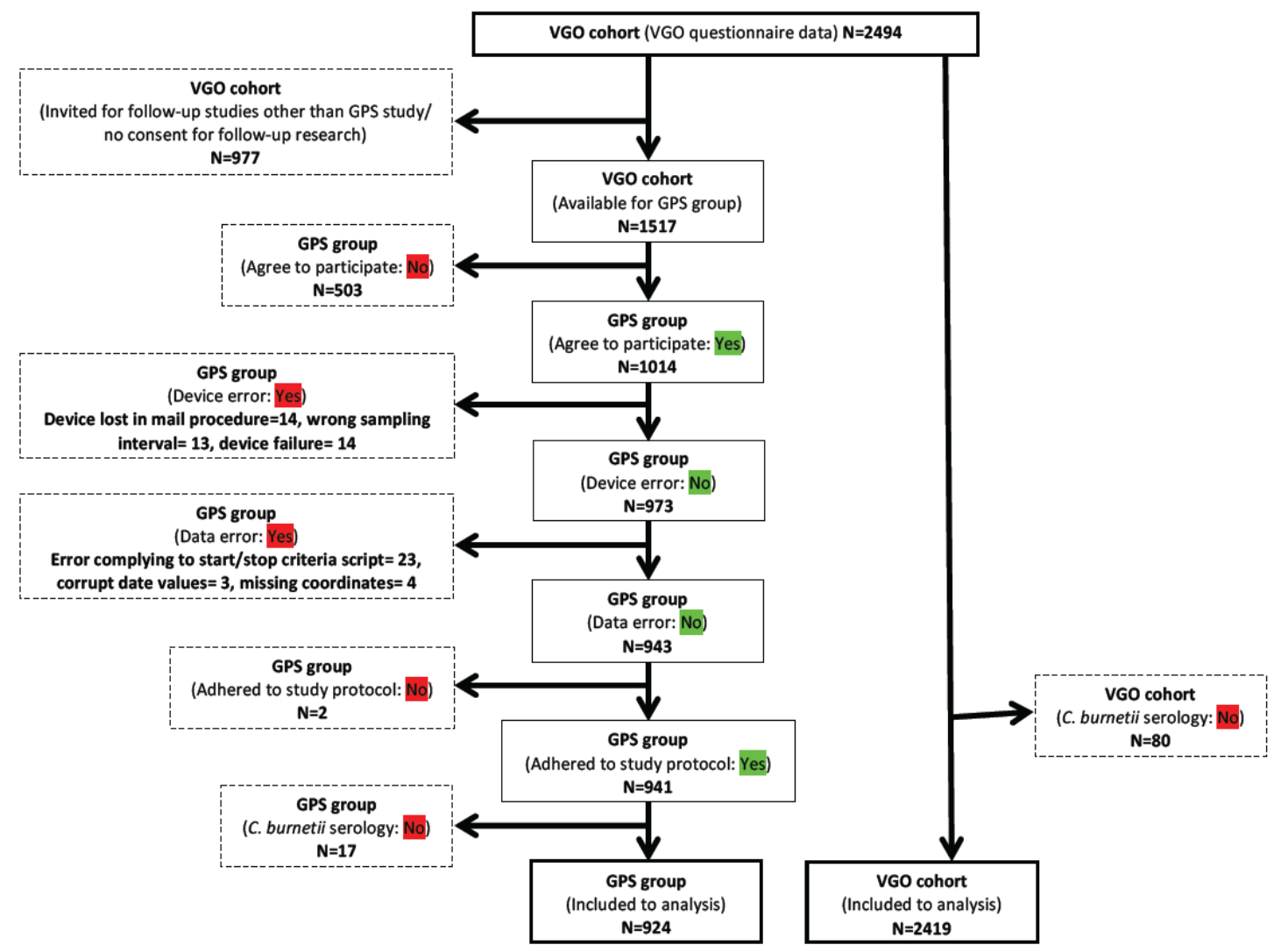

Figure 1. Flowchart of the recruitment, data collection and data cleaning process in the VGO GPS study.

a) 'abortion-wave' positive goat farms, these are farms that experienced $C$. burnetii related abortion waves (>5\% of animals aborted[1]) between 20072009. During these abortion-waves, large amounts of bacteria are excreted[24] and due to the open stables in the Netherlands[4] bacteria can be easily emitted to the direct surroundings of farms. This status was a priori defined to represent our primary source of exposure,

b) 'any C. burnetii signal' positive goat farms, 'abortion-wave' and/or 'bulk milk tank' (real-time PCR tests on milk samples, enabling quantification of bacteria[16]) positive, this status was often used in previous $Q$ fever analyses in the Netherlands $[2,4,10,12,13,9,20]$ and we included it for comparability reasons,

c) goat farms, irrespective of $C$. burnetii status[8],

d) 'negative' goat farms, all goat farms, excluding farms that were 'any $C$. burnetii signal' positive. 


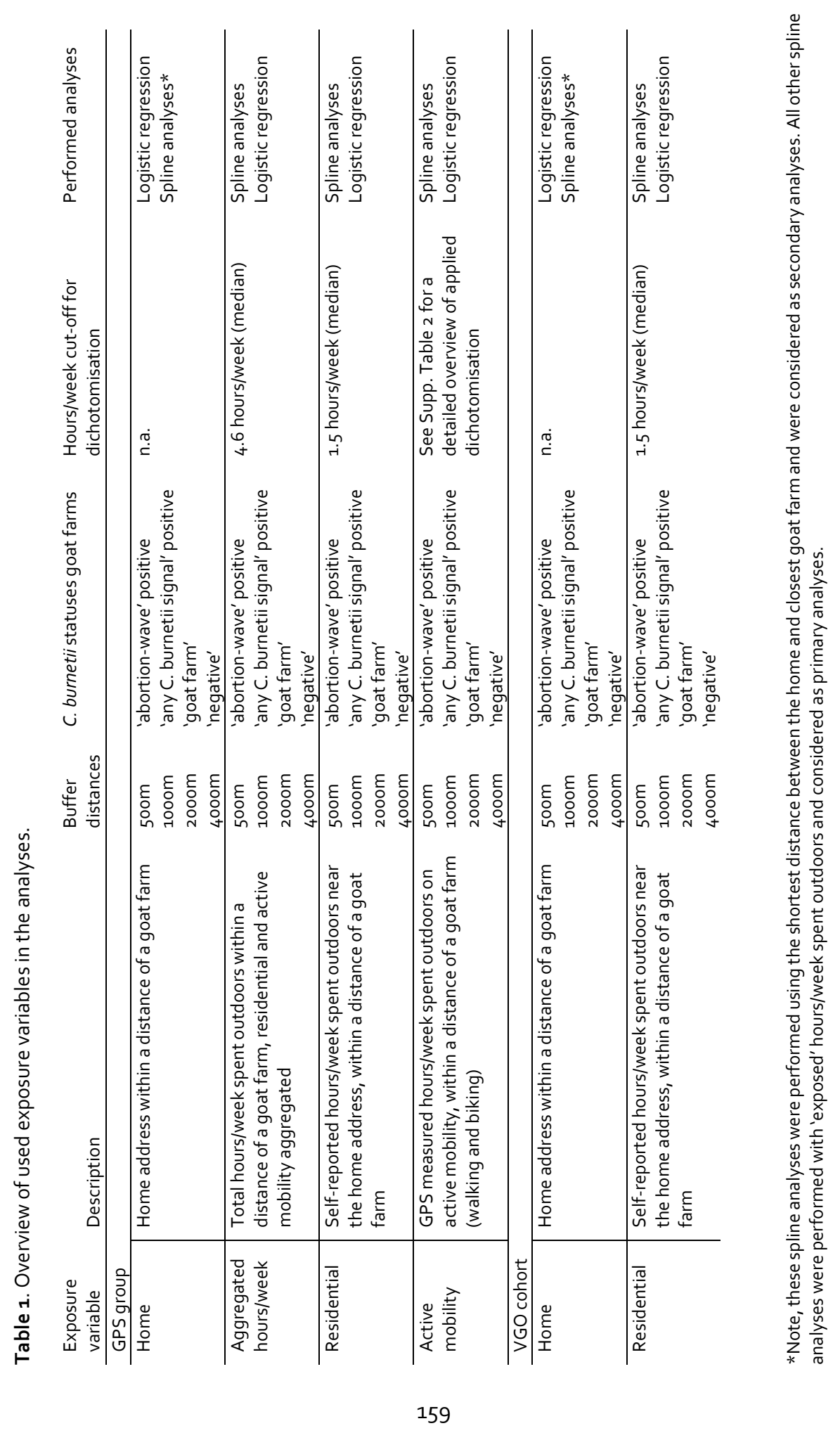


Data about location of goat farms was obtained from the database (2012) of livestockkeeping farms (Dutch abbreviation: BVB-database). These provincial databases (Limburg and Noord-Brabant) include permit registrations for farms, with information pertaining to location of the farm, animal species and numbers[25,26]. Farms with $>50$ goats were defined as goat farms, this cut-off was used because intervention steps were mandatory on farms with $>50$ goats during the outbreak[9,22]. Data concerning abortion-waves occurring on goat farms was provided by $\mathrm{GD}[27]$, data about $C$. burnetii positive bulk tank milk testing was available via the Dutch National Institute for Public Health and the Environment (RIVM), but originally collected by the Dutch food and consumer product safety authority[28].

We calculated aggregated hours/week spent outdoors by adding self-reported hours/week spent outdoors near the home (e.g. gardening, care for animals, do-ityourself activities, sitting in the garden, in hours/week from VGO questionnaire, see Supplement "VGO questionnaire 'time spent outdoors near the home" for the used question) and hours/week spent on active mobility (measured with GPS loggers). Aggregated hours/week spent outdoors were dichotomised into 'not often outdoors' and 'often outdoors' using the median hours/week spent outdoors ( $4.6 \mathrm{~h} /$ week). This frequency categorisation was combined with information about the goat farms to which people were exposed ('abortion-wave' positive farm within $2000 \mathrm{~m}$ of home and/or GPS track).

In line with previous analyses, we defined 'at home exposed' if a participant lived within 200om distance of an 'abortion-wave' positive goat farm. We assigned exposure to selfreported hours/week spent outdoors near the home (from VGO questionnaire). Here, we dichotomised self-reported hours/week into 'not often outdoors' and 'often outdoors' using the median hours/week spent outdoors near home (1.5h/week). Exposure during these hours/week spent outdoors was defined in line with 'at home exposed'.

Next, data from the GPS group was used to evaluate the associations between hours/week spent outdoors on active mobility near 'abortion-wave' positive farms and C. burnetii antibody serology responses. We used GPS coordinates assigned to one of the active modes (walking and biking), that fell within 200om distance around an 'abortion-wave' positive farm. The number of 'exposed' GPS coordinates (one per second) were added, thus providing an estimate of the total hours/week 'exposed' while being actively mobile. Participants were indicated as 'exposed while mobile' if their total logged 'exposed' hours/week exceeded the $20^{\text {th }}$ percentile of 'exposed' hours/week of the group that was actively mobile within the $2000 \mathrm{~m}$ buffer (for 'abortion-wave' positive farms the cut-off was 116 seconds). Participants that logged less than the $20^{\text {th }}$ percentile and those who were actively mobile outside of the used buffers were assigned to the 'unexposed while mobile' reference group. See Supp. Table 2 for an overview of the used time cut-offs.

\section{Serology}

Participants were considered C. burnetii antibody positive, if levels of $\lg G$ antibodies to C. burnetii phase II antigen were above 30 International Units $/ \mathrm{ml}(\mathrm{IU} / \mathrm{ml})$ or between 20 $30 \mathrm{IU} / \mathrm{ml}$ ('borderline' positive). Levels below $20 \mathrm{IU} / \mathrm{ml}$ were considered 'negative', 
according to the manufacturer's standards (Serion ELISA classic, Virion/Serion, Würzburg, Germany)[20,22].

\section{Statistical analysis}

We previously tested whether the GPS group was a representative sample of the VGO cohort[21], but repeated the analyses specified for this study. Chi-square tests of independence were performed for $C$. burnetii antibody serology status, gender, education level and smoking status. Age distributions were compared with a Wilcoxon rank sum test.

We used splines to explore the shape of the association between the different exposure variables (Table 1 ) and $C$. burnetii serology. Penalised regression splines were used applying the (default) 'thin plate' basis of the R package mgcv (mixed generalised additive model computation vehicle). Due to the group size limitations (Supp. Table 1), we preferred to show the results for the $2000 \mathrm{~m}$ buffers, spline plots using the other buffers are provided in Supp. Figures 2,3,4.

We used logistic regression to evaluate associations between $C$. burnetii serology and the different exposure variables (Table 1 ) adjusting for age, gender, educational level (low, medium, high) and smoking status (current, former, never). The analyses for living near a farm and self-reported hours/week spent outdoors near the home were subsequently repeated in the full VGO cohort.

\section{Sensitivity analysis}

In addition, we used splines in a number of sensitivity analyses to assess whether:

I. The distance between the home address and nearest 'abortion-wave' positive farm was associated with positive serology for C. burnetii[29].

II. The case definition influenced the shape of the associations. For this analysis participants indicated as 'borderline' positive ( $C$. burnetii antibody serology: 20$30 \mathrm{IU} / \mathrm{ml}$ ) were assumed to be false positive and thus assigned to the reference group instead of the positive case group.

III. Logging a normal week during the GPS measurements influenced the shape of the associations. For all GPS group members, we had self-reported information whether people had had a 'normal week' during the GPS measurement. We excluded participants that reported not having had a 'normal week' during GPS logging.

IV. Analysis I. was repeated in the full VGO cohort.

All analyses were repeated with the other $C$. burnetii statuses of goat farms ('any $C$. burnetii signal' positive farm, 'goat farm' and 'negative' farm) and buffer sizes (500m, 1000m, and 4000m).

All statistical analyses were performed using $\mathrm{R}$ (3.4.3), and all GIS analyses were performed with ArcGIS ArcMap 10.5 (ESRI, Redlands, CA, USA) and automated using Python 2.7. 


\section{Results}

Participants without $C$. burnetii serology data were excluded from the analyses and 924 (98\%) participants remained in the GPS group, of which 32 (3.5\%) were seropositive, 19 (2.1\%) were borderline positive and 873 (94.5\%) were seronegative. In the VGO cohort, 93 participants (3.8\%) were serology positive, 53 (2.2\%) were borderline positive and $2273(94 \%)$ serology negative. The distributions of age and percentages of serology positive participants, gender, education levels and smoking status displayed similar distribution among the GPS group and VGO cohort (Table 2).

Table 2. General characteristics study population, subset and statistical comparison (a) Chi-square test for independence, (b) Wilcoxon rank sum test.

\begin{tabular}{|c|c|c|c|c|}
\hline Variable & & VGO cohort & GPS group & P-value \\
\hline $\begin{array}{l}\text { Total participants in population }(\mathrm{N}=) \\
\text { Participants, with } \mathrm{Q} \text { fever serology data }\end{array}$ & $(\mathrm{N}=(\%$ of total population $))$ & $\begin{array}{l}2494 \\
2419(97.0 \%)\end{array}$ & $\begin{array}{l}941 \\
924(98.2 \%)\end{array}$ & $\begin{array}{l}\text { n.a. } \\
\text { n.a. }\end{array}$ \\
\hline Q fever IgG serology positive $(\mathrm{N}=(\%))$ & Yes (>30 EU/ml) & $93(3.8 \%)$ & $32(3.5 \%)$ & $0.85^{a}$ \\
\hline & Borderline $(20-30 \mathrm{EU} / \mathrm{ml})$ & $53(2.2 \%)$ & $19(2.1 \%)$ & \\
\hline & $\mathrm{No}(<2 \mathrm{oEU} / \mathrm{ml})$ & $2273(94 \%)$ & $873(94.5 \%)$ & \\
\hline Age (years, median (range)) & & $59(20-72)$ & $59(20-72)$ & $0.22^{\mathrm{b}}$ \\
\hline Gender $(\mathrm{N}$ females $=(\%))$ & & $1315(54.4 \%)$ & $508(55.0 \%)$ & $0.78^{\mathrm{a}}$ \\
\hline Education $(\mathrm{N}=(\%))$ & Low & $609(25.2 \%)$ & $221(23.9 \%)$ & $0.75^{\mathrm{a}}$ \\
\hline & Medium & $1079(44.6 \%)$ & $419(45 \cdot 3 \%)$ & \\
\hline & High & $731(30.2 \%)$ & $284(30.7 \%)$ & \\
\hline Smoking $(\mathrm{N}=(\%))$ & Never & $1024(42.3 \%)$ & $373(40.4 \%)$ & $0.10^{\mathrm{a}}$ \\
\hline & Former & $1157(47.8 \%)$ & $478(51.7 \%)$ & \\
\hline & Current & $221(9.1 \%)$ & $70(7.6 \%)$ & \\
\hline & No data & $17(0.7 \%)$ & $3(0.3 \%)$ & \\
\hline
\end{tabular}

Hours/week spent outdoors near goat farms and positive serology

Spending more aggregated hours/week outdoors within 2000m of 'abortion-wave' and 'any $C$. burnetii signal' positive farms was associated with a statistically significant increased risk for positive C. burnetii serology (OR 3.6, 95\% Cl (1.2-10.6) and OR 4.9, $95 \% \mathrm{Cl}$ (1.9-12.4), respectively, see Table 3). No increased risks were observed for aggregated hours/week spent outdoors within $2000 \mathrm{~m}$ of 'goat farms' or 'negative' farms (OR $1.095 \% \mathrm{Cl}(0.4-2.2)$ and $\mathrm{OR} 1.095 \% \mathrm{Cl}(0.4-2.5)$, respectively, see Table 3). Spline plots for aggregated hours/week spent outdoors within 2000m of farms (Figure 2a-d) confirmed these trends.

We found that with more hours/week spent outdoors near the home while living within 2000m of an 'abortion-wave' (OR 2.1, 95\%Cl (0.6-7.4)), 'any C. burnetii signal' (OR 2.6, $95 \% \mathrm{Cl}(1.0-6.9))$ positive or 'goat farm' (OR 1.4, 95\% Cl (0.6-3.3)), the risk for positive $C$. burnetii serology increased (Table 3 ). These associations were confirmed in the spline analyses for hours/week spent outdoors near the home (Figure za-d). For weekly routine active mobility, we observed that people in general, only spent short periods within the specified buffers around ( $C$. burnetii positive) goat farms (Supplementary Table 3 ). The splines showed that overall, (the limited periods of) active mobility alone was not associated with an increased risk for positive status of $C$. burnetii antibody serology (Figure ze-h). 


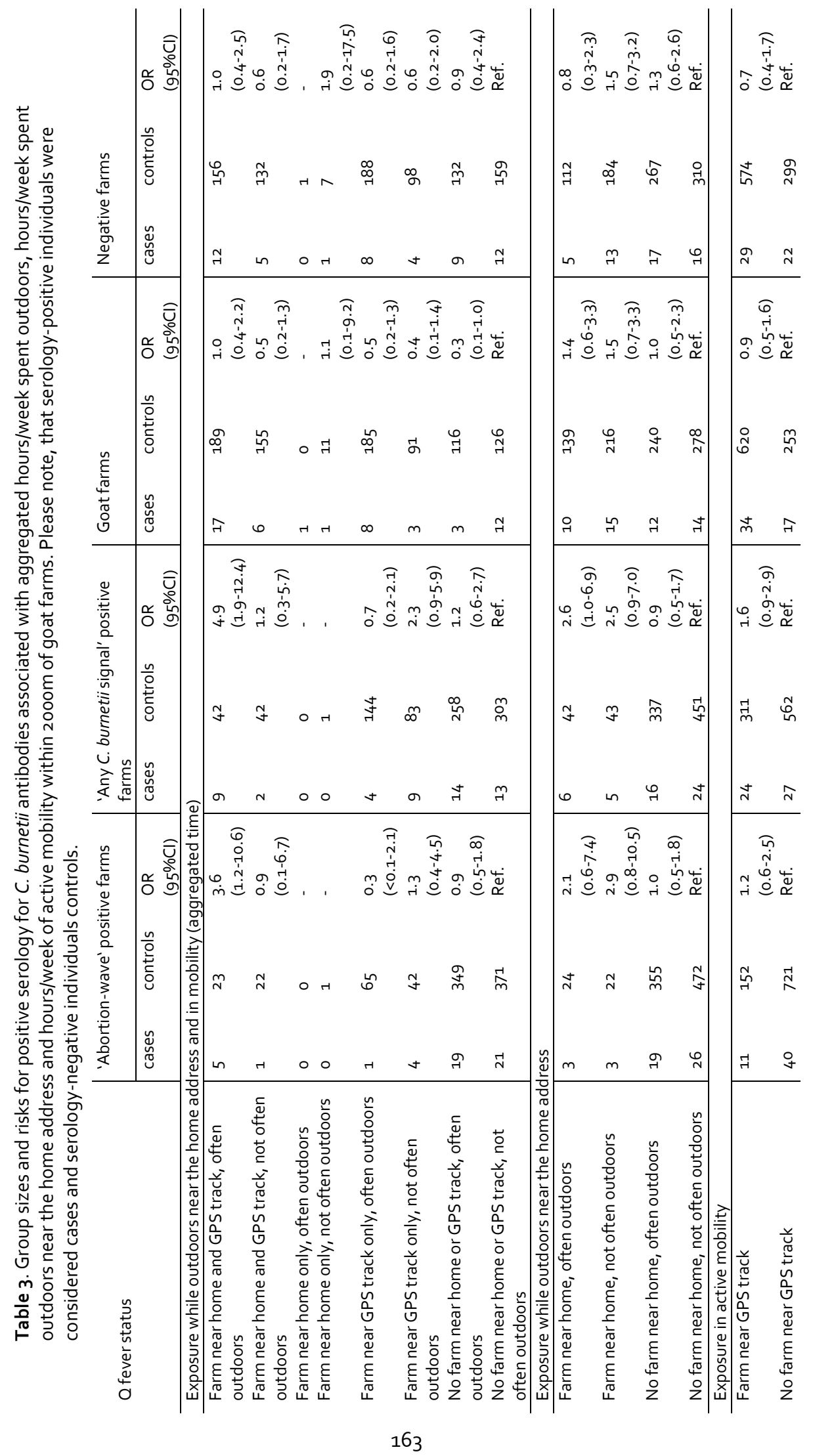



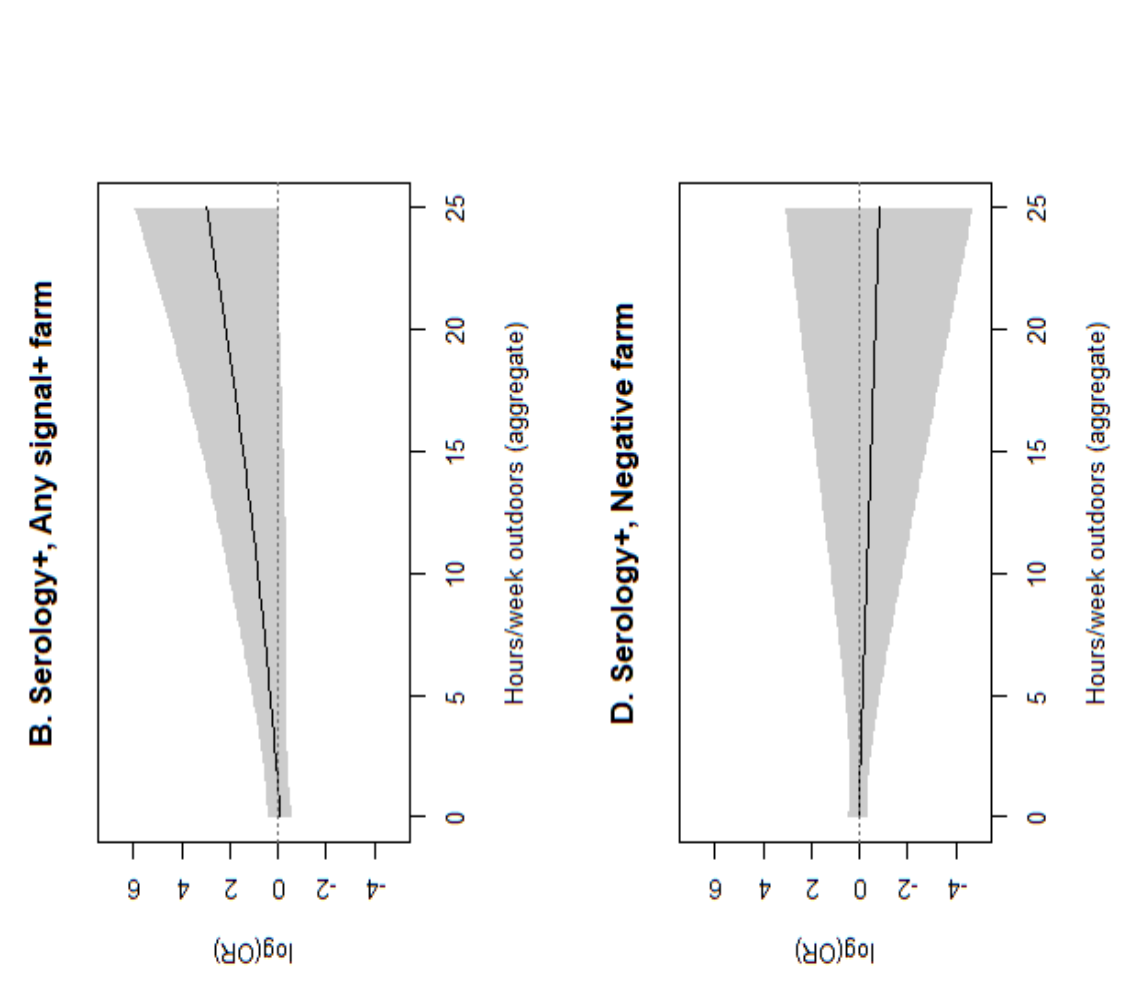

है

部

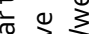

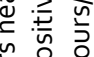

능요오

응 0

ठำ

気 它

in

范

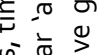

ज品京

응 ज :

ㅎํㅇㅎㅇ

范

唫

जे

ष造部

in

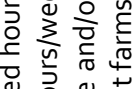

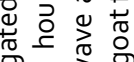

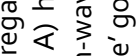

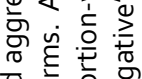

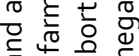
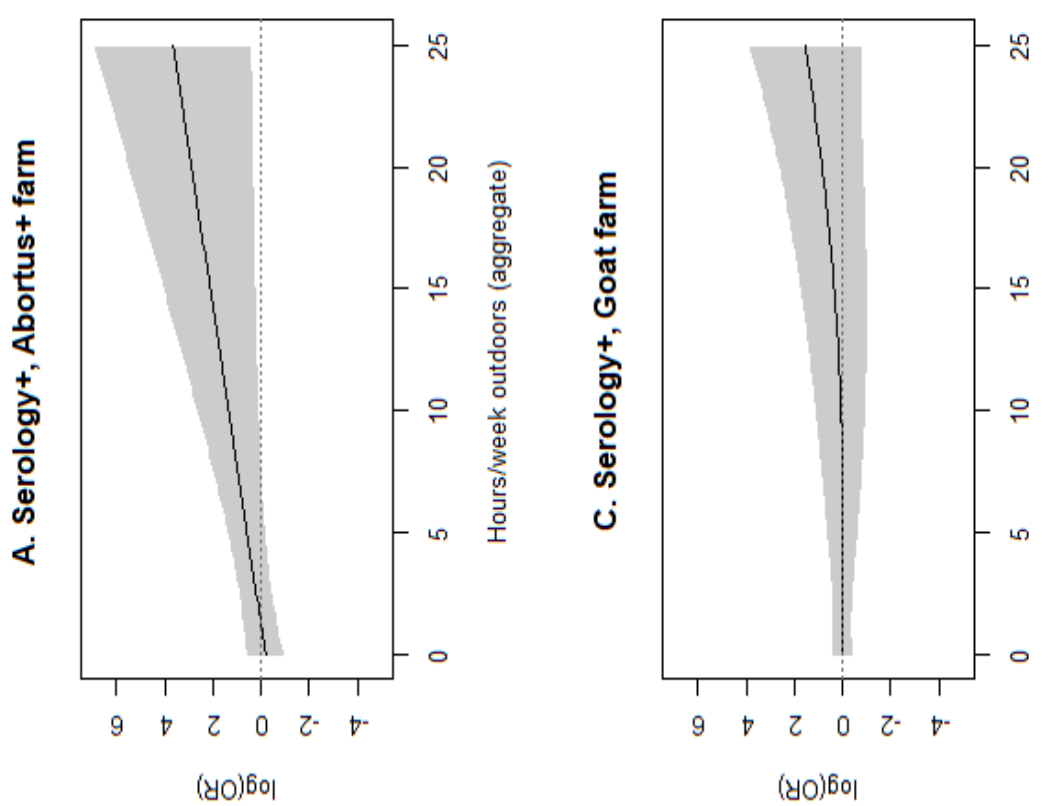

ลิธ兀 음 है

원ㅇำ

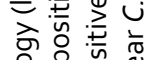
ब \% 兽 :

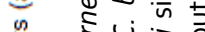

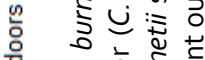
ㅇํㄱ \& है ड 主京范

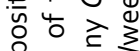
흔 눈 는 论高

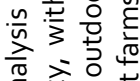

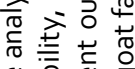
范 की ह के ज. $\stackrel{0}{\square}$

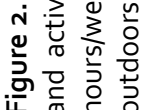


A. Serology+, Abortus + farm

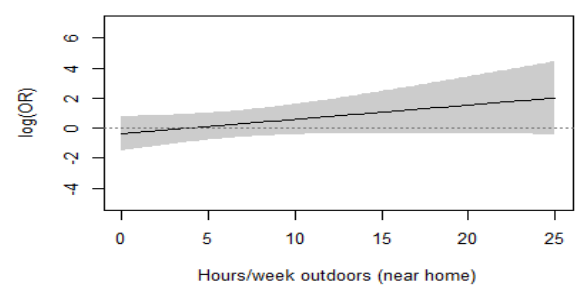

C. Serology+, Goat farm

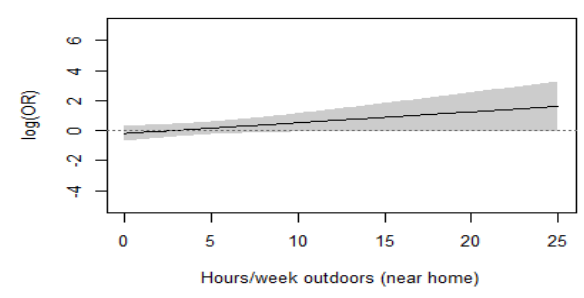

E. Serology+, Abortus + farm

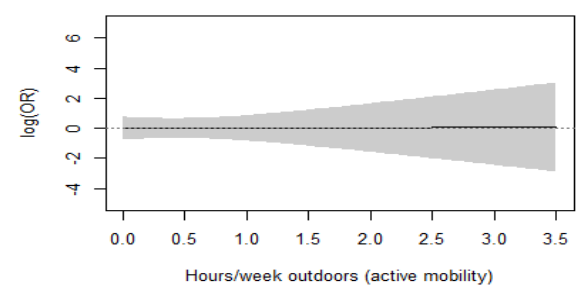

G. Serology+, Goat farm

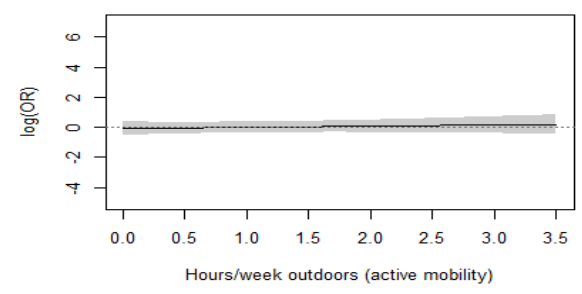

B. Serology+, Any signal+ farm

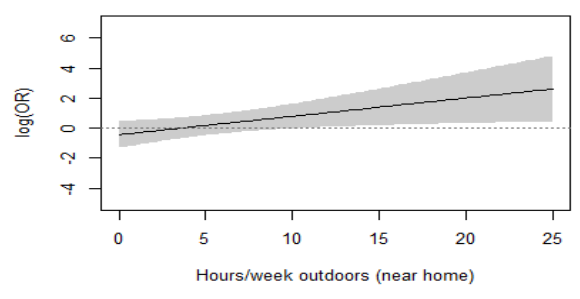

D. Serology+, Negative farm

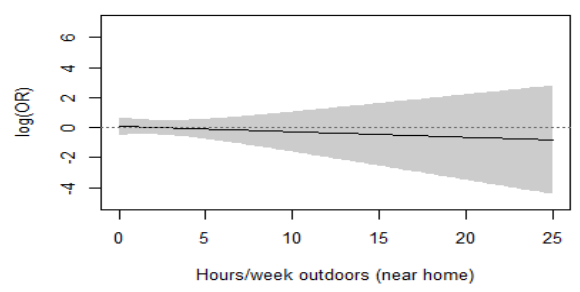

F. Serology+, Any signal+ farm

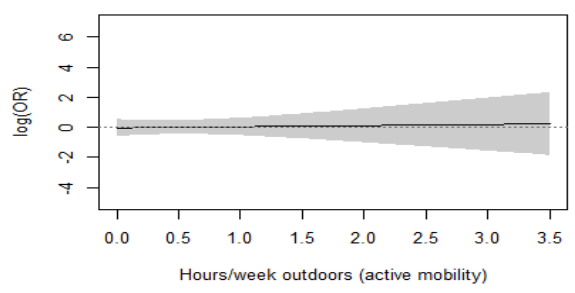

H. Serology+, Negative farm

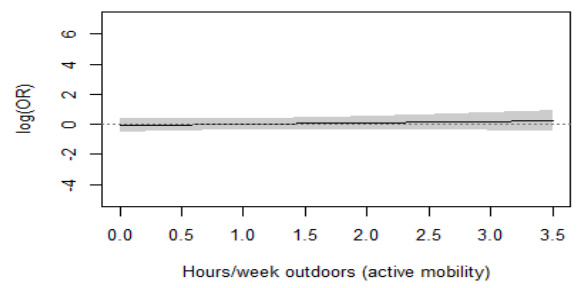

Figure 3. Spline analysis for the risk of positive serology for C. burnetii antibodies (log (OR)) associated with hours/week spent outdoors near the home (A-D) or routine hours/week of active mobility $(E-H)$ within a buffer of $2000 m$ around a goat farm. A. hours/week spent outdoors near the home within $2000 \mathrm{~m}$ of an 'abortus-wave' positive goat farm. B. hours/week spent outdoors near the home within $2000 \mathrm{~m}$ of an 'any C. burnetii signal' positive goat farm. C. hours/week spent outdoors near the home within 2000 m of a goat farm. D. hours/week spent outdoors near the home within 200om of a 'negative' goat farm. E. routine hours/week of active mobility within $2000 \mathrm{~m}$ of 'abortus-wave' positive goat farms. F. routine hours/week of active mobility within 2000 m of 'any C. burnetii signal' positive goat farms. G. routine hours/week of active mobility within $2000 \mathrm{~m}$ of 'goat farms' and $\mathrm{H}$. routine hours/week of active mobility within $2000 \mathrm{~m}$ 'negative' goat farms. Note, the differences in the scaling of the $x$-axis, hours/week spent outdoors near the home (A-D) have a maximum $X$ of 25 hours and the hours/week spent on active mobility $(E-H)$ have a maximum $X$ of 3.5 hours. 
Logistic regression analyses suggested a marginal, not statistically significant, positive association for active mobility within $2000 \mathrm{~m}$ of 'abortion-wave' positive goat farms (OR $1.2,95 \% \mathrm{Cl}(0.6-2.5))$ or 'any C. burnetii signal' positive goat farms (OR 1.6, 95\% Cl (0.92.9)) (Table 3).

The sensitivity analyses showed that with increasing distance to the nearest 'abortionwave' positive, 'any $C$. burnetii signal' positive and 'goat farms' the risk for positive $C$. burnetii antibody serology decreased (I.) in the GPS group and the whole VGO cohort (IV). For 'negative' goat farms no such associations were found (Supp. Figure 5). These associations showed the same tendencies when looking at the increasing buffer distances and types of $C$. burnetii status of the farms: higher ORs were found for risk of serology positivity if 'abortion-wave' or 'any $C$. burnetii signal' positive goat farms were in closer proximity to the home address (Supp. Table 1). Using the stricter case definition (II.) or reducing our data set to participants reporting to have had a 'normal week' (III.) during the GPS measurement did not materially change effects in the spline analyses (Supp. Figure 6 and 7).

\section{Discussion}

Our analyses indicated that spending more hours/week outdoors near former $C$. burnetii positive farms, significantly increased the risk of being $C$. burnetii serology positive. To a lesser extent, these associations were observed for self-reported hours/week spent outdoors in the vicinity of the home only. Routine hours/week of active mobility near former $C$. burnetii positive goat farms only marginally increased the risk for positive $C$. burnetii serology.

The main driver of the increased risk for positive $C$. burnetii serology were self-reported hours/week spent outdoors near the home, while living near farms that were $C$. burnetii positive during the Dutch $\mathrm{Q}$ fever outbreak[1]. This is in line with recent observations in this study population where we observed an increase in pneumonia risk for people living near goat farms that reported to spent more hours/week outdoors near the home[7].

It has been questioned whether mobility played a role in the exposure to, and uptake of, C. burnetii bacteria in people moving through the area during the 2007-2009 $\mathrm{O}$ fever outbreak $[2,5,12]$. Our analyses showed that active mobility as such only marginally increased the risk of becoming serology positive for $C$. burnetii antibodies. In an earlier analysis we did not find such an association for pneumonia[7]. When active mobility (in hours/week) was aggregated with the self-reported hours/week spent outdoors, the spline plots displayed narrower error margins. This indicates that the risk of becoming C. burnetii serology positive is more accurately calculated when active mobility was considered as well.

In line with previous studies[2,8,9,20], we also identified a distance-risk association between positive $C$. burnetii antibody serology in residents and living near previously $C$. burnetii infected goat farms, in our GPS subgroup and the full VGO cohort. We showed that the source of exposure seems to have played a role in the distance-risk associations, since living near 'abortion-wave' positive farms, 'any $C$. burnetii signal' positive farms and, to a lesser extent, just 'goat farms' increased the risk for positive $C$. burnetii antibody serology. These three $C$. burnetii statuses all included farms that had experienced abortion-waves during the Dutch outbreak[1]. 
With kidding and abortions of infected pregnant goats[30], large amounts of $C$. burnetiibacteria are excreted to the environment[24]. While in the environment, $C$. burnetii bacteria are exceptionally durable against dehydration and chemical agents. $C$. burnetii bacteria remain viable and infectious for a long period outside of a host organism[31]. Also adding to the risk of infection is that $C$. burnetii bacteria are extremely infectious to humans[32]. Given the potentially excreted amount and infectivity of emitted $C$. burnetii bacteria during the outbreak, spending time outdoors within close distance to an emitting farm appears to have contributed to $C$. burnetii exposure and infection in the years 2007 through 2009.

\section{Strengths and limitations}

A strength of our study is that main analyses were based on measurements from a large study group (GPS group, N=941), living in a rural area where between 2007 and 2009 a large $\mathrm{Q}$ fever outbreak occurred. In addition, we had detailed information about medical-, occupational- and spatial characteristics of our study participants. GPS group members were recruited from the larger VGO study cohort $(N=2494)[7,19,22]$ and part of the VGO study was a serology screening for $\mathrm{Q}$ fever antibodies[20,22]. Although nearly $6 \%$ of the GPS group were (borderline-) positive for $C$. burnetii antibodies, we were limited in our ability to explore the risks for positive $C$. burnetii antibody serology. Data collection for the VGO study occurred between March 2014 and February 2015[19] and GPS measurements were performed between September 2014 and January $2016[7,21]$. These periods did not coincide with the $Q$ fever outbreak in the Netherlands[1] therefore, our study is based on the assumptions that residential address and activity patterns measured between 2014 and 2016 reflect those during the outbreak period. Daily routines of people have been reported not to change much over time and if they change this is mainly age and life-stage related (e.g. puberty, having children, retirement)[33,34], factors that may not have changed to a large extent within our population (Supp. Figure 8). If outdoor activities changed independently of $C$. burnetii serology status, then this would imply that non-differential misclassification may have attenuated our risk estimates. In this case, our risk estimates may have been biased towards unity. The true effect of time spent outdoors near $C$. burnetii positive farms on $C$. burnetii serology turnover therefore, may be even stronger than the effect we observed in our study.

\section{Conclusions}

We observed that outdoor exposure may have contributed to the risk of becoming $C$. burnetii serology positive. These associations were stronger if people lived closer to $C$. burnetii positive farms.

Depending on the causal pathogen in the event of a future livestock related outbreak of a zoonotic disease[35], if feasible, hours/week spent outdoors or being actively mobile close to infected farms should be included to outbreak management approaches. 


\section{Acknowledgements}

We like to thank all the participants, Lützen Portengen for statistical input and Daisy de Vries for textual input. The VGO GPS Study is funded by UMC Utrecht, publications fees for this article were available from IRAS. The Livestock Farming and Neighboring Residents' Health (VGO) study was funded by the Ministry of Health, Welfare and Sports and the Ministry of Economic Affairs of the Netherlands, and supported by a grant from the Lung Foundation Netherlands (Grant number: 3.2.11.022). 


\section{References}

1. Roest HIJ, Tilburg JJHC, Van Der Hoek W, et al. The $Q$ fever epidemic in the Netherlands: History, onset, response and reflection. Epidemiol Infect. 2011;139(1):1-12.

doi:10.1017/S0950268810002268.

2. Van der Hoek W, Van De Kassteele JVD, Bom B, et al. Smooth incidence maps give valuable insight into Q fever outbreaks in the Netherlands. Geospat Health. 2013;7(1):127-134. doi:10.4081/gh.2012.111.

3. Schneeberger PM, Wintenberger C, van der Hoek W, Stahl JP. Q fever in the Netherlands - 20072010: What we learned from the largest outbreak ever. Med Mal Infect. 2013;44(8):339-353. doi:10.1016/j.medmal.2014.02.006.

4. Dijkstra F, van der Hoek W, Wijers N, et al. The 2007-2010 Q fever epidemic in the Netherlands: Characteristics of notified acute $Q$ fever patients and the association with dairy goat farming. FEMS Immunol Med Microbiol. 2012;64(1):3-12. doi:10.1111/j.1574-695X.2011.00876.x.

5. De Rooij MMT, Van Leuken JPG, Swart A, et al. A systematic knowledge synthesis on the spatial dimensions of Q fever epidemics. Zoonoses Public Health. 2019;66(1):14-25. doi:10.1111/zph.12534.

6. De Rooij MMT, Heederik DJJ, Borlée F, Hoek G, Wouters IM. Spatial and temporal variation in endotoxin and PM10 concentrations in ambient air in a livestock dense area. Environ Res. 2017;153(September 2016):161-170. doi:10.1016/j.envres.2016.12.004.

7. Klous G, Smit L a. M, Freidl GS, et al. Pneumonia risk of people living close to goat and poultry farms - Taking GPS derived mobility patterns into account. Environ Int. 2018;115(October 2017):150-160. doi:10.1016/j.envint.2018.03.020.

8. Smit $L$ a M, van der Sman-de Beer F, Opstal-van Winden AWJ, et al. Q fever and pneumonia in an area with a high livestock density: A large population-based study. PLoS One. 2012;7(6). doi:10.1371/journal.pone.0038843.

9. Commandeur M, Jeurissen L, Van Der Hoek W, Roest HJ, Hermans T. Spatial relationships in the $Q$ fever outbreaks 2007-2010 in the Netherlands. Int J Environ Health Res. 2014;24(2):137-157. doi:10.1080/09603123.2013.800963.

10. Van Leuken JPG, Swart a. N, Brandsma J, et al. Human Q fever incidence is associated to spatiotemporal environmental conditions. One Heal. 2016;2:77-87.

doi:10.1016/j.onehlt.2016.03.004.

11. Van der Hoek W, Hunink J, Vellema P, Droogers P. Q fever in The Netherlands: the role of local environmental conditions. Int J Environ Health Res. 2011;21(6):441-451. doi:10.1080/09603123.2011.574270.

12. Van Leuken JPG, van de Kassteele J, Sauter FJ, et al. Improved correlation of human Q fever incidence to modelled C. burnetii concentrations by means of an atmospheric dispersion model. Int J Health Geogr. 2015;14(1):1-14. doi:10.1186/s12942-015-0003-y.

13. Van den Berg EJ, Wielders CCH, Schneeberger PM, Wegdam-Blans MC, van der Hoek W. Spatial analysis of positive and negative $Q$ fever laboratory results for identifying high- and low-risk areas of infection in the Netherlands. Infect Ecol Epidemiol. 2013;3(1):20432. doi:10.3402/iee.v3i0.20432.

14. Hogerwerf L, van den Brom R, Roest HIJ, et al. Reduction of coxiella burnetii prevalence by vaccination of goats and sheep, The Netherlands. Emerg Infect Dis. 2011;17(3):379-386. doi:10.3201/eid1703.101157.

15. Vellema $P$, van den Brom R. The rise and control of the 2007-2012 human $Q$ fever outbreaks in the Netherlands. Small Rumin Res. 2014;118(1-3):69-78. doi:10.1016/j.smallrumres.2013.12.006.

16. Van den Brom R, Santman-Berends I, Luttikholt S, Moll L, Van Engelen E, Vellema P. Bulk tank milk surveillance as a measure to detect Coxiella burnetii shedding dairy goat herds in the Netherlands between 2009 and 2014. J Dairy Sci. 2015;98(6):3814-3825. doi:10.3168/jds.2014-9029.

17. Hogerwerf L, Borlée F, Still K, et al. Detection of Coxiella burnetii DNA in inhalable airborne dust samples from goat farms after mandatory culling. Appl Environ Microbiol. 2012;78(15):5410-5412. doi:10.1128/AEM.00677-12.

18. Van Roeden SE, Reukers DFM, Van Jaarsveld CHM, et al. Chronic Q fever: Patient and treatmentrelated factors influencing long-term quality of life. Qjm. 2018;111(11):791-797.

doi:10.1093/qjmed/hcy171. 
19. Borlee F, Yzermans CJ, Krop E, et al. Spirometry, questionnaire and electronic medical record based COPD in a population survey: Comparing prevalence, level of agreement and associations with potential risk factors. PLoS One. 2017;12(3):1-16. doi:10.1371/journal.pone.0171494.

20. Pijnacker R, Reimerink J, Smit L a. M, et al. Remarkable spatial variation in the seroprevalence of Coxiella burnetii after a large Q fever epidemic. BMC Infect Dis. 2017;17(1):1-8.

doi:10.1186/s12879-017-2813-y.

21. Klous G, Smit LAM, Borlée F, et al. Mobility assessment of a rural population in the Netherlands using GPS measurements. Int J Health Geogr. 2017;16(1):30. doi:10.1186/s12942-017-0103-y.

22. Freidl GS, Spruijt IT, Borlée F, et al. Livestock-associated risk factors for pneumonia in an area of intensive animal farming in the Netherlands. PLoS One. 2017;12(3):1-16.

doi:10.1371/journal.pone.0174796.

23. Huss A, Beekhuizen J, Kromhout H, Vermeulen R. Using GPS-derived speed patterns for recognition of transport modes in adults. Int J Health Geogr. 2014;13(1):1-8. doi:10.1186/1476-072X-13-40.

24. Arricau Bouvery N, Souriau A, Lechopier P, Rodolakis A. Experimental Coxiella burnetii infection in pregnant goats: excretion routes. Vet Res. 2003;34:423-433. doi:10.1051/vetres:2003017.

25. bvb Brabant. http://bvb.brabant.nl/.

26. bvb Limburg. http://www.limburg.nl/.

27. Royal GD. https://www.gddiergezondheid.nl/.

28. Netherlands Food and Product safety Authority (NVWA). www.nvwa.nl.

29. ArcGIS near analysis. https://pro.arcgis.com/en/pro-app/tool-reference/analysis/near.htm.

30. Angelakis E, Raoult D, Angelakis E, Raoult D, Veterinary Q. Q fever To cite this version : HAL Id : hal00556051. 2011;140:297-309. doi:10.1016/j.vetmic.2009.07.016.

31. Raoult D, Marrie TJ, Mege JL. Natural history and pathophysiology of Q fever. Lancet Infect Dis. 2005;5(4):219-226. doi:10.1016/S1473-3099(05)70052-9.

32. Brooke RJ, Kretzschmar ME, Mutters NT, Teunis PF. Human dose response relation for airborne exposure to Coxiella burnetii. BMC Infect Dis. 2013;13(1):488. doi:10.1186/1471-2334-13-488.

33. Ouellette J a., Wood W. Habit and Intention in Everyday Life: The Multiple Processes by Which Past Behavior Predicts Future Behavior. Psychol Bull. 1998;124(1):54-74. doi:10.1037/0033-

2909.124.1.54.

34. Coltrane S. Research on household labor: modeling and measuring the social embeddedness of routine family work. J Marriage Fam. 2000;62(November):1208-1233.

35. Smith C, Le Comber S, Fry H, Bull M, Hayward A. Spatial methods for infectious disease outbreak investigations: systematic literature review. Euro Surveill. 2015;20(39).

doi:http://dx.doi.org/10.2807/1560-7917.ES.2015.20.39.30026. 


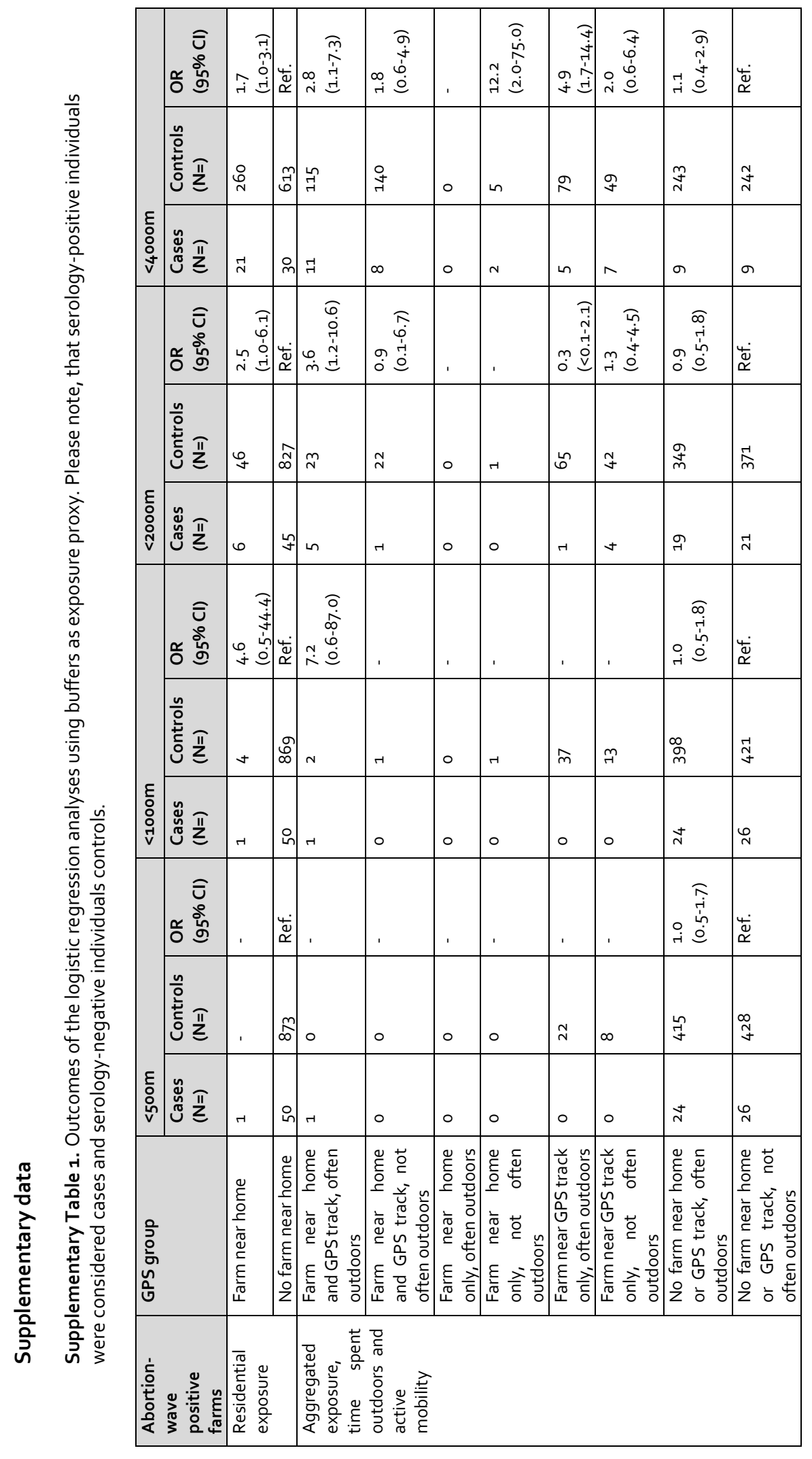




\begin{tabular}{|c|c|c|c|c|c|c|c|c|c|c|c|c|c|c|}
\hline 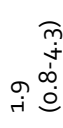 & 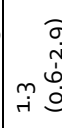 & & & 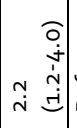 & & 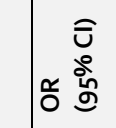 & 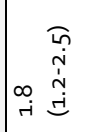 & $\underset{\sim}{a}$ & 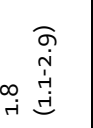 & | & 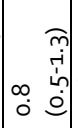 & & 商 & $\stackrel{m}{m}$ \\
\hline nn & 茴 & 促 & స్లి & ळ్m & 过 & 咅 $\frac{\pi}{2}$ & 芯 & 总 & 岕 & 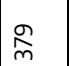 & 我 & సू & 竞 $\frac{\pi}{2}$ & 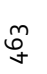 \\
\hline r & F & ก & 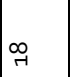 & $\vec{m}$ & i & \begin{tabular}{l|l}
$\vdots$ \\
$\vdots$ \\
$⿱ 亠 乂$ \\
$v$
\end{tabular} & in & की? & $\hat{\imath}$ & $\tilde{m}$ & $\stackrel{\varphi}{m}$ & ก & 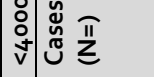 & q \\
\hline ن. & 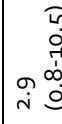 & 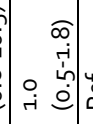 & & 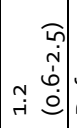 & $\stackrel{4}{\dddot{\Xi}}$ & 言 & 丽 & : & 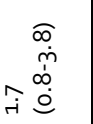 & (ָ) & 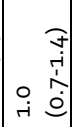 & $\stackrel{\ddot{\tilde{g}}}{\ddot{\alpha}}$ & 言 & $\widehat{i}$ \\
\hline 4 & ก & 嵛 & fr & ș & N & 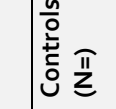 & E్ & ते & $\approx$ & $\infty$ & 苟 & $\begin{array}{l}\mathcal{O} \\
\text { Ṅ }\end{array}$ & 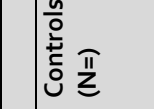 & $\infty$ \\
\hline$m$ & $m$ & I & W & $F$ & q & 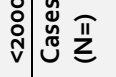 & I & ज्ञी。 & $\infty$ & $F$ & is & m & 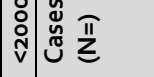 & $F$ \\
\hline 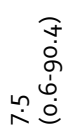 & & 资 & & 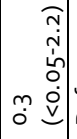 & & 言 & 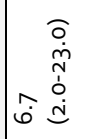 & 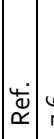 & 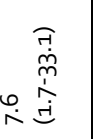 & 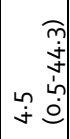 & & $\stackrel{\square}{\dddot{\Xi}}$ & 言 & $\mid \begin{array}{l}n \\
0 \\
0 \\
\end{array}$ \\
\hline N & h & 䎟 & 尔 & $\tilde{n}$ & $\tilde{\infty}_{\substack{0 \\
\infty}}$ & 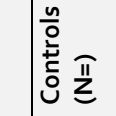 & $\infty$ & 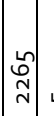 & in & $m$ & 这 & స్ & 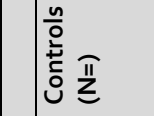 & $\infty$ \\
\hline H & . & i & is & H & in & 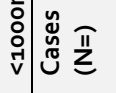 & t & 神 & m & 4 & in & $\infty$ & 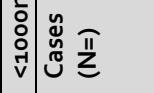 & t \\
\hline & I & 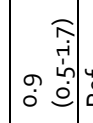 & & 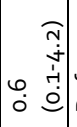 & & 言 & 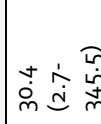 & & 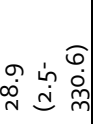 & & 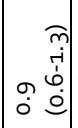 & & 言 & $\hat{i}$ \\
\hline 4 & . & 昰 & 奇 & $\stackrel{\circ}{m}$ & क्ञ & 旾 & 4 & ปิ| & H & . & 夠 & : & 旾 & 4 \\
\hline & ' & 4 & is & H & in & \begin{tabular}{l|l} 
\\
$\vdots$ \\
$\vdots$ \\
$\vdots$
\end{tabular} & N & जे & N & & $\circ$ & $\infty^{+}$ & 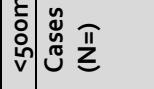 & 4 \\
\hline 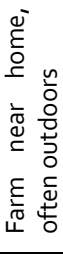 & 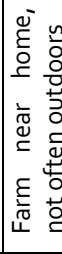 & 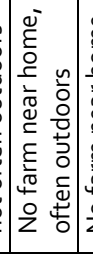 & 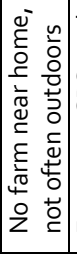 & 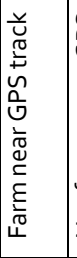 & 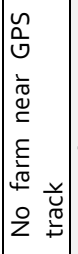 & 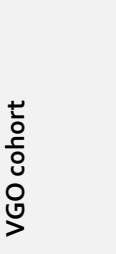 & 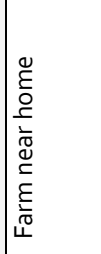 & 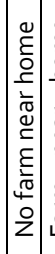 & 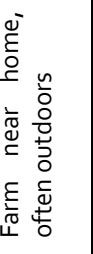 & 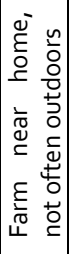 & 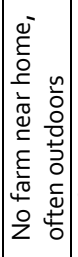 & 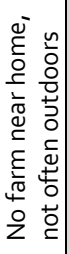 & $\begin{array}{l}0 \\
\vdots \\
\vdots \\
\vdots \\
n \\
\vdots \\
0 \\
0\end{array}$ & 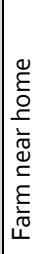 \\
\hline $\begin{array}{l}0 \\
0\end{array}$ & 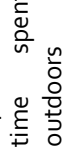 & & & ष्टे & & 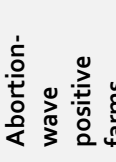 & 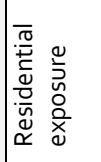 & & & & & & 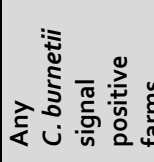 & \\
\hline
\end{tabular}




\begin{tabular}{|c|c|c|c|c|c|c|c|c|c|c|c|c|c|}
\hline 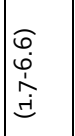 & $\mid \begin{array}{l}\stackrel{\Psi}{\Psi} \\
\propto\end{array}$ & 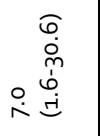 & 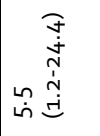 & & 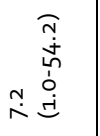 & 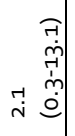 & 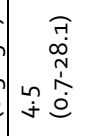 & 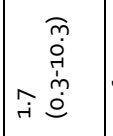 & $\begin{array}{l}\stackrel{\Psi}{\Psi} \\
\propto\end{array}$ & $\begin{aligned} & \widehat{m} \\
& \dot{d} \\
& \stackrel{\dot{m}}{\dot{i}} \\
& \dot{m}\end{aligned}$ & 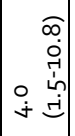 & 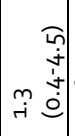 & $\frac{\square}{\alpha}$ \\
\hline & 워 & $\stackrel{\circ}{\text { N }}$ & $\underset{N}{A}$ & $m$ & T) & ০্̊ণ & ڤn' & $\mid \underset{\sim}{\mathbb{A}}$ & $\underset{\sim}{\stackrel{\sim}{m}}$ & 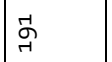 & $\underset{N}{N}$ & 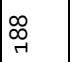 & $\underset{N}{\mathbb{N}}$ \\
\hline & 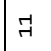 & A & $\hat{A}$ & $\circ$ & $N$ & $m$ & $m$ & $m$ & $N$ & $\underset{r}{0}$ & A & 6 & in \\
\hline 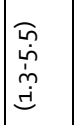 & 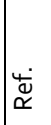 & 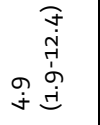 & 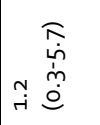 & & & 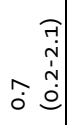 & 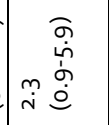 & 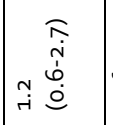 & $\mid \begin{array}{l}\stackrel{\Psi}{\Psi} \\
\propto\end{array}$ & 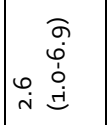 & 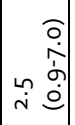 & 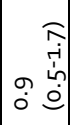 & 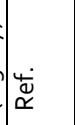 \\
\hline & 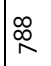 & $\mathcal{F}$ & $\stackrel{N}{\forall}$ & $\circ$ & H & $\underbrace{+}$ & $\infty$ & $\stackrel{\substack{n \\
N}}{ }$ & $\stackrel{m}{m}_{m}^{m}$ & $\mathcal{F}$ & ๆ & $\hat{m}$ & 然 \\
\hline & $\stackrel{\circ}{+}$ & $a$ & n & $\circ$ & $\circ$ & t & $\sigma$ & $\vec{~}^{*}$ & m & 0 & in & ب্ & 4 \\
\hline $\begin{array}{l}\widehat{\alpha} \\
\dot{m} \\
\hat{\alpha} \\
\dot{j}\end{array}$ & $\mid \begin{array}{l}\stackrel{\Psi}{\Psi} \\
\propto\end{array}$ & 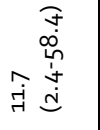 & I. & . & ' & 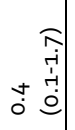 & . & 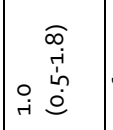 & 㐫 & 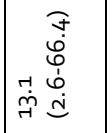 & 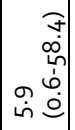 & 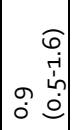 & $\stackrel{4}{\ddot{\ddot{\alpha}}}$ \\
\hline & 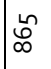 & t & $m$ & 0 & H & $\infty$ & F & 岕 & 柋 & $m$ & t & $\stackrel{n}{n}$ & 离 \\
\hline & f & $m$ & $\circ$ & H & $\circ$ & N & 0 & $\vec{n}$ & it & t & $H$ & ) & $\stackrel{\infty}{\sim}$ \\
\hline 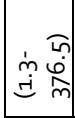 & 4 & 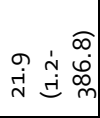 & . & I & ' & ナั & . & 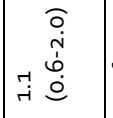 & $\begin{array}{l}\stackrel{4}{\varpi} \\
\propto\end{array}$ & 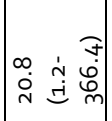 & . & 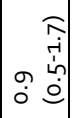 & $\Psi_{\alpha}^{\dot{\alpha}}$ \\
\hline & $\underset{\infty}{N}$ & H & $\circ$ & $\circ$ & $\circ$ & $\stackrel{\llcorner}{\forall}$ & in & 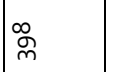 & f̛ & $H$ & , & $\stackrel{\infty}{\stackrel{\infty}{m}}$ & के \\
\hline & in & H & 0 & $\circ$ & $\circ$ & $H$ & 0 & $\stackrel{\sim}{N}$ & N & H & , & H & จे \\
\hline & 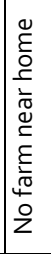 & 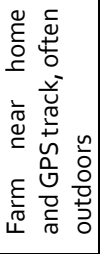 & 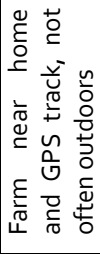 & 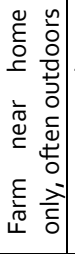 & 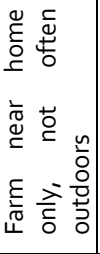 & 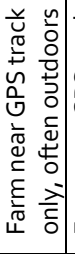 & 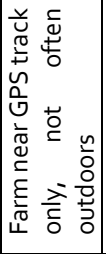 & 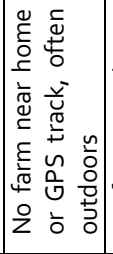 & 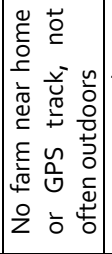 & 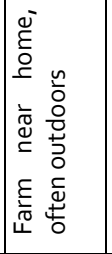 & 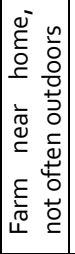 & 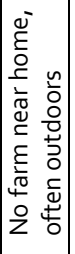 & 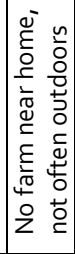 \\
\hline 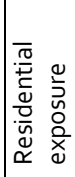 & & \multicolumn{8}{|c|}{ 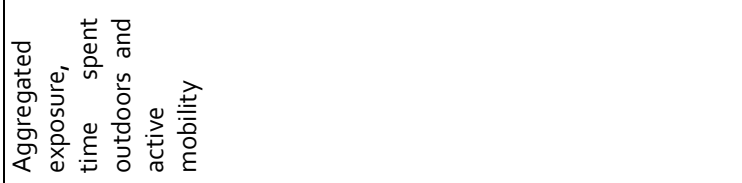 } & \multicolumn{4}{|c|}{ 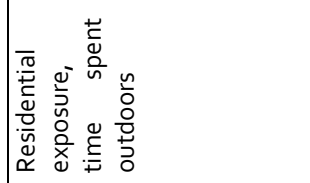 } \\
\hline
\end{tabular}




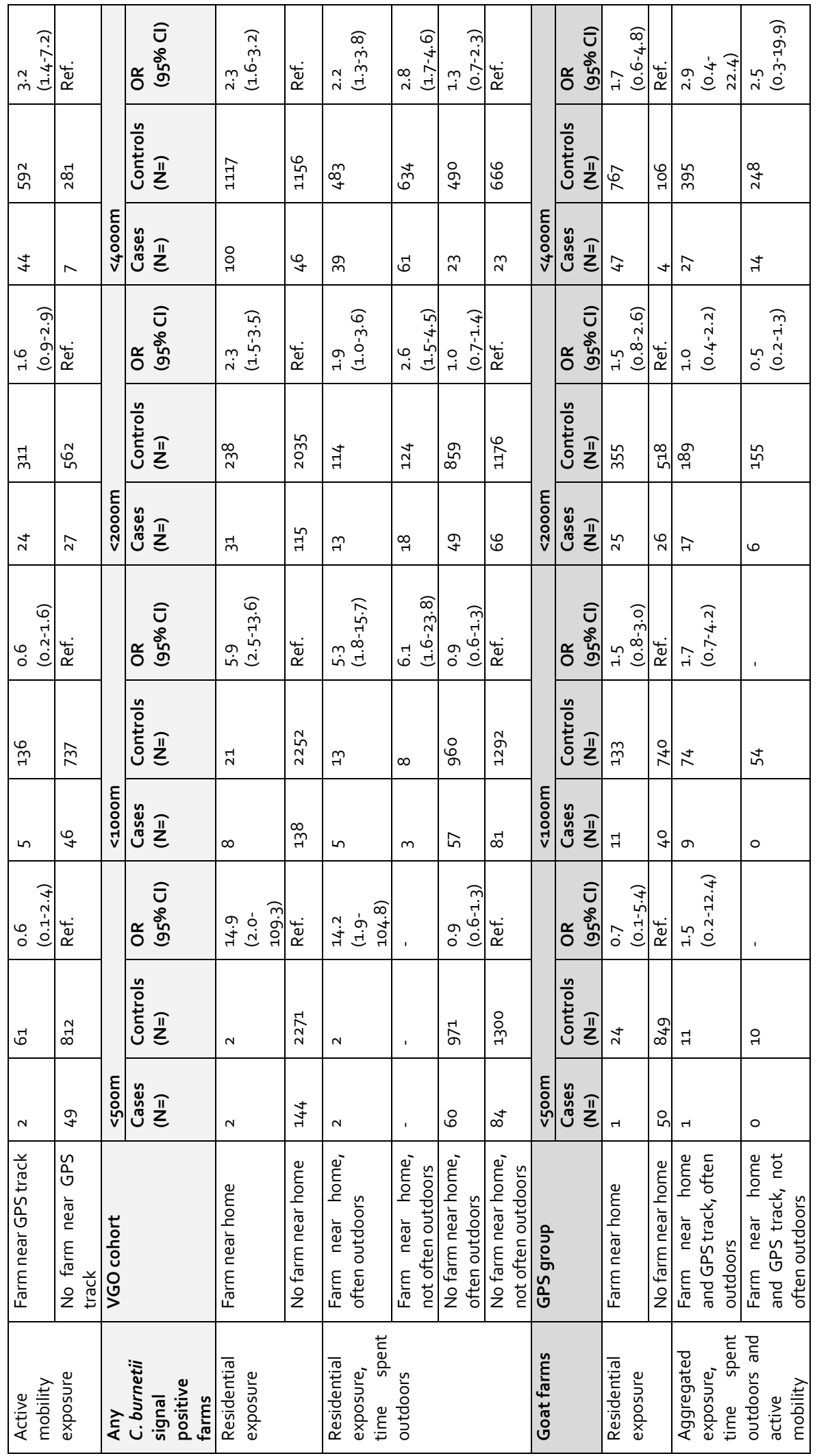




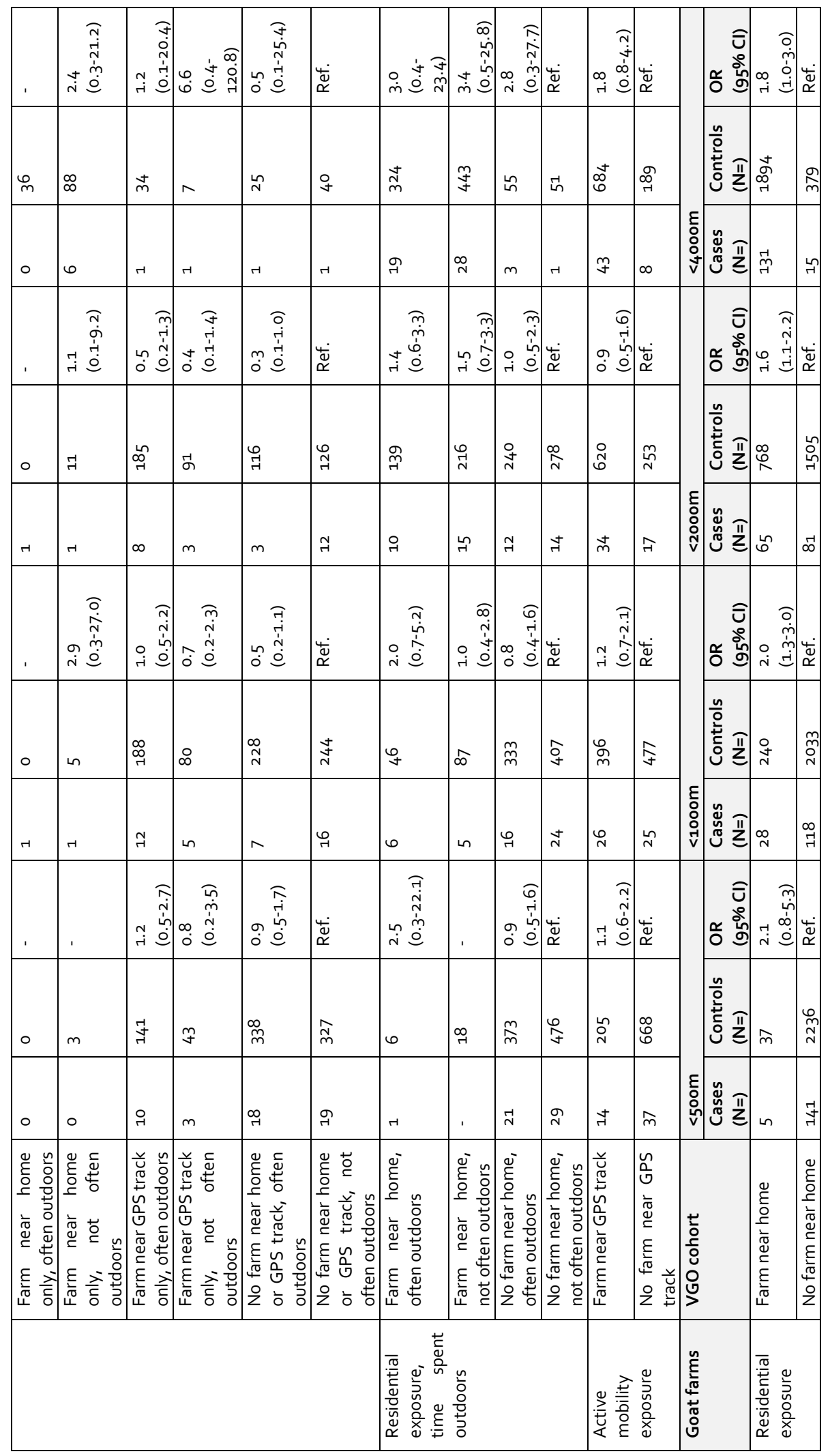




\begin{tabular}{|c|c|c|c|c|c|c|c|c|c|c|c|c|c|}
\hline 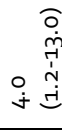 & 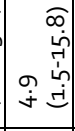 & 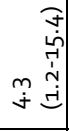 & & 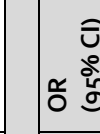 & $\begin{array}{rr}r \\
r \\
\\
\hat{0} & 0\end{array}$ & 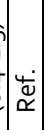 & 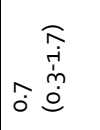 & 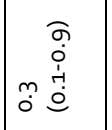 & ' & 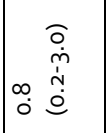 & 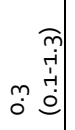 & 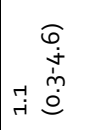 & 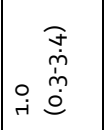 \\
\hline$\stackrel{\mathscr{2}}{\Omega}$ & 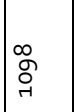 & $\widehat{A}$ & $\stackrel{N}{N}$ & 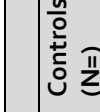 & 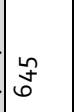 & $\stackrel{\substack{N \\
\sim}}{N}$ & $\vec{m}$ & 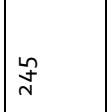 & i & f & $\stackrel{\infty}{\wedge}$ & $\stackrel{\sim}{m}$ & $\stackrel{\infty}{\forall}$ \\
\hline in & $\infty$ & A & $m$ & 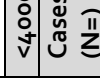 & $m$ & $\mid \begin{array}{c}\infty \\
\pi\end{array}$ & $N$ & 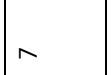 & $\circ$ & t & $N$ & $m$ & in \\
\hline 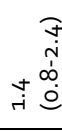 & 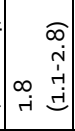 & 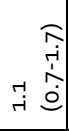 & 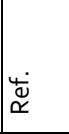 & 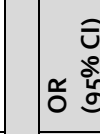 & 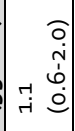 & 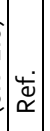 & 角 & \begin{tabular}{ll} 
& \multirow{r}{\dot{H}}{} \\
0 & $\stackrel{\sim}{\dot{N}}$ \\
0 & $\stackrel{0}{0}$
\end{tabular} & . & & $\left|\begin{array}{rrr} & 0 \\
& \stackrel{i}{1} \\
0 & \stackrel{d}{0} \\
0 & 0\end{array}\right|$ & 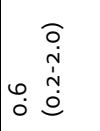 & 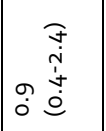 \\
\hline 志 & 柔 & 周 & $\mid \begin{array}{l}0 \\
\vdots \\
\infty\end{array}$ & 营 $\frac{\pi}{2}$ & ) & E & 总 & $\underset{\sim}{\tilde{r}}$ & H & $n$ & 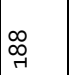 & 祖 & $\underset{\sim}{\sim}$ \\
\hline $\mathrm{n}^{2}$ & 7 & $\stackrel{\infty}{m}$ & $\stackrel{n}{+}$ & : & $\stackrel{\infty}{\sim}$ & $m$ & A & in & $\circ$ & 4 & $\infty$ & t & $a$ \\
\hline in & 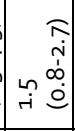 & $\begin{array}{lll} & \widehat{T} \\
& i \\
0 & \dot{0} \\
0 & 0 \\
0 & 0\end{array}$ & 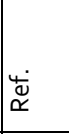 & 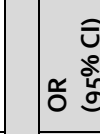 & 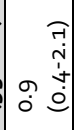 & 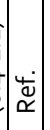 & 离 & ' & ' & 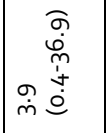 & 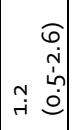 & $\begin{aligned} & \widehat{0} \\
& \stackrel{i}{\dot{m}} \\
\stackrel{\dot{m}}{0} & \end{aligned}$ & 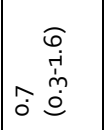 \\
\hline$\stackrel{\sim}{\infty}$ & 惉 & $\begin{array}{l}\infty \\
\infty \\
\infty \\
\infty\end{array}$ & 缹 & ثัँ & $\mathbb{N}^{ \pm}$ & $\stackrel{9}{\uparrow}$ & $\stackrel{R}{R}$ & in & $\circ$ & $t$ & | & $\stackrel{M}{N}$ & 永 \\
\hline$t^{4}$ & ने & $\stackrel{\infty}{+}$ & $\stackrel{2}{1}$ & : & $\lambda$ & 寸ै & 0 & 0 & $\circ$ & $H$ & A & in & - \\
\hline 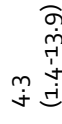 & $\mid \begin{array}{cc} & \\
& 0 \\
& + \\
0 & \dot{1} \\
0 & 0\end{array}$ & $\begin{array}{rr} & \widehat{m} \\
& \dot{1} \\
0 & \dot{0} \\
0 & \dot{0}\end{array}$ & 这 & তิ & & 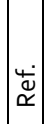 & & ' & ' & ' & 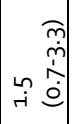 & 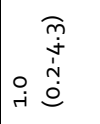 & 일 \\
\hline$\tilde{A}$ & $\stackrel{\sim}{N}$ & ڤ̆ & $\underset{N}{\stackrel{N}{N}}$ & 竞 & $\int_{4}$ & - & F & ○ & $\circ$ & $\mathrm{m}$ & İ & $\hat{m}$ & 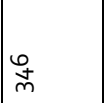 \\
\hline 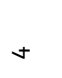 & H & $\stackrel{\infty}{i n}$ & $\infty$ & 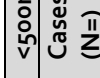 & , & in & 0 & 0 & $\circ$ & 0 & i & $m$ & I \\
\hline 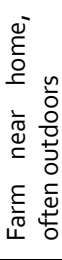 & 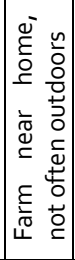 & 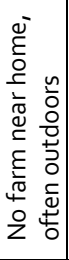 & 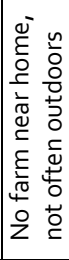 & $\begin{array}{l}0 \\
\vdots \\
0 \\
0 \\
n \\
0\end{array}$ & 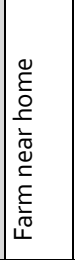 & 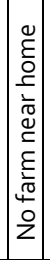 & 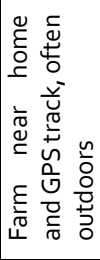 & 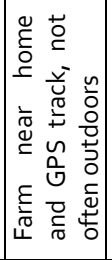 & 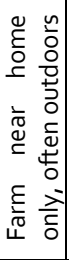 & 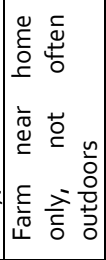 & 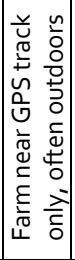 & 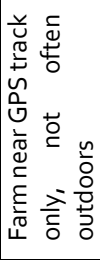 & 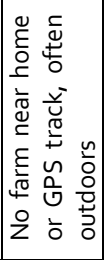 \\
\hline 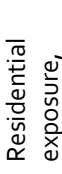 & 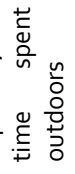 & & & 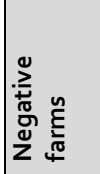 & 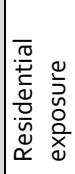 & & 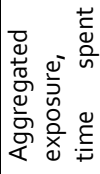 & 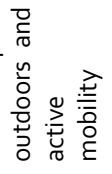 & & & & & \\
\hline
\end{tabular}




\begin{tabular}{|c|c|c|c|c|c|c|c|c|c|c|c|c|}
\hline $\mid \begin{array}{l}\longleftarrow \\
\propto \\
\propto\end{array}$ & 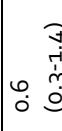 & 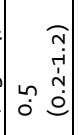 & 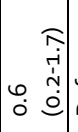 & & $\begin{array}{lll} & 7 \\
0 & 0 & 0 \\
0 & 0 & 0\end{array}$ & & 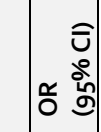 & 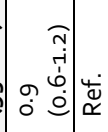 & 㐫 & 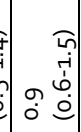 & 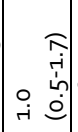 & \\
\hline 2 & 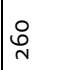 & $\stackrel{\substack{n \\
m}}{m}$ & Fे & : & $\stackrel{\circ}{\circ}$ & ه্লি & $\begin{array}{ll}0 & \pi \\
z\end{array}$ & 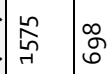 & \begin{tabular}{c|c}
$\infty$ & 0 \\
0 & 0 \\
6 & + \\
0
\end{tabular} & $\stackrel{n}{n}$ & 吕 & 占 \\
\hline$\infty$ & Ln & 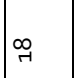 & r & $F$ & $\stackrel{+}{m}$ ? & $\hat{A}$ & 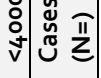 & $\%$ & in $\left.\right|_{m} ^{\infty}$ & $\stackrel{\infty}{i n}$ & $\frac{4}{4}$ & i \\
\hline $\mid \begin{array}{l}\mathbb{\Psi} \\
\propto \\
\propto\end{array}$ & 离 & 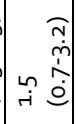 & 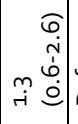 & & 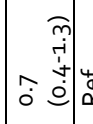 & & 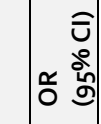 & & 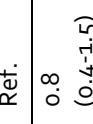 & 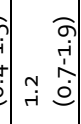 & 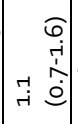 & \\
\hline 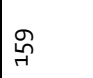 & I & 常 & 容 & 品 & 苟 & ণ্ & $\frac{\tilde{c}}{0} \frac{\pi}{z}$ & 䓦 & 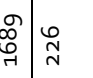 & $\stackrel{\substack{0 \\
m}}{m}$ & 表 & Fै \\
\hline$\tilde{I}$ & in & I & A & ب & i & ก & $\begin{array}{l}\text { ò } \\
\mathrm{v}\end{array}$ & 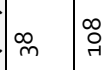 & 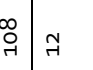 & i & in & i \\
\hline$\underset{\mathscr{L}}{\mathscr{L}}$ & 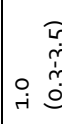 & 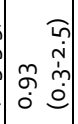 & 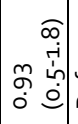 & & 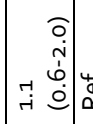 & & 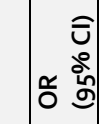 & & 吾 & 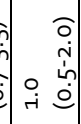 & & \\
\hline$\underset{\sim}{\mathscr{N}}$ & F & मे & 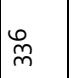 & f & 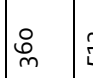 & ڤี & c & : & $\begin{array}{c}\hat{n} \\
\stackrel{n}{n}\end{array}$ & F్ & 各 & $\mid \begin{array}{l}\hat{f} \\
\tilde{f}\end{array}$ \\
\hline lo & $m$ & t & I & $\stackrel{\sim}{N}$ & $\tilde{\sim}$ & $\underset{\sim}{\infty}$ & $\begin{array}{l}: \\
\stackrel{v}{v}\end{array}$ & $A$ & 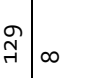 & $\sigma$ & in & $\stackrel{\llcorner}{\wedge}$ \\
\hline $\begin{array}{l}\mathscr{\Phi} \\
\propto \\
\end{array}$ &. & & 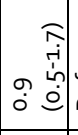 & & d. & & 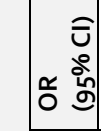 & & 幽 & 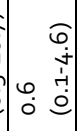 & 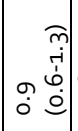 & \\
\hline$\left[\begin{array}{l}0 \\
+ \\
m\end{array}\right.$ & 0 & $\infty$ & $\stackrel{m}{m}$ & 号 & $\stackrel{\infty}{A}$ & ڤ్ & 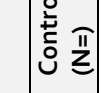 & \begin{tabular}{l|c}
$\stackrel{N}{\tilde{m}}$ & $\tilde{N}$
\end{tabular} & \begin{tabular}{l|l}
$\hat{\tilde{N}}$ & .
\end{tabular} & $\stackrel{n}{N}$ & 苂 & 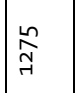 \\
\hline 9 & . & & n & i & $\pi$ & $\stackrel{\infty}{\infty}$ & 党 & \begin{tabular}{l|l}
$m$ & \multirow{f}{f}{}
\end{tabular} & 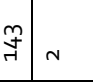 & . & & $\infty$ \\
\hline 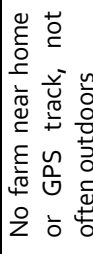 & 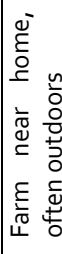 & 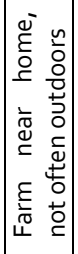 & 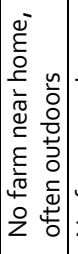 & 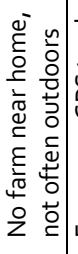 & 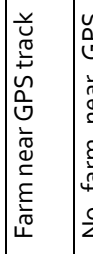 & 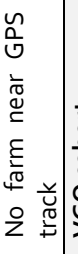 & 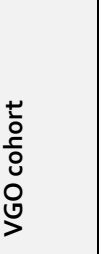 & 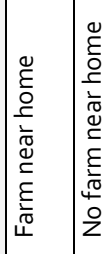 & 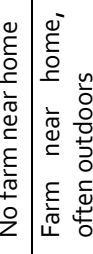 & 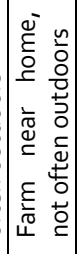 & 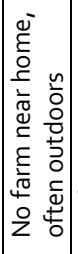 & 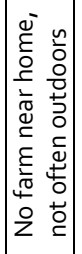 \\
\hline & 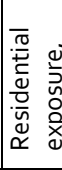 & 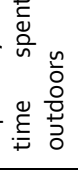 & & & 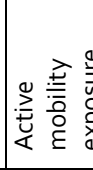 & & 总 & 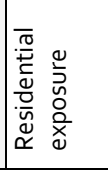 & 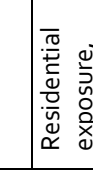 & 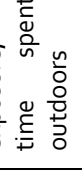 & & \\
\hline
\end{tabular}




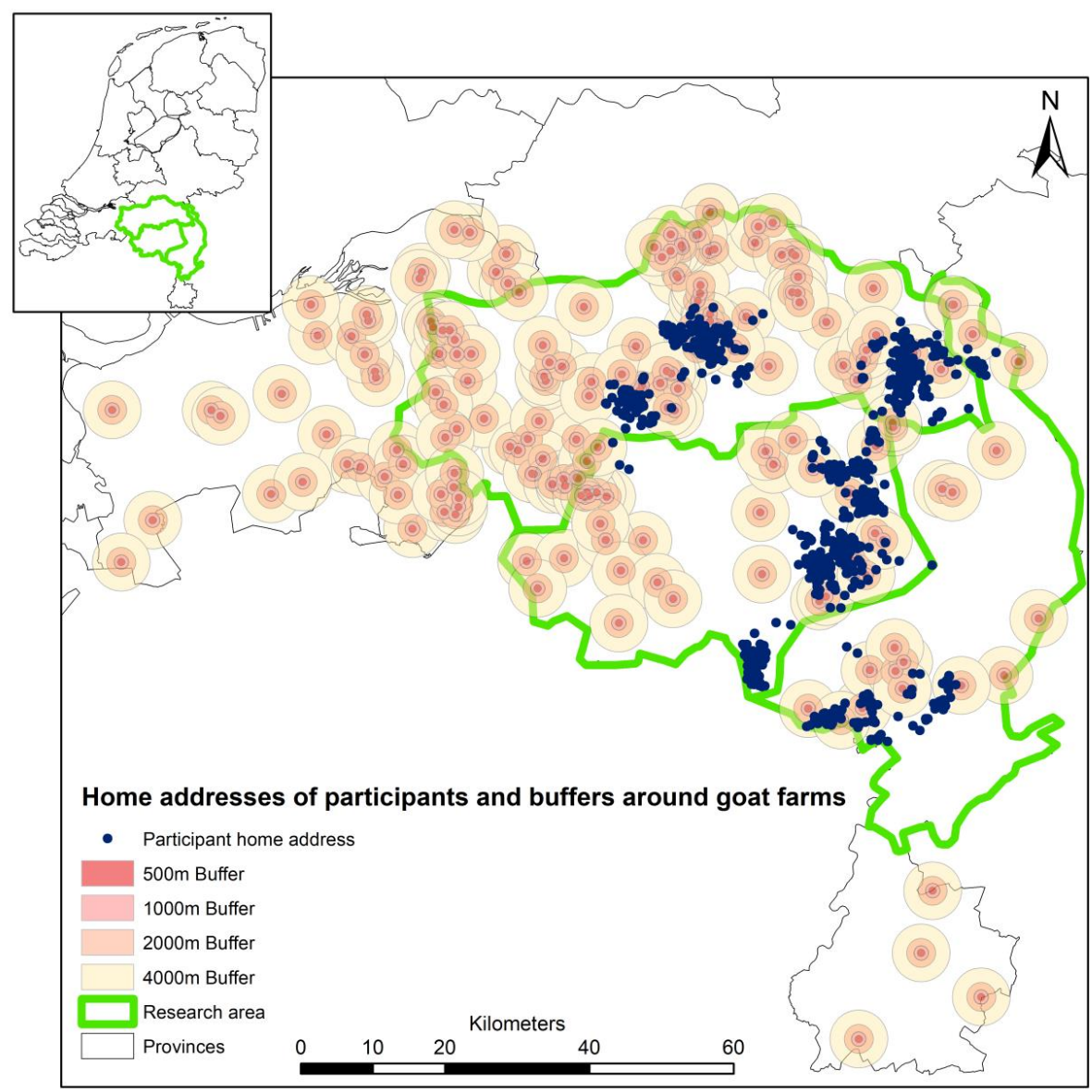

Supplementary Figure 1 Home addresses of participants and buffers around goat farms. This map shows all goat farms present in the area in 2012, regardless of $C$. burnetii status of the farm. Buffers are ranging from $500 \mathrm{~m}$ to $4000 \mathrm{~m}$. This area was also the main area were the $\mathrm{Q}$ fever outbreak occurred in the springs of 2007-2009.[1] 
VGO questionnaire 'time spent outdoors in vicinity of the home'

Question from the VGO baseline questionnaire used as time variable for the analyses considering self-reported time spent outdoors close to home while living within 500m, 1000m, 2000m and $4000 \mathrm{~m}$ of a (C. burnetii positive-) goat farm and C. burnetii antibody serology. (translated from Dutch)

G.8 Which of the following outdoor leisure time activities are in your normal week schedule? (please indicate what is applicable to your situation, multiple answers are allowed, please estimate durations)

\begin{tabular}{|l|c|c|} 
Activity & autumn / winter & spring / summer \\
\hline $\begin{array}{l}\text { Walking (e.g. while shopping, hikes, walking } \\
\text { the dog) }\end{array}$ & Hours per week & Hours per week \\
\hline $\begin{array}{l}\text { Bicycle riding (e.g. from and to shops, } \\
\text { bicycle tours) }\end{array}$ & Hours per week & Hours per week \\
\hline $\begin{array}{l}\text { Outdoor sports (e.g. running, tennis, } \\
\text { football) }\end{array}$ & Hours per week & Hours per week \\
\hline $\begin{array}{l}\text { Spending time close to home (e.g. } \\
\text { gardening, taking care of animals, do-it- } \\
\text { yourself work, relaxing in the garden) }\end{array}$ & Hours per week & Hours per week \\
\hline $\begin{array}{l}\text { Other outdoors activities (e.g. visiting a } \\
\text { playground, angling) }\end{array}$ & Hours per week & Hours per week \\
\hline
\end{tabular}

Supplementary Table 2. Applied time cut-offs in mobility analysis, minimal time spent on active mobility within buffer.

\begin{tabular}{l|llll}
\multirow{2}{*}{ C. burnetii status } & \multicolumn{4}{|c}{$\left(20^{\text {th }}\right.$ percentile of total times, in seconds/week $)$ actively mobile within: } \\
\cline { 2 - 5 } & $500 \mathrm{~m}$ buffer & $1000 \mathrm{~m}$ buffer & $2000 \mathrm{~m}$ buffer & 400om buffer \\
\hline Abortus-wave positive farm & $79 \mathrm{sec}$. & $70 \mathrm{sec}$. & $116 \mathrm{sec}$. & $239 \mathrm{sec}$. \\
Any signal positive farm & $146 \mathrm{sec}$. & $81 \mathrm{sec}$. & $99 \mathrm{sec}$. & $623 \mathrm{sec}$. \\
Goat farm & $93 \mathrm{sec}$. & $165 \mathrm{sec}$. & $348 \mathrm{sec}$. & $2328 \mathrm{sec}$. \\
Negative farm & $92 \mathrm{sec}$. & $122 \mathrm{sec}$. & $269 \mathrm{sec}$. & $1531 \mathrm{sec}$.
\end{tabular}


Supplementary Table 3. GPS measured time spent on active mobility

\begin{tabular}{|c|c|c|c|c|}
\hline \multirow[b]{2}{*}{ Q fever status } & \multicolumn{4}{|c|}{ (Hours/week: median (IQR), maximum (max.)), farm within: } \\
\hline & $500 \mathrm{~m}$ & $1000 \mathrm{~m}$ & $2000 \mathrm{~m}$ & $4000 \mathrm{~m}$ \\
\hline Abortus-wave positive farm & $\begin{array}{l}0.06 \mathrm{~h} \\
(0.03-0.12 \mathrm{~h}) \\
\max : 0.31 \mathrm{~h}\end{array}$ & $\begin{array}{l}0.08 \mathrm{~h} \\
(0.02-0.18 \mathrm{~h}) \\
\max : 1.47 \mathrm{~h}\end{array}$ & $\begin{array}{l}0.24 \mathrm{~h} \\
(0.04-0.58 \mathrm{~h}) \\
\max : 4.63 \mathrm{~h}\end{array}$ & $\begin{array}{l}0.24 \mathrm{~h} \\
(0.03-0.76 \mathrm{~h}) \\
\max : 8.56 \mathrm{~h}\end{array}$ \\
\hline Any signal positive farm & $\begin{array}{l}0.08 \mathrm{~h} \\
(0.05-0.17 \mathrm{~h}) \\
\max : 0.78 \mathrm{~h}\end{array}$ & $\begin{array}{l}\text { o.ogh } \\
(0.02-0.23 \mathrm{~h}) \\
\max : 1.47 \mathrm{~h}\end{array}$ & $\begin{array}{l}0.18 \mathrm{~h} \\
(0.03-1.25 \mathrm{~h}) \\
\max : 4.63 \mathrm{~h}\end{array}$ & $\begin{array}{l}0.37 \mathrm{~h} \\
(0.08-0.97 \mathrm{~h}) \\
\max : 10.15 \mathrm{~h}\end{array}$ \\
\hline Goat farm & $\begin{array}{l}0.11 \mathrm{~h} \\
(0.04-0.23 \mathrm{~h}) \\
\max : 1.76 \mathrm{~h}\end{array}$ & $\begin{array}{l}0.18 \mathrm{~h} \\
(0.06-0.46 \mathrm{~h}) \\
\max : 6.31 \mathrm{~h}\end{array}$ & $\begin{array}{l}0.48 \mathrm{~h} \\
(0.12-1.25 \mathrm{~h}) \\
\max : 13.55 \mathrm{~h}\end{array}$ & $\begin{array}{l}0.31 \mathrm{~h} \\
(0.04-1.03 \mathrm{~h}) \\
\max : 6.80 \mathrm{~h}\end{array}$ \\
\hline Negative farm & $\begin{array}{l}0.10 \mathrm{~h} \\
(0.04-0.22 \mathrm{~h}) \\
\max : 1.68 \mathrm{~h}\end{array}$ & $\begin{array}{l}0.16 \mathrm{~h} \\
(0.05-0.44 \mathrm{~h}) \\
\max : 6.31 \mathrm{~h}\end{array}$ & $\begin{array}{l}0.35 \mathrm{~h} \\
(0.09-1.06 \mathrm{~h}) \\
\max : 13.55 \mathrm{~h}\end{array}$ & $\begin{array}{l}0.28 \mathrm{~h} \\
\text { (0.04-0.90h) } \\
\max : 6.8 \mathrm{oh}\end{array}$ \\
\hline
\end{tabular}



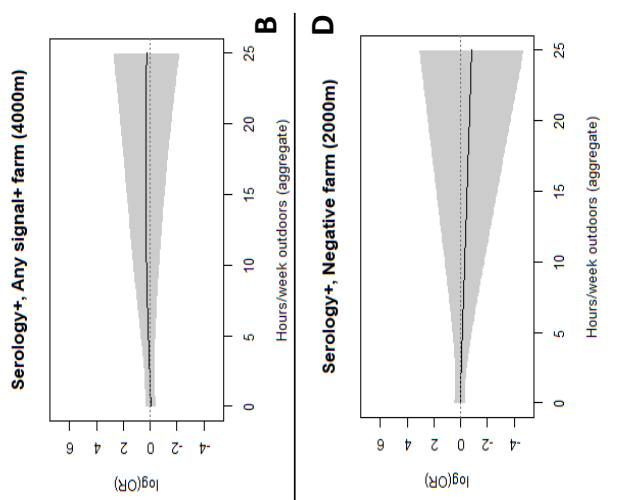

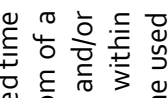

कृ

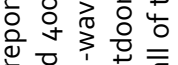

竞它

$n$ ह

ㄴㅎㅎㅇㅇㅇ 웡 응 흥

원

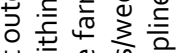

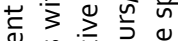

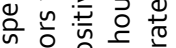

원 은
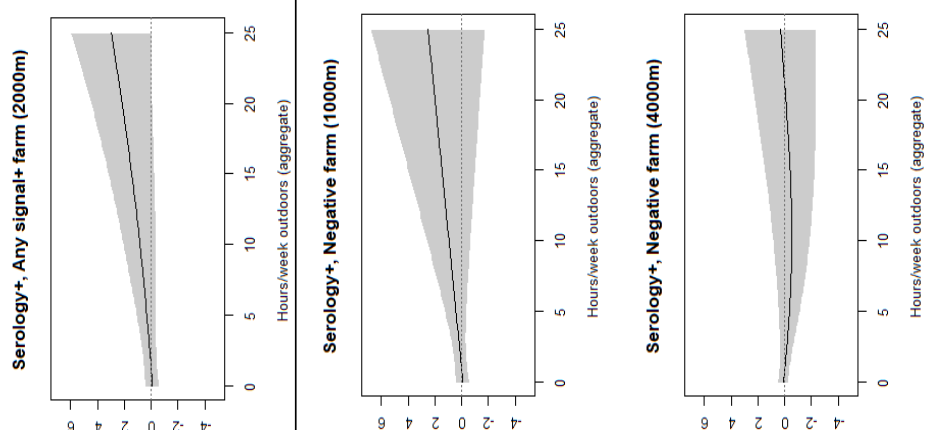

年

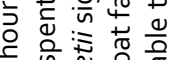

的

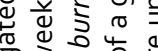

बं

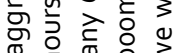

응

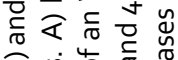

牟它

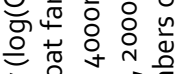

(yo) 600

(미) 600

(yo) 600

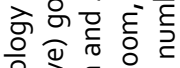

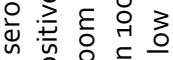
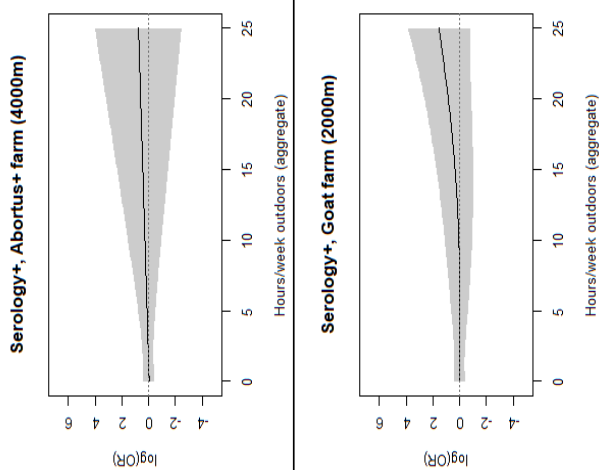

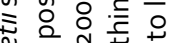

今气 :

ن

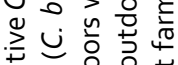

능 윤

은 方

के

는

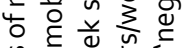

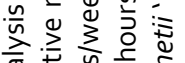

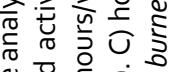

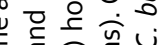
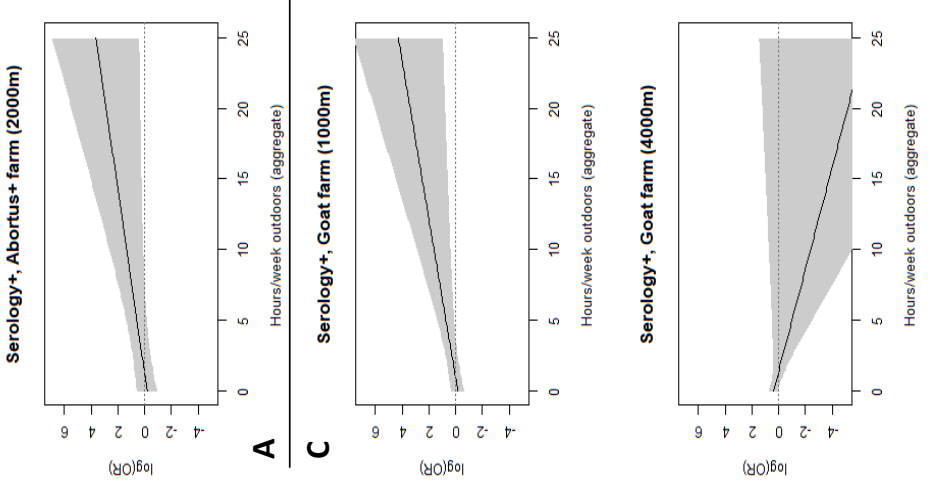

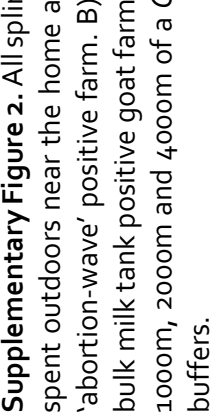



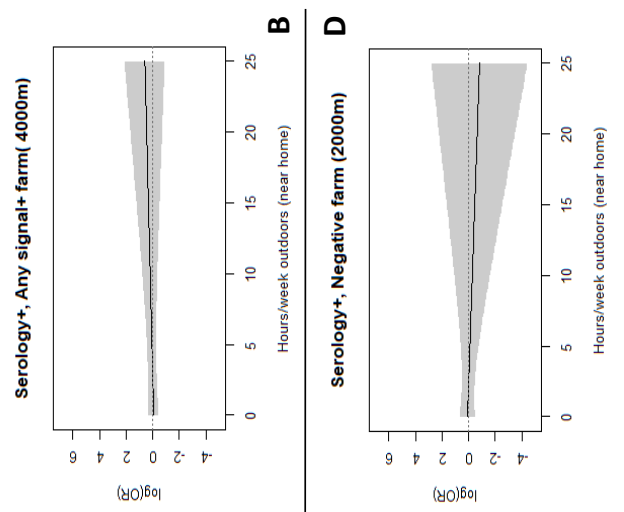

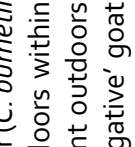

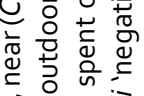

它范

क 은 3

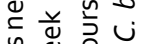

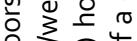

융 ज्ञ

긍

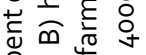

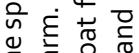
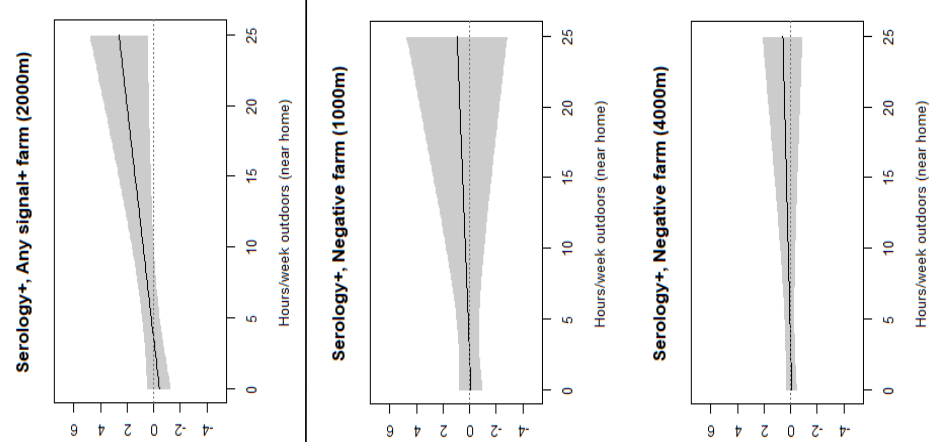

है

空

t⿳亠二口犬

음

\% 㐘

员

드의

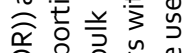

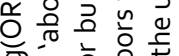

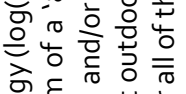

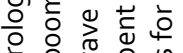

过

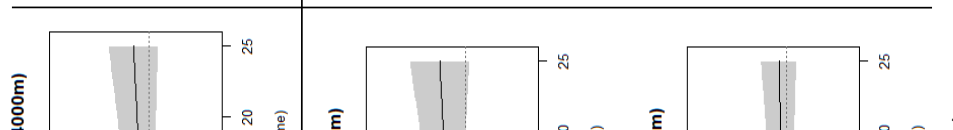

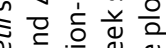

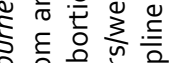

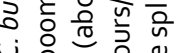

두워

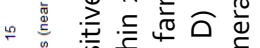

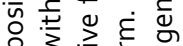

는

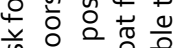

는 운은

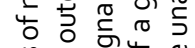

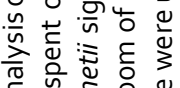
元

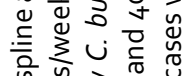

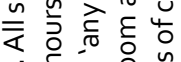
m

ปัँ जे है है 끈 है

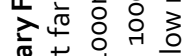

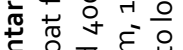

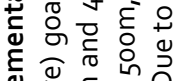

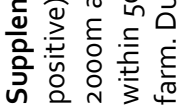
(yo)6이
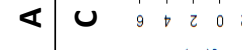

(yo)601 

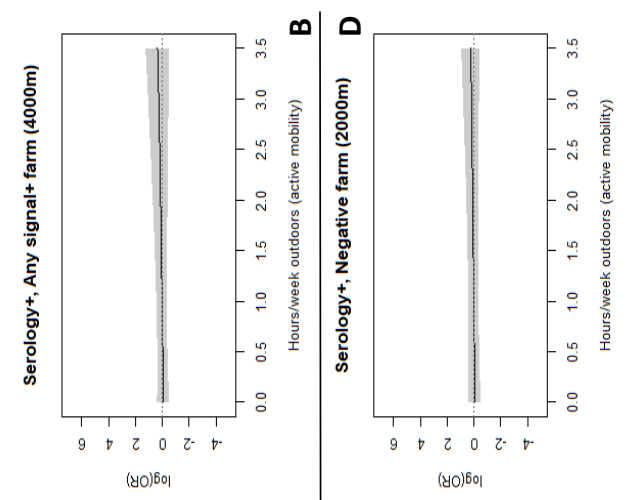

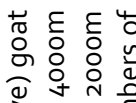

गे गे है

ำ 잉 잉

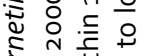

今. 党先

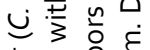

든 은 $\frac{5}{0}$

둥

齐苛
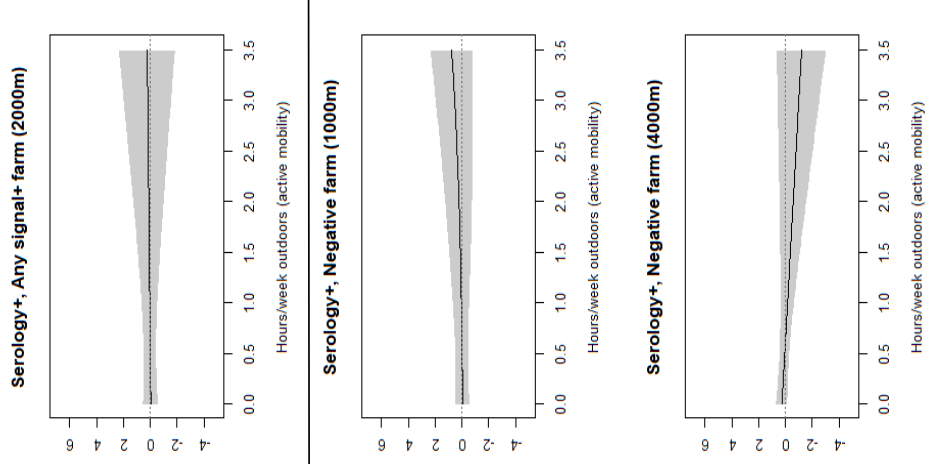

늘 के ए

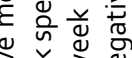

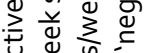

ठै ज्ञ

पํํำ 워

는 옹

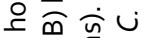

당 हो

ลิ

음 용

음ํㅝㅁำ

文论

응 त

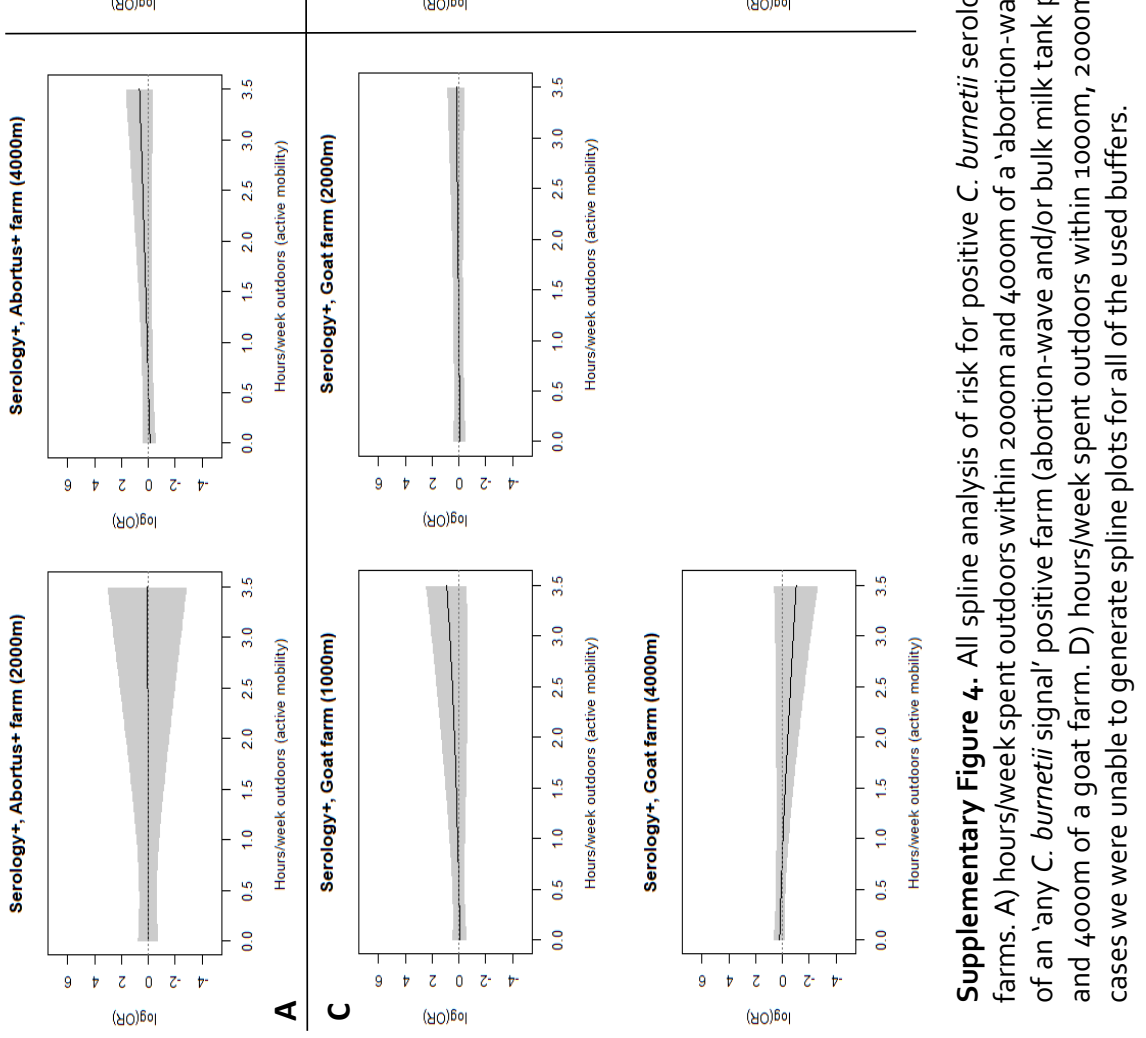



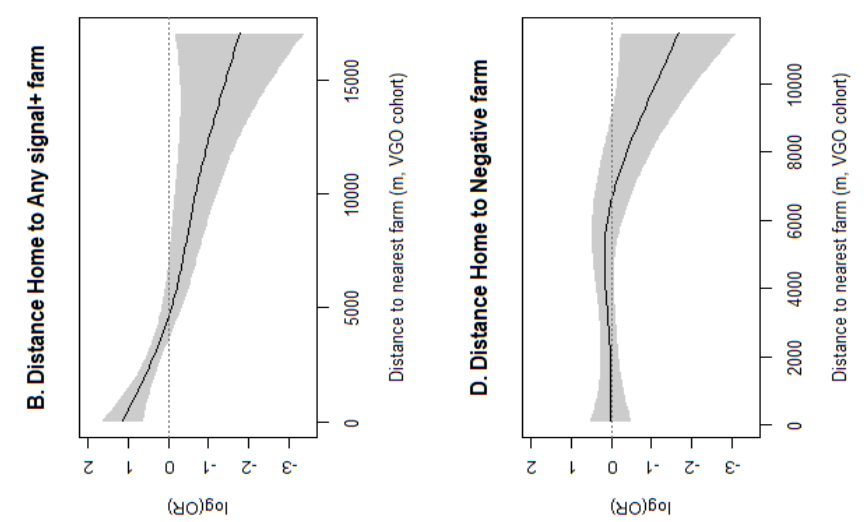

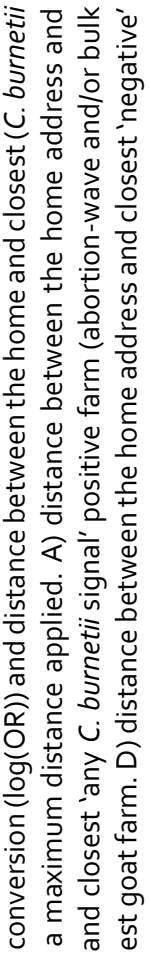

ठे
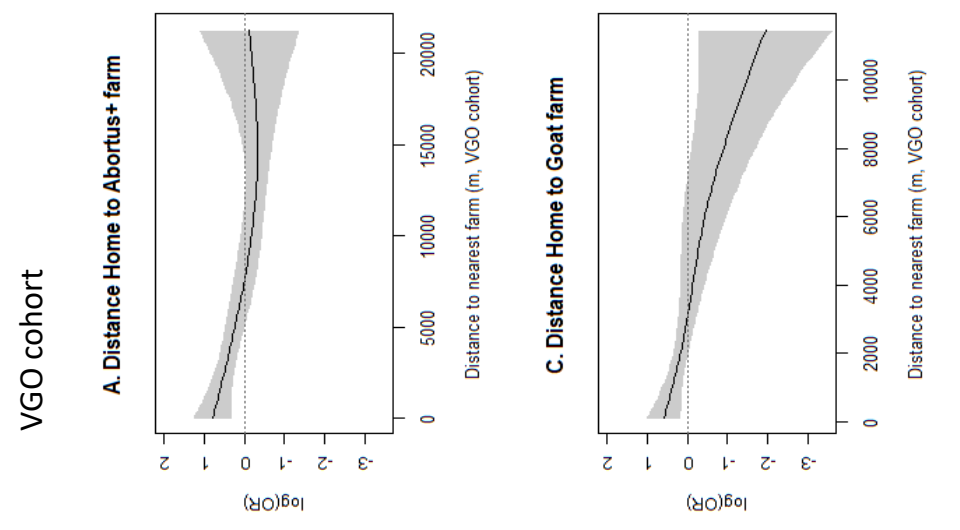

응 든 훙
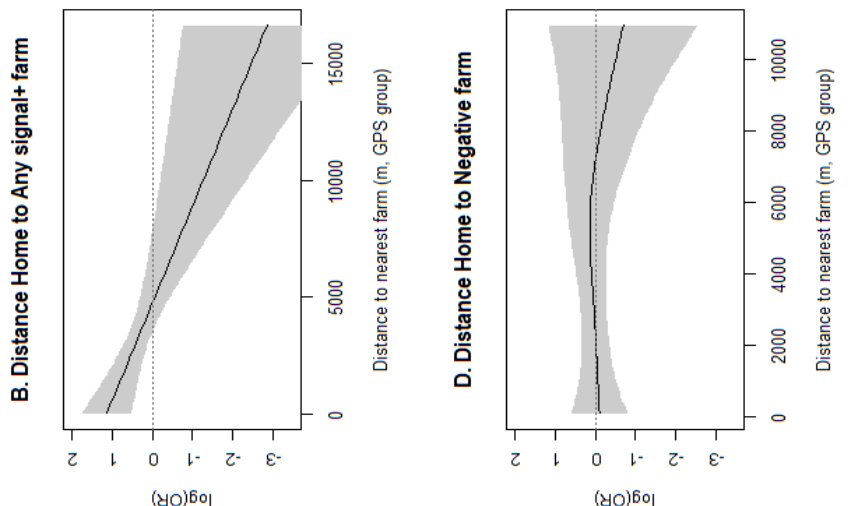

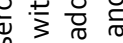

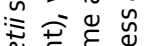

는 흥흐 흠

डิ응

ن 范

등 홍

至

은 웡

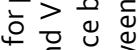

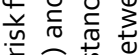

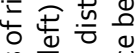

는

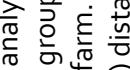

的要
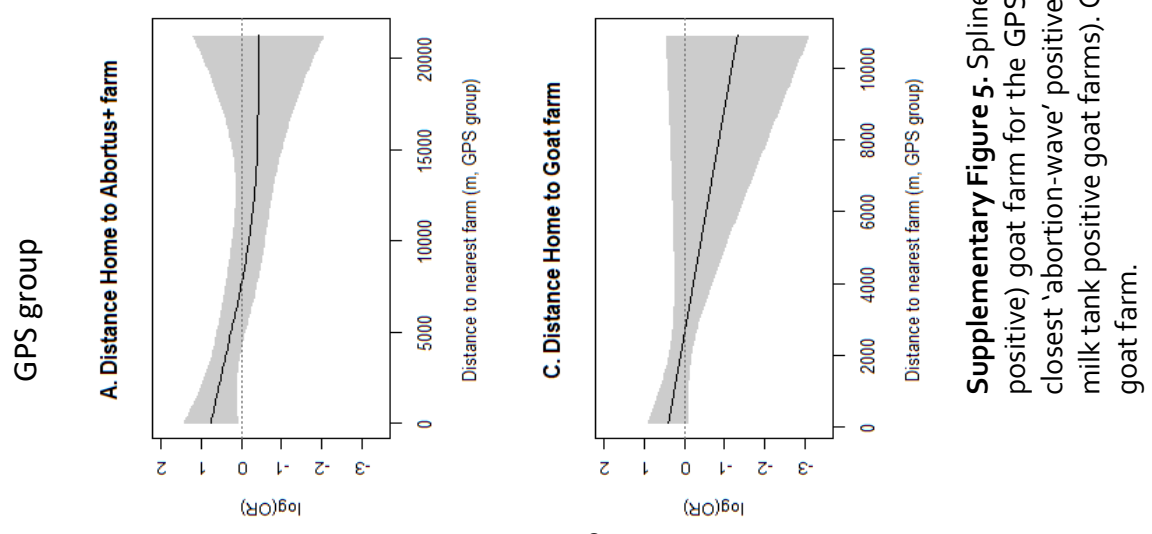

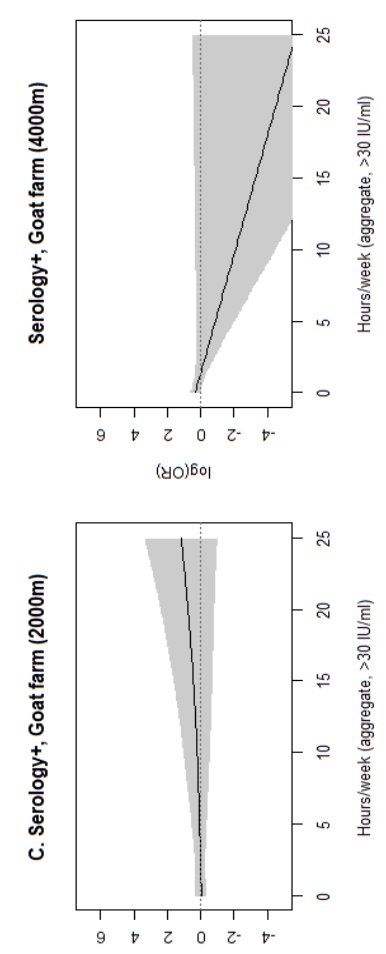

(yo)6이
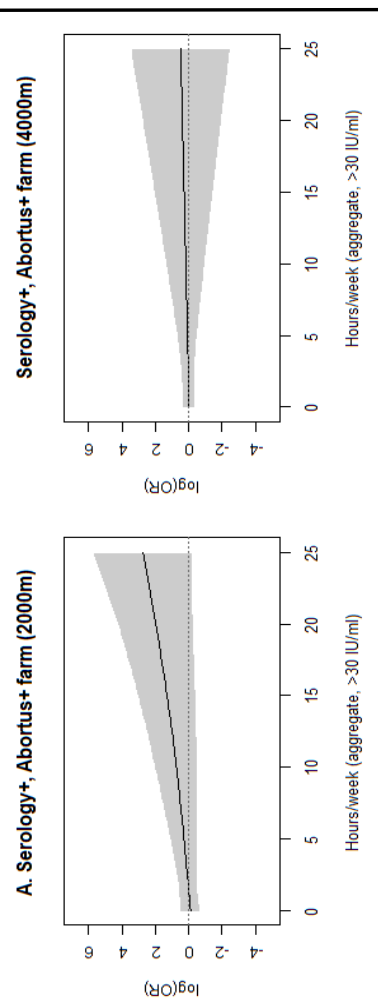
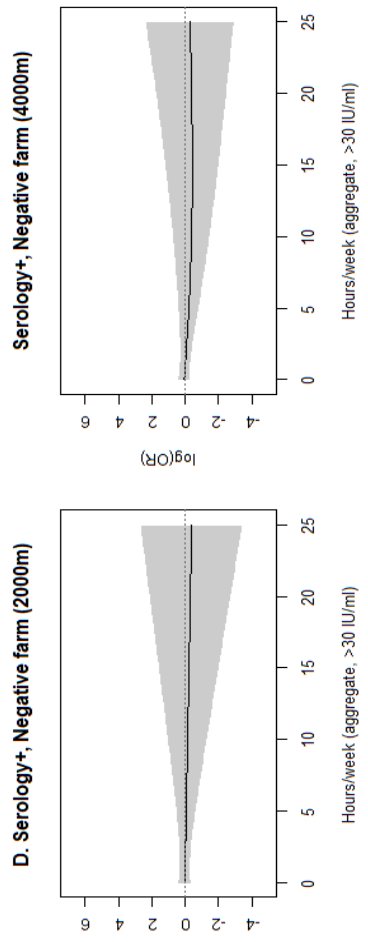

(이이이
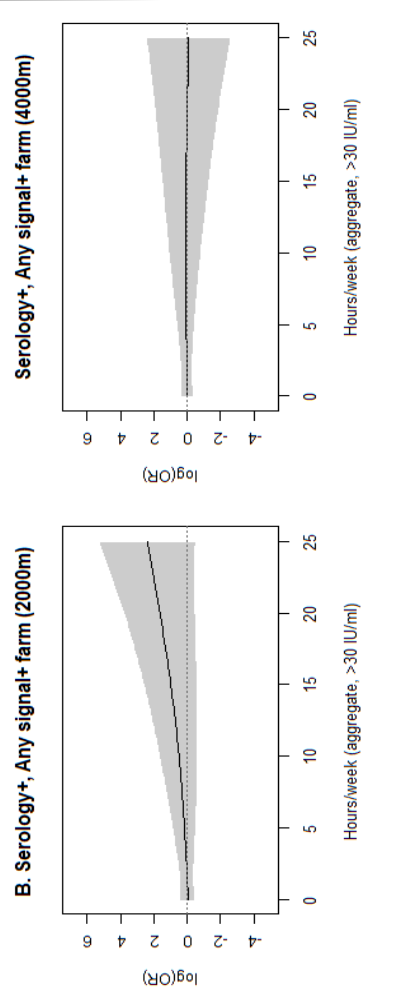

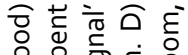

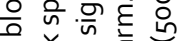

ह

这

जั

屯ै 원

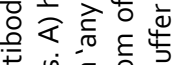

है है ธ

हิ

익의워

กิ๊

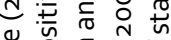

: 을 동

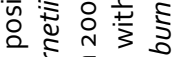

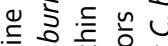

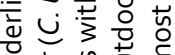

흔

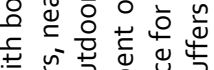

ऊ

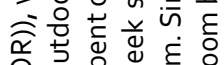

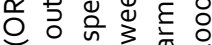

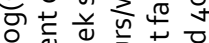

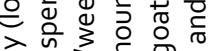

केे जै

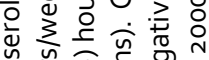

ज约

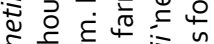

5ิ

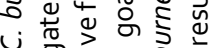

व

它苍谣

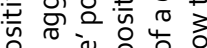

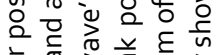

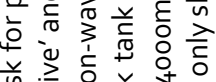

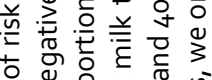

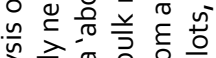

त्रे

든 을 홍 월

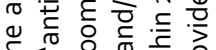

言

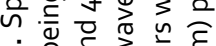

ט。

닌

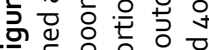

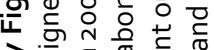

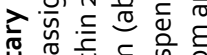

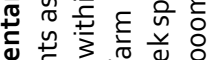

ह

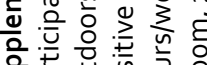

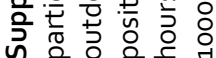



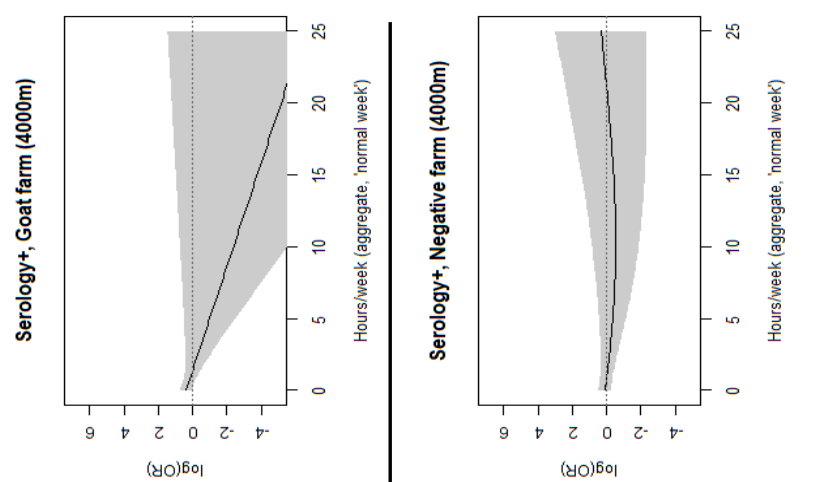

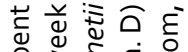
थิ हैบั

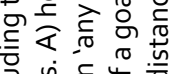

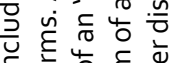

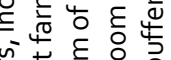

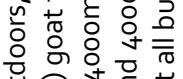

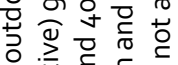

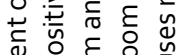
ปั้ ที丶⿺辶寸
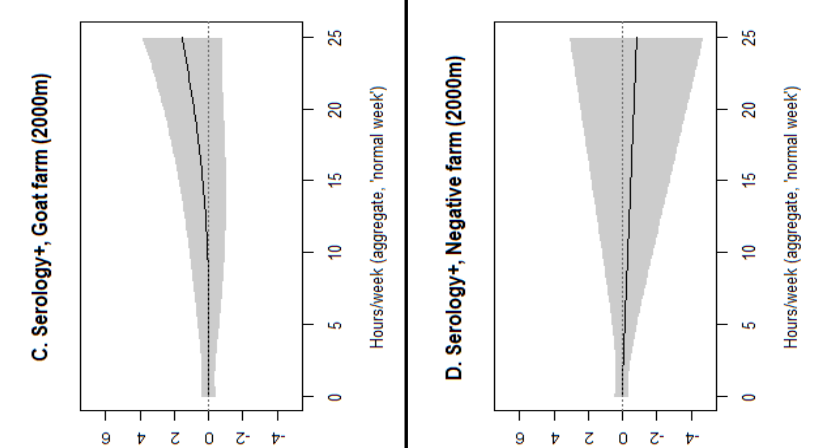

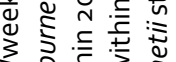

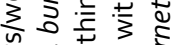

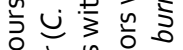

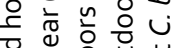
둥 苛 ठัّ ๘ 宁 的芯 ก

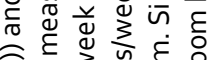

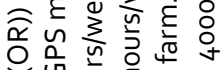

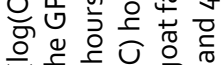

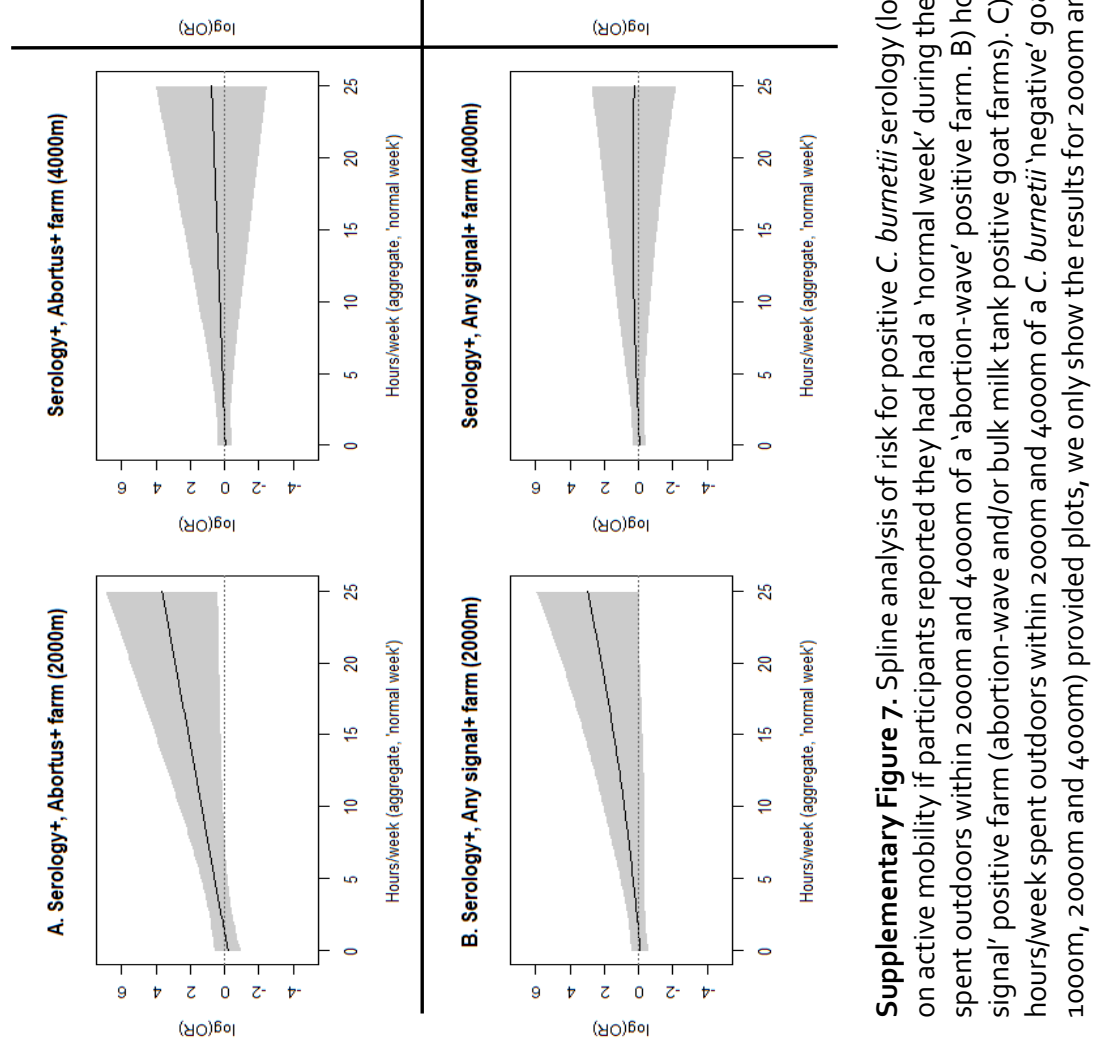


VGO cohort age distribution over the years

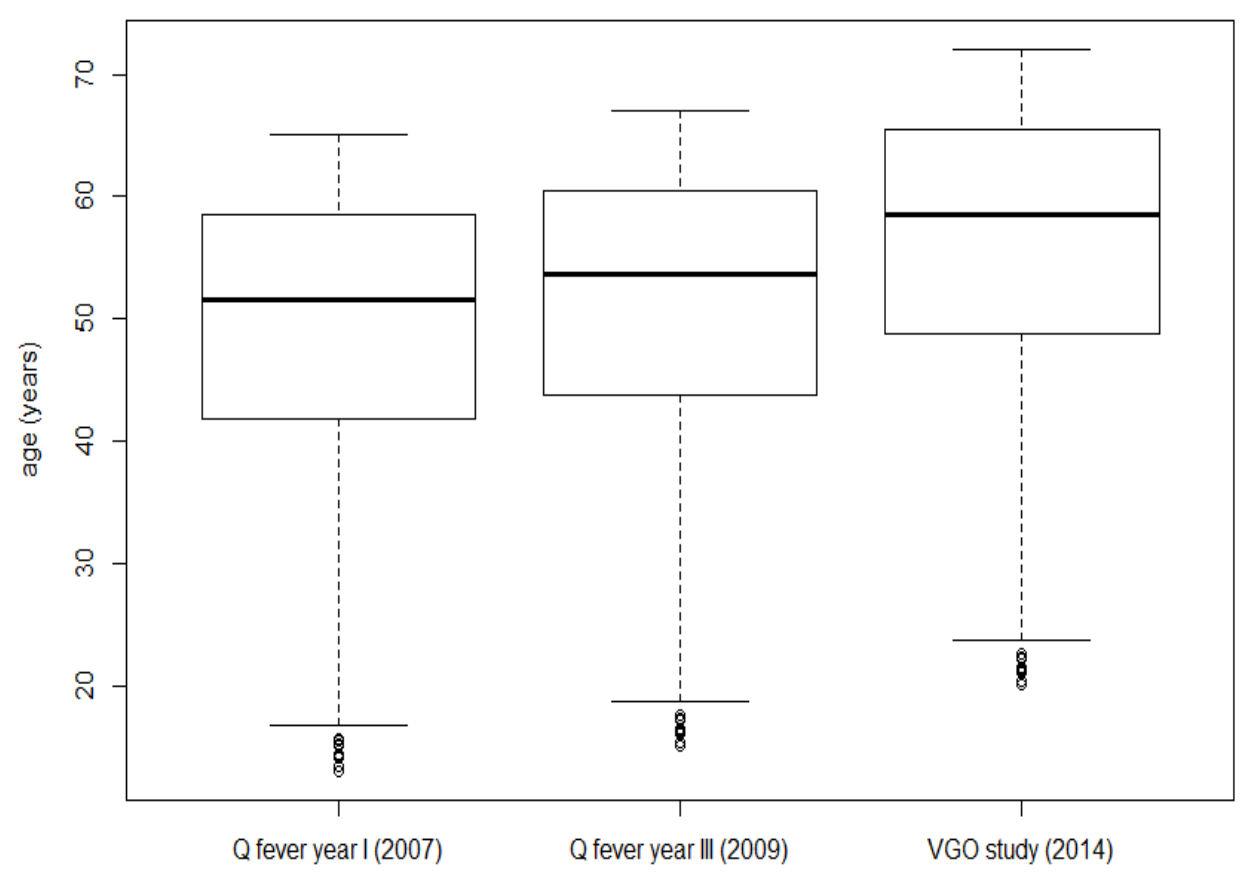

Supplementary Figure 8. Boxplots of the age distribution in the VGO cohort, during the first and last year of the $\mathrm{Q}$ fever outbreak (' $\mathrm{Q}$ fever year I (2007)' and ' $\mathrm{Q}$ fever year III (2009)') and during the fieldwork period of the VGO study (VGO study (2014)). 


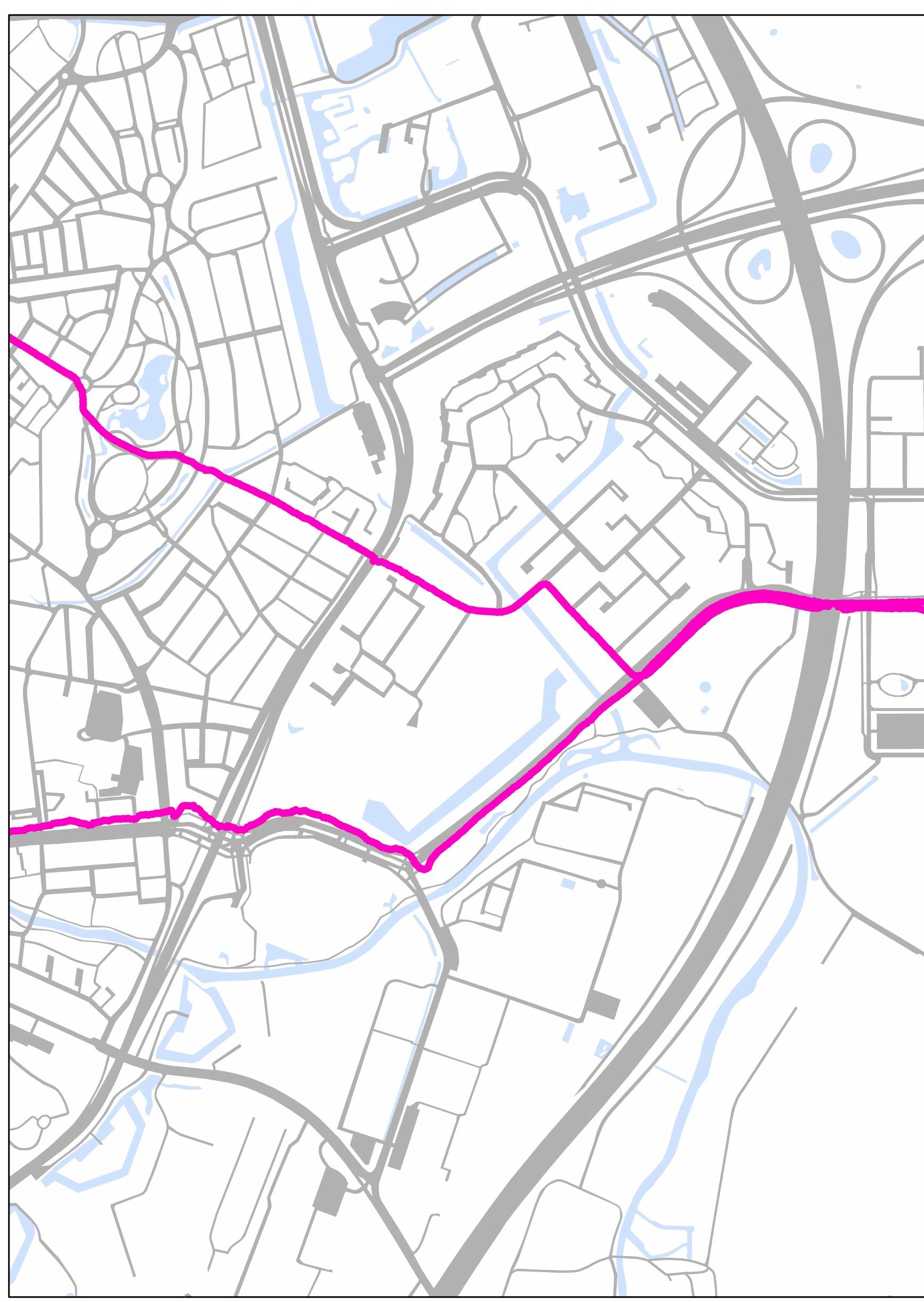


Chapter 7

General discussion 


\section{General discussion}

In environmental epidemiology the effects of environmental exposures on human health are assessed. An important component of this process is the exposure assessment. In exposure assessment three dimensions of exposure are considered: the environmental concentration of the agent people are exposed to (e.g. in $\mathrm{mg} / \mathrm{m}^{-3}$ for air or in $\mathrm{mg} / \mathrm{l}^{-1}$ for water), the duration of the exposure (e.g. minutes, hours) and the frequency of the exposure events (e.g. times per week or per year).[1] Livestock farms emit a wide range of pollutants [2,3], among these are greenhouse gasses such as methane, carbon dioxide and nitrous oxides.[3] More importantly for direct health effects however, are emissions of ammonia [4], Particulate Matter (PM) [2,5], endotoxins (parts of bacterial cell walls potentially causing lung inflammation and allergic reactions when inhaled) [6-8] and (pathogenic) microorganisms. [6,8]

In this thesis the results of the VGO GPS study are described, an additional study to the 'Farming and Neighbouring Residents' Health' study ('Veehouderij en Gezondheid Omwonenden' studie, Dutch acronym: VGO study [9]), in which 2494 people participated in a medical survey. The VGO study aimed to investigate whether living in the vicinity of livestock farms had an impact on the health of neighbouring residents. $[9,10]$ Therefore, the population at risk in the study were residents that were not occupationally exposed to livestock emissions, but lived in a high density livestock farming area in the south-eastern part of the Netherlands.[11-13] The VGO GPS study was designed to measure daily mobility in the area where the VGO study was performed and to relate mobility patterns and time spent outdoors to environmental exposure to farms.[11-14] For the VGO GPS study 1517 VGO cohort members were invited to carry a GPS logger for one week when they left their home. Of the invitees, 1014 people $(67 \%$ of invitees, $41 \%$ of the VGO cohort) responded positively to the invitation. After data cleaning $[11,12]$, a rich dataset was available with information about mobility, general characteristics, health data, weekly time spent outdoors near the home, and home and work addresses for 941 VGO GPS study participants (38\% of VGO cohort). [11-14] These data were used to add to exposure assessment for livestock related emissions and health effects. $[12,13]$

\section{Current exposure assessment methods for livestock emissions}

Environmental epidemiologists depend on observational studies for their research, since exposures arise from the environment and it is often not feasible or ethical to influence these environmental factors.[1]

In the VGO study three study approaches with increasing levels of detail were applied to identify associations between livestock exposure and health effects. First, an ecological study design was used to find differences in prevalence for various aspects of lung health between the VGO population and a population living in a rural area, but with low livestock density.[9,15] Within the VGO population a different prevalence for Coxiella burnetii ( $\mathrm{Q}$ fever) antibodies was identified in people that lived in and near villages with more goat farms in their surroundings.[16] Although these studies were informative and provided an indication whether certain health effects were more prevalent in the VGO study area, this approach only allows for a crude risk estimation. That may be biased if potential confounders were not taken into account. 
In order to investigate these indications into more detail [1,17], a sample of inhabitants was invited (VGO cohort, $\mathrm{N}=2494$ ) for an in-depth health assessment. [10] The data from this VGO cohort were used to investigate disease patterns on an individual level, relate different health variables with livestock exposure and explore whether exposureresponse relationships existed between livestock exposure and health effects. In these studies distances between the home and farms and number of farms in the vicinity of the home were found associated with health effects. $[10,18,19]$ Distance and number of farms in a radius around the home address were considered as independent variables in the models and as proxy for risk of exposure. These studies provided a next step in precision, when compared to the studies using an ecological study design and allowed for adjustment for potential confounding variables.[15,16]

Novel in the VGO study was the use of air pollution research methods to obtain quantitative exposure estimates [20-22] for biological exposures.[8,23] Based on the data from the VGO air measurements study [24], two models, a dispersion model and a Land Use Regression (LUR) model, were developed to predict the annual average concentration of bacterial endotoxins and $\mathrm{PM}_{10}(\mathrm{PM}$ with a size $<10 \mu \mathrm{m}$ ) from livestock emissions at the residential address.[8] Unfortunately, these were such recent developments that combining predictions from the LUR and dispersion models and data from the VGO GPS study was not possible while working on this thesis. In future research, however, combining these two datasets is strongly encouraged.

\section{Time activity patterns in exposure assessment}

\section{Scope and context}

In order to adequately explore associations between (specific) livestock exposures and health outcomes, in each above mentioned method a new layer of sophistication was included to the study for the exposure assessment component. What these three approaches have in common is, that the residential address is the proxy which drives the decision whether a person is exposed or not. $[8,10,15,16,18,19]$ It is generally known that for exposure assessment in principle three dimensions need to be considered, concentration, duration and frequency of the exposure.[1] Thus, the use of home address as a proxy for the concentrations of exposure in exposure response modelling is only a crude proxy for exposure. $[10,18,19]$ The use of LUR and dispersion models to obtain the concentration of endotoxins and $\mathrm{PM}_{10}$ at the home address [8] are an improvement in exposure assessment methodology, but still ignore the time activity pattern, in particular the time an individual is not at home, but for instance, outdoors recreating, traveling or at work, away from home.

In essence such approaches assume that people are always at home and exposed only to the concentrations of emissions at the home address. Still, if the outcomes from the Dutch 'time use study' $[25,26]$ are considered, people are on average 16.5 hours/day at home, of which the night time contributes most, but the other 7.5 hours/day they are most likely spent somewhere else. Therefore, during these hours, people may be exposed to other, or different environmental concentrations of a pollutant. Using the home address as a proxy for exposure may therefore lead to misclassification of the true exposures. Misclassification of exposure can bias associations between exposure and 
disease and the specific form of misclassification (differential or non-differential) does drive the nature of the bias.[27]

Next to misclassification of exposure due to spatial inaccuracies, being indoors or outdoors may also play a role in exposure to livestock emissions. In an urban air pollution study, concentrations of toxic substances were shown to be higher outdoors than indoors. In this study smaller pollution particles were shown to be more likely to penetrate homes than lager particles.[28] When focussing on rural areas, multiple air measurement studies in high livestock dense areas showed lower concentrations of endotoxins indoors, when compared to the outdoor environment.[29-32] These differences in indoors and outdoors concentration are also likely to be the case for livestock-related zoonotic microorganisms. Single bacteria have the small size to penetrate houses.[33] The fact that endotoxin levels are generally lower indoors than outdoors, suggests that spending time outdoors may be an important driver in the uptake of emissions from livestock, the exposure studied in this thesis.[12,13,34] Microorganisms can be transmitted from livestock animals to humans via various pathways.[34] For residents living near livestock farms, transmission may occur by microorganisms that are excreted by infected animals through the respiratory track (e.g. Avian or Swine Influenza [35,36]), faeces (e.g. Enterobacteriea, Clostridium difficile [37,38]), urine (e.g. Leptospira spp. [39]) or reproductive organs (e.g. C. burnetii $[40,41])$. These microorganisms can, once emitted to the environment, be directly taken up by humans through inhalation or ingestion [42], or be taken up after penetration of the home, deposition on the ground and resuspension of microorganisms in the air.[43] When a specific threshold regarding infectivity is exceeded [44,45], inhalation or ingestion of a livestock-related microorganism can cause infections. In a chapter 2 [34] two studies were identified that provided some information regarding duration and frequency of exposure to livestock related pathogens in an occupational setting.[46,47] Although these studies were not designed as exposure assessments, they both indicated that frequency and duration plays a role regarding exposure to livestockrelated zoonotic microorganisms.[34] Information about time activity patterns may therefore be very important for exposure assessment to livestock associated infectious agents and with advances in technology, computational power and big data, this factor can be included to exposure assessment. $[12,13,48]$

The studies in this thesis showed that being more often outdoors played an important role in exposure to livestock-related zoonotic microorganisms.[12,13] When residents spend time outdoors, they can be active in areas with higher environmental contaminant levels due to emissions from livestock stables.[8,49-53] There are two main ways to spent time outdoors close to farms. First, if someone lives within close distance of a farm, time spent outdoors near the home can be considered (e.g. gardening, playing, barbequing).[12,13] Second, when the resident lives further away from farms, time spent on active mobility (e.g. walking, biking) through their surroundings, may bring the resident within close distance to farms.[12,13] Especially the first factor, time spent outdoors near the home, appeared to be associated with a higher pneumonia risk than distance from the source alone.[12] A similar observation was made for the risk of being positive against $C$. burnetii in a serology study. [13] For the C. burnetii serology study, goat farms that were $C$. burnetii positive during the Dutch $\mathrm{Q}$ fever outbreak (2007-2010 [54]) were identified as exposure sources.[13] These two 
studies both indicate that being outdoors increases the risk of being exposed.[12,13] Time spent outdoors is therefore a relevant factor to include to exposure assessment models for livestock related health effects.

\section{Possibilities to Include time activity patterns to exposure assessment}

There are multiple approaches to include time activity data to a study and the method to apply depends on: availability of data, the effort it takes to include the data and the precision in exposure assessment that is gained. For very large population studies, for example modelling exposure to air pollution for the Dutch population, matching information available from independent sources, may be included to the exposure assessment. When data is collected in a study populations using survey methods, questions about time activity patterns may be included to the survey. Small studies dedicated to improve spatial aspects relevant for exposure assessment, may extent exposure assessment models with, respectively, questionnaire data about outdoor activities and/or mobility, or objectively measured information (e.g. GPS tracking or accelerometers [55]).

\section{Data from independent sources}

If the goal is to do an exposure assessment for a whole countries' population, data from existing sources in that country, such as the Dutch 'time use study' $[25,26]$, or large periodically executed mobility assessments [56-58] or mobile phone data [59] may be combined with country specified LUR or dispersion models. $[21,60]$ Including these data may give an idea about the average hours per day people in the country under study spend at home. Thus, providing additional information about actual exposure time for the population at risk which may reduce misclassification of exposure to a certain extent. Although, this approach provides some finesse to the models, nothing can be concluded with regards to personal exposure, for these analyses smaller studies are necessary to apply.

\section{Survey data and estimation methods for time activity patterns}

When researchers gather information in a study population and (electronic-) questionnaires are the applied method, questions regarding time spent outdoors [11] or activity diaries can be used to assess time activity patterns.[61-63] These methods are relatively easy and inexpensive to perform $[11,63]$, however, a major disadvantage with using self-reporting in mobility research is the fact that bias and misclassification can occur.[11,63-65] Within the VGO GPS study, participants largely overestimated the hours/week they spent biking and walking when self-reported data was compared to matching GPS measurements.[11] This overestimation was earlier indicated, but to a lesser extent, in the review of Kelly et al [63] and confirmed in a Swiss study by Fillekens et al.[65] In order to include time activity data to the whole VGO cohort, estimation methods were developed to predict active mobility within the VGO GPS study population.[14] Based on personal characteristics [11], adjusted questionnaire data [11] and spatial predictors three different estimation methods were developed, for the prediction of individual hours/week spent on active mobility.[14] These estimation methods however, did not allow for an accurate prediction of active mobility when validated against matching GPS data. Applying prediction models for time activity 
patterns is therefore not a solution to answer the duration and frequency question in exposure assessment.[14]

Contrary to self-reported data regarding mobility, there is not a vast amount of papers reporting on the average lengths of time spent outdoors. Two reviews were identified that used time spent outdoors as topic, but these reviews have a different focus when it comes to time spent outdoors and health outcomes. One review focussed on experimental settings, and reported stress reduction due to tasks and activities outdoors.[66] Another review found papers that did not distinguish between activities outdoors, but simply focused on sun exposure, vitamin D production and skin health. [67] With regard to time spent outdoors leading to environmental exposure $[12,13]$, only a single paper was identified that described a study focussing on human exposure to soil. In this study, time spent outdoors (hours/day) was measured using an activity diary and a correlation was found between time spent outdoors and soil exposure.[68] These researchers used self-reporting to measure time spent outdoors [68] in a similar way as was done in the studies described in this thesis. $[12,13]$ There were however no studies identified reporting about misclassification of time spent outdoors due to using selfreporting as measuring tool. Since, self-reporting was used to measure time spent outdoors near the home address in this thesis $[12,13]$, it might be that misclassification occurred to a similar extent as occurred with the self-reported data about mobility. $[11,63,65]$ Spending time outdoors, especially in a green environment, has been suggested to be beneficial for physical and mental health.[66,69-71] It be possible that, when people are questioned about this topic, they might answer in a socially desirable way [72], meaning that they report more hours spent outdoors, because of the health beneficial effects, than they have actually spent. In this case, time spent outdoors might be over-reported, introducing misclassification, which may bias the outcome. The true durations of time spent outdoors, in this situation, might be shorter and potential health effects may be even stronger than the effects observed in this thesis.[12,13]

A method to reduce estimation errors of time spent outdoors, measured with questionnaires, may be found in newly developed survey methods, such as map-based questionnaires (MBOs). MBOs were shown to be efficient in registering durations of regular activities and time spent at visited locations. $\mathrm{MBO}$ s may be extended in the near future, including questions regarding health, lifestyle and interactions with people, to supplement the data available for research.[73]

\section{Objective measurements}

So far it was suggested to include data from independent sources to exposure assessment models, or use estimation methods or survey data to included information about how people spent their time to exposure assessment methods. What has not been discussed yet, and what has been performed in the VGO GPS study, are actual objective measurements for time activity patterns. In the VGO GPS study Global Positioning System (GPS) measurements were used, to obtain objective information on weekly time activity patterns.[11-14] Using GPS measurements as a tool in environmental epidemiology, was suggested to be very promising for exposure assessment purposes.[74] This is illustrated by the use of GPS in exposure assessment to date. $[12,13,65,73,75-79]$ By using GPS measurements, time activity patterns can be 
combined with averaged concentration levels of exposures specific for certain locations. $[12,13,65,75-78]$ In the VGO GPS study, GPS data was available for 941 study participants.[11-14] This enabled time activity pattern-linked estimations of exposure for a larger population, especially when compared to other studies using GPS measurements in exposure assessment (number of participants: range $\mathrm{N}=9-27$ $[65,75,76])$. These low numbers of participants in other studies illustrate that GPS data is work intensive and relatively expensive to collect.[63] GPS measurements also have other limitations. In the VGO GPS study, GPS devices were equipped with a motion detector to prevent battery depletion. GPS loggers were set to a 1-second measuring interval when active and this resulted in a median of 187 logged hours of data (Inter Quartile Range: 143-235h).[11-13] Still, there was quite some variability in the length of GPS measurements, GPS tracks with a measuring time $<24$ hours were excluded from the analysis, because these tracks did not meet the start- and stop-criteria of the GPS algorithm.[11]Collecting GPS data from 941 study participants was done during the time frame of over one year (September 2014- January 2016). Mobility patterns may change over time -e.g. due to seasonal and weather changes- and this may not have been well captured in the GPS data. Therefore, misclassification on the individual level may be present in the VGO GPS study, but the data should also reflect a representative picture of mobility patterns in the study population.[11-13] During the data collection period, device failures and errors occurred and GPS loggers got lost in the sending procedure.[11-13] Furthermore, GPS loggers loose measuring accuracy when there are limitations in satellite reception. Beekhuizen et al, showed that in an urban environment GPS loggers can be inaccurate ( $85 \%$ of errors were $<10 \mathrm{~m}$, but $1 \%$ of errors were $>50 \mathrm{~m}$ ) due to blockages of satellite reception by high rise buildings.[74] In the VGO GPS study, measurements were performed in a rural area, so high rise buildings were of limited concern, still when a GPS device was taken indoors this gave rise to a cloud of erroneous data points surrounding buildings. An algorithm was used to assign data points as being 'indoors' or 'outdoors' by applying buffers, based on a visual check, around the home address (6om buffer) or other building polygons with more than 45 data points within the building outline (2om buffer). Data points that fell within these buffers were assigned as being 'indoors'. [11-13] By applying this procedure potential measurement information about time spent outdoors very near to the home -e.g. in the garden- was also lost. Given the developments in positioning techniques [80], an approach as applied in this thesis may not be necessary in the near future. Improvements of, and newly developed software, enables localisation of mobile devices indoors with a very high accuracy.[80] If these trends continue, the issues with indoors and outdoors GPS satellite reception will be solved within the near future, thus introducing new opportunities for objective measurements for time activity patterns. Still, for the analyses concerning routinely hours per week spent outdoors near the home, selfreported data was used and this was found to be the strongest predictor of exposure in this thesis. $[12,13]$

\section{Generalizability of study outcomes and misclassification of exposure}

The measurements in this thesis were performed in residents of a rural area in the Netherlands, results from these studies may therefore not be generalizable to settings in other parts of the world.[11-14] It was identified that study participants spent very 
little time on active mobility (e.g. 20 minutes/week walking and 60 minutes/week biking $[11,12])$. This may be different for people living in urban environments in the Netherlands, people living in the four largest cities (Amsterdam, Rotterdam, The Hague and Utrecht) were shown to spent on average more time on cycling and walking than the rest of the country.[58] These people may not be exposed to livestock emissions, but concentrations of urban exposure agents such as traffic related $\mathrm{PM}_{10}$ were also found higher outdoors than indoors [28], suggesting that actively mobility and time spent outdoors may play a role in exposure to these agents.

Exposure to livestock farms, especially goat farms, could have been misclassified in the studies discussed in this thesis. Misclassification of exposure could have been nondifferential or differential. If non-differential, the errors in exposure classification are random and non-differential misclassification may attenuate risk estimates towards unity. The result is that an exposure response relation is weaker (attenuated towards zero) and has a larger confidence interval.[81]

Differential misclassification, however, means that the error differs between individuals with and without the health effect. This type of misclassification can bias an association both towards unity and away from unity, showing weaker or stronger associations between exposures and health effects. $[17,27,81,82]$ In the analyses showing an association between spending more time outdoors while living near goat farms and pneumonia, people that had experienced a pneumonia spent slightly more time outdoors than controls (median 4 hours/week IQR[2.0-7.0] versus 3.5 hours/week IQR[1.5-7.5]). This difference however fell within the same Inter Quartile Range (IOR) so was unlikely to have biased the outcomes.[12]

\section{Suggestions for further research}

In this thesis information about time spent outdoors was combined with being within the vicinity of livestock farms and associations were identified with the risks for pneumonia and positive C. burnetii serology.[12,13] Unfortunately, there was no opportunity to combine the GPS data with modelled livestock-related concentrations of exposure to $P M_{10}$ and endotoxins, resulting from the LUR and dispersion models developed from the VGO air measurement studies. $[8,23]$ Combining these two datasets to search for associations between exposure and respiratory health effects and atopic sensitisation is something that is strongly encouraged to do in the near future.

Self-reported data about time spent outdoors near the home was found to be the predictor of exposure most strongest associated with health endpoints in this thesis.[12,13] This means that for future environmental epidemiological studies, including questions regarding time spent outdoors to newly developed survey methods (e.g. MBQ's [73]), can provide an additional strong predictor of exposure to exposure assessments.

\section{Public health impact of including time activity patterns to exposure assessment}

The Netherlands government encourages municipalities to design the outdoor environment in such a way, that it invites people to spend time outdoors.[83] This is because spending time outdoors, especially in green environments, has been suggested to be beneficial for physical and mental health.[66,69-71] In this thesis however, associations were identified between time spent outdoors near goat farms and 
increased risks for pneumonia [12] and positive serology for $C$. burnetii antibodies a marker for a former $\mathrm{Q}$ fever infection.[13] Pneumonia and $\mathrm{Q}$ fever are both consequences of infections by microorganisms and while the causative agent giving rise to the increased incidence of pneumonia around goat farms $[12,19]$ is currently subject of investigation[84], the causative agent for $Q$ fever is clear. $Q$ fever is a disease caused by the bacterium C. burnetii and during the Dutch $Q$ fever outbreak (2007-2010) the bacterium was spread in the environment during abortion storms that occurred on infected dairy goat farms.[54,85] C. burnetii is a bacterium that is highly infectious [86] and also very resistant against conditions outside the host organism. [40,41] Thus the bacterium is a threat for human health once it is excreted from a farm to the environment. For $\mathrm{Q}$ fever there are protocols available from the Dutch government in case another outbreak occurs for both the medical field and the veterinary field. $[87,88]$ In the protocol $\mathrm{Q}$ fever for the medical field, there are no measures described with regards to being outdoors near $C$. burnetii infected farms.[87] In the veterinary protocol there are also no measures described regarding being outdoors near $C$. burnetii infected farms, however, the protocol does describe a visiting ban for stables for nonoccupationally involved people when stables are positive for a $C$. burnetii outbreak among livestock.[88] In this example the situation for $Q$ fever is described, this infection can be easily transmitted from livestock animals to humans.[40,86] Still, there are no preventative measures advised with regards to spending time outdoors near affected farms. $\mathrm{Q}$ fever is not special in this sense, there are no preventive measures regarding time spent outdoors near farms when infected by other environmental transmissible zoonotic infectious diseases.[89]

Considering the above, is it advisable not to spend time outdoors anymore in a rural surrounding? No, in 2010 was shown that the health benefits for cycling were larger than the risk relative to car driving.[90] In the case of a zoonotic event, however, next to advising people how to prevent an infection and making people aware of symptoms [89], monitoring of human and veterinary health may be the best option to prevent large scale outbreaks of disease. If an outbreak is so severe that the general public is at risk, as was the case with $\mathrm{Q}$ fever, limiting spending time outdoors near an infected farm should be considered. In the aftermath of such an outbreak potentially exposed people, occupational, non-occupationally exposed residents, but also people actively mobile in an outbreak area, should be monitored to identify the health related impact.

\section{General conclusions}

In this thesis information about outdoors activities -mobility and activities outdoors near the home- were collected using GPS logging and self-reporting, in a rural population in the Netherlands. This information was combined with data about livestock farms in the research area, which acted as exposure source. Time spent outdoors close to home in the presence of goat farms translated into an increased pneumonia risk. The specific agent or mechanism underlying this increased risk for pneumonia was not identified and is currently under study. $C$. burnetii, the causative agent for $\mathrm{Q}$ fever, was however excluded as causative agent, since $C$. burnetii antibody serology and pneumonia were not correlated. Mobility outdoors in the vicinity of goat farms did not markedly change risk estimates, but this could be expected given that the time spent on active mobility was relatively limited.[12] Still, it was observed that outdoor exposure, a combination of 
time spent outdoors near the home and active mobility, contributed to the risk of becoming $C$. burnetii serology positive during the 2007-2010 Dutch $\mathrm{Q}$ fever outbreak. These associations were stronger if people lived closer to $C$. burnetii positive farms.[13] Given these findings, time activity patterns, when included to exposure assessment, provided somewhat stronger associations, than for measures earlier used in spatial epidemiological studies such as distance from the source. Time spent in the vicinity of an emitting infectious source plays a role in exposure assessment to livestock related zoonotic pathogens. Preferably, information about time activity data is therefore included to exposure assessment methods. The method how to include this factor, is a topic for further study. It was shown that study participants significantly overestimated their time spent outdoors in active transport when self-reported data was compared to GPS measured data, still several general characteristics correlating to differences in mobility patterns were identified.[11] Using the identified general characteristics, selfreported data about mobility adjusted for overestimation and location-based information, three different approaches were designed to predict active mobility. These estimation methods however, were equally unable to accurately predict active mobility, when compared to matching GPS data.[14] Therefore, measurements still represent the best possible tool to evaluate outdoor activity and activity mobility.

Depending on the causal pathogen in the event of a future livestock related outbreak of a zoonotic disease, hours/week spent outdoors or being actively mobile close to infected farms should be included to outbreak management approaches. 


\section{References}

Nieuwenhuijsen MJ. Exposure Assessment in Environmental Epidemiology. 2nd ed. Oxford University Press Inc 2015.

Cambra-López M, Aarnink AJA, Zhao Y, et al. Airborne particulate matter from livestock production systems: A review of an air pollution problem. Environ Pollut 2010;158:1-17. doi:10.1016/j.envpol.2009.07.011

Bellarby J, Tirado R, Leip A, et al. Livestock greenhouse gas emissions and mitigation potential in Europe. Glob Chang Biol 2013;19:3-18. doi:10.1111/j.1365-2486.2012.02786.x

Blanes-Vidal V, Suh H, Nadimi ES, et al. Residential exposure to outdoor air pollution from livestock operations and perceived annoyance among citizens. Environ Int 2012;40:44-50. doi:10.1016/j.envint.2011.11.010

Borlee $F$, Joris Yzermans C, Aalders B, et al. Air pollution from livestock farms is associated with airway obstruction in neighboring residents. Am J Respir Crit Care Med 2017;196:1152-61. doi:10.1164/rccm.201701-0021OC Seedorf J. An emission inventory of livestock-related bioaerosols for Lower Saxony, Germany. Atmos Environ 2004;38:6565-81. doi:10.1016/j.atmosenv.2004.08.023

Basinas I, Schlünssen V, Takai $\mathrm{H}$, et al. Exposure to inhalable dust and endotoxin among danish pig farmers affected by work tasks and stable characteristics. Ann Occup Hyg 2013;57:1005-19. doi:10.1093/annhyg/meto29

de Rooij MMT, Smit LAM, Erbrink HJ, et al. Endotoxin and particulate matter emitted by livestock farms and respiratory health effects in neighboring residents. Environ Int 2019;132:105009. doi:10.1016/j.envint.2019.105009

Maassen K, Smit L, Wouters I, et al. Veehouderij en gezondheid omwonenden. Published Online First: 2016.http://rivm.openrepository.com/rivm/handle/10029/617909

Borlée $F$, Yzermans CJ, Krop E, et al. Spirometry, questionnaire and electronic medical record based COPD in a population survey: Comparing prevalence, level of agreement and associations with potential risk factors. PLOS One 2017;12:1-16. doi:10.1371/journal.pone.0171494 Klous G, Smit LAM, Borlée $F$, et al. Mobility assessment of a rural population in the Netherlands using GPS measurements. Int J Health Geogr 2017;16:30. doi:10.1186/s12942-017-0103-y Klous G, Smit LAM, Freidl GS, et al. Pneumonia risk of people living close to goat and poultry farms - Taking GPS derived mobility patterns into account. Environ Int 2018;115. doi:10.1016/j.envint.2018.03.020 Klous G, Smit LAM, van der Hoek W, et al. Relationship between Coxiella burnetii (Q fever) antibody serology and time spent outdoors. Submitted

Klous G, Kretzschmar MEE, Coutinho RA, et al. Prediction of human active mobility in rural areas: development and validity tests of three different approaches. J Expo Sci Environ Epidemiol Published Online First: 26 November 2019. doi:10.1038/s41370-019-0194-6 Van Dijk CE, Smit LAM, Hooiveld M, et al. Associations between proximity to livestock farms, primary health care visits and self-reported symptoms. BMC Fam Pract 2016;17:1-8. doi:10.1186/s12875-016-0421-3 Pijnacker R, Reimerink J, Smit LAM, et al. Remarkable spatial variation in the seroprevalence of Coxiella burnetii after a large $Q$ fever epidemic. BMC Infect Dis 2017;17:1-8. doi:10.1186/s12879017-2813-y Rothman K. Epidemiology, An introduction. 2nd ed. Oxford University Press Inc 2012 Borlee F, Yzermans CJ, Krop EJM, et al. Residential proximity to livestock farms is associated with a lower prevalence of atopy. Occup Environ Med 2018;75:453-60. doi:10.1136/oemed-2017-104769 Freidl GS, Spruijt IT, Borlée F, et al. Livestock-associated risk factors for pneumonia in an area of intensive animal farming in the Netherlands. PLoS One 2017;12:1-16. doi:10.1371/journal.pone.0174796 Eeftens M, Beelen R, De Hoogh K, et al. Development of land use regression models for PM2.5, PM 2.5 absorbance, PM10 and PMcoarse in 20 European study areas; Results of the ESCAPE project. Environ Sci Technol 2012;46:11195-205. doi:10.1021/es301948k Gehring $U$, Gruzieva O, Agius RM, et al. Air pollution exposure and lung function in children: The ESCAPE project. Environ Health Perspect 2013;121:1357-64. doi:10.1289/ehp.1306770 Hoek $\mathrm{G}$, Beelen $\mathrm{R}$, de Hoogh $\mathrm{K}$, et al. A review of land-use regression models to assess spatial variation of outdoor air pollution. Atmos Environ 2008;42:7561-78. 
doi:10.1016/j.atmosenv.2008.05.057

De Rooij MMT, Hoek G, Schmitt H, et al. Insights into Livestock-Related Microbial Concentrations in Air at Residential Level in a Livestock Dense Area. Environ Sci Technol 2019;53:7746-58. doi:10.1021/acs.est.8bo7029 De Rooij MMT, Heederik DJJ, Van Nunen EJHM, et al. Spatial variation of endotoxin concentrations measured in ambient PM1o in a livestock-dense area: Implementation of a land-use regression approach. Environ Health Perspect 2018;126:1-11. doi:10.1289/EHP2252 Roeters A, de Boer A, van den Broek A, et al. Alle ballen in de lucht; Alle ballen in de lucht. 2018;:1223.www.scp.nl SCP. Tijdbestedingsonderzoek (TBO). https://www.scp.nl/Onderzoek/tijdsbesteding occupational exposures. Occup Environ Med 1998;55:651-6. doi:10.1136/oem.55.10.651

Hoek G, Kos G, Harrison R, et al. Indoor-outdoor relationships of particle number and mass in four European cities. Atmos Environ 2008;42:156-69. doi:10.1016/j.atmosenv.2007.09.026

Bari MA, MacNeill M, Kindzierski WB, et al. Predictors of coarse particulate matter and associated endotoxin concentrations in residential environments. Atmos Environ 2014;92:221-30.

doi:10.1016/j.atmosenv.2014.04.025

Pavilonis BT, Anthony TR, O'Shaughnessy PT, et al. Indoor and outdoor particulate matter and endotoxin concentrations in an intensely agricultural county. J Expo Sci Environ Epidemiol 2013;23:299-305. doi:10.1038/jes.2012.123

Wheeler AJ, Dobbin NA, Lyrette N, et al. Residential indoor and outdoor coarse particles and associated endotoxin exposures. Atmos Environ 2011;45:7064-71.

doi:10.1016/j.atmosenv.2011.09.048

Hennekes M VGO personal exposure pilot study: comparing outdoor, indoor and personal PM10 and endotoxin exposure levels in a livestock dense area. 2016. Master thesis Toxicology and Environmental Health Utrecht University

Levin PA, Angert ER. Small but mighty: Cell size and bacteria. Cold Spring Harb Perspect Biol 2015;7:1-11. doi:10.1101/cshperspect.a019216

$4 \quad$ Klous G, Huss A, Heederik DJJ, et al. Human-livestock contacts and their relationship to transmission of zoonotic pathogens, a systematic review of literature. One Heal 2016;2:65-76. doi:10.1016/j.onehlt.2016.03.001 Koopmans M, Wilbrink B, Conyn $\mathrm{M}$, et al. Transmission of $\mathrm{H}_{7} \mathrm{~N}_{7}$ avian influenza $A$ virus to human beings during a large outbreak in commercial poultry farms in the Netherlands. Infect Dis Clin Pract 2004;12:276-7. doi:10.1097/01.idc.0000130890.12611.f3

Wong KK, Greenbaum A, Moll ME, et al. Outbreak of In fl venza A ( $\left.\mathrm{H}_{3} \mathrm{~N}_{2}\right)$ Variant Virus Infection among. 2012;18:1-2.

Wielders $\mathrm{CCH}$, van Hoek AHAM, Hengeveld PD, et al. Extended-spectrum $\beta$-lactamase- and pAmpC-producing Enterobacteriaceae among the general population in a livestock-dense area. Clin Microbiol Infect 2017;23:120.e1-120.e8. doi:10.1016/j.cmi.2016.10.013 Teunis PFM, Evers EG, Hengeveld PD, et al. Time to acquire and lose carriership of ESBL/ pAmpC producing E. coli in humans in the Netherlands. PLoS One 2018;13:1-14. doi:10.1371/journal.pone.0193834

9 Bharti AR, Nally JE, Ricaldi JN, et al. Leptospirosis: A zoonotic disease of global importance. Lancet Infect Dis 2003;3:757-71. doi:10.1016/S1473-3099(03)00830-2

Raoult D, Marrie TJ, Mege JL. Natural history and pathophysiology of Q fever. Lancet Infect Dis 2005;5:219-26. doi:10.1016/S1473-3099(05)70052-9

Angelakis E, Raoult D. Q fever. 2010;140:297-309. doi:10.1016/j.vetmic.2009.07.016

Webber R. Communicable Disease Epidemiology and Control, A Global Perspective. 3rd ed. Cabi Publishing 2004.

Prussin AJ, Marr LC. Sources of airborne microorganisms in the built environment. Microbiome 2015;3:78. doi:10.1186/s40168-015-0144-z

RIVM LCI. LCI RIVM. https://lci.rivm.nl/

CDC. Diseases Conditions. https://www.cdc.gov/DiseasesConditions/ Whelan J, Schimmer B, Schneeberger $\mathrm{P}$, et al. O fever among culling workers, the Netherlands, 2009-2010. Emerg Infect Dis 2011;17:1719-23. doi:10.3201/eid1709.110051

Bridges $\mathrm{CB}$, Lim W, Hu-Primmer J, et al. Risk of Influenza A ( $\left.\mathrm{H}_{5} \mathrm{~N}_{1}\right)$ Infection among Poultry Workers, Hong Kong, 1997-1998. J Infect Dis 2002;185:1005-10. doi:10.1086/340044 

Health Research. Curr Environ Heal reports 2017;4:463-71. doi:10.1007/\$40572-017-0163-y Dungan RS, Leytem AB. Qualitative and quantitative methodologies for determination of airborne microorganisms at concentrated animal-feeding operations. World J Microbiol Biotechnol 2009;25:1505-18. doi:10.1007/s11274-009-0043-1 Green CF, Gibbs SG, Tarwater PM, et al. Bacterial plume emanating from the air surrounding swine confinement operations. J Occup Environ Hyg 2006;3:9-15. doi:10.1080/15459620500430615 Eisenberg SWF, Nielen M, Santema W, et al. Detection of spatial and temporal spread of Mycobacterium avium subsp. paratuberculosis in the environment of a cattle farm through bioaerosols. Vet Microbiol 2010;143:284-92. doi:10.1016/j.vetmic.2009.11.033 Gibbs SG, Green CF, Tarwater PM, et al. Isolation of antibiotic-resistant bacteria from the air plume downwind of a swine confined or concentrated animal feeding operation. Environ Health Perspect 2006;114:1032-7. doi:10.1289/ehp.8910 Don RS. Board-invited review: Fate and transport of bioaerosols associated with livestock operations and manures. J Anim Sci 2010;88:3693-706. doi:10.2527/jas.2010-3094 Roest HIJ, Tilburg JJHC, Van Der Hoek W, et al. The $Q$ fever epidemic in the Netherlands: History, onset, response and reflection. Epidemiol Infect 2011;139:1-12. doi:10.1017/Sog50268810002268 Lee IM, Shiroma EJ. Using accelerometers to measure physical activity in large-scale epidemiological studies: Issues and challenges. Br J Sports Med 2014;48:197-201. doi:10.1136/bjsports-2013-093154 Pasaoglu G, Zubaryeva A, Fiorello D, et al. Analysis of European mobility surveys and their potential to support studies on the impact of electric vehicles on energy and infrastructure needs in Europe. Technol Forecast Soc Change 2014;87:41-50. doi:10.1016/j.techfore.2013.09.002 CBS. OVIN. https://www.cbs.nl/ovin

58 Schaap N, Harms L, Kansen M, et al. Cycling and Walking: the grease in our mobility chain. Published Online First: 2016.http://english.kimnet.nl Dewulf B, Neutens T, Lefebvre W, et al. Dynamic assessment of exposure to air pollution using mobile phone data. Int J Health Geogr 2016;15:1-14. doi:10.1186/s12942-016-0042-z ESCAPE project. http://www.escapeproject.eu/

Deffner V, Kuchenhoff H, Maier V, et al. Personal exposure to ultrafine particles: Two-level statistical modeling of background exposure and time-activity patterns during three seasons. $J$ Expo Sci Environ Epidemiol 2016;26:17-25. doi:10.1038/jes.2014.73 Axhausen K, Zimmermann A, Schönfelder S, et al. Observing the rhythms of daily life: a six-week travel diary Elektronische Daten. 2000;:95-124.http://en.scientificcommons.org/831369 Kelly P, Krenn P, Titze S, et al. Quantifying the Difference Between Self-Reported and Global Positioning Systems-Measured Journey Durations : A Systematic Review Global Positioning Systems-Measured Journey Durations : A Systematic Review. 2013;1647.

doi:10.1080/01441647.2013.815288 Int J Geogr Inf Sci 2018;32:1485-504. doi:10.1080/13658816.2018.1434888 Fillekes MP, Röcke C, Katana M, et al. Self-reported versus GPS-derived indicators of daily mobility in a sample of healthy older adults. Soc Sci Med 2019;220:193-202.

doi:10.1016/j.socscimed.2018.11.010 Kondo MC, Jacoby SF, South EC. Does spending time outdoors reduce stress? A review of realtime stress response to outdoor environments. Heal Place 2018;51:136-50. doi:10.1016/j.healthplace.2018.03.001 Diffey BL. An overview analysis of the time people spend outdoors. Br J Dermatol 2011;164:84854. doi:10.1111/j.1365-2133.2010.10165.x soil and time spent outdoors. J Expo Anal Environ Epidemiol 2000;10:341-54. doi:10.1038/sj.jea.7500097 Klompmaker JO, Hoek G, Bloemsma LD, et al. Associations of combined exposures to surrounding green, air pollution and traffic noise on mental health. Environ Int 2019;129:525-37. doi:10.1016/j.envint.2019.05.040 Klompmaker JO, Janssen NAH, Bloemsma LD, et al. Residential surrounding green, air pollution, traffic noise and self-perceived general health. Environ Res 2019;179:108751. doi:10.1016/j.envres.2019.108751 Bloemsma LD, Gehring U, Klompmaker JO, et al. Green space, air pollution, traffic noise and 
cardiometabolic health in adolescents: The PIAMA birth cohort. Environ Int 2019;131:104991. doi:10.1016/j.envint.2019.104991 self-reports of physical activity. Am J Epidemiol 2005;161:389-98. doi:10.1093/aje/kwio54 Kestens Y, Thierry B, Shareck M, et al. Integrating activity spaces in health research: Comparing the VERITAS activity space questionnaire with 7-day GPS tracking and prompted recall. Spat Spatiotemporal Epidemiol 2018;25:1-9. doi:10.1016/j.sste.2017.12.003 Beekhuizen J, Kromhout $\mathrm{H}$, Huss A, et al. Performance of GPS-devices for environmental exposure assessment. J Expo Sci Environ Epidemiol 2013;23:498-505. doi:10.1038/jes.2012.81 Gerharz LE, Pebesma E. Using geostatistical simulation to disaggregate air quality model results for individual exposure estimation on GPS tracks. Stoch Environ Res Risk Assess 2013;27:223-34. doi:10.1007/s00477-012-0578-9 Breen MS, Long TC, Schultz BD, et al. assessments : Model evaluation in central North Carolina. 2014;24:412-20. doi:10.1038/jes.2014.13.GPS-based Vich G, Marquet O, Miralles-Guasch C. Green exposure of walking routes and residential areas using smartphone tracking data and GIS in a Mediterranean city. Urban For Urban Green $2018 ;: 1-$ 11. doi:10.1016/j.ufug.2018.08.008 Harrison F, Burgoine T, Corder K, et al. How well do modelled routes to school record the environments children are exposed to?: A cross-sectional comparison of GIS-modelled and GPSmeasured routes to school. Int J Health Geogr 2014;13. doi:10.1186/1476-072X-13-5 Chaix B, Méline J, Duncan S, et al. GPS tracking in neighborhood and health studies: A step forward for environmental exposure assessment, A step backward for causal inference? Heal Place 2013;21:46-51. doi:10.1016/j.healthplace.2013.01.003 Xu R, Chen W, Xu Y, et al. Improved GNSS-based indoor positioning algorithm for mobile devices. GPS Solut 2017;21:1721-33. doi:10.1007/s10291-017-0647-0 Spiegelman D. Approaches to Uncertainty in Exposure Assessment in Environmental Epidemiology. Annu Rev Public Health 2010;31:149-63. doi:10.1146/annurev.publhealth.012809.103720 Blair A, Stewart P, Lubin JH, et al. Methodological issues regarding confounding and exposure misclassification in epidemiological studies of occupational exposures. Am J Ind Med 2007;50:199207. doi:10.1002/ajim.20281

83 RIVM. Gezonde leefomgeving. https://www.rivm.nl/gezonde-leefomgeving/wat-verstaan-weonder-gezonde-leefomgeving

84 RIVM. Veehouderij en gezondheid, vervolgonderzoeken VGO. https://www.rivm.nl/veehouderijen-gezondheid/vervolgonderzoeken-vgo de Bruin A, van der Plaats ROJ, de Heer L, et al. Detection of Coxiella burnetii DNA on SmallRuminant Farms during a Q Fever Outbreak in the Netherlands. Appl Environ Microbiol 2012;78:1652-7. doi:10.1128/aem.07323-11 Brooke RJ, Kretzschmar MEE, Mutters NT, et al. Human dose response relation for airborne exposure to Coxiella burnetii. BMC Infect Dis 2013;13. doi:10.1186/1471-2334-13-488

RIVM LCl. Q-koorts. https://lci.rivm.nl/richtlijnen/q-koorts NVWA. Q-koorts. https://www.nvwa.nl/onderwerpen/dierziekten/q-koorts RIVM LCI. Richtlijnen. https://lci.rivm.nl/richtlijnen/ de Hartog JJ, Boogaard $\mathrm{H}$, Nijland $\mathrm{H}$, et al. Do the health benefits of cycling outweigh the risks? Environ Health Perspect 2010;118:1109-16. doi:10.1289/ehp.0901747 
Summary 


\section{Summary}

Between 2007 and 2010 the Netherlands experienced the largest documented Q fever outbreak to date. This outbreak and several other incidents with infectious disease spillovers from livestock to humans, initiated research focussing on the impact on human health of living in the vicinity of livestock farms, of which the results in this thesis are a part.

In chapter 1 the $\mathrm{O}$ fever outbreak and other livestock-related zoonotic incidents are discussed in more detail. Livestock farming in the Netherlands is put into a geographical perspective and the rationale for the research in this thesis is specified.

Chapter $\mathbf{2}$ describes the results of a systematic review of the literature, summarising the current knowledge about human-livestock interactions and transmission modes of microorganisms. In this chapter it is concluded that little is known about the intensity and type of human-livestock interactions and the actual modes of microorganism transmission. Studies performed in occupational settings, in which individuals are usually higher exposed than than individuals whose exposure results from environmental exposures, provided some evidence that more intense exposure to livestock-origin environmental pathogens resulted in increased risks of infection.

The results from chapter 2 provide a starting point for the following chapters in this thesis, that focus on environmental epidemiology and the study of the effects of environmental exposures on human health. An important element in environmental epidemiology is human exposure assessment. Exposure is defined as contact with an agent or contaminant. This is usually operationalised by measuring the agent in a medium (air, water) which acts as a vehicle for exposure. The exposure assessment component of a study usually has three dimensions which need to be considered: the environmental concentration of an agent, duration of exposure and frequency of exposure. Environmental epidemiology is traditionally focussed mostly on chemical contaminants. It was recently emphasized that the same concepts apply to other agents, including infectious agents. While years of research focussed on measuring and modelling concentrations of environmental pollutants, the frequency and duration of exposure have so far received considerable less attention and have not been included routinely into current methodology for environmental exposure assessment. In chapters 3 to 6 the aim was to include a proxy for duration and frequency to exposure in the exposure assessment methodology by including information about time activity patterns. Livestock-associated infectious diseases were the exposures studied in chapters 4 and 6.

Chapter 3 shows the first results of the VGO GPS study. In this study weeklong GPS measurements and self-reported data about weekly mobility and outdoors habits were collected from a group of volunteers $(\mathrm{N}=1014)$. Volunteers in the VGO GPS study were recruited from a larger cohort population $(\mathrm{N}=2494)$ that participated to the 'Farming and Neighbouring Residents' Health' study (VGO study). GPS measurements allow for an objective measurement of location information of an individual. Using an algorithm GPS data points were assigned being either indoors or outdoors, since taking an GPS logger indoors provided inaccurate measurements. Outdoors logged GPS points were translated into hours per week spent walking, biking and in motorised transport. Information from 941 VGO GPS study volunteers remained for further analysis after these steps. Self-reported and GPS data regarding mobility were compared. A 
considerable overestimation was identified for self-reported hours per week spent walking and biking. Furthermore, several general characteristics were identified that seemed explanatory for differences in mobility patterns between individuals.

In Chapter 4 the effect of including time activity patterns as proxy for duration and frequency of exposure was first analysed for pneumonia and exposure to goat and poultry farms. This was after the identification of an association between living near goat and poultry farms with an increased risk for pneumonia in the VGO study. Time activity patterns were generated by combining the GPS measured information and selfreported data about time spent outdoors near the home, since GPS logging in and around indoors location provided many errors. A significantly increased risk for pneumonia was identified when people lived near goat farms and reported to spent more time outdoors near the home. In this study we were unable to identify a causative agent, but $C$. burnetii (causal agent of $\mathrm{Q}$ fever) was unlikely to be the underlying factor for the increase in pneumonia incidence, because there was no association between $C$. burnetii antibody serology and pneumonia.

Including information about active human mobility, as a proxy for duration and frequency of exposure, to larger study populations can be challenging, as mobility measurements are work intensive to collect and expensive to perform. Therefore, in chapter 5 it was attempted to design accurate estimation methods for human mobility, to include this factor in exposure assessments for large populations. Using data from the VGO GPS study three estimation methods for hours/week of active human mobility were developed. These methods were based on: the previously identified general characteristics that explained differences in mobility patterns, for overestimation adjusted self-reported data about weekly mobility and spatial information, the home and work address and location of the closest supermarket. Estimates of hours/week of active mobility were compared with individually matched GPS data. Unfortunately, non of the three estimation methods were able the accurately predict active mobility. Measurements still represent the best possible tool to evaluate mobility patterns.

In the aftermath of the 2007-2010 Q fever outbreak, the role of active mobility and being outdoors near the home address in the vicinity of infected goat farms has been explored. Chapter 6 describes a retrospective study regarding the effect of habitual time spent outdoors near the home and hours/week of active mobility near infected goat farms on C. burnetii antibody serology, a proxy for a previous $\mathrm{Q}$ fever infection. Although, mobility and serology measurements did not coincide with the $\mathrm{Q}$ fever outbreak, a positive association was identified between hours/week spent outdoors near the home near infected farms and risk for positive $C$. burnetii serology. Outdoor exposure may have contributed to the risk of becoming $C$. burnetii serology positive. These associations were stronger if people lived closer to $C$. burnetii infected farms.

Because including information about time activity patterns in exposure assessment for livestock associated infections seemed to influence risk estimates, chapter 7 discusses how time activity information can be included to future exposure assessment methods for various study population sizes. Additionally, this chapter describes the public health significance of including time activity patterns to exposure assessment.

Concluding, in this thesis, information about outdoor activities -mobility and activities outdoors near the home- were collected using GPS logging and self-reporting, in a rural population in the Netherlands. This information was combined with data about 
livestock farms in the research area, which acted as exposure source. Time spent outdoors close to home in the presence of goat farms translated into an increased pneumonia risk. The specific agent or mechanism underlying this increased risk for pneumonia was not identified and is currently under study. Mobility outdoors in the vicinity of goat farms did not markedly change risk estimates, but this might be expected given that the time spent on active mobility was relatively limited. Still, it was observed that outdoor exposure, a combination of time spent outdoors near the home and active mobility, contributed to the risk of becoming $C$. burnetii serology positive during the 2007-2010 Dutch $Q$ fever outbreak. These associations were stronger if people lived closer to $C$. burnetii positive farms.

Given these findings, time activity patterns, when included to exposure assessment, provided somewhat stronger associations, than for measures earlier used in spatial epidemiological studies such as home distance from the source. Time spent in the vicinity of an emitting infectious source is likely to play a role in exposure assessment to livestock related zoonotic pathogens and information about time activity data should therefore be considered for exposure assessment methods. The method how to include this factor is a topic for further study. It was shown that study participants significantly overestimated their time spent outdoors in active transport when self-reported data were compared to GPS measured data, but several general characteristics correlating to differences in mobility patterns were identified. Using this information, three different approaches were designed to predict active mobility for exposure assessment. These estimation methods however, were equally unable to accurately predict active mobility, when compared to matching GPS data. Measurements still represent the best possible tool to evaluate outdoor activity and active mobility.

Given the identified associations in this thesis, in the event of a future livestock related outbreak of a zoonotic disease, depending on the causal pathogen, active mobility and outdoors activities should be limited in the vicinity of infected farms. Among residents living near future infected farms, health and time-activity data should be collected, this will provide additional data that may strengthen the findings in this thesis. 
Samenvatting 


\section{Samenvatting}

In de jaren 2007 tot en met 2010 beleefde Nederland de tot nu toe grootste gedocumenteerde Q-koorts uitbraak ooit. Deze uitbraak, en andere incidenten met veehouderij-gerelateerde van dier-op-mensen overdraagbare infectieziekten, leidden tot wetenschappelijk onderzoek naar het effect op de menselijke gezondheid van het wonen nabij veehouderijen. Dit proefschrift maakt gebruik van data die zijn verzameld in dit onderzoek en richt zich voornamelijk op methodeontwikkeling voor blootstellingsinschattingen, waarbij specifieke aandacht wordt besteed aan veehouderij-gerelateerde infectieziekten.

In hoofdstuk 1 wordt kort de Nederlandse Q-koorts-epidemie beschreven, ook wordt ingegaan op andere incidenten met zoönotische infectieziekten afkomstig vit de veehouderij. Verder wordt de Nederlandse veehouderij in geografische context geplaatst en worden de achterliggende gedachten voor dit proefschrift viteengezet.

Hoofdstuk 2 beschrijft de uitkomsten van een systematisch literatuuronderzoek betreffende de kennis over mens-vee-interacties en de hieraan gerelateerde overdracht van micro-organismen. Geconcludeerd wordt dat er weinig bekend is over de intensiteit en typen mens-vee-interacties en de werkelijke transmissiewegen van microorganismen van dier naar mens. Uit studies, uitgevoerd binnen beroepsgroepen die intensief contact hebben met vee (boeren, slachthuiswerkers, dierenartsen), blijkt dat dit leidt tot een verhoogd risico op een infectie met een veehouderij-gerelateerd zoönotisch pathogeen.

De uitkomsten van hoofdstuk 2 zijn het startpunt voor de verdere hoofdstukken in dit proefschrift. Deze zijn vooral gericht op de effecten van veehouderij-gerelateerde blootstellingen, via het milieu, op de gezondheid van de mens. Een belangrijke component binnen het milieu-epidemiologisch onderzoek is de karakterisering van de humane blootstelling. Blootstelling is hierbij gedefinieerd als contact met een agens of verontreiniging. Blootstelling wordt voornamelijk gekwantificeerd aan de hand van de hoeveelheid van een agens in een medium zoals lucht of water. Een blootstellingsinschatting wordt gedaan aan de hand van drie dimensies: de concentratie van een agens in het milieu en de duur en frequentie van de blootstelling.

Milieu-epidemiologisch onderzoek heeft van oudsher een focus op chemische agentia. Recentelijk is echter aangetoond dat de geldende concepten binnen het vakgebied ook gebruikt kunnen worden voor andere agentia, zoals micro-organismen. $\mathrm{Er}$ is veel onderzoek gedaan naar het meten en moduleren van chemische milieuverontreiniging, terwijl de dimensies duur en frequentie van blootstelling onderbelicht zijn gebleven in het onderzoek en de toegepaste methoden.

Daarom ligt de focus van hoofdstuk 3 tot en met 6 op de inclusie van de factoren duur en frequentie van blootstelling in blootstellingsinschatting-methoden. Hiervoor is gebruik gemaakt van tijd-activiteiten patronen. In de hoofdstukken 4 en 6 worden blootstellingsinschatting-methoden beschreven voor veehouderij-gerelateerde infectieziekten, deze methoden zijn inclusief tijd-activiteiten patronen.

Hoofdstuk 3 laat de eerste resultaten zien van de Veehouderij en Gezondheid Omwonenden Global Positioning System studie (VGO GPS studie). In deze studie zijn data verzameld over wekelijkse mobiliteit van omwonenden van veehouderijbedrijven middels GPS-metingen en zelfrapportage. Deelnemers hebben een week lang een GPS- 
tracker bij zich gedragen zodra zij het huis verlieten en middels het GPS satelliet systeem zijn gedurende deze week locatie data gemeten. Ook werd deelnemers $(\mathrm{N}=1014)$ gevraagd naar hun gedrag buiten. Deelnemers aan de VGO GPS studie zijn geworven uit het deelnemerscohort van de eerder uitgevoerde VGO studie ( $N=2494)$. De GPS-metingen maken het mogelijk om op een objectieve manier individuele locatie data te verzamelen van personen. Door middel van een eerder toegepast algoritme werden GPS-datapunten ingedeeld als binnen- of buitenshuis, dit omdat metingen binnenshuis leiden tot forse fouten in GPS-precisie. De buitenshuis gemeten GPSpunten werden vervolgens vertaald in het aantal uren per week dat is gelopen, gefietst of doorgebracht in gemotoriseerd vervoer. Na deze verwerkingsstappen bleef er informatie beschikbaar van 941 deelnemers voor nadere analyses. Een van deze analyses was een vergelijking tussen met GPS-gemeten en zelf gerapporteerde mobiliteit per week. Hierbij werd een aanmerkelijke overschatting van de zelf gerapporteerde tijd per week lopend en fietsend doorgebracht geconstateerd. Ook werden persoonlijke karakteristieken gevonden die een verklaring gaven voor verschillen in mobiliteitspatronen

In hoofdstuk 4 worden tijd-activiteiten patronen als een maat voor de duur en frequentie van blootstelling geïncludeerd in een risicoanalyse voor longontsteking gerelateerd aan wonen in de buurt van pluimvee- en geitenbedrijven. Dit werd gedaan nadat een eerdere analyse met de VGO-data aantoonde dat wonen nabij een pluimveeof geitenbedrijf een verhoogd risico gaf op pneumonie. Tijd-activiteiten patronen werden gegenereerd door GPS-data te combineren met zelf gerapporteerde tijd besteed aan activiteiten buitenshuis nabij de woning. Dit laatste vanwege de precisiefouten die ontstaan bij GPS-metingen nabij en binnenshuis. Er werd een significante verhoging van het risico op pneumonie geobserveerd wanneer iemand meer tijd buitenshuis nabij de woning doorbracht en de woning dichtbij een geitenbedrijf stond. Lopen en fietsen (actieve mobiliteit) in de nabijheid van geitenbedrijven leek hierbij geen rol van betekenis te spelen. Dit kan verklaard worden door het feit dat er maar relatief weinig tijd werd besteed aan actieve mobiliteit. In deze studie was het niet mogelijk om naar een specifieke ziekteverwekker te zoeken, maar Coxiella burnetii (de bacterie die Q-koorts veroorzaakt) kon op basis van C. burnetii antilichaam-serologie worden uitgesloten als oorzaak voor het verhoogde risico op pneumonie.

Informatie over actieve mobiliteit als maat voor de duur en frequentie van blootstelling toevoegen aan studies met grote studie populaties kan erg lastig zijn. Mobiliteitsmetingen zijn over het algemeen arbeidsintensief en brengen vaak hoge kosten met zich mee. Daarom is in hoofdstuk $\mathbf{5}$ getracht om accurate methoden te ontwikkelen voor het inschatten van mobiliteit, zodat deze factor kan worden toegevoegd aan de inschatting van blootstelling voor grote populaties. Met data uit de VGO GPS studie werden drie methoden ontwikkeld om het aantal actieve mobiliteitsuren per week te schatten. Er werd gebruik gemaakt van de eerder geïdentificeerde persoonlijke karakteristieken die verschillen in mobiliteitspatronen verklaarden. Verder werd zelf gerapporteerde (voor overschatting gecorrigeerde) data over wekelijkse mobiliteit gebruikt. Als laatste werd er getracht om met een geografische methode, gebruik makend van het huis- en werkadres en de locatie van de dichtstbijzijnde supermarkt, een inschatting te maken van de wekelijkse actieve mobiliteit. De inschattingen volgend uit deze modellen werden per individu vergeleken 
met de GPS-gemeten mobiliteit van deze persoon. Helaas was geen van deze drie methoden in staat om een accurate voorspelling te doen van de individuele wekelijkse actieve mobiliteit. Metingen blijven daarom de beste methode om mobiliteitspatronen te evalueren.

Na de Nederlandse Q-koorts epidemie (2007-2010), is onderzocht in hoeverre actieve mobiliteit en tijd doorgebracht buitenshuis nabij de woning in de nabijheid van geïnfecteerde geitenbedrijven een rol kan hebben gespeeld in de uitbraak. In hoofdstuk 6 wordt deze retrospectieve studie beschreven. Er is gezocht naar associaties tussen tijd buiten doorgebracht in de nabijheid van voormalig Q-koorts positieve geitenbedrijven en $C$. burnetii antilichaam serologie. De metingen van mobiliteit en tijd doorgebracht buitenshuis werden niet uitgevoerd tijdens de Q-koorts vitbraak, maar 5 jaar na de uitbraak. Toch is ervan uit gegaan dat de gebruikte tijd-activiteiten patronen weinig afweken van de patronen tijdens de uitbraak, omdat tijd-activiteiten patronen over de tijd weinig veranderen. Er bleek een positieve associatie te zijn tussen totaalaantal uren per week buiten doorgebracht nabij voormalig Q-koorts positieve geitenbedrijven en het doorgemaakt hebben van Q-koorts op basis van de C. burnetii serologie. Deze associaties waren sterker als mensen dichterbij voormalig Q-koorts positieve bedrijven woonden. Deze bevindingen duiden erop dat hoe meer tijd buiten werd doorgebracht, hoe groter het risico op Q-koorts was.

Het toevoegen van informatie uit tijd-activiteiten patronen aan tot nu toe gebruikte blootstellingsinschatting-modellen voor veehouderij-gerelateerde infectieziekten (bijvoorbeeld gebaseerd op afstand tussen stallen en woningen), lijkt associaties tussen blootstelling en risico op infectieziekten te beïnvloeden. In hoofdstuk 7 wordt daarom bediscussieerd hoe tijd-activiteiten patronen in de toekomst kunnen worden toegevoegd aan blootstellingsinschatting-methoden. Daarnaast wordt in dit hoofdstuk nagegaan wat de implicaties zijn van de gevonden associaties in dit proefschrift voor de publieke gezondheidszorg. Mobiliteit en gedrag buiten kunnen een factor zijn bij de overdracht van veehouderij-gerelateerde zoönotische infectieziekten en dienen daarom opgenomen te worden in uitbraakprotocollen

Samenvattend, in dit proefschrift zijn tijd-activiteiten patronen toegevoegd aan blootstellingsinschatting-methoden als maat voor de frequentie en duur van blootstelling. Hierdoor werden sterkere associaties aangetoond tussen blootstelling aan veehouderij en gerelateerde zoönotische infectieziekten, vergeleken met studies waar deze factor niet werd toegevoegd.

Voornamelijk blootstelling aan geitenbedrijven was geassocieerd met zowel een verhoogde kans op longontsteking als op positieve $C$. burnetii antilichaam-serologie, alhoewel deze uitkomsten niet met elkaar gecorreleerd waren. De sterkste associaties werden gevonden bij mensen die dichtbij geitenbedrijven woonden.

Informatie over tijd-activiteiten patronen zou daarom als vaste factor moeten worden toegevoegd aan blootstellingsinschatting-methoden. De manier waarop deze informatie kan worden toegevoegd is echter een punt van discussie. Uit een vergelijking tussen GPS-metingen en zelfrapportage, blijkt dat mensen de wekelijkse gerapporteerde tijd die zij besteden aan lopen en fietsen sterk overschatten. Ook bleek het onmogelijk om accuraat actieve mobiliteit te voorspellen middels 
inschattingsmethoden. Metingen blijven daarom de beste manier om gegevens te verzamelen over tijd-activiteiten patronen.

Gezien de gevonden associaties is het, afhankelijk van het pathogeen, zinvol om bij een toekomstige uitbraak van een veehouderij-gerelateerd zoönotische ziekte, bewegingen rond een getroffen bedrijf te beperken. Bovendien zouden zowel gezondheidsdata als tijd-activiteiten patronen verzameld dienen te worden bij omwonenden van een getroffen bedrijf. Op deze manier kunnen de gevonden associaties in dit proefschrift versterkt worden. 


\section{Author affiliations}

\section{Gijs Klous}

Julius Centre for Health Sciences and Primary Care, University Medical Centre Utrecht, the Netherlands

Institute for Risk Assessment Sciences (IRAS), Division Environmental Epidemiology and Veterinary Public Health, Utrecht University, the Netherlands

\section{Anke Huss}

Institute for Risk Assessment Sciences (IRAS), Division Environmental Epidemiology and Veterinary Public Health, Utrecht University, the Netherlands

\section{Roel Coutinho}

Julius Centre for Health Sciences and Primary Care, University Medical Centre Utrecht, the Netherlands

Faculty of Veterinary Medicine, Utrecht University, the Netherlands

\section{Dick Heederik}

Institute for Risk Assessment Sciences (IRAS), Division Environmental Epidemiology and Veterinary Public Health, Utrecht University, the Netherlands

\section{Mirjam Kretzschmar}

Julius Centre for Health Sciences and Primary Care, University Medical Centre Utrecht, the Netherlands

National Institute for Public Health and the Environment (RIVM), the Netherlands

\section{Lidwien Smit}

Institute for Risk Assessment Sciences (IRAS), Division Environmental Epidemiology and Veterinary Public Health, Utrecht University, the Netherlands

\section{Floor Borlée}

Institute for Risk Assessment Sciences (IRAS), Division Environmental Epidemiology and Veterinary Public Health, Utrecht University, the Netherlands Netherlands Institute for Health Services Research (NIVEL), the Netherlands

\section{Gudrun Freidl}

National Institute for Public Health and the Environment (RIVM), the Netherlands European Programme for Intervention Epidemiology Training

\section{Joris IJzermans}

Netherlands Institute for Health Services Research (NIVEL), the Netherlands

\section{Wim van der Hoek}

National Institute for Public Health and the Environment (RIVM), the Netherlands

\section{Piet Vellema}

Department of Small Ruminant Health, Royal GD (GD), Deventer, the Netherlands 


\section{List of publications}

Klous, Smit, Van der Hoek, Kretzschmar, Heederik, Vellema, Coutinho and Huss Relationship between Coxiella burnetii ( $Q$ fever) antibody serology and time spent outdoors Journal of Infection (2020) 81(1) 90-97

Presented at the 2019 ISEE congress in Utrecht.

Klous, Kretzschmar, Coutinho, Heederik and Huss (2019) Prediction of human active mobility in rural areas: development and validity tests of three different approaches Journal of Exposure Science and Environmental Epidemiology (2019) Presented at the 2019 ISEE congress in Utrecht.

Klous, Smit, Freidl, Borlee, Van der Hoek, IJzermans, Kretzschmar, Heederik, Coutinho and Huss (2018) Pneumonia risk of people living close to goat and poultry farms - taking GPS derived mobility patterns into account

Environment International 115 (2018) 150-160

Presented at the 2016 One Health/Ecohealth congress in Melbourne.

Klous, Smit, Borlee, Coutinho, Kretzschmar, Heederik and Huss (2017) Mobility assessment of a rural population in the Netherlands using GPS measurements International Journal of Health Geographics (2017) 16:30

Presented at the 2016 ISEE congress in Rome.

Klous, Huss, Heederik and Coutinho (2016) Human-livestock contacts and their relationship to transmission of zoonotic pathogens, a systematic review of literature One Health 2 (2016) 65-76

Presented at the 2015 ISEE young congress in Utrecht

Klous and Van der Giessen (2012) Is er een link tussen veehouderij en het voorkomen van zoonosen bij mensen in Nederland?

Infectieziekten Bulletin (2012) 23(7):188-93 


\section{Dankwoord (Acknowledgements)}

Na zeven jaar werken komt dan toch het moment dat je het laatste, meest gelezen, minst gecontroleerde, deel van je proefschrift schrijft: het dankwoord. In de wetenschap bestaat alleen werken eigenlijk niet, promovendi maken veel, soms eenzame uren, maar uiteindelijk werk je in een team van mensen die elkaar aanvullen in hun kennis en kunde, mensen die ik voor deze samenwerking heel graag wil bedanken.

Allereerst dank aan de mensen zonder wie dit proefschrift nooit geschreven had kunnen worden: de 1014 deelnemers aan de VGO GPS studie. Alhoewel, het werk wat jullie geleverd hebben in de analyses is gereduceerd tot anonieme uren 'lopen', 'fietsen' en 'gemotoriseerd vervoer', zonder jullie inzet, tips, bezorgdheid en terechte commentaar zou er geen data en dus geen proefschrift zijn geweest!

Dann, mein Doktor-Mutti, Anke. Ohne dich hätte ich dieses Doktorandenprojekt nie abgeschlossen. Ihr Realismus, Ihr Glaube an meine Fähigkeiten, Ihr kritischer Stift und Ihre stets offene Tür haben dafür gesorgt, dass dieses Buch jetzt fertig ist. Nicht umsonst haben wir Sie zum 'Co-Promotor' des Jahres ernannt. Ich wünsche allen einen CoPromotor wie Sie und danke dir sehr.

Roel, tijdens mijn jaren als student aan de VU, toen jij nog bij het RIVM directeur was, heb ik steevast gezegd, "die Coutinho, die mag later wel mijn baas worden", niet wetend dat dit zo een directe relatie zou worden. Jouw kunde om een gecompliceerd probleem, wat niet specifiek binnen jouw expertise ligt, in mum van tijd tot in de essentie te doorgronden is iets waarvan iedereen kan leren, bedankt voor de leerzame jaren.

Dick, het was heel fijn om bij jou binnen te kunnen lopen om even te mopperen als er uit een analyse niet kwam wat ik vooraf verwachtte. Jij zag daar dan toch het positieve van in, immers geen associatie is ook een belangrijke uitkomst, zie hoofdstuk 5 . Het is bijzonder prettig om zo iemand in het team te hebben, ontzettend bedankt hiervoor.

Mirjam, ook al ben je wegens bureaucratische redenen in december uit het team gegaan, toch heb ik je altijd beschouwd als een erg fijne (co-)promotor. Het was heel prettig om iemand in het team te hebben die niet dagelijks betrokken was bij de analyses en daarom stukken vaak onafhankelijk kritisch kon bekijken. Dit heeft veel reviewcommentaar voorkomen, ontzettend bedankt voor de fijne samenwerking.

Commissieleden, Mirjam, Erik, Jan, Jan-Hendrik en Christian, ondanks dat een aantal van jullie direct betrokken is bij de bestrijding van de huidige Coronapandemie, hebben jullie toch tijd gevonden om mijn proefschrift te beoordelen en te opponeren. Mijn dank hiervoor is groot.

Leden van team VGO-IRAS: Lidwien, Floor, Max, Jack, Inge, Marieke, Siegfried, Esmeralda en hen die ik hier vergeet. Waar ik als eerste mijn deelnemers bedank voor hun geleverde werk, zijn jullie verantwoordelijk voor het tweede deel van de data waarmee ik gewerkt heb. Dat ik bij jullie binnen kon lopen om even snel een vraag hierover te stellen en ook het feit dat een aantal van jullie commentaar heeft geleverd op mijn stukken was erg mooi. Ik vind het super om mee gedraaid te hebben in een groep mensen die zo gemotiveerd en gedreven zijn voor hun werk, dank.

Ook de mensen die meegewerkt hebben aan mijn stukken maar van buiten het IRAS betrokken waren, Wim, Gudrun, Joris, Piet en Romin bedankt voor het meedenken en 
de terechte commentaren, de papers zijn hierdoor zeker beter geworden. Andere VGO'ers: Joke, Kitty, Roan, Jeroen, Thomas, Arno, Gert-Jan en vele anderen, het was heel fijn om af en toe mijn werk te presenteren aan jullie, bedankt voor de mooie vragen en leuke gesprekken. Marc, dit laatste geldt ook voor jou en je teamleden, het was erg leuk om eens in de zoveel tijd een 'anders dan anders' praatje te geven bij de WMM.

Dear collegues at IRAS, Roel, Hans, Angèle, George, Bernadette, Eef, Mieke, Ulrike, Gert, Bert, Erikken, Luuk, Liese, Nahid, Mariana, Roosmarijn, Hicham, Marije, Calvin, Daniel, Jules, Ilse, los Alejandros, Wietske, Petra's, Len, Boyd, Jelle, Virissa, Ana Maria, Johan, Aileen, Denise, Maartje, José, Aart, Daan, Damay, Fleur, Jochem, Lizan, Joris, Lotte, Maciek, Christina, Machteld, Jannie, Peter, Paul, Frans, Sara, Tom, Warner, Yvette, Jeroen, Kees, Isabella, Heike, Ingrid, Lützen and those who I forget here, thank you for the warm welcome in 2013 and always feeling 'at home' while working. Speciale dank gaat uit naar Ingrid voor de laatste check van de samenvatting en Lützen voor het zijn van alwetende op het gebied van statistiek en R-programmeren. In deze rij ontbreken nog de kamergenoten gedurende mijn tijd op het IRAS, roomies Johan, Kristel, Annemarie, Marianne's, Astrid, Beyene, Adeylson, Mara, Bernice, Wouter, Jie and Dongsheng, sorry for all the plants, but I really liked working in a green/jungle environment thank you all so much!

Frank, Debra, tante Ina, Ad, Hanneke, Marco, Robin, Ricardo, Fred, Alessio, Kims en vele anderen. Een gezonde geest kan alleen huizen in een gezond lichaam, bedankt voor de vele uren ontspanning door inspanning en de groei binnen mijn budo-disciplines.

Oud-studiegenoten, Simone, Gert, Bart, Gilles en Femke, het was erg fijn om het contact na het afstuderen weer te herstellen en deel te zijn van de samen-eten-club.

Stef en Myrna, wat gaaf dat jullie paranymf zijn. Myrna, over de jaren zijn wij van collega's vrienden geworden, bedankt voor het vele meedenken tijdens het project en de ontspannen wandelingen gedurende de werkweken. Stefanie, ooit zijn we bij elkaar in de klas gekomen en sinds toen zijn we samen het academische avontuur aangegaan. Het is dan ook meer dan toepasselijk dat jij bij het ultieme 'afstuderen', de verdediging van mijn proefschrift, naast mij staat tegenover de opponenten, het was een stuk minder leuk geweest zonder jou.

Lilian, Piet, Cindy en Mathijs, Lotte en Jim, ooms, tantes, neefjes en nichtjes, bedankt voor jullie interesse in mijn werk en de mooie reacties als er weer een publicatie gelukt was, je kunt je geen betere (schoon-) familie wensen.

Papa en Mama, "ga jij nou maar doorstuderen" dat hebben jullie altijd gezegd en verder dan dit gaat het niet. Bedankt voor jullie onvoorwaardelijke steun, liefde en vertrouwen. Mango, je bent een best hondje, $5000 \mathrm{~km}$ heb ik tijdens de jaren bij IRAS gefietst om jou dagelijks naar de opvang te brengen, ik had het niet anders gewild.

Daisy, als studenten aan de VU hebben we een systeem ontwikkeld van in-huis-peerreview. Niet voor niets ben je in ieder artikel bedankt voor je 'textual input', maar viteraard was dit maar een frase om jou te kunnen bedanken voor alles wat je over de jaren gedaan en gelaten hebt voor mij en het proefschrift. Zonder jou was dit project niet tot een einde gekomen, ik hou van je.

Gijs

Ps. Voor hen die ik niet genoemd heb, en hierdoor beledigd zijn, mijn welgemeende excuses, neem contact met mij op dan stuur ik een bedankt-kaartje (gijs.klous@hotmail.com). 


\section{Curriculum Vitae}

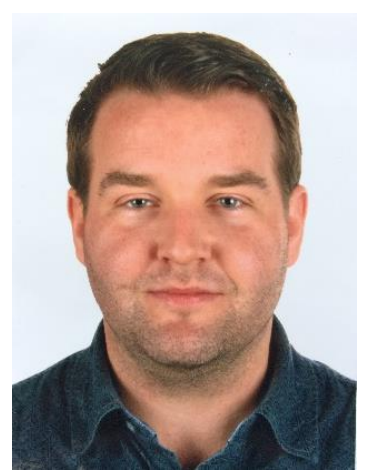

Gijs Klous was born and grew up in De Rijp, Noord-Holland (Figure 1). After graduating secondary school (2006 Jan van Egmond college, Purmerend), he studied biomedical sciences at VU Amsterdam. In 2011 he obtained his Masters, specialising in infectious diseases and cell biology. During his Masters he developed an interest in zoonotic infectious diseases, thus getting familiar with the topic One Health. Taking a course in Health Geography inspired him to search for a PhD position where he could combine his interests in zoonotic infectious diseases with spatial analyses, something he previously did for his Masters' thesis, of which parts were published in 2012. This position was found at University Medical Centre Utrecht's Julius Centre and the Institute for Risk Assessment Sciences (IRAS), an interfacultary research institute within the faculties of sciences, medicine and veterinary medicine at Utrecht University. As part of his PhD educational program he obtained a postgraduate Masters in epidemiology specialising in environmental and occupational epidemiology (2017). In 2018 he worked at the Municipal Health Services (GGD) of the province of Noord-Brabant, in the team specialised in environment and health. The year 2019 was spent to finalise the PhD research described in this thesis. As of January 2020 he returned to VU Amsterdam, where he is currently working as a lecturer at the faculty of beta sciences within the department Environment and Health.

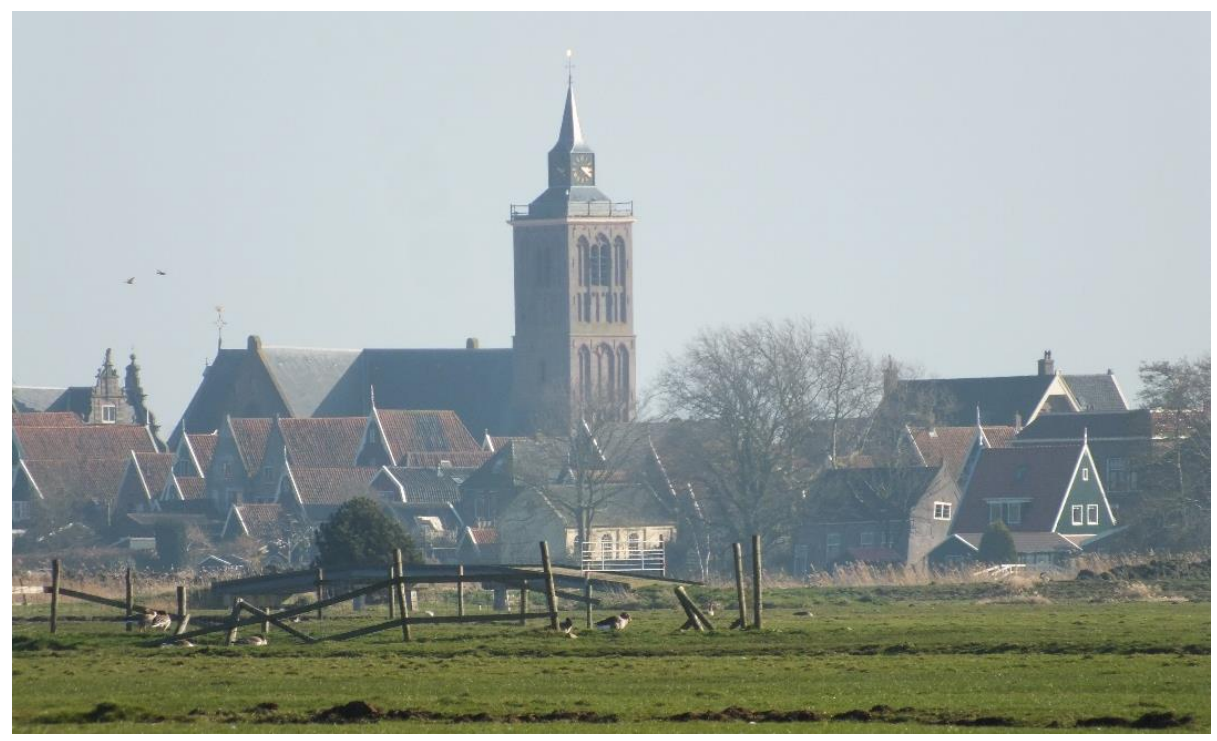

Figure 1. De Rijp, Noord-Holland, view from the Eilandspolder. (picture by Daisy de Vries MSc) 

